Illinois State University

ISU ReD: Research and eData

Theses and Dissertations

3-3-2014

\title{
An Examination Of Teachers' Perceptions And Implementation of Learning Trajectory Based Professional Development
}

Megan Hope Wickstrom

Illinois State University, megawicks@gmail.com

Follow this and additional works at: https://ir.library.illinoisstate.edu/etd

Part of the Science and Mathematics Education Commons

\section{Recommended Citation}

Wickstrom, Megan Hope, "An Examination Of Teachers' Perceptions And Implementation Of Learning Trajectory Based Professional Development" (2014). Theses and Dissertations. 87.

https://ir.library.illinoisstate.edu/etd/87

This Dissertation is brought to you for free and open access by ISU ReD: Research and eData. It has been accepted for inclusion in Theses and Dissertations by an authorized administrator of ISU ReD: Research and eData. For more information, please contact ISUReD@ilstu.edu. 


\title{
AN EXAMINATION OF TEACHERS' PERCEPTIONS AND IMPLEMENTATION OF LEARNING TRAJECTORY BASED PROFESSIONAL DEVELOPMENT
}

\author{
Megan H. Wickstrom
}

342 Pages

May 2014

The aims of this study were to investigate how teachers incorporated learning trajectory based research into practice, specifically how they made sense of students' thinking in relation to classroom instruction. To conduct this study, I used an ethnomethodological approach (Garfinkel, 1967) across several months, with three fourthgrade teachers in a diverse, high needs school. Each of the teachers participated in professional development on using learning trajectories (Sarama \& Clements, 2009) as a tool to formatively assess individual student's thinking as a means to inform classroom instruction. During the study, the teachers were asked to conduct clinical interviews with students in their classroom and note events during the interviews that revealed students' thinking. They were also asked to note revealing events during their instruction of a month-long mathematics unit. Following student interviews and classroom instruction, the teachers participated in debriefing interviews in which we discussed each of the noted events, what they implied about the students' understanding, and if they provided any implications for instruction. Each of the debriefing interviews was audio recorded and 
transcribed verbatim resulting in approximately 200 pages of transcribed interviews. Using the construct of mathematics teacher noticing (Jacobs, Lamb, \& Philipp, 2010) as an analytical lens, I qualitatively explored (Miles, Huberman, \& Saldana, 2014) what teachers noticed about their students and how they used knowledge of students, gained from task-based interviews and classroom interactions, to inform whole-classroom instruction and planning. I investigated how the teachers referenced learning trajectory based research in their noticing and if and how it surfaced in their practices. I also looked across the three cases to compare and contrast themes.

Findings indicate that the teachers noticed student thinking constantly in their daily work through actions such as students' measurement strategies, counting strategies, language, interactions with other students, and written accounts. However, the actions were not always connected with instructional implications. Across the cases, mathematical tasks and curriculum were critical in helping teachers understand students' thinking and implement it into practice. Interview tasks were relevant in instructional planning when they were similar or connected to future classroom tasks. Within the classroom setting, the teacher's willingness to supplement or modify current curriculum determined how she used knowledge of students' thinking in practice. Teachers unwilling to modify curriculum had difficulty using knowledge of students' thinking in practice. Findings also indicate that knowledge of an individual student's thinking gained from interviews informed teachers of student misconceptions and current understandings of a topic, but much of what informed the teachers' instruction came from a complex framework of past education and daily experiences with students. Lastly, teachers interpreted, redefined, and even rejected learning trajectory research in their own ways 
depending on how well it agreed with their current practices and belief systems. These findings have implications for the design and conduct of teacher professional development and indicate the need for modifications to current learning trajectories (Sarama \& Clements, 2009) to make them more accessible to teachers. 


\title{
AN EXAMINATION OF TEACHERS' PERCEPTIONS AND IMPLEMENTATION OF LEARNING TRAJECTORY BASED PROFESSIONAL DEVELOPMENT
}

\author{
MEGAN H. WICKSTROM
}

A Dissertation Submitted in Partial

Fulfillment of the Requirements for the Degree of

\section{DOCTOR OF PHILOSOPHY}

Department of Mathematics

\section{ILLINOIS STATE UNIVERSITY}


C2014 Megan H. Wickstrom 


\title{
AN EXAMINATION OF TEACHERS' PERCEPTIONS AND IMPLEMENTATION OF LEARNING TRAJECTORY BASED PROFESSIONAL DEVELOPMENT
}

\author{
MEGAN H. WICKSTROM
}

COMMITEE MEMBERS:

Cynthia W. Langrall, Co-Chair

Jae M. Baek, Co-Chair

Beth Hatt

Jeffrey E. Barrett

Tami S. Martin 


\section{ACKNOWLEDGMENTS}

This dissertation and all of my graduate work would not be possible without the support, guidance, and love of so many people in my life. Through each year at Illinois State University, I have been fortunate enough to encounter supportive, creative, and challenging souls that have shaped my journey thus far. I would first like to thank Dr. Cynthia Langrall. She and Dr. Edward Mooney encouraged me to continue toward the doctorate after finishing my master's degree. Their faith and support started me on this journey. Since then, Cindy has been ever present in my life giving me just the right amount of support and guidance throughout the process. I am so thankful to have worked with Cindy.

Secondly, I would like to thank Dr. Beth Hatt. Beth has continually encouraged me to go out of my comfort zone and explore the many facets of qualitative research. Without Beth, I would not have had the courage to conduct this study. Each step of the dissertation process, she has been an amazing mentor and friend.

I would also like to thank Dr. Jeffrey Barrett, Dr. Jae Baek, Dr. Craig Cullen, and Dr. Jennifer Tobias for allowing me to be a part of their work with teachers. Each of these professors provided me with support, guidance, and feedback as I learned how to study teachers at work. My work with them helped to spark my dissertation idea and shape my future research plans. I would also like to thank Dr. Tami Martin for her support throughout graduate school and for acting as one of my committee members. I am also grateful for the support and guidance of all of my other professors at Illinois 
State. They have challenged me to grow and expand my understanding of mathematics education.

This dissertation would not exist without Mrs. Grey, Mrs. Purl, Mrs. Brownstein, and the students of Terrace Elementary. Each of these women is an outstanding member of the teaching profession and I am so thankful that I had the opportunity to get to know and work with them. No matter what I asked them to do, they went out of their way to help me. I hope that we can continue to stay in touch and collaborate on future projects.

Throughout the graduate school experience, I have found that the journey is much better when shared with friends and colleagues. I would like to thank Chepina Rumsey and Josh Hertel for their support and mentorship throughout the process. They helped me to see the light at the end of the tunnel. I would also like to thank Nicole Enzinger for her encouragement and willingness to collaborate on many projects and presentations throughout our time at Illinois State. Thank you also to my other graduate student colleagues, Elif Safak, Melike Kara, Cheryl Eames, Amanda Miller, and Vince Kirwan. It has been a pleasure completing the graduate program with you.

Above all, I would like to express the utmost gratitude to my family and friends. I am extremely grateful for the love and support of my husband, Daric Wickstrom. Thanks for following me to the cornfields of Illinois to pursue my dreams. We have had so much fun and I cannot wait to experience the next phase of our journey in Montana. Thank you to my mom, dad, and brother, James, for supporting me through the ups and downs of my academic career. Each step of the way, through triumphs and tribulations, I knew all of you were there for me. Thank you to my Saint Mary's sisters, Erica, Gail, and Emily for making time for weekends away to de-stress and to just have fun. I also need to thank my 
dogs, Yogi and Zoey. They convinced me to put my work aside and take a walk every now and then to clear my mind. Thank you lastly to all the friends I have made while living in Normal, especially the Thompson family.

M.H.W. 


\section{CONTENTS}

Page

ACKNOWLEDGEMENTS $\quad$ i

CONTENTS $\quad$ iv

FIGURES

CHAPTER

I. THE PROBLEM AND ITS BACKGROUND 1

The Problem 1

A Personal Account 5

Rationale $\quad 10$

Epistemological and Ontological Groundings $\quad 14$

Classroom Ecology 15

Teacher Research 17

II. REVIEW OF RELATED LITERATURE 21

Defining Learning Trajectories $\quad 21$

Implications of Learning Trajectories for Instruction 23

Learning Trajectory Based Professional Development 25

Teachers' Initial Reactions to Learning Trajectories 26

Teachers' Skepticism of Learning Trajectories $\quad 26$

Noticing Students' Actions and Understanding $\quad 27$

Issues in Implementation 31

Role of the Learning Trajectory in Understanding Students' Thinking 32

Use of Learning Trajectories within Instruction $\quad 33$

Criticism of Integrating Learning Trajectory Research in

Practice $\quad 35$

Informing This Study 36

III. METHODOLOGY 39 
Research Context 40

Selection of Participants 41

Data Collection 43

Data Analysis $\quad 50$

Analysis of Each Phase $\quad 58$

Analysis Across The Three Cases 63

My Perception 64

Trustworthiness and Validity $\quad 64$

$\begin{array}{ll}\text { Summary } & 68\end{array}$

$\begin{array}{lll} & 70\end{array}$

Description of Mrs. Grey and Her Classroom $\quad 70$

School Year Events $\quad 72$

Interview 1

Interview $2 \quad 80$

Interview 3

Instructional Unit on Area Measurement 99

Smartboard Lesson $\quad 100$

Relating Units of Measure Lesson 109

Area Conservation Lesson 120

$\begin{array}{ll}\text { Summary } & 124\end{array}$

Interviews: Events Noticed and Implications for Instruction 125

Instructional Unit: Events Noticed and Implications for Instruction.

Mrs. Grey's Perceptions of Learning Trajectory Based

Professional Development

Perceived Strengths of the Professional Development 130

Perceived Difficulties of the Professional Development 134

My Perspective and Interpretation of Mrs. Grey

Student Interviews

137

Classroom Instruction

Role of Professional Development 
Description of Mrs. Purl and Her Classroom 141

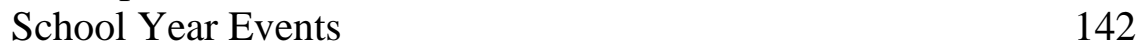

Interview $1 \quad 143$

Interview $2+148$

Interview $3 \quad 156$

Instructional Unit on Area Measurement 162

Smartboard Lesson 163

Relating Units of Measure Lesson $\quad 170$

Area Conservation Lesson 187

$\begin{array}{ll}\text { Summary } & 192\end{array}$

Interviews: Events Noticed and Implications for Instruction

Instructional Unit: Events Noticed and Implications for Instruction.

Mrs. Purl's Perceptions of Learning Trajectory Based

Professional Development

Perceived Strengths of the Professional Development 198

Perceived Difficulties of the Professional Development 203

My Perspective and Interpretation of Mrs. Purl

Student Interviews

Classroom Instruction and Role of the Professional

Development

VI. MRS. BROWNSTEIN

Description of Mrs. Brownstein and Her Classroom

Interview 1

Interview 2

Interview 3 
Building and Filling Lesson 239

Volume Assessment 249

$\begin{array}{ll}\text { Summary } & 257\end{array}$

Interviews: Events Noticed and Implications for Instruction 258

Instructional Unit: Events Noticed and Implications for Instruction. 260

Mrs. Brownstein's Perceptions of Learning Trajectory Based Professional Development

Perceived Strengths of the Professional Development 262 Perceived Difficulties of the Professional Development 265

My Perspective and Interpretation of Mrs. Brownstein

Student Interviews

Classroom Instruction and Role of the Professional

Development

VII. LOOKING ACROSS THE TEACHERS

A Characterization of Mrs. Grey

A Characterization of Mrs. Purl

A Characterization of Mrs. Brownstein

282

What Do We Learn From the Teachers in This Study

VIII. DISCUSSION AND FUTURE RESEARCH

Teacher's Perceptions of Learning Trajectory Research

Perceived Advantages

292

Perceived Disadvantages

Implications for Learning Trajectory Based Professional

Development

Accessibility of Research

299

Accountability

300

Research and Teachers' Beliefs

302

The Role of the Interview

303

Realizations During the Study 
Theoretical Grounding of the Study and the Role of Reciprocity

APPENDIX A: Description of Professional Development 320

APPENDIX B: Area Learning Trajectory 326

APPENDIX C: Noticing Reflection Prompts for Student Interviews and Teacher Lesson Plan Packet

APPENDIX D: Interview Questions for Student Interviews and Classroom Lessons 


\section{FIGURES}

Figure $\quad$ Page

1. Progression of phases of data collection 43

2. Artifact collection by phases 49

3. Learning trajectory and teacher noticing comparison 54

4. Description of event 56

5. Teacher noticing in relation to this study 58

6. Example of event within matrix 60

$\begin{array}{ll}\text { 7. Codes for event types } & 61\end{array}$

$\begin{array}{lll}\text { 8. Mrs. Grey's interview tasks } & 74\end{array}$

9. $\quad$ Events that Mrs. Grey noticed during Interview 1 75

10. Events that Mrs. Grey noticed during Interview 2 81

11. Events that Mrs. Grey noticed during Interview 3

12. Events that Mrs. Grey noticed during Smartboard Lesson 102

13. Events that Mrs. Grey noticed during Relating Units of Measure Lesson 111

14. Events that Mrs. Grey noticed during Area Conservation Lesson 121

15. Summary of all student actions Mrs. Grey noticed 125

16. Mrs. Grey professional development questions 130

17. Events that Mrs. Purl noticed during Interview 1 144

18. Events that Mrs. Purl noticed during Interview 2

19. Events that Mrs. Purl noticed during Interview $3 \quad 157$ 
20. Events that Mrs. Purl noticed during Smartboard Lesson

21. Events that Mrs. Purl noticed during Relating Units of Measure Lesson

22. Events that Mrs. Purl noticed during Area Conservation Lesson

23. Summary of all student actions Mrs. Purl noticed

24. Mrs. Purl professional development questions

25. Mrs. Brownstein interview tasks

26. Events that Mrs. Brownstein noticed during Interview 1

27. Events that Mrs. Brownstein noticed during Interview 2

28. Events that Mrs. Brownstein noticed during Interview 3

29. Events that Mrs. Brownstein noticed during Candy Filling Task

30. Events that Mrs. Brownstein noticed during Building and Filling Lesson

31. Events that Mrs. Brownstein noticed during Volume Assessment

32. Summary of all student actions Mrs. Brownstein noticed

33. Mrs. Brownstein professional development questions

34. Categories of events noted by Mrs. Grey during interviews and classroom instruction

35. Aspects of students' understanding and implications for instruction that Mrs. Grey discussed with regard to student interviews and the instructional unit.

36. Categories of events noted by Mrs. Purl during interviews and classroom instruction

37. Aspects of students' understanding and implications for instruction that Mrs. Purl discussed with regard to student interviews and the instructional unit.

38. Categories of events noted by Mrs. Brownstein during interviews and classroom instruction 
39. Aspects of students' understanding and implications for instruction that Mrs. Brownstein discussed with regard to student interviews and the instructional unit. 


\section{CHAPTER I}

\section{THE PROBLEM AND ITS BACKGROUND}

\section{The Problem}

In mathematics education research, it has been established that knowledge of children's thinking influences the work of teachers. Several groups of researchers (e.g., Carpenter et al., 1989; Clements, Sarama, Spitler, Lange, \& Wolfe, 2011; Cobb, Wood, \& Yackel, 1990; Fennema et al., 1996, Schifter \& Fosnot, 1993) have documented that this knowledge is important because it affects a teacher's understanding of her students' thinking in relation to mathematics and also the enactment of instruction. It has been documented that teachers involved in professional development with a focus on student thinking become more knowledgeable about student strategies and confident in their teaching abilities (e.g., Carpenter et al., 2000; Carpenter et al., 1989; Fennema et al., 1996). They also spend more time discussing mathematics, questioning students and listening to their responses, and allowing more classroom time for mathematics (e.g., Clarke et al., 2003; Fennema et al., 1996). These practices have been related to changes in students' mathematical understanding and achievement as well as students' confidence in their mathematical abilities (Carpenter et al., 1989; Clements, Sarama, Spitler, Lange, \& Wolfe, 2011; Fennema et al., 1996). For these reasons, there is a consensus in the research community that knowledge of students' mathematical thinking is valuable in the education of teachers. 
To share knowledge of students' thinking with teachers, researchers have developed frameworks and tools that describe and categorize student thinking in different mathematical domains (e.g., Clarke et al., 2003). One such tool is the learning trajectory (e.g., Battista, 2004; Confrey, 2008; Sarama \& Clements, 2009). A learning trajectory or progression is a theoretical framework that describes how a student may come to know a mathematical concept over time. As students learn about a mathematical topic they progress through levels of sophistication and a series of cognitive plateaus before they reach an understanding of a formal mathematical concept (Battista, 2004; Daro, Mosher, \& Corcoran, 2011). Using interviews with students and small-group instruction, researchers have developed learning trajectories in several mathematical domains that describe progressions of student actions and thinking in relation to a topic and also instructional tasks that may help students progress in their understanding (Sarama \& Clements, 2009).

Because learning trajectories describe student thinking over time, researchers have hypothesized that knowledge of trajectories would allow teachers to develop a deep and connected knowledge base of student thinking across grade levels, which could help to inform instruction (Sarama \& Clements, 2009). Researchers (e.g., Daro, Mosher, \& Corocoran, 2011) have further hypothesized that learning trajectories could be used as a tool to help teachers formatively assess student thinking (Ginsburg, 2009) as well as accommodate varied levels of ability within the classroom (Sztajn et al., 2012). Teachers could use a learning trajectory to evaluate and interpret student thinking through evidence collected during classroom instruction such as student work, classroom dialogue, or oneon-one interviews. They could then be able to assess students' understanding and 
determine what instruction or feedback was needed to reach the instructional goal. Daro, Mosher, and Corcoran (2011) stated:

(A learning trajectory) offers one promising approach to developing the knowledge needed to define the "track" that students may be on or should be on. Learning progressions can inform teachers about what to expect from their students. They provide an empirical basis for choices about when to teach what to whom. (p. 14)

Researchers who have introduced learning trajectories in professional development settings for mathematics have documented changes in both teaching and learning. Teachers grew in ability to compare student strategies and use this information to justify instructional tasks (Wilson, 2009). The teachers' mathematical expectations for students changed as well as their instruction (Bardsley, 2006), including allowing more time for discussion and posing a variety of problems (McCool, 2009). Most importantly, these professional development settings led to both growth in students' mathematical achievement, as measured through test scores, and teachers' pedagogical content knowledge and mathematical knowledge over time (Clements, Sarama, Spitler, Lange, \& Wolfe, 2011; Wilson, 2009).

Although researchers have found a relationship between teachers' knowledge of student thinking and effects on instruction and student achievement, how this relationship unfolds and develops is still relatively unclear. Many of the ways that researchers have hypothesized that learning trajectories could be used in instruction have proved difficult for teachers to enact. For instance, it is hypothesized that teachers could use a learning trajectory to explain and define different levels of thinking within the classroom (Stzajn 
et al., 2012), but several researchers (Bardsley, 2006; McCool, 2009; Wilson, 2009) documented that it was a difficult task for teachers to use the trajectory in this way. The teachers were able to conduct one-on-one interviews with students and evaluate findings, but analyzing levels of thinking became more difficult when analyzing an entire classroom of students. It was also proposed that learning trajectories could be used as a tool to aid in formative assessment, but Heritage et al. (2009) documented that it is difficult for teachers to use student strategies as a tool to guide instruction.

In studies by Bardsley (2006), McCool (2009), and Wilson (2009), teachers had difficulty enacting research into practice in the theoretically proposed manner, but instruction and student achievement were still influenced in a positive way as measured through standardized test scores. This begs the question of how exactly the teachers were using knowledge of student thinking gained from interviews and observations to inform classroom instruction.

Little is known, as reported in the research literature, about the process of thinking and reflection a teacher goes through when implementing knowledge of a learning trajectory into classroom practice to identify and reflect on students' thinking, but perhaps much is known, within the minds of the teachers, that has not been expressed in words or perhaps has been overlooked by researchers. To help frame this study, I present the following personal account of my experiences as a teacher and a researcher in the field of learning trajectories that led to the research questions I proposed for this work. 


\section{A Personal Account}

I entered the field of teaching following several years working as a graduate research assistant in mathematics education. During my time as a graduate student, I learned of, and worked with, frameworks that described student thinking and I found them to be powerful tools that helped me to analyze student thinking and propose instructional tasks. As a researcher, I was excited to step into the world of teaching and apply this knowledge. I felt that knowledge of student thinking and frameworks that described student thinking would help me to become a better teacher because I would be able to relate my instruction to the needs of my students. When I entered the classroom, I held the belief that I could make sense of my students' thinking in the same way that I had done as a researcher.

Unlike my experiences as a researcher, I found that as a classroom teacher, I struggled to get to know each of my students' thinking, and I had difficulties categorizing and monitoring student strategies. I often referred to this as the "tension" between research and teaching. Other researchers have expressed the word "tension" to describe the difficulties that teachers face when incorporating research into practice (e.g., Burkhardt \& Shoenfeld, 2003; Heid et al., 2006). The tension that I felt was specific to analyzing student thinking. I knew that I needed to pay attention to what my students were doing and saying, but I often did not have the time or energy to make sense of it all. I found that when I studied student work, tutored individual students, or listened to small groups I was able to see and understand individual strategies, but I struggled to figure out what it meant in terms of whole classroom practice and instructional decisions. I constantly felt that I was failing to incorporate my research knowledge into my teaching. 
After several years of teaching, I decided to return to graduate school to pursue my doctorate in mathematics education. I returned to the university to work as a research assistant on a professional development grant with elementary teachers. The goals of the professional development were for teachers to use a learning trajectory (Sarama \& Clements, 2009) as a tool to understand student thinking in the domain of measurement and also to use learning trajectories as a formative assessment tool for classroom instruction. In this professional development program, the teachers learned about student strategies in the domain of measurement by watching and analyzing individual students through video and interviews with their own students. Teachers were asked to use information from the interviews they conducted to design and implement lessons that responded to the needs of the students.

In the initial year of the grant, I found that many of the teachers were successful in interviewing their students and describing student thinking in detail, but it was not always evident that they connected knowledge of the individual students with classroom instruction (Wickstrom et al., 2012). Teachers did not use the same level of description and analysis when describing classroom instruction as they did in individual interviews with students. In individual interview reflections, teachers would discuss each child's actions, thinking, and what level they thought the student's thinking exemplified in the trajectory, but, during classroom instruction, it was more difficult for teachers to provide the same level of analysis. When reflecting on instruction, many of them expressed the tension that I had experienced. It was not an easy task for the teachers to incorporate this new knowledge into their classroom. One teacher expressed it best when she said, "I am a teacher! Not a researcher!" 
Initially, when reflecting on these teaching episodes, I believed that the teachers were not learning or enacting what they had learned in the professional development. After reading The Consortium for Policy Research in Education (CPRE) report (Daro, Mosher, \& Cocorcoran, 2011), I had expected teachers to use the trajectory in the same way they had done in their interviews. I thought they would classify types of thinking they saw in the classroom and propose instruction based upon what they saw and interpreted. In the classroom setting, this process became very difficult for them. After a group meeting with several teachers, I began to think about their perspective. Many of the teachers were expressing the same exasperation that I felt as a teacher. It was not an easy task to integrate the worlds of research and teaching. I began to wonder why this was and wanted see the world from their point of view.

As a pilot study, I decided to recreate the teacher's situation for myself to gain a broader understanding of the issue (Wickstrom, in press). During the spring of 2012, I spent three months observing, interviewing, and teaching students in a second-grade classroom. Just as the teachers had done, I identified focus students and interviewed them individually. I kept notes of their strategies and what I thought it meant in terms of their thinking. After the interviews, I planned a unit on perimeter that I taught to the entire class. During classroom instruction, I found that I poured over each lesson thinking about levels of thinking and how to address each student. For the most part, I was successful at planning in this way, but, unlike the regular classroom teachers, I had the luxury of time. As each lesson was enacted, I tried to jot down notes about students to later reflect on. I realized that I struggled with many of the same issues as the teachers. Following each lesson, I found that I had a general sense of student strategies, in that I could name a few 
that I saw during instruction, but I often could not remember exactly what my focus students had done. I was unable to successfully attend to and analyze individual thinking to the same degree of specificity as I had done in student interviews. I believe this was because my attention was constantly divided among the 24 seven- and eight-year-olds in the classroom and I never had the time to sit and watch a child work for more than thirty seconds to a minute.

Even though attending to individual students proved difficult, I found that my experiences conducting student interviews and using the learning trajectory to analyze student thinking informed several components of instruction. I felt that these individual experiences helped me to anticipate possible student responses, interpret and address student misconceptions, and connect student representations during classroom discussion. Because I had conducted interviews connected to the lesson, I had an idea of how students might respond and I had witnessed firsthand common mistakes that they might make. The experience of interviewing allowed me to notice these errors during instruction and have students discuss and work through them.

Reflecting on these experiences, I realized that, as a researcher, I had made certain predictions, rooted in research, of ways in which a teacher would use knowledge of students to inform instruction. These predictions clouded what I saw and biased my evaluation of teacher's growth. I had to step into the role of the teacher before I could see all of the growth that was possible. Changing perspective brought me to the realization that professional development settings are often framed through the experiences and knowledge of the researchers rather than teachers (Cochran-Smith \& Lytle, 1993). This disconnect in bodies of knowledge creates a transition and tension between research and 
practice that teachers must navigate to implement research. Sometimes professional development does not always provide a clear path for teachers to follow in their attempts to apply their knowledge of research into practice and often teachers create this path for themselves.

Following this realization, I began to explore the philosophies of other professional development programs rooted in student thinking and student strategies to explore how to best study the ways in which teachers implement knowledge of student thinking into classroom instruction. I found that, in the past, several groups of researchers (Carpenter et al., 1989; Fennema et al., 1996; Simon and Schifter, 1991) recognized that the transition between research and practice exists. Instead of hypothesizing or suggesting how teachers might use research and frameworks on student thinking, the researchers let the teachers decide how information about student thinking should be implemented within instruction. When Cognitively Guided Instruction (CGI) was introduced to teachers, teachers expressed concern about implementing what they had learned into their practice. Fennema et al. (1996) wrote:

We did not ignore the concerns of the teachers. Rather we tried to communicate that they had certain unique knowledge, and so did we. Although we attempted to communicate that we could help them to understand what their own students knew, we emphasized that they were professionals who should decide how their emerging knowledge of children's thinking should and could be used in the classroom. (p. 408)

From these initials studies, the researchers were able to identify ways in which the teachers used research and frameworks on student thinking and they used that knowledge 
to inform future professional development activities. It was also noted that teachers within these programs felt empowered as learners and researchers because they were making sense of student thinking and using it in a way that made sense to them (Richardson, 1990).

It was my initial research (Wickstrom et al., 2012), reflections on that research, and review of similar studies that led me to question how teachers interpret and use learning trajectories in conjunction with formative assessment to inform their classroom instruction. If it is difficult for teachers to use knowledge of student thinking gained from experiences like individual interviews in ways researchers have hypothesized, then it is important to explore other ways teachers might interpret and implement the ideas and knowledge encapsulated within such learning trajectories and gleaned from individual interviews with students. Furthermore, it is important to understand contextual factors that shape the ways teachers interpret and implement knowledge gained through professional development in order to better bridge the research-practice divide.

\section{Rationale}

Based on the existing research on teachers' uses of learning trajectories in mathematics education (e.g., Bardsley, 2006; McCool, 2009; Wilson, 2009) and my personal experiences, there is a clear need to investigate how teachers make sense of student thinking using learning trajectory research and how teachers may implement their findings regarding student thinking into classroom instruction. In the mathematics education community, the process of analyzing student thinking and discussing it in terms of instruction is valued both within pre-service teacher education as well as the professional development community (e.g., Cobb, Wood, \& Yackel, 1990; Fennema et 
al., 1996, Schifter \& Fosnot, 1993) because of noted effects on student achievement. As with any process, it is important not only to consider the result, but to also make sense of the steps in between. By making sense of the process of integrating knowledge of students' thinking and strategies for learning into instructional practice, teachers and teacher educators can become better informed.

Ball, Thames, and Phelps (2008) stated that the connection between students and classroom instruction, defined as knowledge of content and students, is an important domain of the mathematical knowledge for teaching. They stated:

When assigning a task, teachers need to anticipate what students are likely to do with it and whether they will find it hard or easy. Teachers must also be able to hear and interpret students' emerging and incomplete thinking as expressed in the ways that pupils use language. Each of these tasks requires an interaction between specific mathematical understanding and familiarity with students and their mathematical thinking. (Ball, Thames, \& Phelps, 2008, p. 401)

It is my belief that the process of understanding student thinking and implementing this knowledge into practice are possibly two different subdomains of knowledge of content and students and it takes effort to relate the two. Teachers may be able to recognize and understand student thinking, but it is not entirely clear how this information is related to their enactment of instruction.

The way that teachers use knowledge of student strategies within classroom instruction may not be completely visible by looking at their outward actions and may be missed. It is important to consider the perspectives of teachers to fully understand the process that occurs when transitioning knowledge into practice. Surprisingly, almost all 
research on teacher growth when using learning trajectories is framed from the researcher's perspective looking into the classroom. Several studies have documented how the teacher enacts instruction over time following professional development and the effects on student achievement, via standardized test scores (e.g., Bardsley, 2006; Fennema et al., 1996, McCool, 2009; Wilson, 2009), but none have explored why the teacher made certain instructional decisions and her thoughts and reflections about those decisions. It is unclear how teachers utilize their understanding of students' thinking, gained through individual student interviews and mediated by their knowledge of learning trajectories, to make decisions about instructional practices.

Research and practice should form a synergistic loop (e.g., Cochran-Smith \& Lytle, 1999; Lewis, 2002). Cochran-Smith and Lytle (1999) argued for "knowledge-inpractice" with regard to professional development. Professional development programs should be "embedded in practice and in teachers' reflections on practice" (p. 250). In order to inform this process, it is important to shed light on how the teacher, the interpreter of the research on student thinking, makes sense of the information she collects and how she modifies it for classroom instruction. Her thoughts and decisions are important information that can be used to bridge the gap between research and practice and further refine professional development.

The purpose of this study was to investigate this issue by working with three elementary teachers who were engaged in professional development on learning trajectory based instruction in the domain of measurement (Sarama \& Clements, 2009). My goal was to examine what these teachers noticed about their students' mathematical thinking and how they integrated what they noticed into their instructional practice. I was 
particularly interested in documenting whether and how the teachers referred to the learning trajectory and the related research they had examined during the professional development program. Through an ethno-methodological perspective (Garfinkel, 1967) and working cooperatively with the teachers, I addressed the following research question: What are the advantages and disadvantages teachers perceive in participating in learning trajectory based professional development to improve classroom instruction and student learning?

a. What aspects do teachers identify as important in revealing student thinking during clinical interviews that are intended to assess students' thinking?

i. What information does the teacher say that she gleans from these events?

ii. What claims, if any, does the teacher make about how these events inform her instruction?

iii. How does the teacher acknowledge or draw on her understanding of the learning trajectory when referring to the clinical interviews?

b. What classroom events do teachers identify as important in revealing student thinking during daily classroom instruction?

i. What information does the teacher say that she gleans from these events?

ii. What claims, if any, does the teacher make about how these events inform her instruction? 
iii. How does the teacher acknowledge or draw on her understanding of the learning trajectory when referring to classroom instruction?

\section{Epistemological and Ontological Groundings}

In this section, I explore theories that have shaped the nature of the study and the way in which it was conducted. Epistemology describes how a specific knowledge can be acquired and ontology is the ability to describe the nature and existence of an idea. In this section, I describe theories that I think appropriately address the existence of teacher knowledge and how it can be accessed.

In mathematics education several paradigms have been used to determine how teaching is researched and framed. A paradigm of the past that was prominent in research on teaching, is the process-product paradigm (Brophy \& Good, 1986; Dunkin \& Biddle, 1984). Process-product is based on the belief that effective teaching can be measured by determining if teacher behavior can be linked to student performance, usually in the form of achievement tests. It characterizes teaching much like a science with fundamental laws (Cochran-Smith \& Lytle, 1993). A fundamental law indicates that a causal relationship exists between two things based upon repeated measures such as the observation that the state of water changes from liquid to gas at 100 degrees Celsius. Even though some would argue that the process-product paradigm is something of the past in education, many tenets still remain in education today. For example, to determine if professional development is effective, it is common practice to first compare standardized test scores

of students from the classrooms of participating teachers to look for differences between methods and repeatability over time. 
Teaching and learning is much more complex of an activity than a simple causal relationship. Behaviors and actions may often fit into a larger schema. Sometimes by looking for a fundamental law or a cause and effect relationship, smaller details that could add meaning are ignored or overlooked, such as the knowledge and life experiences students bring into the classroom and use to interpret school curriculum. In this study, I attempted to address such complexities. Two interpretivist theories, together, have guided the framing of this study: classroom ecology and teacher research. These theories are described in detail below.

\section{Classroom Ecology}

The theory of classroom ecology (Cazden, 1986; Evertson \& Green, 1986) acknowledges that the classroom environment is complex and interactive. Researchers within this paradigm examine the perspectives of teachers and students to describe the interrelationships within the classroom. The paradigm is an interpretive paradigm with an emphasis on finding how the participants (i.e., teachers and students) co-create meaning and interpret mathematical content and instruction within the classroom instead of searching for a fundamental law of teaching (Shulman, 1986). In essence, it allows for classroom practice to be understood in a real life setting with the complexity and messiness of real life teaching rather than a sterile or non-realistic research environment that is far removed from the actual daily experience of teachers by trying to reduce complexity through prediction, explanation, and control.

Hamilton (1983) argued that the theoretical construct of classroom ecology is composed of four key tenets. The first tenet is that attention should be paid to "the interaction between persons and their environments, especially in reciprocal terms rather 
than in terms of simple directional causality from teachers to students" (Shulman, 1986, p. 19). This tenet helped to frame the research design of this study by considering the interaction between teacher and student. The interplay between teacher and student is ongoing. A teacher may make decisions based on what she sees a student doing or conjectures about what a student might be thinking, but the student, in turn, reacts to what the teacher has just done. Whether knowingly or unknowingly, both the teacher and the student interact and inform one another in an endless loop.

The second tenet of classroom ecology is that teaching and learning are interactive and continuous rather than unidirectional and discrete (Hamilton, 1983). Events and experiences within the classroom and within the life of the teacher and student are repeatedly accessed and referenced over time. In this study, the teacher's understanding of the students is viewed in this fashion. The way that a teacher comes to know and interpret student thinking is a complex process that combines all of her classroom experience, and possibly non-classroom related experiences, past and present. An individual interview may help to inform a teacher's understanding of student thinking, but other factors such as prior experiences with the child, past experiences teaching, and day-to-day interactions also may be informing the teacher's decisions.

The third tenet of classroom ecology is that the classroom can never be an isolated system (Hamilton, 1983). It is an entity that is nested within other contexts such as culture, community, and family. Thus the classroom culture that the teacher and the students in this study created was based on the students' and teachers' experiences and knowledge, classroom norms, familial structures, and school structures. This study was 
framed so that outside contexts such as school structure or knowledge of students outside of classroom life were acknowledged and taken into account.

The final tenet of classroom ecology is that unobservable processes such as thoughts, attitudes, perceptions, and feelings are important data sources (Hamilton, 1983). This particular tenet played a key role in the conduct of this study. The primary goal of this study was to make sense of the perspective of the teacher and how she noticed and made sense of student thinking to inform instruction. Her perception was vital in making meaning of the classroom environment because she was the primary interpreter and decision maker on a daily basis.

\section{Teacher Research}

One of the limitations of the theory of classroom ecology is that classroom research is investigated, framed, and reported through the perspective of the researcher (Cochran \& Lytle, 1993). Even though classroom ecology acknowledges the complexities of the classroom and the different voices that exist, the research questions, interpretation, and analysis of the study still stem from the researcher rather than the teacher. Because of this, research in classroom ecology usually emerges from analysis of theoretical and empirical literature rather than problems situated within classroom practice (CochranSmith \& Lytle, 1993).

The epistemological perspective of this study is unusual because the research questions stemmed directly from classroom experience rather than theory, but were investigated by a researcher attempting to interpret and convey the teachers' perspectives. To further support the last tenet of classroom ecology and acknowledge the perspective of the teacher within the classroom, the design and conduct of this study was grounded in 
several of the tenets of the theory of teacher research (Cochran-Smith \& Lytle, 1993). Cochran-Smith and Lytle (1993) defined teacher research as "systematic, intentional inquiry by teachers about their school and classroom work" (p. 24). Teacher research usually stems from issues and questions that arise within the practice of teaching. Teacher research is grounded in the epistemological belief that teachers should have a voice and a presence in the research community and acknowledges that the teacher's perspective is critical when implementing and evaluating research on practice.

Even though the teacher participants were not the primary investigators in this study, the study itself was guided by several of the tenets of the teacher research paradigm. The first tenet is that the perspective of the teacher matters when conducting research on teaching (Cochran-Smith \& Lytle, 1993). Teachers have continual interaction with the classroom environment and a wealth of experiences to draw upon, so issues and concerns that teachers face when teaching should be valued and investigated. Reynolds (1989) stated that "what is known and worth knowing about teaching...should be related to the practical knowledge possessed by teachers of how and when to act in actual teaching situations" (p. x). Teachers can provide insights and perspectives of the classroom that researchers might not be able to see. This tenet guided the structure and design of this study. Instead of a researcher observing the classroom from the outside in, the teacher was the primary voice. She was an active participant in the research and helped to make sure that her perspective was accurately framed.

The second tenet of teacher research is that research should stem from problems of practice (Cochran-Smith \& Lytle, 1993). These can sometimes be described as differences or tension between the theoretical and the actual. In this study, the problem 
arose from my own experiences as a teacher and from a problem of practice experienced by the teachers within the professional development context. It was unclear how the teachers made sense of students' thinking and used it to inform classroom instruction. This was a problem discussed by the teachers and felt by the researchers conducting the professional development.

The final tenet is that knowledge of individual teachers and their instructional practices are important. These add to the overall understanding of classroom dynamics (Cochran-Smith \& Lytle, 1993). Since the aim of teacher research is to further clarify meaning within the classroom environment, any and every case adds to the community's understanding. A critique of teacher research has been that one or a few cases say very little about classrooms in general. Researchers (Guba, 1980; Zumwalt, 1982) have countered this by arguing that the classroom is a complex environment and no two are alike. When researchers make generalizations or claim fundamental truths about teaching and learning, those generalizations are, by default, context free, but when considering any real classroom, none is without context. Both of these researchers (Guba, 1980; Zumwalt, 1982) advocated the position that information from classrooms should not be generalized. Instead, information collected should be rich and descriptive to better understand and give insight into what is happening and why certain practices do or do not work in particular classrooms.

With regard to this study, it was important to investigate from the teachers' perspectives how they used knowledge of student understanding to inform classroom instruction. The theories of classroom ecology and teacher research provide 
epistemological and ontological frameworks that acknowledge the complexity of the classroom environment and value the perspective of the teacher. 


\section{CHAPTER II}

\section{REVIEW OF RELATED LITERATURE}

This section is a review of the literature related to learning trajectory based professional development. The review begins with defining learning trajectories and the ways in which different researchers view this term. Following this, there is a discussion of how different researchers have viewed the theoretical implications of learning trajectories for classroom instruction and curricular implications. From there, the theoretical actualizations of learning trajectory based professional development are discussed. This includes teachers' perspectives of learning trajectories, teachers' uses of the trajectories to notice and interpret student thinking, findings related to instructional practices, and findings regarding student achievement. The literature review concludes with a discussion of how all of these ideas directly informed this study.

\section{Defining Learning Trajectories}

A learning trajectory is a theoretical framework to aid in understanding young children's mathematical thinking. Simon (1995) thought of a learning trajectory as teacher's prediction of a likely path for learning. He recognized that the paths might be hypothetical because student understanding is not knowable in advance. He also stated that even though students learn in different ways, they may move along similar paths so many students can benefit from the same task. 
Since then, other researchers (Sarama and Clements, 2009; Battista, 2004) have further conceptualized the meaning of learning trajectories. Battista (2004) described a learning progression or trajectory through levels of sophistication. Students move from pre-instructional reasoning through a series of cognitive plateaus to formal mathematical concepts. Battista emphasized that students may not progress through the terrain in the same way or in a linear fashion. Daro, Mosher, and Corcoran (2011) defined learning trajectories as "empirically supported hypotheses about the levels or waypoints of thinking, knowledge, and skill in using knowledge, that students are likely to go through as they learn mathematics" (p. 12).

Sarama and Clements (2009) defined a learning trajectory as a pedagogical construct with three parts: a mathematical goal, a learning path through which students move through levels of thinking, and instruction that will help them move along that path. Sarama and Clements (2009) stated, "learning trajectories are descriptions of children's thinking as they learn to achieve specific goals in a mathematical domain, and a related, conjectured route through a set of instructional tasks designed to engender those mental processes or actions hypothesized to move children through a developmental progression of levels of thinking” (p. 19). In this study, I implement Sarama and Clements (2009) definition of learning trajectory.

In each of these definitions, a learning trajectory is seen as a path through which students grow and change in their understanding of a mathematical topic, in conjunction with a complementing set of conjectured tasks to help the student progress through understandings. The learning trajectory not only defines student thinking at different 
levels, but it also informs tasks that may build further understanding fostering sophistication.

\section{Implications of Learning Trajectories for Instruction}

Research on the structure of learning trajectories is recent and ongoing with constant revision. Several studies (e.g., Barrett, Jones, Thornton, \& Dickson, 2003; Barrett et al., 2012) have noted the theoretical benefits of learning trajectories when implemented in an instructional setting. These implications include formatively assessing students over time, analyzing and accommodating multiple levels of thinking within the classroom, and creating a more connected pedagogical content knowledge across grade levels.

Daro, Mosher, and Concoran (2011) recently hypothesized that learning trajectories could be used as a tool to help teachers formatively assess student thinking. Teachers could use trajectories or curriculum informed by trajectories as an evaluative tool to determine students' understanding and appropriate instructional responses. The authors argued that learning trajectories provide teachers with a progression so they can order instructional tasks and experiences to develop higher levels of reasoning. Instruction based on hierarchical thinking alone is not enough, because progression of instruction is directly connected to progression of learning. In order to use the learning trajectory appropriately, Daro, Mosher, and Concoran argued that a teacher must be able to use it to assess instruction and student thinking, as well.

Sarama and Clements (2009) compared learning trajectories or knowledge of learning progressions to that of Cognitively Guided Instruction (CGI) (Carpenter, Fennema, Peterson, \& Carey, 1988). They hypothesized that knowledge of learning 
trajectories will directly impact student achievement. Teachers would be able to help students move through levels of sophistication because the teacher would have a deeper, extended understanding of the child's knowledge in relation to the curriculum overall.

In relation to levels of sophistication, one of the most promising aspects of the learning trajectories is a resource to possibly differentiate instruction. Sarama and Clements (2009) stated, "thus, learning trajectories can facilitate developmentally appropriate teaching and learning for all children" (p. 18).

Sztajn et al. (2012) proposed the theory of Learning Trajectory Based Instruction (LTBI). They defined learning trajectory based instruction as teaching that uses students' LTs as the basis for instructional decisions. Building on Shulman's (1987) theory of pedagogical content knowledge, Ball, Thames, and Phelps (2008) mathematical knowledge for teaching, and Smith and Steins (2011) The 5 Practices for Orchestrating Effective Mathematics Discussions, the researchers connected knowledge of students to knowledge of teaching through research on learning trajectories. The work of Sztajn et al. (2012) is different from the learning trajectories themselves in that the learning trajectories focus on specific instructional tasks to promote learning while Sztajn and colleagues focus on creating a bridge between current frameworks that describe teaching and knowledge of students' thinking imbedded in learning trajectory research. The researchers reference that these concepts are still abstract and research is being done to see how ideas about teaching, learning, and mathematics fits together.

LTBI focuses on current teaching frameworks to show how learning trajectories can help teachers with many instructional actions in the classroom. They describe teaching practices such as analyzing and differentiating tasks to accommodate varied 
levels within the classroom, facilitating discussions, and formatively assessing students' thinking. LTBI connects many practices of teaching with the ideas presented on students' learning in learning trajectories.

\section{Learning Trajectory Based Professional Development}

In the last decade, several learning trajectory based professional development have been enacted, each in slightly different ways. The primary difference between the programs is the learning trajectory implemented. Several groups of researchers (e.g. Bardsley, 2006; McCool, 2009; Clements et al., 2011) implemented trajectories created by Sarama and Clements (2009) primarily focused on measurement, geometry and shape, as well as counting strategies. Other groups (Mojica, 2009; Wilson, 2009) implemented trajectories related to equipartitioning (Confrey et al., 2009).

In relation to this, a secondary difference in the programs is the decision to integrate a curriculum within the professional development. Some professional developments have developed curricular materials to complement trajectory research during classroom use (e.g., Bardsley, 2006) while others opted to integrate it with teachers' existing materials (e.g., McCool, 2009; Wilson, 2009).

Professional developments also differed in their approach to conveying the idea of learning trajectory research to teachers. Many of the studies (e.g., McCool, 2009; Wilson, 2009) focused on clinical interviews as a way for teachers to learn about students thinking and to discuss it in relation to research. By learning about individual students, researchers hypothesized that this information would transfer to classroom practice. Professional developments with curricular materials (Bardsley, 2006) primarily focused on the enactment within classroom instruction. 
Lastly, the number of participants in each of the professional developments varied. Many of the professional developments were conducted with large groups of inservice teachers (e.g., Bardsley, 2006; Wilson, 2009; Clements et al., 2011), but one focused on pre-service teachers (Mojica, 2009) and another on a single teacher (McCool, 2009).

\section{Teachers' Initial Reactions to Learning Trajectories}

A small group of researchers (Bardsley, 2006; McCool, 2009; Wilson, 2009) has documented teachers' initial perceptions about trajectories as well as perceptions over time. A common response from teachers throughout the studies is that of being overwhelmed. Both Bardsley (2006) and Wilson (2009) documented that teachers felt that the trajectory document itself was too large, in terms of number of pages, as well as too verbose. They complained that the terms were big, and the language was confusing, even comparing it to learning a foreign language. Researchers (Bardsley, 2006; McCool, 2009) also found that teachers were skeptical of using it within the classroom. They felt overwhelmed at the thought of integrating knowledge of multiple levels of thinking into practice.

\section{Teachers' Skepticism of Learning Trajectories}

As teachers were introduced to student strategies and actions related to learning trajectories, research (Bardsley, 2006; McCool; 2009) has indicated that they initially experienced a period of doubt. Many teachers were skeptical that students progress through levels of understanding when they had experiences in which students had seemed to learn and master a task with relative ease. For example, Bardsley (2006) documented that initially kindergarten teachers viewed the process of counting as a three-step process, 
the inability to count, emerging ability, and mastering the ability to count. Many of the teachers felt that mastering counting was the ability to count numbers aloud in succession or the route counting sequence. When the teachers were challenged to think about whether their students understood what number a collection of toys represented, they realized that this task was difficult for students and that the ability to count encompassed more than then reciting numbers in order.

For many teachers, their skepticism is often followed by amazement that students do not understand what the teacher thought he or she had taught them through mastering a set skill. While working one-on-one with an elementary teacher, McCool (2009) documented that the teacher thought that the students had mastered the idea of unit following learning how to measure by reading the endpoint on a meter stick. McCool (2009) stated,

When she (the teacher) found that the students did not understand the units on a meter stick, she was "amazed". I (McCool) said that we force students to label, label, label their answers and she (the teacher) said "but they don't know what they (the labels) mean" (p. 84).

This reaction of amazement and surprise seems to legitimize the idea of learning trajectories for the teachers and they begin to open their minds to the idea that students may understand mathematical topics in varying ways or ways the teacher had not thought about before (Bardsley, 2006; McCool; 2009).

\section{Noticing Students' Actions and Understanding}

After teachers begin to see that different student strategies exist their focus on student actions and strategies often becomes more acute and they are able to "see" or 
notice student strategies in new ways both during interview assessments, as well as classroom instruction. Researchers (Bardsley, 2006; McCool, 2009; Wilson, 2009) noted that initially teachers begin to focus more closely on students as they solve problems. Teachers discussed that, prior to professional development, they often focused solely on correct versus incorrect solutions. Solutions that were nonroutine or incorrect were often disregarded because the teacher could not completely understand the methodology of the solution. Bardsley (2006) found that one teacher in particular recognized strategies that were non-routine or incorrect prior to professional development but did not understand what they meant. This teacher, Mrs. Cousin, referred to these strategies as the "weird" ones and knew they were different but did not know why they were important or if they had any implications for instruction. Her focus shifted from correctness to inquiry about what the student was doing, following learning trajectory based professional development. Bardsley (2006) stated,

Mrs. Cousin had several groups of objects on a table. She asked a girl who could count to 10 to point to the group of 4 . The girl responded incorrectly. Mrs. Cousin, curious, asked, "Does that have 4?" Mrs. Cousin reported the girl said, "Well, if you take one away it will." Mrs. Cousin explained that before she would have thought the child was "weird", pondered about it but not understood why she would think a group of 5 was 4 . "Now I ask, trying to get to their thinking"... Mrs. Cousin found that she wanted to know how children count and solve problems, not just whether they could. (p. 120)

This idea was also evident in McCool's (2009) study. Kathy, the teacher she worked with, initially focused on formulas, and whether students had the correct answer. 
As she progressed in the professional development, she began to pause more frequently during class to observe students working and to ask them what they were doing.

Even though Bardsley (2006) found that teachers' attention became more focused, it was, nevertheless, difficult for teachers in her study to document students' strategies when teaching an entire classroom. When teachers were given a sheet to help record their observations, they found it difficult to coordinate teaching and note taking and became overwhelmed by the documentation. Bardsley (2006) reported that many of the teachers stated they would not continue to use the observation sheet to document student thinking in the future.

From the few studies conducted, the literature suggests that teachers become more aware of students' strategies as they progress in learning trajectory based professional development. Their focus shifts from observing who is correct and incorrect to observing details of all solutions and thinking more deeply about the meaning behind the strategy. It still remains difficult for teachers to coordinate and organize this information during classroom instruction.

Even though teachers began to notice students' actions more clearly over time, researchers (Bardsley, 2006; McCool, 2009; Mojica, 2009; Wilson, 2009) have indicated that, for many teachers, it is often still unclear to them what these actions indicate in terms of students' thinking. Wilson (2009) found that early in professional development teachers made broad and nonspecific comments about students' thinking, especially at the initiation of the professional development. Teachers were able to point out details as well as notice commonalities and differences in student strategies but were unable to describe the understanding associated with the action. 
If teachers were able to provide a description of students' understanding, it often arose from a deficit perspective (Wilson, 2009). This meant that they discussed understanding that they knew the students did not know based on their actions. In many cases, teachers initially interpreted describing students' understanding as simply matching a trajectory level to a particular student without providing justification or evidence. (Bardsley, 2006; McCool, 2009; Mojica, 2009; Wilson, 2009).

As teachers progress in the professional development programs, some teachers' understanding of their students becomes more detailed (Bardsley, 2006; McCool, 2009; Mojica, 2009; Wilson, 2009). They are able to see things that they had not noticed before as well as provide justification and evidence supporting their thoughts about students' thinking. Because of this, the teachers' perceptions of their classrooms often changed. Bardsley (2006) documented that teachers initially thought several tasks would be too difficult for their students, but as the teachers worked with students, their perceptions about task difficulty changed. They became more confident that the students could attempt to solve the problem in some way.

One group of researchers (e.g., Myers et al., 2013) has classified stereotypes or representations of students as learners of mathematics that emerge as teachers discuss student actions and thinking over time within a professional development setting. These stereotypes included ideas such as ability, effort, luck, task difficulty, grade level, cultural context, and teaching. Although these ideas have been expressed, researchers have not yet explored how these stereotypes change over time and what they imply, except for ability. Myers et al. (2013) described that, as teachers observed students, they were often surprised by students that they considered "low" that could solve a task or "high" that 
couldn't solve a task. Myers and colleagues expressed that the instructors expected that the teachers' language use of "low" and "high" would fade as they learned about and explored levels of student thinking, but this was not the case. The teachers still used labels of "low" and "high" but they began to approach student thinking with an emphasis on what students could do in relation to the learning trajectory rather than from a deficit approach.

\section{Issues in Implementation}

Along with difficulty in interpretation of students' thinking, it has also been documented that teachers often find writing about student thinking to be an arduous process. Researchers (Bardsley, 2006; McCool, 2009; Mojica, 2009; Wilson, 2009) found that teachers' writing is informal and vague and they often understand more about their students than they feel comfortable or have time to write down. McCool (2009) found that even though it appeared that the teacher, Kathy, had not completed her reflection on students' thinking in written form she had, in fact, given it much thought. McCool (2009) states,

I was surprised that Kathy (the teacher) did not record her responses to this task. In our meeting, she said that she should have written her thoughts down on paper, but was able to give reasons for her placements quick enough to make it clear that she had spent time on the task...This led me to think that Kathy had really given each of her decisions a lot of thought because she was ready and able to defend her claims. (p. 83). 
Following this interaction, McCool (2009) discussed that it is important to allow time for interviews with teachers so that they have the time to reflect and discuss student thinking in a comfortable manner.

\section{Role of the Learning Trajectory in Understanding Students' Thinking}

It is difficult to pinpoint exactly how the learning trajectory surfaces in teachers' understandings of students' actions and thinking and how to assess the impact of the professional development. In studies reported, teachers changed in their abilities to discuss students actions, students' thinking, and instructional planning, but it is unclear what pieces of this can be accredited to the trajectory and what pieces are a results of the professional development or a combination of both. One idea that has permeated across several studies is that of the language of the trajectory. Wilson (2009) noticed that pieces of the trajectory language had surfaced in teachers' discussions, and he concluded that the trajectory allowed teachers to communicate more precisely about students' knowledge of equipartioning.

Teachers used mathematically precise words, such as "radial", "quantity", and "equipartition", in their discussions in other professional development learning activities...one group of teachers even attempted to use the terms "quotative" and "partitive" in their discussions...Though they had not fully incorporated the terms into their vocabulary, this is an indication that the teachers were adopting and trying to use the words from their work with the learning trajectory to communicate clearly their ideas with one another. (p. 139-140)

Language can be deceiving though because it does not always indicate a strong understanding or application to classroom practices. Bardsley (2006) documented an 
interesting account of two teachers, Ms. Agnes and Mrs. Cousin. In the professional development setting, Ms. Agnes appeared to be an expert because she readily demonstrated knowledge of the learning trajectory with regard to student thinking and instruction and correctly used terminology. Mrs. Cousin did not use the learning trajectory language as frequently or as well. Bardsley was surprised when she visited their classrooms, because Mrs. Agnes did not implement her knowledge into the classroom and quickly moved through topics in a procedural manner while Mrs. Cousin taught the material in a manner more consistent with the values of the trajectory-based curriculum. The story of these two teachers implies that perhaps knowledge of the trajectory and the language of the trajectory are separate from understanding implications for classroom instruction.

\section{Use of Learning Trajectories within Instruction}

Using a learning trajectory for teaching and designing lessons appears to be more problematic and difficult then observing student behaviors and inferring student thinking. One phenomenon that occurred in several studies is a lack of confidence in designing and implementing lessons and the importance of a support structure. Initially, teachers were unsure of themselves and the lessons they designed. McCool (2009) documented that the teacher she advised consistently asked for reassurance that she was doing the right thing. Bardsley (2006) documented teachers grouped together within the professional development to act as a support structure for each other. These teachers commented that they would not have been able to make it through without the support they received from each other. 
Another problem that emerged both during student interviews and classroom instruction is the role of formative assessment versus instruction. When teachers interviewed students it was to assess their thinking and determine what level it might represent within the trajectory. When teachers taught, they had specific goals to accomplish and skill sets for students to master. Several studies documented that teachers had difficulty meshing these two ideas together and interpreting what the assessment means for instruction. It was difficult for them to not advise students what to do next (Bardsley, 2006; McCool, 2009). In addition to this, teachers commented that they realized a student's idea or action was important but was unsure of what to do instructionally (McCool, 2009).

In relation to teaching practices, researchers (McCool, 2009; Mojica, 2009; Wilson, 2009) documented that teachers' current curriculum was a factor in teachers' abilities to design and implement lessons using a learning trajectory. Experiences with teaching material and curricular resources directly impacted how the teacher taught lessons and whether values from the learning trajectory professional development were integrated into instruction (Bardsley, 2006; McCool, 2009; Mojica, 2009; Wilson, 2009). In relation to this, impending standardized tests also influenced teachers' instruction. Bardsley (2006) documented that teachers often rushed through topics to cover them before a standardized test even though they knew it was not appropriate developmentally for the student.

Also in relation to instruction, researchers documented that teachers found it very difficult to pre-plan lessons and scaffold these lessons according to individual students' needs and reasoning (Bardsley, 2006; Mojica; 2009). Teachers often questioned 
researchers for a pre-planned script to assist them in asking question and responding to students' responses.

\section{Criticism of Integrating Learning Trajectory Research in Practice}

Research on learning trajectories and their use in practice has not gone without criticism. In 2011, Susan Empson wrote an article critiquing the value of learning trajectories in mathematics education. She posed two important criticisms. Empson stated that learning trajectories focus on narrow domains of conceptual development. By focusing on specific domains, other components of students' understanding and thinking within the mathematics curriculum may be ignored. Empson stated that students often produce mathematical strategies that are not consistent with the path of a trajectory but they are still worth exploring and discussing within the classroom. She stated, "There was a progression in what students learned but 'deviations' were consistent and numerous, and, I am suggesting, fruitful - not anomalies to be ignored but significant occurrences that teachers could use to advance everyone's learning" (p. 580).

Empson also expressed that learning is a multi-dimensional process. Teaching and learning mathematics involves the intersection of many different processes like modeling, argumentation, explanation, and problem posing. Empson stated that she thought learning trajectories were too narrow in their content domains and did not take into account the multiple dimensions involved in "doing" mathematics.

Lastly, Empson (2011) stated "too tight a focus on learning trajectories may lead us to oversimplify or ignore critical drivers of learning associated with the teacher" (p. 572). Empson argued that teaching is a complex act that we, as a field, are still learning more about. The idea presented by learning trajectory researchers that teachers could 
watch for students' behaviors and respond to them with a corresponding task may be oversimplifying the complex relationship between teachers and students.

\section{Informing This Study}

Learning trajectories have been identified as a possible way for teachers to attend more closely to students within their classroom, help students meet standards, and foresee problems that they might have during instruction (Daro, Mosher, \& Corcoran, 2011). From the literature, learning trajectory based professional development programs seem to help teachers become better aware of students' strategies and the students' thinking associated with them, but it appears that it remains difficult for teachers to determine what these ideas imply for instruction (e.g., Bardsley, 2006; McCool, 2009; Wilson, 2009). In a critique of learning trajectories, Empson (2011) stated:

We know very little about how teachers do these things, in contrast to what we know about children's learning, whether it falls under the rubric of learning trajectory or not. As teachers interact with students and decide how to proceed, there are many types of decisions to be made - how to gather information about children's thinking, how to respond to it appropriately in the moment, how to design tasks that extend it, and even what to pay attention to...Further, learning mathematics in school takes work and depends fundamentally on interpersonal relationships of trust and respect, which cannot be designed into a tool or list of learning goals. (p. 587)

It is clear from the literature reported here that little is known about how teachers use knowledge of students' thinking in relation to learning trajectories for classroom instruction. A limitation of the studies referenced in this review (McCool, 2009; Mojica, 
2009; Wilson, 2009) is that they focused primarily on teachers' interpretations of clinical interviews and provided very little information about the teachers' daily classroom practices. Following her study, McCool (2009) called for varied teacher accounts with more classroom contact time.

In response to this call, I designed an ethno-methodological study (Garfinkel, 1967) in which I immersed myself into the classroom culture of three teachers and documented not only findings from the clinical interviews they conducted with their students but also their daily thoughts about students' thinking and their classroom practices. By spending an extended period of time with the teachers, I hoped to learn about their daily practices and thus, add to the literature on bridging the gap between research and practice.

From the literature it has also been noted that reflecting on students' thinking is a difficult process especially in written form (Bardsley, 2006; McCool, 2009; Wilson, 2009). This idea guided my data collection in that I allowed teachers to voice themselves in many mediums, but primarily through informal, one-on-one interviews.

Related to expression, it is relatively unclear how to classify teachers' understanding in relation to a particular learning trajectory because it is difficult to determine what is prior knowledge and what is knowledge gained from the learning trajectory based professional development. Wilson (2009) documented that the learning trajectory was impactful because the language of the trajectory surfaced in the teachers' language over time, but Bardsley (2006) documented that using language from the trajectory did not always correlate with a teacher's understanding of students' thinking. Based on these findings, I designed this study so that my interviews with teachers 
focused on their perceptions of students' thinking and instructional implications rather than how they assessed their students in terms of placement within the trajectory levels. I wanted to investigate whether and how the trajectory language emerged naturally and how the teacher viewed the trajectory in relation to students' thinking and instructional implications.

Lastly, it has been documented in the literature that learning trajectory based professional development effects both teachers' pedagogical knowledge and content knowledge as well as students' mathematical knowledge, as measured through standardized tests (e.g., Clements et al., 2011; Wilson, 2009). Wilson (2009) and Bardsley (2006) documented that knowledge of learning trajectories and instructional practices are not always correlated to each other. These cases helped to guide my study in that I wanted to explore facets and experiences that affected instructional practices beyond professional development practices (i.e., teaching experience, past experiences with students). If a teacher was successful at integrating knowledge of student thinking into practice, I wanted to investigate what experiences she attributed her success to. 


\section{CHAPTER III METHODOLOGY}

\section{Design of Study}

In this study, I used an ethno-methodological, multi-case study approach to examine how teachers perceive and use learning trajectory based research in clinical interviews, as well as classroom instruction. The purpose of an ethno-methodological study is to make sense of familiar, daily activities that often go unnoticed or undocumented. Garfinkel (1967) stated:

(Ethno-methodological) studies seek to treat practical activities, practical circumstances, and practical sociological reasoning as topics of empirical study, and by paying to the most commonplace activity of daily life the attention usually accorded extraordinary events, seek to learn about them as phenomena of their own right. (Garfinkel, 1967, p. 1)

Ethno-methodological studies acknowledge that classrooms are complex environments; this emphasis on the need to unpack the complexity in practical situations parallels this study's epistemological framework of classroom ecology. By using an ethno-methodological approach, the thoughts and actions of the teacher could be elaborated and shared. The ethno-methodological approach embraces the belief that the more that is known about an activity, the better it can be studied and explained. In sum, 
this approach helped me to make sense of the routines of teaching from the teachers' perspectives.

Several researchers (e.g., Ball \& Hill, 2009; Ball \& Forzani, 2009) have considered what the work of teaching entails. According to Ball, Thames, and Phelps (2008) one of the skills that the work of teaching requires is to be able to attend to students' mathematical thinking and determine if and how it will be used in instruction. Every day throughout the world, teachers are engaging in this work and making connections between individual students and whole classroom instruction, but it is important to know more about this process and how it occurs from the teacher's perspective. The ethno-methodological perspective allowed for a rich and detailed description from the teachers' perspectives to shed light on the practice of teaching.

With this perspective in mind, no phenomena can ever be understood in its entirety. Contained within the ethno-methodological perspective is the belief that, "though they (events) are intendedly conditional in their logical form, the nature of the conditions is such that they can often not be spelled out completely or fully" (Garfinkel, 1967, p. 2). Through this perspective, this study clarified the work of the teacher from the teacher's perspective and added a deeper understanding to the understanding of the work of teaching.

\section{Research Context}

All of the teachers in the study were at the same urban, public, K-6 elementary school, Terrace Elementary, located in the Midwestern United States. At the time of the study, 554 students attended Terrace and of these students $54 \%$ were boys, $46 \%$ were girls. They identified according to the following ethnicities: 54.7\% Black, 23.3\% White, 
10.3\% Multiracial, 9.6\% Hispanic, 1.6\% Asian, 0.4\% Native American, and 0.2\% Native Hawaiian. The average class size of the school was 18 students and the student to teacher ratio was 12 to 1 . At the time of this study, $80 \%$ of the students came from low-income households and were eligible for free or reduced-price school meals.

\section{Selection of Participants}

Three teachers were selected as case studies from a group of 24 elementary school teachers (grades 1-5): Mrs. Grey, Mrs. Purl, and Mrs. Brownstein. At the time of the study, the teachers were participating in a two-year professional development project. The aim of the professional development was for teachers to learn to use a learning trajectory as a formative assessment tool in a one-on-one interview setting to inform classroom instruction. This professional development is explained in more detail in Appendix A and an example of the learning trajectory that was used to inform the professional development is given in Appendix B.

Within the professional development, the teachers were introduced to the book, 5 Practices for Orchestrating Mathematics Discussion (Smith \& Stein, 2011), as a framework to help them integrate into practice individual knowledge of student thinking from the learning trajectory. Smith and Stein (2011) encourages teachers to enact five different practices as they plan and execute their daily lessons. These practices include anticipating student responses, monitoring student work and thinking, selecting appropriate student responses, sequencing responses by sophistication, and connecting students' responses. The teachers had practice using the Smith and Stein (2011) framework to use knowledge gained from individual interviews to inform classroom planning and instruction. 
Eight teachers of the twenty four in the professional development project volunteered to participate in the study. Three teachers were chosen, two fourth-grade teachers and one fifth-grade teacher, all females, because they taught similar grade levels. It was important to choose teachers at or around the same grade level because the grade determined the measurement content they would teach. For example, first- and secondgrade teachers focused on length measurement while third-, fourth-, and fifth- grade teachers focused on area measurement.

The teachers selected were also all from the same school, Terrace Elementary. It was important to choose teachers from the same school because the demographics of the schools varied widely throughout the district and I wanted to compare teachers with similar students. The background and experiences of each teacher are described in greater detail in chapters 4, 5, and 6 .

Because the level of detail sought regarding daily classroom practices for this study was extensive, only three teachers were chosen so that their experiences could be explored in greater depth. All of the teachers had experience designing tasks and conducting individual interviews with students as well as describing and analyzing student thinking using the trajectory as a tool. Two of the teachers, Mrs. Purl and Mrs. Brownstein, were first-year participants in the professional development, while Mrs. Grey was a second-year participant. I chose teachers who had varying levels of experience in the professional development to gain insight into the role of the professional development. 


\section{Data Collection}

There were four data collection phases for the study, shown in Figure 1. In Phase I, occurring in September of the school year, the teachers conducted initial clinical interviews on measurement topics with four students from their classroom. In Phase II, the teachers conducted follow up interviews with students in December and February of the school year prior to a unit of mathematics instruction on measurement. In Phase III, the teachers enacted a mathematics unit focused on a measurement topic lasting about three weeks. Lastly, in Phase IV, the teachers conducted a final, follow-up interview with their students. As part of each phase, the teachers participated in debriefing interviews with me to discuss the experience. The following section describes in detail what took place during each phase of the study. Each of the phases is described in detail with an adjoining timeline indicating when the events occurred.
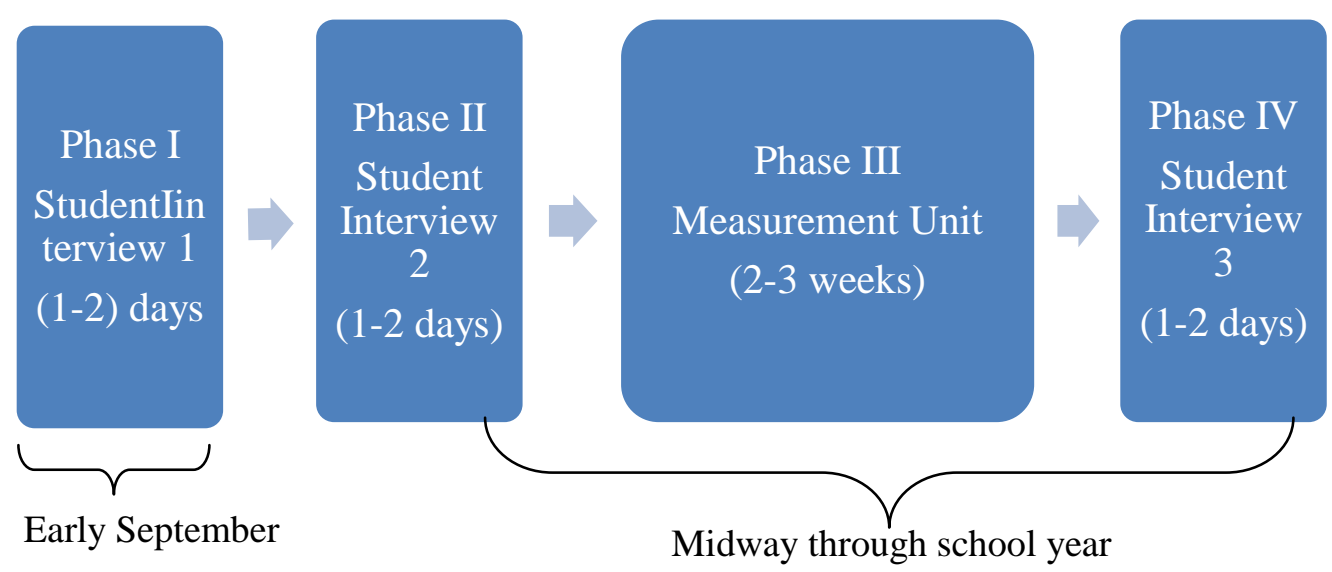

Figure 1. Progression of the phases of data collection.

Phase 1. Phase 1 occurred at the beginning of the school year in early September.

I asked the teachers to conduct individual interviews with three to four students from their classroom whom they felt would give them a representative sample of different 
types of thinking within their classrooms. The purpose of these interviews was to inform the teacher of student thinking within the classroom for lesson planning and to also act as a way for the teacher to monitor student thinking across the measurement unit.

Prior to Phase 1, I asked each teacher to select interview tasks that she believed were appropriate to assess the students' mathematical understanding as well as write a pre-interview reflection that described the tasks in a way that was clear enough for another teacher or researcher to replicate the tasks. I also asked the teachers to provide a rational for choosing these particular tasks. The reflection prompt that I gave the teachers is provided in Appendix C.

During Phase 1, each teacher posed tasks to students and wrote notes throughout the interview describing the students' actions and what the student did in response to the task. These interviews were video recorded. I was not present during the student-teacher interviews, because I assumed the role of the classroom teacher during that time.

During the interview, the teacher was given a small paperweight. The teacher was asked to move the paperweight to the front of the interview table when she felt that she noticed something important about a student's thinking or when she made an important decision related to the interview based on a student's thinking. The teachers used this motion as a silent indicator to me, when watching the video that something important had occurred and needed to be flagged as an event to discuss.

Phase 2 and 4: Phase 2 and phase 4 were similar to phase 1 . They occurred later in the school year, prior to and following a unit on measurement. In Phase 2 and 4 teachers conducted student interviews in a similar manner to Phase 1 . The teachers each sat down with four focus students and conducted follow-up interviews that lasted around 
30 minutes. During Phase 2 and 4 interviews, I offered each teacher the opportunity to add interview tasks or questions to supplement student interviews if she felt it would help her to better understand or clarify students' thinking. The purpose of Phase 2 and Phase 4 was for the teachers to reexamine students' thinking midway through the school year prior to a unit on measurement and following the unit on measurement, respectively.

Phase 3. Following Phase 2, each teacher was asked to enact an instructional unit on measurement. The fourth-grade teachers indicated that they taught measurement during December and the fifth-grade teacher indicated that she taught measurement in February, so this is when the units occurred for each teacher. The unit of instruction was situated in the context of length, area, and volume measurement because the professional development the teachers received was rooted in the study of these topics. I thought that if the teachers were to use learning trajectory based ideas or terminology, these concepts would most likely emerge within the unit that related to their professional development.

During the unit, the teachers were asked to design two lessons on measurement that each occurred over three to five days each. The teachers chose to teach these measurement lessons when other teachers in their building were teaching similar concepts. Other teachers in the building usually spent one to two days on measurement concepts, so the teachers in this study allocated more time than customary to investigating measurement concepts.

During the days that the unit occurred, each teacher was asked to wear a Déjà Vu camera to record events that were important to her. This camera was a small device pinned to the teacher's shirt that is connected to a collection box clipped to the teacher's pants. When the teacher pressed a button on the collection box, the camera collected and 
saved a 30-second video clip of the events prior to her pressing the button. Similar to the paperweight in the student interviews, each teacher was be asked to press the button on the camera when she felt that she had noticed something important about students' thinking or when she made an important decision related to the interview based on student thinking. All of the lessons that the teachers enacted were videotaped with a main camera at the back of the classroom as well as the Déjà Vu camera.

Teacher-Researcher interviews. During each of the four phases, I watched the videotapes and marked the time stamps on the main video camera for each of the events that the teachers found important. This process was also repeated daily during the lessons conducted during the unit on measurement during Phase 3. These clips were then used as the main focus of the teacher-researcher interview.

Each teacher sat down for one 60-minute teacher-researcher interview following each of the student interviews she conducted. Initially, the teacher was asked why she had chosen the tasks and what she hoped to learn about her students through using the tasks. I began each interview by having the teacher describe events or student actions that stood out to her during the interview. I had the teacher recall from memory first, to help capture events that still stood out in her mind as well as events that she may have thought about after the fact. From these events, I often asked the follow up questions of what the teacher thought this event meant in terms of the student's understanding and how it might inform her lesson. After the teacher had freely discussed all the events she remembered, I repeated the process with the video clips. The video clip was played, along with a transcription, and again the teacher was asked why the event was important to her along with follow up questions regarding the student's thinking and implication for instruction. 
At the end of the interview, the teacher was asked how, if at all, she felt the interviews connected to her instructional practices. Interview questions are described in more detail in Appendix D.

During Phase 3, the unit on measurement, each teacher and I were able to sit down for an interview almost daily as well as discuss students informally at lunch or recess. These encounters amounted to approximately 10-15 hours of discussion and interviews with each teacher. Every day during the unit, I asked the teacher to reflect on two questions immediately after the lesson. These questions were (a) What did you learn about your students while teaching today? And (b) How did what you learn today effect what you teach tomorrow?

In addition to these questions, after almost every day of instruction, the teacher sat down for a 40-60 minute teacher-researcher interview with me. In the interview, the teacher was first asked to describe why she chose this lesson or activity from that day, what she expected to see, and the goals of the lesson. Because the video had not been processed, the teacher was asked to recall freely any important events or student behaviors that she noted during instruction that day. Usually, I would ask the teacher why this event was important to her, what she learned about students' thinking, and also if she thought the event had implications for instruction.

Following this discussion, we examined the processed video clips that the teacher recorded from the previous day of instruction. Initially, I asked the teacher to recall freely what she remembered from the day before in terms of important events. After she recalled what she could and also discussed the events in terms of student thinking and instruction, we began to analyze the video clips. The teacher was shown each video that 
she clipped as well as transcription of what was said in the video. After watching each video, the teacher was first asked to provide some context about what she remembered. She was then asked why this particular clip held meaning for her and what it told her about her students' thinking or instructional practices. After watching and discussing all of the video clips, I usually ended the session with a recap of what the teacher thought her classroom understood as well as a review of her teaching plans for the next day. Throughout the interviews, I often asked the teachers about their experiences teaching and how this informed their day-to-day practice. These experiences were informative for me in determining how other factors influenced their teaching practices.

Twice during the instructional unit (middle and end), I asked the teachers about their perceptions of research in practice. My goal was to get a sense of the teachers' perceptions of professional development in general and, more specifically, the learning they experienced as a result of this particular professional development. I asked them questions such as; (a) What qualities define an effective or non-effective professional development? and (b) Tell me about a professional development that you found very effective in your classroom. Why did you value it? I then asked the teachers more specific questions about the learning trajectory-based professional development; (a) What were elements of this professional development that you found helpful or transitioned well into your classroom? and (b) What were elements of this professional development that were difficult to enact in your classroom? All interview questions can be found in Appendix D. The teachers' responses to these questions acted as jumping off points to investigate their perceptions of this particular study and the professional development in general. 
Figure 2 is presented below to help clarify the events and the data collection for

this study.

\begin{tabular}{|l|r|r|}
\hline \multicolumn{1}{|c|}{ Phases } & \multicolumn{1}{c|}{ Artifacts Collected } \\
\hline $\begin{array}{l}\text { Phases 1, 2, and 4: Student- } \\
\text { Teacher Interviews } \\
\text { (3 instances): The teacher } \\
\text { conducted individual interviews } \\
\text { with three or four students from } \\
\text { her classroom. }\end{array}$ & $\begin{array}{l}\text { Teacher was videotaped conducting student } \\
\text { interviews. } \\
\text { Teacher used paperweight to indicate when } \\
\text { she observed something important about } \\
\text { student thinking/ or felt she had made an } \\
\text { important } \\
\text { instructional decision. }\end{array}$ \\
\hline $\begin{array}{l}\text { Phase 3: } \\
\text { Measurement Unit: The teacher } \\
\text { designed 2-3 lessons focused on } \\
\text { measurement concepts lasting } \\
\text { for approximately 2-3 weeks. }\end{array}$ & - $\begin{array}{l}\text { The teacher completed the Lesson Plan } \\
\text { Guide. }\end{array}$ \\
& - $\begin{array}{l}\text { I videotaped classroom instruction. } \\
\text { I conducted formal observations of the } \\
\text { instruction. }\end{array}$ \\
& - $\begin{array}{l}\text { Teacher wore Déjà Vu camera and clicked to } \\
\text { capture 30 second video clips when she } \\
\text { observed something important about student } \\
\text { thinking/ or felt she has made an important } \\
\text { instructional decision. }\end{array}$ \\
\hline
\end{tabular}

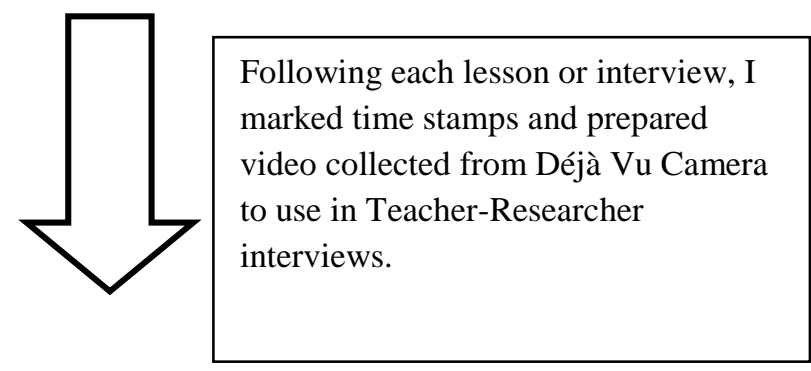

\begin{tabular}{|l|ll|}
\hline \multicolumn{1}{|c|}{ Part of All Phases } & & \multicolumn{1}{c|}{ Data Collected } \\
\hline $\begin{array}{l}\text { Teacher-Researcher Interviews: } \\
\text { conducted after each student } \\
\text { interview and lesson (approximately }\end{array}$ & $\bullet$ & Interviews were audio taped. \\
12 interviews per teacher) & & $\begin{array}{l}\text { Researcher took notes throughout the } \\
\text { interview. }\end{array}$ \\
\hline
\end{tabular}

Figure 2. Artifact collection by phases. Figure 2 highlights what occurred in each phase followed by the types of artifacts and data collected. In the upper part of figure 2, the phases are shown in the left hand column with the types of artifacts collected shown in the right hand column. The arrow indicates how I processed the artifacts collected and then used them to inform debriefing interviews. The lower part of the figure shows the main data source, the teacher-researcher interview, and the types of data collected from this source.

In summary, data collection produced the following kinds of data: observational data, interview transcripts, and classroom artifacts such as lesson plans and student work. 
Across all of the phases, each teacher participated in about 15 hours of teacher-researcher interviews, which resulted in approximately 70 pages of transcribed interviews for each teacher or approximately 200 pages total. The teachers also collected and submitted lesson plans, written reflections, and student work, that results in approximately 60 to 80 pages of artifacts per teacher. In addition to this, across each of the phases, I recorded approximately 100 pages of observational notes. Because of the quantity of data collected, the teacher-researcher interview transcripts acted as the primary data source for this study. In the next section, I describe in more detail the process used to analyze the data.

\section{Data Analysis}

To examine how teachers incorporate knowledge of individual interviews into whole classroom instruction and decision making, I began with the teacher noticing framework (Jacobs, Lamb, \& Philipp, 2010) as my primarily analytical tool. I had found this construct to be productive in previous work with teachers. However, the construct of teacher noticing has been primarily used in clinical interview settings and I experienced limitations in analyzing the data I had collected for this study. Thus, I incorporated provisional coding (Miles, Huberman, \& Saldana, 2014) to expand and elaborate codes to better fit the aims of this study. Miles, Huberman, and Saldana (2014) stated, "This approach begins with a 'start list' of researcher-generated codes, based on what preparatory investigation suggests might appear in the data before they are collected and analyzed. Provisional codes can be revised, modified, deleted or expanded to include new codes" (p. 77). I began the study with the provisional codes drawn from the construct of mathematics teacher noticing: attending to students' strategies, interpreting students' 
strategies, and deciding how to respond based on students' thinking. Then I used qualitative data analysis methods (Miles, Huberman, \& Saldana, 2014) to further refine and develop codes to analyze my data. I also used open coding throughout to capture themes possibly unrelated to noticing and to describe key themes related to teacher perceptions and beliefs throughout teacher-researcher interviews. Within this section, I discuss the teacher noticing framework and limitations as well as modifications that I made and the analyses that followed.

Teacher noticing. Initially, I framed my study through the construct of professional noticing of children's mathematical thinking (Jacobs, Lamb, \& Philipp, 2010) often referred to as teacher noticing. Jacobs, Lamb, and Philipp introduced this construct as "a way to begin to unpack the in-the-moment decision making that is foundational to the complex view of teaching endorsed in the national reform documents" (p. 169). They defined teacher noticing as "a set of interrelated skills including (a) attending to children's strategies, (b) interpreting children's understandings, and (c) deciding how to respond on the basis of children's understanding" (p.169). In the following paragraphs each of these tenets is described as well as the ways in which Jacobs, Lamb, and Philipp employed them.

In the Jacobs, Lamb, and Philipp (2010) study, the researchers worked with 131 teachers at varying stages in a professional development focused on children's mathematical thinking. To study teachers' knowledge of student thinking over time, they developed a noticing activity. During this activity, the teachers were shown a video of a student working on a task or students' written work to a mathematics problem. After watching the video and examining written work, they were given three prompts to reflect 
and write about. These prompts were stated as follows: "please describe in detail what you think each child did in response to this problem" (p. 178), "please explain what you learned about these children's understandings" (p. 179), and "pretend that you are the teacher of these children. What problem or problems might you pose next?" (p. 179). Each of these prompts was meant to address one of the three tenets of teacher noticing.

Attending to student strategies. The question "please explain in detail what you think each child did in response to this problem" (p. 178) was meant to address the tenet of attending to students' strategies. Jacobs and her colleagues expressed that teachers often make sense of situations by calling out important details. They have highlighted that these details are important because they provide a glimpse of what a student might understand mathematically. They hypothesized that teachers with greater expertise in children's mathematical thinking would be better able to attend to details and use them to decipher meaning.

Attending to student strategies refers to the teacher's ability to attend to particular events in an instructional setting. Jacobs, Lamb, and Phillip used a 2-point scale to assess each teacher's response based on the extent of evidence. The researchers coded the response as a 1 if it showed evidence that the teacher attended to important mathematical details and 0 if it did not show evidence.

Interpreting student strategies. The second prompt, "please explain what you learned about these children's understandings" (p. 179), acted as a way to assess teachers' interpretations of students' strategies. The researchers realized that the teachers could not construct a complete picture of a students' understanding from one video, but they wanted to see if the teachers' reasoning was consistent with the strategy, as well as research on 
students' thinking. They further defined interpreting student strategies as the teacher's ability to make claims about student understanding based on evidence gathered while attending to the students' strategies.

In the Jacobs et al. study, the researchers analyzed this particular prompt through a 3-point scale. They evaluated the amount of evidence the teacher provided in his or her response to justify reasoning about students' understanding and coded the response as either (0) lack of evidence, (1) limited evidence, or (2) robust evidence.

Deciding how to respond. The third prompt, "pretend that you are the teacher of these children. What problem or problems might you pose next?" (p. 179) acted as a way for Jacob's and her colleagues to investigate how teachers might response to students' thinking. The researchers realized that there was not one best response but instead they were interested to see how teachers use what they learn about students' thinking to propose and justify a task. They defined deciding how to respond as the teacher's ability to link his or her interpretation of student understanding to instruction.

This prompt was also analyzed using a 3-point scale. They evaluated the amount of evidence and justification for the instructional task that the teacher provided in his or her response and coded the response as either (0) lack of evidence, (1) limited evidence, or (2) robust evidence.

Teacher noticing in relation to this study. Teacher noticing was initially selected as a potential analytical framework for interpreting how the teachers in this study made sense and used student thinking because in prior research (Wickstrom et al., 2012) it was an effective framework for interpreting three skills that teachers used when implementing formative assessment using learning trajectories. I found that the tenets of 
noticing complemented the components of the learning trajectory. A learning trajectory has three main components; observable behaviors, mental actions on objects, and instructional tasks or, in simpler terms, what students are doing, what they understand, and a proposed instructional task to follow. I found that the way teachers enact the components of the learning trajectory is through the three tenets of teacher noticing; attending to student's strategies, interpreting student strategies, and deciding how to respond. This comparison is shown in Figure 3.

\begin{tabular}{|c|c|}
\hline $\begin{array}{c}\text { Learning Trajectory } \\
\text { (Sarama \& Clements, 2009) }\end{array}$ & $\begin{array}{c}\text { Teacher Noticing } \\
\text { (Jacobs, Lamb, and Philipp, 2010) }\end{array}$ \\
\hline $\begin{array}{c}\text { What students do } \\
\text { (observable behaviors) }\end{array}$ & Attending to Student Strategies \\
\hline $\begin{array}{c}\text { What students are thinking } \\
\text { (mental actions on objects) }\end{array}$ & Interpreting Student Strategies \\
\hline $\begin{array}{c}\text { Instructional Tasks } \\
\text { (developmental Progression) }\end{array}$ & $\begin{array}{c}\text { Deciding how to respond based on } \\
\text { children's understanding }\end{array}$ \\
\hline
\end{tabular}

Figure 3. Learning trajectory and teacher noticing comparison. Figure 3 compares the construct of learning trajectories (Sarama \& Clements, 2009) on the right with the construct of mathematics teacher noticing (Jacobs, Lamb, \& Philipp, 2010) on the left.

Limitations of teacher noticing. I chose teacher noticing as an initial starting place because I thought that it illuminated the teacher's view of the classroom from her perspective and thus complemented the theoretical construct of teacher research. One of the key tenets of the construct of teacher research is that teaching is a complex act that can be better understood by attending to the unique perspective of the teacher (Cochran Smith \& Lytle, 1993). Instead of looking from the outside at teachers' actions and student behavior, the framework of noticing allowed me to look from the teachers' perspective.

One of the limitations of the teacher noticing construct is that the researchers within the study developed the construct within a clinical environment. The teachers were shown a video of a student that was already chosen, analyzed, and deemed 
mathematically important by researchers. Within this study, I allowed teachers to freely choose what they found to be important within interviews with their students and classroom instruction. I had no idea what events teachers would choose or why they would choose them, so I found the original tenets and numerical scoring to be too narrow given the context of my study.

Using qualitative methods (Miles, Huberman, \& Saldana, 2014), I instead envisioned the three tenets of teacher noticing as broader analytical categories to be explored. I wanted to explore the types of actions teachers noticed, what understandings, if any, these actions revealed, and which actions the teachers connected to future instruction. I decided to call each episode that the teacher noticed an event. The event was then composed of four components: what the teacher noticed, interpreted understanding, implications for teaching, significance to the teacher. These components are described in greater detail below and shown in Figure 4. Figure 5, also shown below, shows how the components of teacher noticing translated into the constructs explored within this study. 


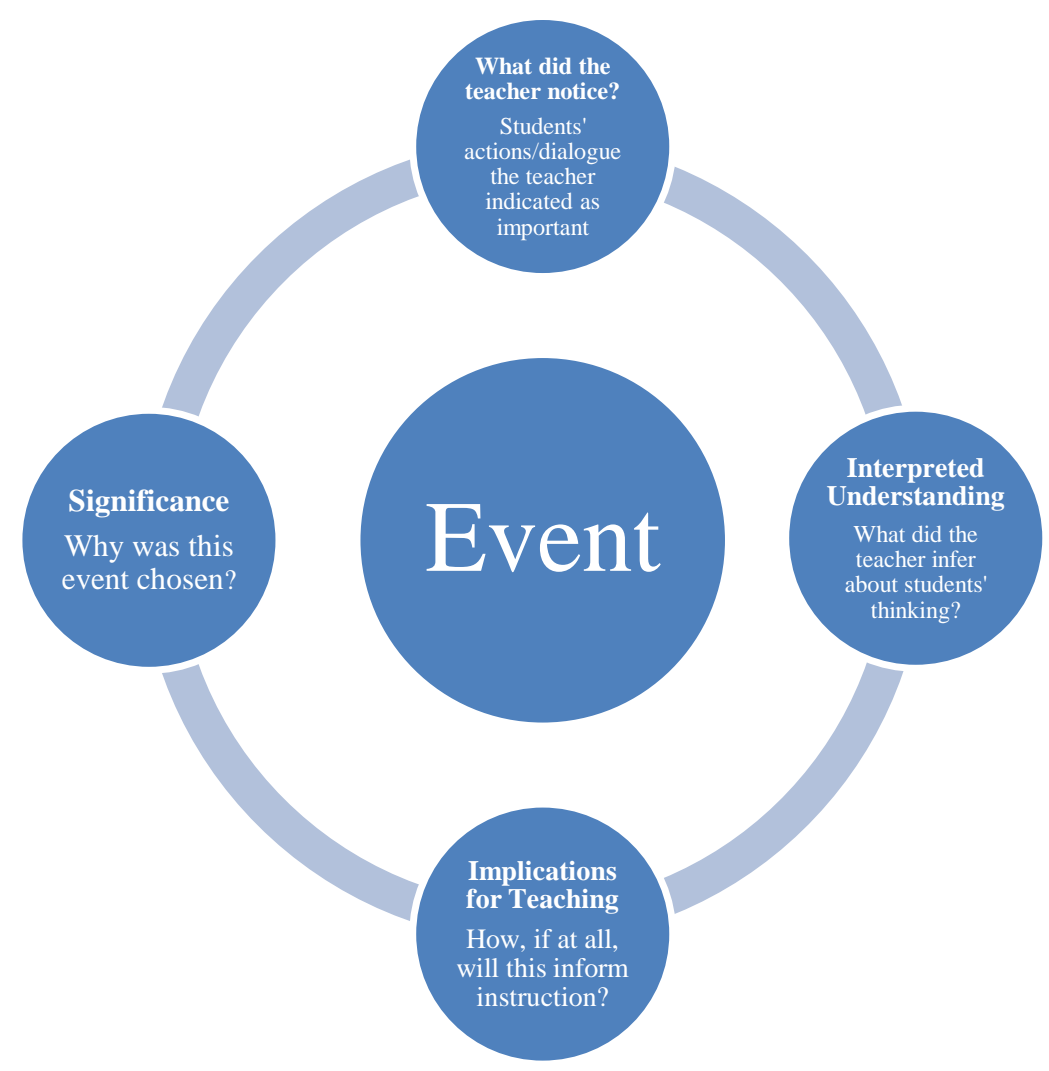

Figure 4. Description of event. The teacher began by discussing why the event was important followed by each of the other three circles in the figure. It is important to note that all components of the event were not always discussed.

What the teacher noticed. The student actions component of the event stemmed from Jacobs, Lamb, and Philipp's (2010) construct of attending to student strategies. An event was defined as the thirty-second video clip selected by the teacher. Within each event, teachers noted students doing one or more actions (e.g., drawing in square units as well as counting). Jacobs and her colleague's construct measured whether or not the teacher attended to pre-determined actions presented within a video. In this study, the teachers determined what actions were noticed, so I used this construct to elaborate on the types and ranges of actions as well as what classroom activities the actions were connected to. 
Interpreted understanding. The interpreted understanding component stemmed from Jacob, Lamb, and Philipp's (2010) construct of interpreting student strategies. For this component, I wanted to explore the multiple facets of students' understanding. Within the Jacobs et al. study, the teachers were viewing a single student with whom they had no personal experience. I found that when teachers discussed their own students, there was other facets of understanding like past instructional experiences and students' personalities that effected the teachers' interpretations. I also did not have multiple teachers viewing the same event. Instead of evaluating the depth of the understanding the teachers provided, I explored the types of understanding or attributions the teachers provided, if any, for what they noticed.

Implications for teaching. The implications for teaching component of an event stemmed from Jacob, Lamb, and Philipp's (2010) construct of deciding how to respond based on children's understanding. In the Jacob et al. (2010) study, they investigated the tasks the teachers posed and the level of justification related to students' understanding the teachers used when proposing the task. In my particular study, I found that not every event yielded in an implication for teaching. Instead of investigating the level of depth and justification, I investigated and explored the events that lead to implications for teaching, why, and what the implications were.

Significance. While analyzing my data, I saw a fourth analytical category emerge related to the other three. Because the teachers freely chose each event, they often described the importance of the event to them such as an unexpected response or a student showing growth. I felt that the importance to the teacher was critical to record because it gave insight on the reasons teachers notice and record events. 


\begin{tabular}{|c|c|}
\hline $\begin{array}{c}\text { Mathematics Teacher Noticing } \\
\text { (Jacobs, Lamb, \& Philipp, 2010) }\end{array}$ & Analysis Within This Study \\
\hline Attending to Student Strategies & What the Teacher Noticed \\
\hline Interpreting Student Strategies & Interpreted Understanding \\
\hline $\begin{array}{c}\text { Deciding how to respond based on } \\
\text { children's understanding }\end{array}$ & Implications for Instruction \\
\hline & Significance to Teacher \\
\hline
\end{tabular}

Figure 5. Teacher noticing in relation to this study. This figure shows the three constructs of mathematics teacher noticing (Jacobs, Lamb, \& Philipp, 2010), in the left column, and the analytical constructs they informed in this study in the right column.

\section{Analysis of Each Phase}

For the student interview phases and the instructional unit, I used the transcripts of my interviews with the teachers as the primary data source. The transcripts from my interviews with each teacher were separated into events. The 30-second video clip, noted by the teacher, determined an event. When the teacher discussed each clip and the students within the clip that was considered an event and the event was composed of what the teacher noticed or the student actions, her interpreted understanding, implication for instruction, and significance to the teacher. It is important to note that an event could be composed of multiple student actions because a child could be doing two things simultaneously (e.g., drawing and counting area units). If an event was composed of multiple actions it was coded as all of the actions contained within the event. Once a new video was presented that signified the end of an event in the transcript. Responses to other interview questions, related to the broader professional development, were grouped by responses to each question. The process of how these events were analyzed is described below. 
Analysis of events teachers indicated as important. I began the analysis by first reading the transcripts and taking qualitative, descriptive notes about each of the events. I recorded where an event began and ended and notes related to each of the constructs if the teacher mentioned those ideas. I repeated this process for each of the teachers.

Following the note-taking phase, I used an event-listing matrix (Miles, Huberman, $\&$ Saldana, 2014) to record the events the teacher noted in a chronological manner. I devised a matrix for each teacher in which the columns were the analytical categories described above and the rows represented each event in terms of those categories. An example of the matrix is shown below in Table 6

In the first column, I began by noting student or students that the teacher commented on for each event. Initially, I thought it might be important to record whom the teacher discussed and how frequently. Following that, in the second column I recorded the teacher's description of the event. If the teacher described the student's understanding or an implication for teaching, this was also recorded as well as the teacher's reason for selecting this particular event. Lastly, I noted whether what prompted the event was stimulated by video or from actual events that occurred that day. 


\begin{tabular}{|c|c|c|c|c|c|c|}
\hline Student(s) & $\begin{array}{c}\text { What the Teacher } \\
\text { Noticed }\end{array}$ & $\begin{array}{c}\text { Interpreted } \\
\text { Understanding }\end{array}$ & $\begin{array}{l}\text { Implication for } \\
\text { Teaching }\end{array}$ & Significance & Video & Actual \\
\hline $\begin{array}{l}\text { Ali } \\
\text { (Interview } \\
\text { Student) }\end{array}$ & $\begin{array}{l}\text { Ali was not making } \\
\text { whole boxes } \\
\text { (square units) } \\
\text { anymore except for } \\
\text { the last row (when } \\
\text { tiling a rectangular } \\
\text { region). She knew } \\
\text { that one (rectangle) } \\
\text { has } 36 \text { and the other } \\
40 \text { but she kept } \\
\text { drawing in } 37 \text { for } \\
\text { the rectangle that } \\
\text { measured } 36 \text {. }\end{array}$ & $\begin{array}{l}\text { Mrs. Brownstein } \\
\text { thinks that Ali } \\
\text { intuitively knows } \\
\text { what the area will } \\
\text { be, but doesn't } \\
\text { know how to } \\
\text { express herself } \\
\text { with a drawing }\end{array}$ & $\begin{array}{l}\text { Does not know the } \\
\text { implications for } \\
\text { teaching }\end{array}$ & $\begin{array}{l}\text { Mrs. } \\
\text { Brownstein } \\
\text { thought the } \\
\text { event was } \\
\text { interesting }\end{array}$ & & $\mathrm{x}$ \\
\hline
\end{tabular}

Figure 6. Example of event within matrix. Figure 6 shows an example of an event after it was collapsed into matrix form. The first column indicates the student that the teacher referred to. The second, third, fourth, and fifth columns are the pieces of the events such as what the teacher noticed. The last two columns indicate whether the event was noted by video camera or freely recalled.

Descriptive coding. Miles, Huberman, and Saldana (2014) stated that the first step in coding is to provide descriptive information about the data chunks or, in this case, events. They also stated that coding is an essential part of the reflective process in data analysis. It can be used to help organize each event and see commonalities or differences. They stated, "coding is used to retrieve and categorize similar data chunks so that the researcher can quickly find, pull out, and cluster the segments relating to a particular researcher question, hypothesis, construct, or theme" (p. 72). I began by using descriptive codes to define loosely each event; it's significance to the teacher, the teacher's description of student thinking, and implications for instruction. After the initial swipe through each teacher's data, I began to collapse and/or separate codes and use more rigid definitions to describe the coding. As new codes emerged, the data were reanalyzed with attention to the new codes. This process was repeated three times.

What the teacher noticed. For each event, I began by coding what the teacher noticed within the event and what task the action centered around. After each event was coded, I scanned the events again to see if codes were similar in nature or could be 
collapsed. I repeated this process for each lesson and each teacher. For this piece of analysis, the codes centered usually centered around specific tasks or routines within the classroom. As new codes emerged in the analysis, I reanalyzed each event for each teacher looking to see if the code had been missed.

For each teacher, I created codes that described what the event pertained to. In figure 7 , each of the codes in shown along with a short description. It is important to note that not everything the teacher attended to involved a student's actions. Sometimes it involved students' statements, word choices, and written accounts. Each of these different categories was ways in which teachers' noticed events in the classroom.

\begin{tabular}{|c|c|}
\hline What the Teacher Noticed & Description \\
\hline Drawing Strategy & $\begin{array}{l}\text { The event involved a student drawing a picture to represent or } \\
\text { help find their answer. }\end{array}$ \\
\hline Statement & $\begin{array}{l}\text { The student makes a claim or states a response in class. Example: } \\
\text { The teacher asks what is the area of the figure and the student } \\
\text { responds } 4 \text {. }\end{array}$ \\
\hline Written Answer & A solution written on a page without work shown. \\
\hline Question & The student poses a question to the teacher. \\
\hline Written Strategy & $\begin{array}{l}\text { The student's strategy for finding the solution is written down on } \\
\text { paper. }\end{array}$ \\
\hline $\begin{array}{r}\text { Length/Area/Volume Measurement } \\
\text { Strategy }\end{array}$ & $\begin{array}{l}\text { The student uses tools to find the length, area, or volume. } \\
\text { Example: laying tiles down and counting them to find the area of a } \\
\text { rectangle. }\end{array}$ \\
\hline $\begin{array}{r}\text { Length/Area/Volume Counting } \\
\text { Strategy }\end{array}$ & $\begin{array}{l}\text { The way in which the child counts the length, area, or volume. } \\
\text { Example: For area, students may count individual units, skip count } \\
\text { by rows, or use the algorithm. }\end{array}$ \\
\hline Area/Volume Visualization & $\begin{array}{l}\text { A statement, the student makes, involving how they see volume or } \\
\text { area. Example: students states that the volume of a prism is like an } \\
\text { elevator visiting multiple floors. }\end{array}$ \\
\hline Building Strategy & Students using tools to build a rectangle with a given area. \\
\hline Journal Account & Written reflections/definitions made by students in their journal. \\
\hline Student to Student Interactions & $\begin{array}{l}\text { Interactions, discussions, conversations made by students to each } \\
\text { other within groups or pairs. }\end{array}$ \\
\hline Behavior & $\begin{array}{l}\text { Mainly non-mathematical events such as students rushing to } \\
\text { complete a problem or not attempting a task. }\end{array}$ \\
\hline Language Comprehension/Usage & $\begin{array}{l}\text { The way in which students use and interpret language. Example: } \\
\text { The teacher notices the student is confusing the words area and } \\
\text { perimeter. }\end{array}$ \\
\hline
\end{tabular}

Figure 7. Codes for event types. Figure 7 shows the codes used to capture what the teacher noticed. The left column shows different types of events the teacher noticed and the right column gives a short description of that event.

Interpreted understanding. Following coding of events, if a student understanding was provided with the event it was coded next. Initially, I noted whether 
an understanding was provided or not and I also wrote out descriptions of what the teacher understood about the student. From this initial description, I then analyzed the type of understanding. This included understandings such as mathematical reasoning in terms of a specific content, the student's personality or past instruction, and factors related to the question posed or language used. I also analyzed the events in relation to the learning trajectory by analyzing each event for learning trajectory terminology or description of different levels of thinking related to the measurement trajectories. After each understanding was coded loosely, each event was coded again and codes were collapsed or separated to create more concrete definitions. As new codes emerged, the data was reanalyzed with attention to these codes. This process was repeated three times.

Implications for instruction. If an implication for instruction was provided for the event, it was coded next. Initially, for each event, I wrote out whether an implication for instruction was provided or not and wrote a description of the implication. As with the other two components, from the initial description, I analyzed the implication. After each implication event was loosely coded, each event was coded again and codes were collapsed or separated to create more concrete definitions for each code. As new codes emerged, the data was reanalyzed with attention to these codes.

Significance. Throughout the study, the teachers would often discuss the importance of the event and their rational for selecting the event. For each event, I initially wrote out if the teacher provided importance for the event. I analyzed different types of importance the teacher provided and then coded each event attending to these explanations. As new types emerged, I reanalyzed the data with attention to them. 
Through the matrix representation (Miles, Huberman, \& Saldana, 2014), for each teacher, I was able to see which actions the teachers were able to link to understandings and implications for instruction. This was also repeated by comparing events to instructional implications to see what types of events lead to implications for instruction and what types of instructional implications. I also monitored to see how many times the teacher completed a loop of event, understanding, implication when describing an event and its importance.

Interview questions unrelated to video clips. Interview questions that were unrelated to the video clips were chunked by interview questions. Using a descriptive method of analysis (Miles, Huberman, \& Saldana, 2014) the response to each question was transcribed and described. Following this, the interview questions were analyzed to draw out themes within the response or ideas that the teacher indicated as important. I noted each theme that emerged from each source and compared interview questions within each source to one another to support themes. If new themes emerged later in the analysis, I reexamined the data to evaluate this new evidence. If dis-confirming evidence arose, I reevaluated the interpretation of my data. This process entailed reflection and multiple re-readings of the data collected.

\section{Analysis Across the Three Cases}

After each teacher-indicated event and interview question had been thoroughly analyzed and codes and themes had been defined and noted for each teacher, I began to look across the cases. After completing a formal summary for each, I used a cross-case analysis to look beyond individual teachers to consider the group. This was done by comparing themes across participants and events looking for similarities and differences 
as well as evidence that confirmed or disconfirmed themes. I discussed types of events that each of the teachers found important as well as types that were unique to each teacher. I also discussed and contrasted the types of understanding the teachers provided and how this informed their instructional practices.

\section{My Perception}

The purpose of this dissertation is to make sense of research in practice from the teacher's perspective. I realized that often this perspective was disjoint and the teacher did not always reach a conclusion about her experience. As I analyzed each teacher and wrote her account, I realized that there were themes that I noticed across time in relation to each teacher. Following the analysis of each teacher, I analyzed broader themes that I observed through my notes, and that arose during my time with each teacher.

\section{Trustworthiness and Validity}

The idea of establishing validity and trustworthiness within qualitative research is often debated within the research community (Glesne \& Peshkin, 1992). Glesne and Peshkin (1992) stated, "Most agree that we cannot create criteria to ensure that something is 'true' or 'accurate' if we believe concepts are socially constructed" (p. 49). Within this study, there were potential threats to trustworthiness such as researcher bias or agenda.

To address validity, using Creswell (1998), I implemented several procedures to help establish trustworthiness. Each of these is described in detail below.

Prolonged engagement. Creswell (1998) described prolonged engagement as "extended time in the field so that you are able to develop trust, learn the culture, and check out your hunches" (p. 49). Within this study, I spent several months with each teacher to get to know her, her classroom, and her daily teaching practices. Throughout 
the study, I was able to reflect on my observations of teachers and continually follow up with them to check my hunches.

I found prolonged engagement to be important within this study because it allowed me to document normal classroom life. To better assimilate into the teachers' classrooms, I spent time throughout the semester observing and working with students. I also set up my video camera and began taping a week early so that students were somewhat accustomed to my presence. I allowed the students to look through my camera lens so they could see what I was videotaping as well as ask me questions throughout the process. For the most part, the students were only fascinated the first day and came to see me as another teacher or classroom helper. The students felt comfortable asking me to tie their shoes, button coats, or help them with spelling problems. I think, for the most part, the students were comfortable with me there.

Related to prolonged engagement, is the role of reciprocity in my research. Glazer (1982) defined reciprocity as "the exchange of favors and commitments, the building of a sense of mutual identification and feeling of community" (p. 50). Within this research study, I felt that I needed to participate in the community and work with the teachers to gain their trust and also understand their perspectives.

Early on in the study, while working with the first teacher, I ran into an obstacle when collecting my data and capturing the teacher's perspective. I realized that each teacher needed more time in her day to be able to reflect with me then she had available. The teachers at Terrace Elementary School were only allotted one 40-minute planning period a day. They used this time to make copies and plan lessons, so I felt that it was unfair for me to ask for this time. 
I decided to design an agreement that would allow the teachers more time to work with me, but still be able to use their planning period as they wanted. For each teacher, I agreed to take on one of their non-mathematics teaching responsibilities. This included teaching math intervention, reading and spelling, and science. I am a certified classroom teacher as well as substitute teacher, so the school approved this agreement. While I taught, the teachers took their 40-minute planning period and during their regularly scheduled planning period they sat down for interviews with me. This extra time allowed for a teacher reflection almost daily.

This agreement complemented the epistemological and ontological groundings of Teacher Research and Classroom Ecology, because the teachers and students began to see me as a part of their community. The teachers often regard teaching at Terrace and within Terrace's district as a difficult task because of the student population. By taking on teaching responsibilities, the teachers began to respect me and often complemented my work with their students to other teachers in the building. By teaching in the classrooms, I got to know the teachers' students and this helped in interviews. The teachers felt comfortable discussing students by name because they knew that I was familiar with their students, as well.

The role of the researcher and researcher bias. Creswell (1998) also discussed that is important to reflect on subjectivity and how it will be addressed in the research. In this study, my goal was to document and record the perspective of the teachers as they attempted to integrate knowledge of student strategies into their daily lessons. From the beginning, I realized that my perspective may influence how the teachers react to lessons and plans, so I reiterated to them that I am documenting their story and my experience 
may bias their decisions. I told them that my role would be to observe and document their experiences. I tried my best not to provide feedback or input to the teachers during the study, even when asked to do so. Throughout the study, I reflected on my bias and also looked for incidences in which I may have biased the research.

Triangulation and peer review. Within this study, I also implemented the ideas of triangulation and member checking to help establish validity. I collected many different forms of data to establish what occurred within the classroom. I collected video data of the classroom and student interviews, artifacts of student work, audio data of teachers' perceptions of the classroom, and I, myself, was also in the classroom daily taking observational notes.

I also participated in peer review with my advisors, Cindy Langrall and Beth Hatt. I shared interview transcripts, tables, analytical thoughts, and drafts of my writings with both of them. Each of them provided reflection and input on my work.

Participant checking. Participant checking was crucial in the validity of this study. Participant checking is "sharing interview transcripts, analytical thoughts, and drafts of the final report with research participants to make sure you are representing them and their ideas accurately" (Glesne \& Peshkin, 1992, p. 49). Within this study, I wanted to accurately describe the perspective of the teachers. Following data collection and analysis, each of the teachers involved was asked, if willing, to read through interviews and analysis. I also contacted each teacher and scheduled a follow up interview to discuss my writings with him or her. I asked them for their feedback, comments, and possible amendments. Comments included further elaboration on statements made during interviews and clarifying misunderstandings. The teachers were 
also given the opportunity to omit statements that I had made within the document. The teachers chose not to omit any of the data or findings from the study.

Ethics and institutional review board. This study was contained within a larger study, described in Appendix A. This study was approved by the IRB under the number 2011-0170 and entitled Formative Assessment Improving Teachers' Instructional Practices. Consent was sought from each of the teachers prior to the study.

\section{Summary}

In summary, the aim of this study was to explore teachers' perceptions and use of learning trajectory based research. This study was conducted using an ethnomethodological multi-case approach in which I spent an extended period of time with three elementary teachers over the course of the school year. The teachers participated in four phases of data collection, which included student interviews and classroom instruction. Across the phases, the teachers participated in researcher-lead debriefing interviews, which acted as the primary data source for the study.

I analyzed the data using mathematics teacher noticing (Jacobs, Lamb, \& Philipp, 2010) as an initial qualitative construct and then I used provisional coding (Miles, Huberman, \& Saldana, 2014) to extend and define new codes related to the initial construct. To establish trustworthiness, I spent an extended time in the field and collected multiple forms of data. I also participated in peer review as well as member checking with my participants.

In the next three chapters, a case of each teacher is presented. Each chapter begins with a background description of the teacher, her experiences, and a description of the classroom. Following this description, the teacher's interviews and lessons that composed 
her unit on measurement are discussed. Within each interview or lesson, the tasks are described followed by a table that highlights the events the teacher noticed. Each of the events is described by the action or actions noted, students' understanding, implications for teaching, and the importance to the teacher. After each activity is described in relation to the events, noted, the teacher's perceptions and my perceptions of the study are discussed within the conclusion. 


\section{CHAPTER IV}

MRS. GREY

\section{Description of Mrs. Grey and Her Classroom}

At the time of the study, Mrs. Grey was a fourth-grade teacher at Terrace Elementary School. Mrs. Grey had six years of teaching experience with three years at the fourth-grade level. Mrs. Grey held a bachelor's degree in elementary education and was considered a highly qualified teacher. Teaching was Mrs. Grey's second career. Prior to becoming an elementary school teacher, Mrs. Grey was an activities director at a nursing home.

Mrs. Grey's classroom matched the typical demographics of Terrace Elementary. There were 20 students in Mrs. Grey's classroom. There were nine girls and 11 boys. Of the students, 16 students were Black, three students were White, and one student was Hispanic.

Mrs. Grey's classroom was very clean and organized. Since she was a relatively new teacher, she had little furniture, such as bookshelves or storage units, in comparison to other teachers. Her desk, the main chalkboard, and a group carpet were at the front of the room. She would often call the class up to sit on the carpet while introducing a topic. The students' desks were arranged in groups scattered across the classroom. In the back of the room, there were two student computer tables and a semi-circle shaped table where Mrs. Grey could meet individually with students. Mrs. Grey conducted her interviews 
with students at the semi-circle table. On the walls, Mrs. Grey had classroom procedures posted and important grammatical and mathematical terms and formulas for students to reference during standardized tests. On the back wall, Mrs. Grey had a bulletin board with 20 clipboards, one for each student. On these clipboards, she highlighted something she thought the student was doing well and also something for students still needed to master.

Mrs. Grey expected her classroom to be relatively quiet during instruction and work time. For Mrs. Grey, instruction and teaching was a serious matter and students were expected to listen and be respectful. When students followed directions, they were rewarded with candy or cards they could redeem for prizes from the principal.

As stated above, Mrs. Grey arranged students' desks in groups. She determined these groups based on which students worked well together and would remain focused on the task. Even though students, physically, were arranged in groups, Mrs. Grey did not always have them work together in groups on tasks. For mathematics instruction, students worked together in groups once a week with a set structure for how group work should be enacted. Each student in the group had a particular role and responsibility. She stated:

When we have done group work in math, they have task cards where each person has a job because we have been doing it on Fridays, in the mornings, during the problem solving portion of the unit. Each person has a specific job. One person is in charge of clarifying the questions, and one person is in charge of getting the materials they need. (Mrs. Grey, September 28)

Another component of Mrs. Grey's instruction was the mathematics journal. Mrs. Grey had students keep mathematics journals to help them express their ideas about 
mathematics in writing. She said that she thought this would help them to prepare for standardized tests. To maintain order and keep the classroom quiet, Mrs. Grey would often have students write in their mathematics journals. For instance, if students were working in groups and discussion became too loud, Mrs. Grey would ask them to stop discussion and begin to write their thoughts within their mathematics notebooks.

On a normal day, Mrs. Grey's classroom was usually quiet and students only discussed ideas or questions when directly asked. Students who acted out or misbehaved were sent outside or to the principal's office.

Mrs. Grey participated in group planning with the other fourth-grade teachers in the building to help maintain a consistent pace among the different classes. Mrs. Grey usually adhered to what was planned and sometimes supplemented with other activities.

This was Mrs. Grey's second year as a participant in the learning trajectory based professional development. She participated in a two-week summer session the first and second year of the professional development, summer 2011 and 2012, as well as a yearlong lesson study process. She had practice interviewing students using learning trajectory tasks as well as designing and implementing lessons.

\section{School Year Events}

In this section, I discuss activities that Mrs. Grey participated in as part of the study. These activities included three student-teacher interviews as well as a measurement area unit composed of several sets of lessons. In each activity, events that Mrs. Grey indicated as important are described in terms of the action noted as well as student understandings and implications for instruction. 
Mrs. Grey was asked to choose four students to interview throughout the school year as a means to inform lessons and planning on measurement activities. Mrs. Grey chose four students based on her perception of their mathematical ability, which was determined by the students' standardized test scores, as well as their behavior during classroom instruction. The students she chose were Hailey, a white female, John, a black male, Lisa, a black female, and Devan, a black male. The students are listed in the order of their perceived ability.

During each of the three student-teacher interview, Mrs. Grey posed four tasks to her students. Mrs. Grey chose each task because she thought the task closely resembled a specific measurement lesson that would be enacted during the school year. The interview tasks and Mrs. Grey's purpose for posing each task are presented in Figure 8.

\section{Interview 1}

Mrs. Grey's first set of student-teacher interviews took place in late September. School had been in session for about a month. Mrs. Grey interviewed each of her four students for a half hour, using four interview tasks, described below. Mrs. Grey took detailed notes of what each child did in response to each task. At this point in time, I had not yet acquired the Déjà Vu camera, so Mrs. Grey was asked to keep track of student actions during the interview that were important to her and revealed to her something about students' thinking. Directly following her interviews, I interviewed Mrs. Grey, so that she would be less likely to forget any details. 


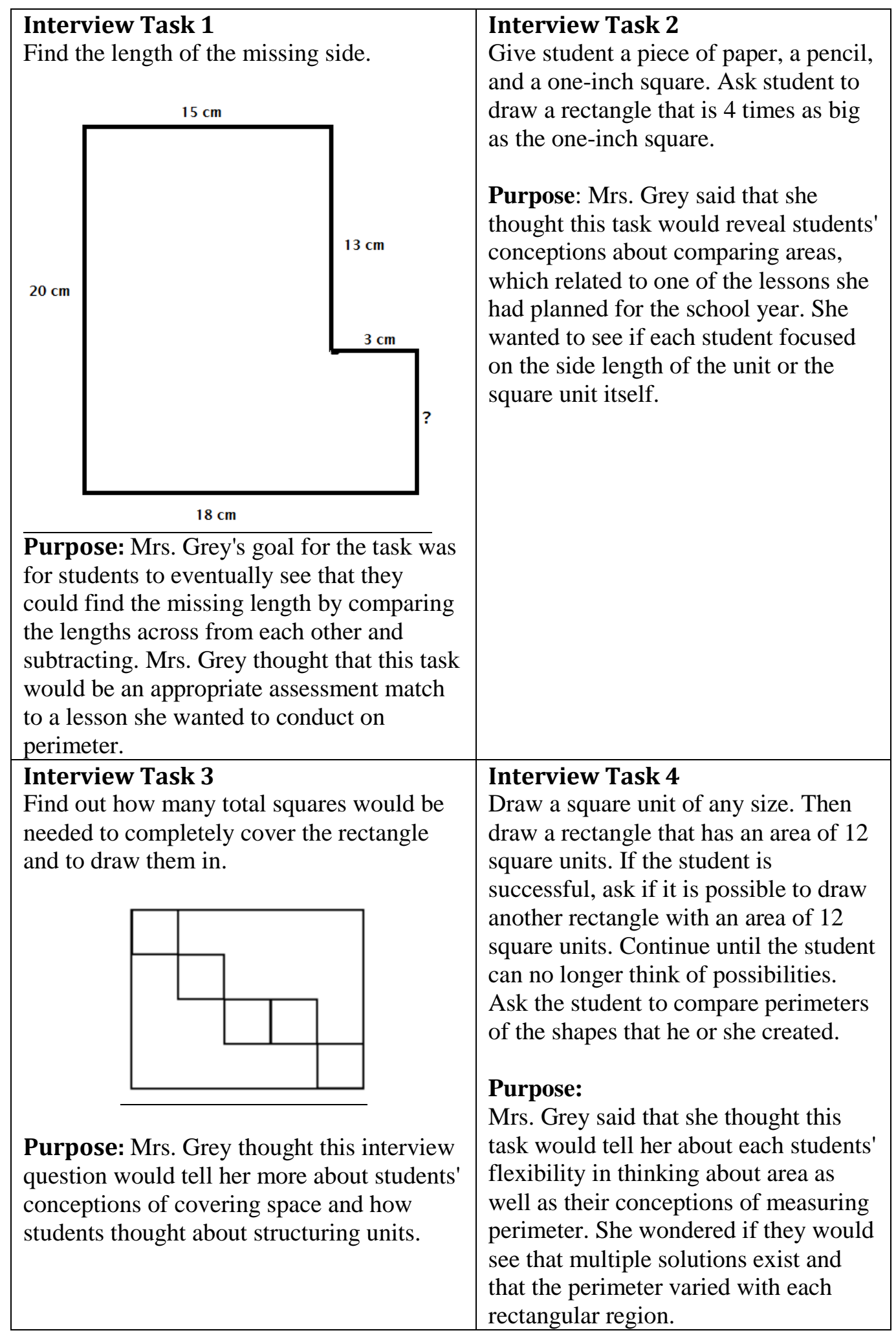

Figure 8. Mrs. Grey's interview tasks. 
What Mrs. Grey noticed. During the first student-teacher interview, Mrs. Grey noticed six events that were either drawing strategies or statements made by students. Mrs. Grey discussed students' understanding in two of the events as well as implications for teaching in two of the events, as noted in gray. Two of these events referenced specific students and three referenced two or more students. Mrs. Grey primarily commented on interview tasks in which she asked students to draw a rectangle four times as big as a unit square and an area conservation task because she said they were more closely related to what she would be initially teaching with area.

\begin{tabular}{|c|c|c|c|}
\hline \multicolumn{4}{|c|}{ Interview 1: September } \\
\hline What the Teacher Noticed & Interpreted Understanding & $\begin{array}{l}\text { Implication for } \\
\text { Teaching }\end{array}$ & Significance \\
\hline \multicolumn{4}{|c|}{ Four Times as Big Task } \\
\hline $\begin{array}{l}\text { Drawing Strategy: Traced around the } \\
\text { outside of the rectangle four times. } \\
\text { (Hailey) }\end{array}$ & $\begin{array}{l}\text { Four times as big means to grow } \\
\text { rather than four connected units. }\end{array}$ & (none provided) & $\begin{array}{l}\text { Unexpected } \\
\text { response. }\end{array}$ \\
\hline $\begin{array}{l}\text { Statement: Student stated drawing } \\
\text { four units is not the same as four times } \\
\text { as big. (John) }\end{array}$ & (none provided) & (none provided) & $\begin{array}{l}\text { Unexpected } \\
\text { response }\end{array}$ \\
\hline $\begin{array}{l}\text { Drawing Strategy: Connected four } \\
\text { squares together. (two students) }\end{array}$ & (none provided) & (none provided) & $\begin{array}{l}\text { Student completed } \\
\text { task correctly. }\end{array}$ \\
\hline $\begin{array}{l}\text { Drawing Strategy: Partitioned } \\
\text { rectangle into four smaller units. (no } \\
\text { students) }\end{array}$ & (none provided) & (none provided) & $\begin{array}{l}\text { Expectation from } \\
\text { prior students. }\end{array}$ \\
\hline \multicolumn{4}{|c|}{ Conservation of Area Task } \\
\hline $\begin{array}{l}\text { Drawing Strategy: Some left gaps } \\
\text { between units while others do not. } \\
\text { (interview students, entire class) }\end{array}$ & $\begin{array}{l}\text { Trajectory Placement: Side to } \\
\text { Side Area Measurers to Row and } \\
\text { Column Structurers } \\
\text { Even if there are gaps, the } \\
\text { structure still has a rectangular } \\
\text { shape. }\end{array}$ & Practice. & (none provided) \\
\hline $\begin{array}{l}\text { Statement- Students stated all } \\
\text { rectangles or rotated rectangles are the } \\
\text { same because of number of units are } \\
\text { the same. (Whole class) }\end{array}$ & $\begin{array}{l}\text { Attending to the square units. } \\
\text { Attribute determines size. }\end{array}$ & $\begin{array}{l}\text { Have students } \\
\text { make more } \\
\text { rectangles/explore } \\
\text { attributes. }\end{array}$ & (none provided) \\
\hline
\end{tabular}

Figure 9. Events that Mrs. Grey noticed during Interview 1. Events highlighted in gray indicate an instructional implication.

Drawing strategies. Mrs. Grey noticed four events in which students drew something. Mrs. Grey first discussed her interview student Hailey in response to the four times as big task. On this particular task, Hailey traced a larger square around the square 
unit four times to make a rectangle that she thought was four times as big. Mrs. Grey described Hailey's response in the following way,

When I said to draw it (four times as big) she just did $1,2 \ldots$ she just went around it four times and said there you go four times bigger. When I saw that I was like, um, I don't know what to say to that (Mrs. Grey, September 28).

Mrs. Grey then described a second student John's drawing. When posed the same task, John told Mrs. Grey that he could draw something that was composed of four units but he could not draw something that was four times as big. Mrs. Grey described this event in the following way:

And I had another student that just said that he could draw four but he couldn't make one (a rectangle) four times as big. So he drew four that were pretty close to the same size as the other one (original square unit) but they weren't connected (Mrs. Grey, September 28).

Mrs. Grey then described the other two interview students' drawing strategies and said that they both did the task the way that she had expected. One student drew a 1 x 4 rectangle while the other drew a 2 x 2 square. Mrs. Grey also commented that none of the students partitioned the square unit into four smaller squares and reflected that she expected this response from students based on her experiences with her prior class.

Statements. Mrs. Grey also discussed statements and conjectures made by students when she posed interview questions to her entire classroom. She commented that two dividing issues emerged when she posed the area conservation task to her students. Several of the students discussed that the units must be connected to make a rectangle, but others thought that the units could be arranged in a rectangular fashion without being 
connected. In the excerpt below, Mrs. Grey described the discussion that arose when she posed the area conservation task to the entire classroom.

When we were talking about the rectangle that was 12 units there were several that had the spaces in between and the class discussion about whether that was okay or wasn't okay never really came to a firm decision. There were kids that said no that can't be a rectangle because those are separate squares but then there were some that said well there are 12 of them and if you trace the outline of the 12 then it would make a rectangle, so it's a rectangle (Mrs. Grey, September 28). Mrs. Grey noticed statements when students discussed what constituted a new rectangle composed of 12 square units. Several of the students were unsure if a 3 x 4 rectangle was the same as a $4 \times 3$ rectangle, and a couple of students thought that all rectangles (e.g., 1 x 12, 2 × 6, 3 x 4) were the same because they all were composed of 12 square units. She stated,

Most of my students that drew the rectangles with 12 units, would say that it was the same if it was a $3 \times 4$ rectangle or a $4 \times 3$ rectangle. They said it was the same rectangle, not different. They couldn't count it twice. But I did have a couple that would say every rectangle, $2 \times 6,6 \times 2,12 \times 1,1 \times 12,3 \times 4$, was the same (Mrs. Grey, September 28).

Interpretation of understanding. Mrs. Grey was able to discuss students' understanding about three of the six events that she noticed. Mrs. Grey discussed students' conceptions of area in all three of the events.

When Hailey outlined the unit square four times to make a rectangle that was four times a big, Mrs. Grey wondered if Hailey thought about the square growing and getting 
bigger rather than it being composed of four units. Mrs. Grey conjectured that possibly Hailey was envisioning the square growing. In the excerpt below she discussed what she thought Hailey might be thinking, she stated:

The only thing that I could kind of relate it to for her was that it was kind of growing and it kept getting bigger instead of thinking I could put four together and make it bigger...because I said I wanted to make it bigger (Mrs. Grey, September 28).

Mrs. Grey also described her classroom's understanding of area specifically in relation to structuring units. After posing the conservation task to her students, Mrs. Grey was asked where she thinks her class might be in their understanding of area. At this point, Mrs. Grey referenced levels within the learning trajectory. Mrs. Grey stated that she thought she had students ranging from side to side area measurers to row and column structurers because of the gaps that the students left when arranging the units to make a rectangle with 12 square units.

Mrs. Grey described her classroom's conceptions of area in relation to perimeter, as well. Several of the students were unsure if different representations of a rectangle with 12 square units formed unique rectangles. She stated, in the past, when students examined perimeter, the students thought that the rectangle with the largest perimeter would have the largest area because it was the biggest number. She stated, "even if they (the area of the rectangles) are all the same... even if it (the area) is actually smaller they will still say the one with the biggest number, always" (Mrs. Grey, September 28). Mrs. Grey thought that the students were unsure if the rectangles were different from one 
another because they each measured 12 square units but had different perimeters. To the students, they were just concerned with the number itself rather than what it represented.

Significance to Mrs. Grey. Several times, when Mrs. Grey was asked to describe students' understanding, she instead described why the event was chosen or why it was important to her. For all four of her comments regarding the four times as big task, she provided a rationale for selecting these events. For two of the events, she found them significant because the students' strategies were unexpected and she had never seen them before or even thought to expect them. She stated, "That wasn't expected. That wouldn't have been one of the things that I ever thought they would do" ( Mrs. Grey, September 28). It also surprised her that none of her interview students thought in the same way as her previous class (from the prior year). In the first interview, it seemed that Mrs. Grey chose events based on what she expected and didn't expect in a range of possible answers.

Implications for instruction. For two of the six events, Mrs. Grey discussed possible implications for instructions. Both of these events related to posing the area conservation task to her classroom. In both implications, Mrs. Grey was very broad in her response and a specific task was not named.

With regard to the students leaving gaps between units, she commented, "I think that realistically if we put enough work into it that they could all get to row and column structurer" (Mrs. Grey, September 28). Mrs. Grey then stated that she had found many real world activities online that she could use to help them practice although she did not describe the types of activities. In the second event, Mrs. Grey described that she would 
like to have students create their own rectangles and describe them to help see differences in attributes.

Mrs. Grey was also asked if there was anything from the interviews that she could see impacting instruction. Mrs. Grey was unsure of what was important from the interviews because instructionally she had not thought about teaching area measurement concepts since the unit was in December.

\section{Interview 2}

Student-teacher Interview 2, took place in December of the school year. Mrs. Grey could modify any of the interview tasks if she thought she needed more information from students, but she decided to administer the same tasks in a similar fashion to Interview 1.

During Interview 2, Mrs. Grey recalled 11 events that were important to her, which are shown in figure 10. For nine of the events, Mrs. Grey discussed students' understanding and two of the events led to an instructional implication (as highlighted in gray). During this interview, Mrs. Grey discussed each of the interview students individually marking one event for John, one event for Lisa, two events for Hailey, and five events for Devan. She also discussed two events that referenced all of her interview students. 


\begin{tabular}{|c|c|c|c|}
\hline \multicolumn{4}{|c|}{ Student Interview 2: December } \\
\hline What the Teacher Noticed & $\begin{array}{c}\text { Interpreted } \\
\text { Understanding }\end{array}$ & Implication for Teaching & Significance \\
\hline \multicolumn{4}{|c|}{ Missing Length Task } \\
\hline $\begin{array}{l}\text { Length Measurement Strategy: } \\
\text { Correctly answered } 7 \text { by using finger } \\
\text { to measure. (Most interview students) }\end{array}$ & $\begin{array}{l}\text { Understood iteration of } \\
\text { finger to mean length } \\
\text { rather than numerical } \\
\text { values. }\end{array}$ & (none provided) & $\begin{array}{l}\text { Unexpected } \\
\text { strategy }\end{array}$ \\
\hline $\begin{array}{l}\text { Written Strategy: Subtracted } \\
\text { incorrectly. (Hailey) }\end{array}$ & $\begin{array}{l}\text { Student rushed to find } \\
\text { solution }\end{array}$ & (none provided) & (none provided) \\
\hline \multicolumn{4}{|c|}{ Four Times As Big Task } \\
\hline $\begin{array}{l}\text { Drawing Strategy/Statement: } \\
\text { Traced around the outside of the } \\
\text { rectangle four times. Stated it is not } \\
4.5 \text { times as big. (John) }\end{array}$ & $\begin{array}{l}\text { Area is the space } \\
\text { inside of a figure. }\end{array}$ & $\begin{array}{l}\text { Teacher language when } \\
\text { posing a task. } \\
\text { Anticipated whole classroom } \\
\text { difficulty. }\end{array}$ & $\begin{array}{l}\text { Change from } \\
\text { Interview } 1 . \\
\text { Reference to past } \\
\text { experience/person } \\
\text { ality. }\end{array}$ \\
\hline $\begin{array}{l}\text { Area Measurement } \\
\text { Strategy/Drawing } \\
\text { Strategy/Statement: To draw, } \\
\text { dragged square across without } \\
\text { iterating. Says it is } 3 \text { times as big, but } \\
\text { cannot draw in units. (Devan) }\end{array}$ & (none provided) & $\begin{array}{l}\text { Anticipated whole classroom } \\
\text { difficulty. }\end{array}$ & $\begin{array}{l}\text { Difficulty } \\
\text { understanding } \\
\text { child's } \\
\text { perspective. }\end{array}$ \\
\hline $\begin{array}{l}\text { Drawing Strategy: Connected four } \\
\text { squares together. (Hailey) }\end{array}$ & $\begin{array}{l}\text { Less sophisticated } \\
\text { strategy. }\end{array}$ & $\begin{array}{l}\text { Anticipated whole classroom } \\
\text { difficulty. }\end{array}$ & $\begin{array}{l}\text { Change from } \\
\text { Interview } 1 .\end{array}$ \\
\hline \multicolumn{4}{|c|}{ Tiling the Space Task } \\
\hline $\begin{array}{l}\text { Drawing Strategy: Did not fill in } \\
\text { rows and columns. Started with boxes } \\
\text { that were almost made and went in a } \\
\text { circular motion one box at a time. } \\
\text { (Devan) }\end{array}$ & $\begin{array}{l}\text { Understanding has } \\
\text { improved/area is the } \\
\text { space inside/ Does not } \\
\text { know that units need to } \\
\text { be consistent. }\end{array}$ & (none provided) & $\begin{array}{l}\text { Different from } \\
\text { other students' } \\
\text { strategies. } \\
\text { Event helped } \\
\text { justify claim } \\
\text { made about } \\
\text { understanding. }\end{array}$ \\
\hline \multicolumn{4}{|c|}{ Area Conservation Task } \\
\hline $\begin{array}{l}\text { Statement: Did not hear students } \\
\text { interchange area and perimeter. (All } \\
\text { Interview Students) }\end{array}$ & $\begin{array}{l}\text { Better understanding } \\
\text { of the meaning of area } \\
\text { due to classroom } \\
\text { instruction. }\end{array}$ & (none provided) & (none provided) \\
\hline $\begin{array}{l}\text { Drawing Strategy: Drew tetris-like } \\
\text { shapes. (Lisa) }\end{array}$ & $\begin{array}{l}\text { Area is the units, as } \\
\text { long as there are } 12 \text {, } \\
\text { then it is correct. }\end{array}$ & $\begin{array}{l}\text { Teacher language when } \\
\text { posing the task. } \\
\text { Have students both draw and } \\
\text { discuss. }\end{array}$ & $\begin{array}{l}\text { Change from } \\
\text { Interview } 1 .\end{array}$ \\
\hline $\begin{array}{l}\text { Drawing Strategy: Started with a unit } \\
\text { in the middle and tiled around/ units } \\
\text { not connected until he heard the word } \\
\text { area. (Devan) }\end{array}$ & $\begin{array}{l}\text { Understood area } \\
\text { means tiles must be } \\
\text { connected. }\end{array}$ & (none provided) & $\begin{array}{l}\text { Interesting } \\
\text { Strategy. }\end{array}$ \\
\hline $\begin{array}{l}\text { Statement: Impossible to find } \\
\text { perimeter without ruler (Devan) }\end{array}$ & (none provided) & (none provided) & $\begin{array}{l}\text { Unexpected } \\
\text { Change from } \\
\text { Interview } 1 . \\
\end{array}$ \\
\hline $\begin{array}{l}\text { Drawing Strategy/Statement: Drew } \\
\text { a row of } 6 \text { and then another row of } 6 \\
\text { and stated } 6+6=12 \text {. (Devan) }\end{array}$ & $\begin{array}{l}\text { Thinking about } \\
\text { making } 12 \text { by doubling } \\
\text { two columns or rows. }\end{array}$ & (none provided) & $\begin{array}{l}\text { Different from } \\
\text { other students' } \\
\text { strategies. } \\
\text { Strategy that has } \\
\text { not been taught } \\
\text { yet. }\end{array}$ \\
\hline
\end{tabular}

Figure 10. Events that Mrs. Grey noticed during Interview 2. Events highlighted in gray had instructional implications. 
What Mrs. Grey noticed. In student-teacher Interview 2, Mrs. Grey discussed important events that involved primarily drawing strategies as well as statements, area measurement strategies, and written strategies. She began the interview by discussing her initial thoughts about the interview in relation to all of the students and her surprise in the change of her students' answers from the initial interview in September to this interview.

Drawing strategies. Seven of the events that Mrs. Grey noticed involved students drawing something in response to the interview task. Mrs. Grey first commented that John, similar to Hailey in interview 1, decided to trace around the square four times. Mrs. Grey commented that John's new square was not accurate, so she asked John to show her how his new rectangle was 4 times as big. He replied that maybe it is four and a half times bigger. Also in relation to this task, Mrs. Grey stated that Hailey lined up the square four times and drew a rectangle four times as big. She stated, "This time she (Hailey) switched back to tracing it four times. I don't know if she just thought that was easier to do at the time, like she could just trace it instead" (Mrs. Grey, December 7).

Mrs. Grey also attended to students' drawings when they were asked to tile a rectangular region. She described that her student, Devan, tiled the figure from the inside out and not in a systematic way using rows or columns, unlike her other students. She said that he began by drawing squares that were partially made (squares where an adjoining square already formed one of the sides) and then continued drawing from there. Mrs. Grey described this event in the following way:

I was thinking about this one back here (pointing to task 3) or even he when filled it in. He didn't fill in rows and columns. He started with the boxes that were almost made and then he would make a box and he kind of went in a circular 
motion from the inside out to where he was doing it one at a time. Instead of....kids who can see the rows and columns and fill it in quickly (Mrs. Grey, December 7).

Mrs. Grey also discussed Devan's drawing strategies as well as a counting strategy for the area conservation task. Similarly to tiling the rectangular region, he started with a pre-existing unit from another task and tiled around it without connecting the square units. He would stop periodically to count and see if he had enough units to make 12. After he constructed the first representation, Mrs. Grey asked him if he could make a second rectangle. Mrs. Grey commented that when she asked him to draw the second rectangle, he crossed out his first representation and then connected the units together.

When Mrs. Grey asked Devan if he could draw another rectangle with 12 square units, he told her that he knew $6+6$ was 12 . So he made two rectangles composed of six units each and connected them together. Mrs. Grey was surprised by this response. She said that normally students start to see relationships like this during the unit on area but not prior to.

Also in relation to the area conservation task, Mrs. Grey noticed that Lisa drew shapes that were nonrectangular. Mrs. Grey referred to these shapes as tetris-like (referring to the game tetris). When Mrs. Grey recalled this event, she stated:

When I asked her to see how many 12-unit rectangles she could draw, she never made a rectangle this time. All of them had 12 units, but they were like tetris kind of shapes, not like a rectangle (Mrs. Grey, December 7). 
Measurement strategies. Mrs. Grey noticed two strategies related to area and length measurement. Mrs. Grey noticed that most of the students correctly answered that the missing length would be seven to the missing length problem by holding up a finger and comparing the length of an unknown side to a marked side. She commented:

The other part that surprised me was at the beginning when we did the first task, and this was true of all four students that I interviewed, everyone looked at this piece right here (the known length of three) and just went like this (moving finger to show iteration) and said well seven. Which is correct, but they didn't think $20-7=13$. They would hold their finger up to the three and compare the sides (Mrs. Grey, December 7).

Mrs. Grey discussed an area measurement strategy in relation to her student Devan that was also a drawing strategy. She said that Devan dragged the foam square across the page, in an imprecise manner, marking as he went. In the end, Mrs. Grey noticed the rectangle looked a little off and asked Devan to show her where the four units would be. Devan replied that it looked more like three units but he was not able to show her where the three units would be. Mrs. Grey stated:

He takes the foam square, when I asked him to make a rectangle four times as big, first he takes a foam square and he just does 1, 2, 3, 4 (Mrs. Grey drags the foam square along the table counting) and he moves it and then he draws it and it looks a little off. So I said, "can you show me so that when I look back later I can see it in case I forget?" He goes to draw them in and says that it is probably more like three (square units)...So he said that's probably three but could not draw where they would be (Mrs. Grey, December 7). 
Written strategy. For one event, Mrs. Grey noticed a student's written subtraction strategy. She noticed that Hailey tried to solve the missing length problem in a different way by adding the lengths together. Hailey incorrectly added two sides together $13+3$ to get 16 and then subtracted 16 from 20 to get a length of 4 . Mrs. Grey noticed this from Hailey's paper.

Statement. Mrs. Grey also noticed several statements that students made as they were solving problems. She noticed that Devan stated he could not find the perimeter of the rectangles he made without using a ruler. Mrs. Grey found this especially surprising considering Devan knew in his rectangle that there were two rows of 6 . She was surprised that he did not see that the side length was also 6 .

She also noticed statements that students made about their drawings. She noticed that even though John was asked to draw a rectangle that was four times as big he conjectured that it was probably 4.5 times as big.

In student-teacher Interview 2, Mrs. Grey noticed many things about each student in relation to each task and was more detailed. This may be because her student-teacher Interview 1 acted as a comparison for her to judge what is important or different in Interview 2. She had also known her students for a longer period and knew more about her day-to-day interactions with them.

Interpreted understanding. During student-teacher Interview 2, Mrs. Grey discussed students' understanding in nine of the eleven events that she indicated as important. Mrs. Grey provided an explanation of understanding, though brief for some, for each student. Her explanations centered on students' understandings related to area, 
length, understanding of area in relation to perimeter, and students' personalities and past experiences.

Understanding of area. In five of the nine events, Mrs. Grey discussed a component of the student's understanding of area. With regard to all of the students, Mrs. Grey expressed that, based on the students' responses; she thought that they all had a better understanding of area in relation to perimeter. She thought this because the students' seemed less confused of what she was asking when answering the questions.

Mrs. Grey also discussed individual student's conceptions of area and was often able to describe these understandings in depth. For example, when Lisa drew tetris-like shapes when asked to draw a rectangle with 12 square units, Mrs. Grey thought that perhaps Lisa thought that as long as the shape has 12 units it was a solution and she forgot that it needed to be a rectangle. She stated, "I think when she was thinking about area she was just thinking about all of the tiles, or squares, or units. As long as there was 12 of them then she was giving me the answer" (Mrs. Grey, December 7).

Several times when Mrs. Grey was asked what she thought the student understood, she would reply that the student understood "area was the space inside". For example, when John created a rectangle that was four times as big by tracing around the outside four times, Mrs. Grey responded, "I think he knows that the area is the space inside like the space that it takes up inside" (Mrs. Grey, December 7), but does not provide any further details.

For another student, Devan, Mrs. Grey stated that he understood area was the space inside but she was also able to provide more detail. When Devan tiled units during the partially covered rectangle in task 3, Mrs. Grey stated that Devan knew that area is 
the space inside of a figure, but he did not know that he needed to be consistent or equal with his units. She described how he tiled the rectangle to justify her reasoning about Devan not seeing row and column structure. She also stated that she thought he knew more than he did at the beginning of the school year but did not reference past events. The following is an excerpt where Mrs. Grey discussed Devan's understanding:

Megan: That's interesting. So what do you think he understands about area? Mrs. Grey: I think he probably understands more now than he did at the beginning of the year but I think he probably knows that it is the space inside but he doesn't know that it needs to be consistently equal like it needs to be the same amount of space.

Megan: Was there an event that made that clear to you? or something that he did? Mrs. Grey: I don't know. I was thinking about this one back here (pointing to task 3) or even he when filled it in. He didn't fill in rows and columns. He started with the boxes that were almost made and then he would make a box and he kind of went in a circular motion from the inside out to where he was doing it one at a time. Instead of kids who can see the rows and columns and fill it in quickly (Mrs. Grey, December 7).

Mrs. Grey also discussed that she thought Devan might understand that area is made up of multiple rows or columns of the same length. She thought this because when he was asked to build a rectangle with 12 square units he created two rows six units in length. She was not exactly sure about this though.

Understanding of length. Mrs. Grey also discussed students' understanding of length as it pertained to the missing length task. When most of the students correctly 
found the answer to task 1, the missing length task, by using their finger, Mrs. Grey commented that the students were thinking about length visually rather than arithmetically. She also commented that this strategy is correct given the current format of the problem, but if the scale were off then this strategy would not be accurate.

Student personality and past experiences. In three of the events, Mrs. Grey discussed students' personality and past experiences related to their action rather than the students' understanding. This was particularly true for Hailey because Mrs. Grey considered Hailey to be one of the brightest students in her classroom. Hailey had highstandardized test scores both in reading and math. In both incidents when Hailey did something that Mrs. Grey found important, she attributed Hailey's actions to her ability or said that Hailey was rushing and not thinking through the task. For example, when Hailey was asked to find the missing length, she incorrectly added the pieces 13 and 3 together and reached 16. She then subtracted 16 from 20 to say that the missing length was 4 . When asked what she thought Hailey was thinking, Mrs. Grey responded:

She was the one that incorrectly added the 13 and the 3 , so I am wondering if she just um..She's the one in the enriched group for intervention that usually finishes her work you know fairly quickly. So I don't know if she was just rushing through it. Because I asked her to explain and she said, "well this is 13 (pointing to one length) and 3 (pointing to the other length) and that's 16 and over here (pointing to the opposite side) you have $20 "$. So I said, " this is 3 (pointing to the segment marked $3 \mathrm{~cm}$ ) and this is four (pointing to the unmarked side). And she (Hailey) said yes. So she didn't even make the connection that (the missing 
length) had to be more than 1 unit longer. But, she just I think she kind of rushed. She was probably the fastest one (Mrs. Grey, December 7).

Even though the missing length looked longer than four and Mrs. Grey asked Hailey about it, Hailey still responded that the length was four. Hailey's answer was incorrect, but Mrs. Grey attributed Hailey's thinking to a rushed response rather than a conceptual misunderstanding.

This occurred again when Hailey was asked to draw a rectangle that was four times as big as a the unit square. In the first interview, Hailey traced around the square four times to accurately make a square that was four times as big as the original unit square. In this interview, Hailey iterated the square unit four times and made a rectangle that was four times as big. Even though Hailey's solution was correct and more accurate, Mrs. Grey viewed it as "less sophisticated" than her original answer.

Mrs. Grey also attributed past experiences to another interview student John. When John showed difficulty on many of the area tasks, Mrs. Grey explained that John transferred from a different school. At John's previous school, students use Every Day Mathematics as their curriculum. Mrs. Grey said that usually students who transfer from this school have a better grasp at hands-on mathematics, so she was surprised that John does not seem to have this skill.

Significance to Mrs. Grey. Mrs. Grey described the significance of the event for 10 of the 11 events. Mrs. Grey primarily chose events that related to prior interviews, comparing students to one another, or events were she was confused or surprised by students' thinking. 
Comparison to prior interview. In four of the 10 events, Mrs. Grey stated that they stood out to her based on what the students said or did in a prior interview. For example, when John traced around the square four times to find a rectangle that was four times as big, this stood out to Mrs. Grey because it was different from the first interview where he connected four units together and made a rectangle four times as big. Mrs. Grey often looked for changes in student actions as a signifier of something important.

Comparison to other students. Related to the idea of contrast, Mrs. Grey also selected two events where a student described stood out from all of the other students in his or her thinking. When Devan tiled the area of a rectangle, he was the only student that did not see row and column structure easily, and this stood out to Mrs. Grey. His thinking was in contrast to her other interview students. Similarly, when drawing rectangles, he was also the only student to count by groups of six and this also stood out to Mrs. Grey.

Confused or interested in the student's thinking. Throughout the student interview, Mrs. Grey also selected events because she was intrigued by the students' answer and was unsure of their thinking. In some instances, she was confused by the strategy while others were just unexpected. Mrs. Grey selected two events, both involving Devan, because his thinking confused her. When Devan was asked to make a rectangle that was four times as big, he dragged the rectangle across counting 1, 2, 3, 4 . Mrs. Grey did not understand how Devan could not just see the four units and make them. She stated, "He couldn't draw the three (square units). And I thought you (Devan) put it in there, you saw it move"(Mrs. Grey, December 7). Mrs. Grey was confused as to why Devan could not draw the units. 
Implications for instruction. Of the 11 events that Mrs. Grey noted, she only linked implications for instruction in four of the events. Implications centered on the importance of students expressing themselves in multiple forms, word choices when posing problems, and task difficulty.

Area conservation task difficulty. Mrs. Grey reflected collectively on the area conservation task in relation to instruction. She said that of the four students, only one, Hailey, was able to accurately and correctly answer this problem. Her goal in her first unit was to have students discover relationships between units, like square feet to square yards. She thought that Task 4 was the most like what she was going to ask students to do in her lesson. In the following excerpt, she stated that students might have trouble with this first task so she decided to reflect on ways to make the task easier or harder. She stated:

I guess maybe drawing the four times as big as the square and since I guess about $25 \%$ of the time they didn't do that correctly they might have trouble iterating like when we go up to a larger scale. If there is a group that can't get from the foot to the yard, there might be a group that does the square feet for the room, and there might be a group that does the square yards for the room and there might be a group that does a taped off part of my rug since my rug does not have anything that they could easily use to measure (Mrs. Grey, December 7).

Multiple representations. In addition to thinking about task difficulty, Mrs. Grey found Lisa's drawings to be very informative throughout her unit on measurement. Mrs. Grey stated that, Lisa's response showed her that sometimes there is a disconnect between what students draw and what they are thinking. Everything that Lisa was saying was 
correct but her drawings did not match her words. The following is an excerpt taken from a subsequent interview on December 13 with Mrs. Grey where she described how the interview informed her first lesson of the unit.

Megan: After you finished your interviews, and you were planning the first lesson, was there anything from the interviews that you connected with during planning?

Mrs. Grey: I think probably the fact that um their explanations and their drawings in their interviews didn't match up, so that is why I was trying to, every time, (tell the students) draw me a picture and then write down an explanation.

Megan: Of what the picture was?

Mrs. Grey: Because I felt like, if I just had one or the other, I might not Megan: Get the whole picture?

Mrs. Grey: get what they were saying or where they were coming from. Megan: So when they (the students) were interviewing were there times when there was a mismatch between what they were saying and what it (the picture) looked like?

Mrs. Grey: the picture especially, the one that really sticks out was Lisa's. They weren't rectangles but she kept saying rectangles and she kept coming up with an area of 12 and her explanation said that (Mrs. Grey, December 13).

Meaning of words. Mrs. Grey also took time to reflect on herself and her word choices during instruction during two of the events. She wondered how words like "big" influenced how students attempted to solve a task. She wondered if she had been 
descriptive enough when asking students different questions. She also wondered, after students solved a task, if she forgot to mention a word. For example, when Lisa drew a tetris-like shape, she wondered if maybe she forgot to say the word rectangle. Mrs. Grey reflected that she will be more conscious of her word choices in the future during instruction and interviews but did not say how.

\section{Interview 3}

Interview 3 occurred following the instructional unit on area measurement.

During student-teacher interview 3, Mrs. Grey recalled five events that were important to her. Mrs. Grey recalled freely one of the events and marked four events using the camera. For four of the events, Mrs. Grey was able to discuss students' understandings but she did not provide an instructional implication for any of the events. Mrs. Grey discussed each of the interview students individually. She marked one event for Josh, one event for Lisa, one event for Hailey, and one event for Devan. She also discussed one event that referenced two of her interview students collectively. 


\begin{tabular}{|c|c|c|c|}
\hline \multicolumn{4}{|c|}{ Interview 3: December } \\
\hline What the Teacher Noticed & Interpreted Understanding & $\begin{array}{l}\text { Implication for } \\
\text { Teaching }\end{array}$ & Significance \\
\hline \multicolumn{4}{|c|}{ All Interview Tasks } \\
\hline $\begin{array}{l}\text { Behavior: Rushed through tasks and } \\
\text { did not want to explain. (All interview } \\
\text { students) }\end{array}$ & $\begin{array}{l}\text { Remembered answers from prior } \\
\text { interview }\end{array}$ & (none provided) & (none provided) \\
\hline \multicolumn{4}{|c|}{ Four Times as Big Task } \\
\hline $\begin{array}{l}\text { Drawing Strategy: Traced around the } \\
\text { outside of the rectangle four times. } \\
\text { Not as accurate. (Hailey) }\end{array}$ & (none provided) & (none provided) & $\begin{array}{l}\text { Different from } \\
\text { other students' } \\
\text { strategies. } \\
\text { Similar to } \\
\text { Interview } 1 .\end{array}$ \\
\hline \multicolumn{4}{|c|}{ Area Conservation Task } \\
\hline $\begin{array}{l}\text { Drawing Strategy: Was able to make } \\
\text { several different rectangles by making } \\
\text { one unit and attaching units to that one } \\
\text { until totaling 12. (Lisa) }\end{array}$ & $\begin{array}{l}\text { Thought about area and the } \\
\text { properties of a rectangle. }\end{array}$ & (none provided) & $\begin{array}{l}\text { Different from 2nd } \\
\text { interview. }\end{array}$ \\
\hline $\begin{array}{l}\text { Drawing Strategy/Statement: Made } \\
\text { one rectangle with } 12 \text { units but made a } \\
\text { second rectangles as } 2 \text { disconnected } \\
\text { rectangles. Said it has an area of } 12 \text { if } \\
\text { you put them back together. (John) }\end{array}$ & $\begin{array}{l}\text { Relates area to building things at } \\
\text { home. Putting blocks } \\
\text { together/taking them apart. }\end{array}$ & (none provided) & $\begin{array}{l}\text { Similar to past } \\
\text { interviews. } \\
\text { Confusing } \\
\text { strategy. }\end{array}$ \\
\hline $\begin{array}{l}\text { Statement: Stated the side lengths of } \\
\text { the rectangle are } 12 \text { when in reality } \\
\text { the area is } 12 \text {. (Devan) }\end{array}$ & $\begin{array}{l}\text { Confused side length with area. } \\
\text { Forgot meaning of perimeter }\end{array}$ & (none provided) & $\begin{array}{l}\text { Surprising } \\
\text { strategy. } \\
\text { Language issues }\end{array}$ \\
\hline
\end{tabular}

Figure 11. Events that Mrs. Grey noticed during Interview 3. Events highlighted in gray had instructional implications.

What Mrs. Grey noticed. The five events that Mrs. Grey noticed centered on students' drawing strategies, behaviors, and statements. At the beginning of the interview, Mrs. Grey was asked if she remembered anything from the interviews that was important to her and that she would like to discuss. Mrs. Grey commented on students' behaviors. In general, she felt that because Interview 2 and Interview 3 were so close together many of the student rushed through the tasks and did not want to explain what they did.

Um, I think with these two sets of interviews being so close together there were a couple of people that even...the people that had gotten it right last time like on the missing perimeter task that just wanted to tell me what they told me last time.

Because they automatically remembered and they did not want to check it again.

(Mrs. Grey, December 17) 
Drawing strategy. Many of the events that Mrs. Grey noticed were in relation to students' drawing strategies. She commented that Hailey had drawn differently with regard to the four times as big task in past interviews. In the first interview, Hailey traced around the square four times to make a square with an area four times as big. In the second interview, Hailey linked four square units together to make a rectangle that was four times as big. In the third interview, Hailey reverted back to her initial strategy. Mrs. Grey commented that Hailey was not accurate in this particular interview.

Mrs. Grey also discussed students' drawing strategies in relation to the area conservation task. Mrs. Grey commented that, in Interview 1, Lisa was able to draw one rectangle and flipped it to make a second when asked to make a rectangle with an area of 12 square units. In Interview 2, Lisa had drawn tetris-like shapes when posed this task. During Interview 3, Lisa drew two different rectangles with an area of 12 square units without making any tetris-shapes or flipping the rectangles. Mrs. Grey stated:

She was the one who had made the tetris shapes last time and this time she didn't. She drew the unit. It was fairly close to a one inch square unit and then she always makes squares around that one...She made a $3 \times 4$ and then a $2 \times 6$ and then a $4 \times$ 3. It wasn't even that she had flipped one sideways. She did do two separate (rectangles) (Mrs. Grey, December 17).

Mrs. Grey also discussed John's drawing strategy in relation to this task. She stated that John made a rectangle that was composed of 12 square units, but when asked to make a second rectangle he drew the units as two separate rectangles. Although Mrs. Grey did not comment on this strategy until this interview, she stated that John had used 
this strategy in both prior interviews and this is why it stood out to her. In the transcript below, Mrs. Grey and I discussed John's drawing strategy.

Mrs. Grey: He is making one with 12 square units but when I asked him to make a second one with 12 units he makes one (rectangle) with 4 and one (rectangle) with 8 or a 6 and a 6 or a 10 and a 2 .

Megan: So they are disconnected?

Mrs. Grey: He does the same thing it's like the 2 x 6 at the top and then at the bottom he just snaps it all apart

Megan: So they are still connected or no?

Mrs. Grey: No, and that's what I asked, I said can you show me how this shape has an entire area (of 12 square units) and he says, "well you have to put them back together" (Mrs. Grey, December 17).

Statements. Mrs. Grey discussed two statements students made. While working with Devan, she noticed that he was able to make rectangles with an area of 12 , but had completely forgotten how to find perimeter and could not even express what perimeter meant. When John drew his units apart from each other, Mrs. Grey noticed that John stated the area would be 12 if he drew the units together.

Interpreted understanding. Mrs. Grey reflected on students' understanding for all but one of the events. Each of these understandings related back to a component of the students' understanding of area. Mrs. Grey primarily focused on the growth students made in their thinking as well as misconceptions that were still being exhibited.

For one of the students, Lisa, Mrs. Grey thought that she made growth in her understanding of area. Mrs. Grey thought this because Lisa could now construct multiple 
rectangles with an area of 12 , unlike before. She thought that perhaps what they had done in class had helped and possibly the word rectangle had finally "clicked" in her mind. She was no longer just focusing on area but also on the idea of the area being a rectangular region. Mrs. Grey stated:

I don't know if the practice we did in class had anything to do with it...a lot of the examples were rectangles but we didn't talk about, you know, specifically making them. So I don't know if it just clicked in her head when I said rectangle today and the other day maybe she was just focusing on the area of 12 maybe? (Mrs. Grey, December 17).

Mrs. Grey also discussed misconceptions that were still prevalent among the interview students. Mrs. Grey commented that Devan's understanding was representative of several students in her classroom. She commented that some students still could not distinguish between area and perimeter and were getting the two words confused with one another when solving problems. With regard to Devan, she stated:

Megan: Why do you think he thought that?

Mrs. Grey: So I don't know if he is stuck as to...he is thinking about area, and he can't go back and forth at all. Like he has to stick with one. If the area is 12 it's 12 on every side (the length all of sides of the rectangle is 12). Because then I asked him what it would be altogether (the perimeter) and he said "I don't know"...Because the last two times we did this task he did it appropriately and he had those little tally marks where he was counting and got the right answer. But this time he was like he was stumped. He couldn't figure it out. It was just like it was gone! (Mrs. Grey, December 17). 
Mrs. Grey also discussed misconceptions with regard to John creating disjoint rectangles. Although John called them new solutions, he recognized that the rectangles would only have an area of 12 square units if pushed back together. When Mrs. Grey was asked what she thought John was thinking, she wasn't exactly sure. She said that she could not think of a reason he would break the rectangle apart into two separate rectangles because they had never done anything like this in class. She thought that maybe he played with blocks or toys at home that impacted his understanding of the problem. She stated:

He did this in both interviews, and I couldn't think of a reason why he would break those apart. Because there weren't a lot of activities that we had done (in class) where we had broken things apart and put them back together in exactly the same way. Like we would construct things and say okay let's make a different one using the same pieces but never break them and putting them back together. So I don't know if he builds a lot of things at home. He has three brothers; maybe he plays with blocks, that is the only thing I can think of (Mrs. Grey, December 17).

Implications for instruction. In this particular interview, Mrs. Grey did not link any of the events that she saw directly to instruction. This could be because Mrs. Grey conducted her third set of student-teacher interviews toward the end of her unit of instruction. Mrs. Grey was asked in a final researcher-teacher interview how she thought if at all, the interviews had informed her lesson planning. She said that the interviews had helped her to see where students were in their understanding and also identify any misconceptions. I asked Mrs. Grey if she could give me a specific example that 
highlighted this idea. Mrs. Grey discussed an idea that had arisen in the first interview of students not tiling a space that she had tried to address in her lessons. She stated:

I think that probably at the beginning of the area lessons when we were talking about filling up a space, there were students on the first interview that weren't completely filling up the space or they weren't making a rectangle, they were just making 12 units together. So I think having the Smartboard activity where the columns and rows were already there helped them work through that misconception, I guess (Mrs. Grey, December 19).

\section{Instructional Unit on Area Measurement}

In the month of December, Mrs. Grey taught a two-week instructional unit on area measurement that was organized as three lessons. In Mrs. Grey's school district, each school adheres to a set of guidelines and standards for mathematics for each quarter called the four quarter plan. This plan advises teachers of what they should teach each quarter for each grade level, but it does not advise a length of time for each topic. The second quarter was designated as the measurement and data collection quarter and finding the perimeter and area of rectangles was an expectation for grade four.

The other fourth-grade teachers at Terrace elementary, excluding Mrs. Grey and Mrs. Purl, had decided one to two days would be an appropriate amount of time to cover finding the area and perimeter of rectangles. They created an interactive Smartboard lesson to introduce area to the students and review finding area by counting units. Mrs. Grey used this as her introduction lesson. Mrs. Grey also decided she wanted students to see relationships between different size units. After the introduction lesson, she enacted a lesson that spanned several days on using different size units to measure the area of a 
space. Midway through the unit, she administered an assessment, and, following this, she enacted a short lesson, lasting two days, on area conservation.

As with the student-teacher interviews, Mrs. Grey was asked to wear the Déjà Vu camera and indicate any events that she thought revealed something important about students' thinking. Within this section, each of these lessons is described in more detail as well as events Mrs. Grey indicated as important.

\section{Smartboard Lesson}

Mrs. Grey used the Smartboard file developed by other teachers as her introduction lesson. She began the lesson by asking students to write in their mathematics journals for about five minutes on what they thought area was. She told the students that they would be able to modify their definition as the unit progressed, and this was just their initial thoughts.

Next, Mrs. Grey showed the students several rectangles with units already drawn inside of the figure. The students were asked to decide what the area was and then drag virtual pieces of candy or bugs onto the squares to help them count. As the slides progressed, the problems became more difficult. Mrs. Grey showed the students several rectangular regions where the figure was partially filled, such as one row and one column and asked them to predict the area and perimeter and then find it. Lastly, Mrs. Grey showed students rectangles with only side lengths labeled and asked to draw in the units and/or find the area of the region.

In this particular lesson, Mrs. Grey asked students to work independently by drawing the pictures they were shown into their mathematics notebook to solve. Following this, they were asked to share with others in their group. Throughout each 
example, Mrs. Grey asked students how they found the areas of the rectangles and different strategies that they used.

What Mrs. Grey noticed. In the Smartboard lesson, Mrs. Grey noticed eight events that were of importance to her (as shown in Figure 12). Mrs. Grey noticed many different types of events such as journal entries, statements, drawings strategies, studentto-student interactions, and area counting strategies. Three of these events were recalled during our discussion while five of the events were noted with the Déjà Vu camera. Six of the events involved individual students, while two referenced a small group or several students. Mrs. Grey was able to discuss students' understanding for each of the events she noticed and developed implications for teaching from two of them (highlighted in gray in Figure 12). 


\begin{tabular}{|c|c|c|c|}
\hline \multicolumn{4}{|c|}{ Smartboard Lesson: December } \\
\hline What the Teacher Noticed & Interpreted Understanding & $\begin{array}{c}\text { Implication for } \\
\text { Teaching }\end{array}$ & Significance \\
\hline \multicolumn{4}{|c|}{ Students Journal Writing About Meaning of Area } \\
\hline $\begin{array}{l}\text { Journal Entry: Student initially } \\
\text { wrote area is the inside of a } \\
\text { triangle, rectangle or square, but } \\
\text { changed it to the inside of any } \\
\text { shape following lesson. (Carrie) }\end{array}$ & $\begin{array}{l}\text { Square units are only used for } \\
\text { rectilinear spaces. }\end{array}$ & (none provided) & (none provided) \\
\hline \multicolumn{4}{|c|}{ Students Drawing and Finding Area of Rectangles } \\
\hline $\begin{array}{l}\text { Drawing strategy/Statement: } \\
\text { Made tetris-like shapes, but is still } \\
\text { getting correct answer verbally. } \\
\text { (Lisa) }\end{array}$ & $\begin{array}{l}\text { Mismatch between her } \\
\text { drawing and her thinking. }\end{array}$ & $\begin{array}{l}\text { Use manipulatives to aide } \\
\text { in expression. }\end{array}$ & $\begin{array}{l}\text { Same action as } \\
\text { interview. }\end{array}$ \\
\hline $\begin{array}{l}\text { Area Counting Strategy: } \\
\text { Counted } 5+5+4+4=18 \text { which } \\
\text { showed attention to perimeter } \\
\text { rather than area even after } \\
\text { instruction. (several students) }\end{array}$ & $\begin{array}{l}\text { Confusion between terms area } \\
\text { and perimeter. }\end{array}$ & $\begin{array}{l}\text { Differentiate, do a } \\
\text { smaller scale activity } \\
\text { because they are having } \\
\text { difficulty. } \\
\text { Manipulatives, use more } \\
\text { tiles to reinforce area. }\end{array}$ & $\begin{array}{l}\text { Surprised given } \\
\text { instruction. }\end{array}$ \\
\hline $\begin{array}{l}\text { Statement: Stated the area of the } \\
\text { rectangle is } 6 \text { and } 10 \text {. (Trey) }\end{array}$ & $\begin{array}{l}\text { Understands math as } \\
\text { memorization so area could } \\
\text { be } 6 \text { and } 10 . \\
\text { Personality and past } \\
\text { experience. }\end{array}$ & (none provided) & (none provided) \\
\hline $\begin{array}{l}\text { Drawing Strategy/Student to } \\
\text { Student Interaction: One } \\
\text { column off when tiling rectangle. } \\
\text { Saw mistake when another } \\
\text { student pointed it out. } \\
\text { (Kirby) }\end{array}$ & $\begin{array}{l}\text { Unsure of students' thinking. } \\
\text { Personality and past } \\
\text { experience. }\end{array}$ & (none provided) & (none provided) \\
\hline $\begin{array}{l}\text { Written Strategy: Heard area is } \\
66 \text { and begins to write number } \\
\text { combinations that would equal } 66 \\
\text { as perimeter. (Nadine) }\end{array}$ & $\begin{array}{l}\text { Confusion between terms area } \\
\text { and perimeter. }\end{array}$ & (none provided) & $\begin{array}{l}\text { Surprised given } \\
\text { instruction. }\end{array}$ \\
\hline $\begin{array}{l}\text { Area Counting Strategy: Uses a } \\
\text { doubling strategy to find the area } \\
11+11=22,22+22=44 \text {. (Rey) }\end{array}$ & $\begin{array}{l}\text { Sees rows and counts by } \\
\text { them. } \\
\text { Understands multiplication } \\
\text { but is not comfortable with it. }\end{array}$ & (none provided) & $\begin{array}{l}\text { Surprised student } \\
\text { is not using the } \\
\text { formula. }\end{array}$ \\
\hline $\begin{array}{l}\text { Drawing Strategy/Area } \\
\text { Counting Strategy: Counting } \\
\text { strategy did not match } \\
\text { drawing/skip counted by 2's. } \\
\text { (Jessica) }\end{array}$ & $\begin{array}{l}\text { Preferred counting strategy. } \\
\text { Influenced by focus on skip } \\
\text { counting. }\end{array}$ & (none provided) & $\begin{array}{l}\text { Confusing } \\
\text { strategy. }\end{array}$ \\
\hline
\end{tabular}

Figure 12. Events that Mrs. Grey noticed during Smartboard Lesson. Events highlighted in gray had instructional implications.

Journal responses and written strategies. At the beginning of the lesson, Mrs.

Grey asked students to describe what they thought area was in their math journal. Mrs.

Grey noted one event during this time that she thought was revealing. As she walked

around reading student responses, she marked something that a student, Carrie, had

written. Mrs. Grey stated, "When I looked at it (her notebook) she said, 'area is the inside 
of a triangle, rectangle, or square'. So that was when I whispered to her, 'well but what is the inside of a circle?"' (Mrs. Grey, December 11). Mrs. Grey marked this because she thought it was interesting that Carrie was thinking of area as the inside of only rectilinear regions and was not sure about areas of shapes with curves.

Later in the lesson, as students were finding the area of a 6 x 11 rectangle, Mrs. Grey noticed Nadine writing something down in her journal. Nadine had heard the number 66 and was trying to label the picture her classmates had shown on the front board. Mrs. Grey noticed that Nadine was writing down number combinations and asked her what she was doing. Mrs. Grey stated,

She was telling me that she was adding up all four of her sides and telling me that 66 was the perimeter. I think she was trying to figure out how she could get these (the numbers written on the page) to add up to 66. I then asked her to tell me where she got her four and five (numbers written down) (Mrs. Grey, December $13)$.

Drawing strategies and statements. As Mrs. Grey walked around the classroom, she noted three drawing strategies. In each of these strategies, the students drawing of the area of a rectangle did not match their statements. Mrs. Grey noticed that Lisa continued to draw the tetris-like shapes similar to what she had done in the interview setting. Mrs. Grey commented, "I noticed that the student in the interview (Lisa) that had the tetrisy ones, she did that again in the picture she drew to explain. I don't know if her drawing is not matching what she is thinking, because she is getting the answers correct" (Mrs. Grey, December 11). 
Mrs. Grey also noticed that Kirby had correctly found the area of the rectangle but was missing a column in his drawing. He did not correct his mistake until another student came to the board and counted each unit to show him that he was incorrect in his representation. Mrs. Grey said it was hard to tell if he thought that his drawing was correct or if he was just rushing.

For one student, Jessica, Mrs. Grey noticed that she drew the units inside a 6 x 11 square unit rectangle with great precision using a ruler to draw rows and columns rather than each square unit. Based on her drawing, Mrs. Grey was surprised to see that Jessica, rather than counting by rows or columns, counted by twos. When Mrs. Grey walked up on Jessica, she was correctly explaining to another student that each row contained 11 units but when counting she skip counted $2,4,6,8$, etc.

Mrs. Grey also attended to statements that she found confusing. She noticed that Trey had written down that the area of the rectangle was two different numbers and told her that both numbers represented the area. She said that she marked it because Trey is one of her highest testing mathematics students, but he does not seem to understand hands-on mathematics.

Area counting strategies. Mrs. Grey noticed two events in which students were counting area units. As describe above, Mrs. Grey noticed that Jessica skip counted by twos to find the area of the rectangle. She noticed that Jessica's partner, Rey, used a doubling strategy to find the area of the rectangular region. Mrs. Grey stated, "He was doubling. He said that he knew $11+11$ was 22 and $11+11$ was 22 and $22+22$ was 44 , going all the way down"(Mrs. Grey, December 13). Mrs. Grey thought this was odd 
because Rey had referenced the formula for multiplication and the beginning of the unit. She thought that he would not need to count each row.

Mrs. Grey also noticed incorrect area counting. Even though students had practiced filling in several rectangles, at the end of the lesson many of them were still counting around the outside and finding the perimeter when asked for the area. For a $4 \mathrm{x}$ 5 square rectangle, Mrs. Grey stated, "Then some of them had, when I asked how they got their area of 18 , they did $5+5+4+4 \ldots$ Even after that, even after filling it (the rectangle in), there were still counting the outside, which was surprising" (Mrs. Grey, December $13)$.

Interpreted understanding. As Mrs. Grey discussed students' actions, for each of the eight events recalled, Mrs. Grey was able to provide some explanation of what she thought students were thinking in relation to the action. Themes that emerged centered around the shape of a unit, drawings, the influence of other mathematical understandings, area and perimeter confusion, and students' personalities and past experiences.

Square unit relates to shape of object. As the students were describing what they thought area was, Mrs. Grey noticed that a student, Carrie, thought that area was only defined for rectilinear regions. Mrs. Grey thought that Carrie, and possibly other students in the classroom, thought that the unit must match the shape of the object in some way. She stated, "It looks like maybe even from her drawing, that the units that we use to fill in a shape, maybe are, they don't fit the right way into a circle or an oval" (Mrs. Grey, December 13). Mrs. Grey thought that Carrie was thinking about the unit in relation to the shape to help determine what it would be best to measure. 
Understanding is not always clear through drawings. In several of the incidences, Mrs. Grey realized that the student's understanding of area as expressed verbally was not always the same as expressed pictorially. In three of the incidences that Mrs. Grey marked, she approached the student and looked at the student's drawing and then discussed the drawing with the student. The drawings did not exactly match what Mrs. Grey thought the student would say. For instance, when she approached Rey, Rey had accurately drawn row and columns within the rectangle by using a ruler and drawing continuous lines across the rectangle. Rey also told Mrs. Grey that he knew that the area was the number of rows and the number of columns. Mrs. Grey was surprised though when Rey insisted that he needed to count each row. She stated, "I think he can see the rows because that is what he went back to and then that was what he was counting by, the rows. He kept saying he knew it was this way (length) and this way (width) but he would still go through and count each row. He didn't necessarily just do the multiplication" (Mrs. Grey, December 13).

\section{Other mathematical strategies influence understanding of area. For one}

particular student, Jessica, Mrs. Grey realized that other components of mathematics instruction influenced how Jessica thought about area. Mrs. Grey thought that Jessica understood row and column structuring based on her drawings and her discussions of how many units were in each row and each column. She was surprised, though, that Jessica skip counted by twos to find the area of the region. Mrs. Grey stated that, as a class, they had been working on skip counting as a mathematical strategy and perhaps Jessica had incorporated this strategy into her understanding of area. She stated, "we have been breaking into groups and we have been working on skip counting and strategies like 
that. She just explained it (the area) really well to me, so I was surprised" (Mrs. Grey, December 13).

Mistaking the word area for perimeter. Even after instruction, several of the students in the classroom along with one particular student, Nadine, were attending to perimeter instead of area. In two instances, when Mrs. Grey asked them to find the area of the rectangle they were counting each side and then adding each of the sides together. Mrs. Grey interpreted this to mean that they were simply confusing the two words. This surprised her because students were still confused after the instruction and physically using tiles to cover the space. She thought that the lesson itself would have helped define the words for the students.

Students' personalities and past experience. In two of the incidences, Mrs. Grey was not really sure what the student was thinking, but attributed the student's thinking to his or her personality and past. When Kirby tiled the area of the rectangle on the Smartboard, he knew the correct answer but did not have enough columns. Mrs. Grey stated, "He is one of those quick finishers. So like whenever I want him to elaborate or go back and check his work again. He is trying to do it as fast as he can, so it is hard for me to tell if it is just an error of trying to not have homework or to be finished or if he really thinks that" (Mrs. Grey, December 13).

Mrs. Grey also discussed Trey's past experiences. Trey stated that the area of a rectangle was 6 and 10. Mrs. Grey attributed this to his past experiences. She thought that several of the teachers in the third grade taught procedurally and just told students to multiply length and width. Even though Trey scored very well on standardized tests, he seemed to have trouble solving problems conceptually. 
Significance to Mrs. Grey. For five of the events, Mrs. Grey discussed why the event was important to her. For almost all events, Mrs. Grey selected the event because she was surprised by the students' thinking and, for one, it was because she saw a similarity between her clinical interview and the students' classroom performance.

Mrs. Grey selected several events because the students' thinking surprised her. For some of the events, she was surprised that students were still thinking in a particular way about area even after some instruction, such as students confusing area and perimeter or Rey not using the area algorithm even though he referred to it.

For one of the events, Lisa drawing the tetris-like shapes, Mrs. Grey indicated it as important because this was the same strategy Lisa had used during the second interview. Surprisingly, Lisa was the only interview student that Mrs. Grey noticed something about during this lesson.

Implications for instruction. After reflecting on the lesson and student's actions, Mrs. Grey discussed that two of the events held implications for instruction. These events included Lisa drawing tetris-like shapes as well as students mistaking area for perimeter. Both of these events caused Mrs. Grey to think about the tools students are given and the area they are asked to measure.

When Lisa drew tetris-like shapes and when many in the class were confusing area and perimeter, Mrs. Grey realized that students were having difficulty structuring space, and this would become even more difficult if the space became larger. She decided that she should ask different groups to measure different spaces with different tools. These tasks would be representative of what the student understood. She stated, 
I think I am probably thinking about having 3 groups tomorrow. I will have one group that does an even smaller scaled activity because of the ones today that were having more difficulty. So that group might have enough (tiles) to make a whole row instead of just one (tile). I think I will give another group two (tiles) to challenge them (Mrs. Grey, December 11).

Mrs. Grey thought, following the lesson that many students would benefit from hands-on tools like square manipulatives to help them visualize structure.

\section{Relating Units of Measure Lesson}

Following Mrs. Grey's introduction lesson, she taught a three-day lesson relating different units of measure to one another. As a team, the fourth-grade teachers involved in the professional development had designed this unit, with the help of the professional development facilitators. The fourth-grade teachers thought that this lesson was appropriate for the fourth-graders because it not only addressed the area standard for the fourth quarter but also a second standard of unit conversion.

On the first day of the lesson, students compared a square foot to a square yard. They were first shown a cut out of both a square foot and a square yard and asked to predict how many square feet would it take to cover the square yard. Mrs. Grey also taped the outline of several square yards around the classroom. After the students predicted how many square feet were in a square yard, they were asked to measure using their square foot unit. Some groups of students were only given one unit while other groups were given two or three to help them check. If students finished this task quickly, they were asked to try and measure other things in the classroom either using the foot or the yard, like the classroom rug or a bulletin board. 
On the second and third days of the lesson, the students investigated how many 3inch square units it would take to tile a square foot and a square yard and also how many square inches it would take to tile all three of the larger units. The students were asked to relate these smaller units to each of the larger size units. The goal of this lesson was for students to start to see a multiplicative relationship between different size units. The teachers thought that by introducing smaller and smaller units, the students would develop short cuts or strategies to help them measure using the transitional units.

What Mrs. Grey noticed. Over the course of three days of instruction, Mrs. Grey noticed 12 events that were important to her. These included drawings, journal entries, area measurement and counting strategies, and statements (as shown in Figure 13). For nine events, Mrs. Grey discussed students' understandings in relation to the event and four of the events lead to implications for instruction (shown in gray in figure 13). 


\begin{tabular}{|c|c|c|c|}
\hline \multicolumn{4}{|c|}{ Relationship Between Units Lesson: December } \\
\hline What the Teacher Noticed & Interpreted & $\begin{array}{l}\text { Implication for } \\
\text { Teaching }\end{array}$ & Significance \\
\hline \multicolumn{4}{|c|}{ Day 1 of the Lesson } \\
\hline \multicolumn{4}{|l|}{ Writing in Journal } \\
\hline $\begin{array}{l}\text { Drawing/Journal Entry: No tetris-like } \\
\text { figures, predictions true to drawings. } \\
\text { (all students) }\end{array}$ & $\begin{array}{l}\text { Size of unit determines } \\
\text { number of units. }\end{array}$ & $\begin{array}{l}\text { Introduce smaller } \\
\text { units. }\end{array}$ & $\begin{array}{l}\text { Showed } \\
\text { improvement }\end{array}$ \\
\hline $\begin{array}{l}\text { Journal Entry: Prediction was very far } \\
\text { off. (Nadine) }\end{array}$ & (none provided) & (none provided) & $\begin{array}{c}\text { (none } \\
\text { provided) }\end{array}$ \\
\hline $\begin{array}{l}\text { Journal Entry: Predicted } 4 \text { square feet } \\
\text { in a square yard. (Rey) }\end{array}$ & Visually off in understanding. & (none provided) & $\begin{array}{l}\text { Unexpected } \\
\text { response } \\
\text { given test } \\
\text { scores. }\end{array}$ \\
\hline \multicolumn{4}{|c|}{ Measuring Square Feet in Square Yard and Larger Spaces } \\
\hline $\begin{array}{l}\text { Area Measurement Strategy: } \\
\text { Students struggled to predict and find } \\
\text { the area of larger spaces. (some groups) }\end{array}$ & (none provided) & $\begin{array}{l}\text { Give students time } \\
\text { to think. }\end{array}$ & $\begin{array}{l}\text { Surprised } \\
\text { students } \\
\text { could not } \\
\text { handle } \\
\text { extension. }\end{array}$ \\
\hline $\begin{array}{l}\text { Language Usage: Interchanged the } \\
\text { words square feet and square yards. } \\
\text { (Caitlin) }\end{array}$ & $\begin{array}{l}\text { Does not understand } \\
\text { differences between units. }\end{array}$ & (none provided) & $\begin{array}{c}\text { (none } \\
\text { provided) }\end{array}$ \\
\hline $\begin{array}{l}\text { Statement: Said she uses } 3 \text { equal lines } \\
\text { to make square yards into square feet. } \\
\text { (Hailey) }\end{array}$ & $\begin{array}{c}\text { Confused by statement/ } \\
\text { Student understands each row } \\
\text { as a unit. }\end{array}$ & (none provided) & $\begin{array}{c}\text { (none } \\
\text { provided) }\end{array}$ \\
\hline \multicolumn{4}{|c|}{ Day 2 of Lesson: Measuring Number of Square Feet and 3-inch Squares in Different Spaces } \\
\hline $\begin{array}{l}\text { Statement: Area includes perimeter. } \\
\text { (many in class) }\end{array}$ & $\begin{array}{l}\text { Confusing the words area and } \\
\text { perimeter. }\end{array}$ & (none provided) & $\begin{array}{c}\text { Pervasive } \\
\text { misconception }\end{array}$ \\
\hline $\begin{array}{l}\text { Journal Entry: Estimates are } \\
\text { becoming more accurate. (many in } \\
\text { class) }\end{array}$ & (none provided) & $\begin{array}{l}\text { Provide } \\
\text { manipulatives to } \\
\text { help check } \\
\text { estimates. }\end{array}$ & $\begin{array}{l}\text { Surprised/conf } \\
\text { used by } \\
\text { students' } \\
\text { perceptions. }\end{array}$ \\
\hline $\begin{array}{l}\text { Statement/Area Counting Strategy: } \\
\text { Area can be found by multiplying the } \\
\text { number of rows by the number of } \\
\text { columns, but never said that is the } \\
\text { formula for area. (two groups) }\end{array}$ & (none provided) & (none provided) & $\begin{array}{l}\text { Past } \\
\text { experiences. } \\
\text { Instructional } \\
\text { disconnect. }\end{array}$ \\
\hline $\begin{array}{l}\text { Area Measurement Strategy: Laid out } \\
\text { one column and one row to find the } \\
\text { area. (one group) }\end{array}$ & $\begin{array}{l}\text { Area is repeated addition/so } \\
\text { many rows with so set } \\
\text { number of tiles in each row. }\end{array}$ & (none provided) & $\begin{array}{l}\text { Past } \\
\text { experiences. } \\
\text { Instructional } \\
\text { disconnect. }\end{array}$ \\
\hline $\begin{array}{l}\text { Area Measurement } \\
\text { Strategy/Counting Strategy: } \\
\text { Measured the area of the rug to be } 12 \times \\
12 \text { but multiplied } 12 \times 2 \text { to find the } \\
\text { number of square units. (Devan and } \\
\text { Rey) }\end{array}$ & $\begin{array}{l}\text { Mixed up and maybe is } \\
\text { thinking about } 2 \text { sets of } 12 \\
\text { rather than } 12 \text { sets of } 12 .\end{array}$ & (none provided) & $\begin{array}{c}\text { (none } \\
\text { provided) }\end{array}$ \\
\hline \multicolumn{4}{|c|}{ Day 3 of the Lesson: Measuring number of inch squares in square foot and square yard } \\
\hline $\begin{array}{l}\text { Area Measurement Strategy: used } 20 \\
\text { tiles to cover rectangle and still had } 3 / 4 \\
\text { left to cover but only asked Mrs. Grey } \\
\text { for } 20 \text { more times. (Group of students) }\end{array}$ & $\begin{array}{l}\text { Are not connecting number } \\
\text { with space. }\end{array}$ & $\begin{array}{l}\text { Students need } \\
\text { more individual } \\
\text { attention with } \\
\text { prediction. }\end{array}$ & Surprising. \\
\hline $\begin{array}{l}\text { Journal Entry: Did not want to make a } \\
\text { prediction for the number of square } \\
\text { inches in a square foot. (Kirby) }\end{array}$ & $\begin{array}{l}\text { Personality-rushed in } \\
\text { everything he does. }\end{array}$ & (none provided) & $\begin{array}{c}\text { (none } \\
\text { provided) }\end{array}$ \\
\hline
\end{tabular}

Figure 13. Events that Mrs. Grey noticed during Relating Units of Measure Lesson. Events highlighted in gray had instructional implications. 
Journal entries and drawings. Many of the events that Mrs. Grey noted centered on students' entries and drawings into their mathematics journals. Each day of the lesson, Mrs. Grey asked students to make predictions involving the units that they used. Because of this, she noted an event related to students' predictions of area daily. On the first day, Mrs. Grey noticed three events related to students' predictions in their journals and drawings. Mrs. Grey noticed that as the students related square feet to square yards, they stopped drawing tetris-like regions and their predictions were fairly accurate in relation to their drawings.

In relation, she also noticed predictions that were not accurate. She noticed that her student Rey predicted that four square feet would fit in a yard and was surprised that he would be so far off from nine square feet given his past successes. She also noticed that Nadine predicted 60 square feet would tile a square yard.

On the second day, Mrs. Grey noted that students written estimates were becoming more accurate, specifically focusing on students' understanding of smaller units. For square inches into a square yard she had estimates from 300 square inches to 10 square inches. She noted that 10 square inches were still pretty far off, but at least she did not have any estimates in the thousands as were seen in Mrs. Purl's classroom.

On the last day of instruction, Mrs. Grey specifically focused on one group's predictions. She noticed that the students considered higher performing than the other students refused to write predictions. They wanted to rush right into the task without taking time to predict how many square units it would take to fill the space of the square yard. After a long discussion, the group agreed with Mrs. Grey that they should predict the measurement of the space. 
Area measurement and counting strategies. Mrs. Grey noticed area measurement and counting strategies across the three days of the lesson. Mrs. Grey noted two events that related to how students were using counting strategies to find the area of the region. On the second day of the lesson, Mrs. Grey noticed that several of the students were making the connection that the area could be the number of rows multiplied by the number of columns, but none of them wanted to define a formula. She stated, "I thought it was interesting that two could would tell me that it was length times width. They would say it was this row (number in a row) and this many (number of rows) and I multiplied but they never said 'and that's the formula for area' " (Mrs. Grey, December 15).

She also noted that one group was laying out only one row and one column and knew that they could skip count by rows to find the total area. For one particular group, the short cut of multiplication had thrown them off in their answer. They saw that a space was 12 rows with 12 units in each row, but when they went to multiply Mrs. Grey noted that the students were saying the area was 144 square units by saying what they multiplied was $12 \times 2$.

Mrs. Grey also noticed students' area measurement strategies, or how students used tools to help them find the area, within four of the events. On the first day of the lesson Mrs. Grey noticed that students experienced difficulty using their tools to measure the area of a larger spaces, like their classroom. She found this surprising, given the success that they experienced when comparing the square foot to the square yard.

On the second day of the lesson, she noticed that students were laying out one row of tiles and one column of tiles to help them find the total. She also noticed, on the last day of the lesson, that one of the student groups still needed all the tiles to be able to find 
the area of a space. When the students had filled a fourth of the space with 20 tiles, they ran out of tiles and had to ask Mrs. Grey for more. Mrs. Grey asked them to think about what an appropriate number would be to ask for given what they had already used. The students decided they should ask Mrs. Grey for another 20 tiles. Mrs. Grey was very surprised by this because she could not believe her students did not see that they had only covered a fourth of the space and should ask for more than 20 tiles.

Statements and language usage. Mrs. Grey noticed two events on the first day of the lesson involving language or a statement and one on the second day of the lesson. Mrs. Grey noticed that Hailey stated that she needed to make three lines to divide a square yard into equal square feet. Mrs. Grey was not sure what Hailey meant by lines and wondered if the word lines represented something else to Hailey. Reading from Hailey's journal she states,

I am reading Hailey's journal, she said "I think 9 square feet will fit in one square yard. She said, "each foot is 3 lines" but then even when they go back to explain at the end. She said, "we started at one corner and put a finger there to mark our spot" I never... I don't know if she is just saying these lines here, or here or what she means by lines. Maybe she means equal units? (Mrs. Grey, December 14). On that same day, as students measured other parts of their classroom, a student, Caitlin, used square feet to measure a bulletin board. When she reported her answer to Mrs. Grey she called the square feet square yards. Mrs. Grey noted this event because other students were also confusing the names of the units, as well.

On the second day, Mrs. Grey noted that some students were still confused about the words area and perimeter and what the two meant. Students were saying that area 
included perimeter or were unsure of how perimeter and area differed. Mrs. Grey noted this because she was surprised that these two words and ideas still seem to be so confusing for students and she wonders why they tend to mix the two.

Interpreted understanding. For many of the events, nine of 13, Mrs. Grey was able to provide justification about what she thought the student understood. The understandings that Mrs. Grey provided centered on the themes of area visualization, or counting area, understanding of mathematical terminology, and the student's past or personality as influencing their actions.

Visualization of area and counting strategies. As the Mrs. Grey taught each lesson, she noticed that students predictions seemed more accurate and stated that she thought that the students were starting to see that the size of the unit would determine the number of units. Mrs. Grey conjectured that Rey, a student who had predicted the area was 4 square feet, had trouble visualizing the space. She related this skill back to herself and stated, "So I don't know, I don't know if visually he was just off. I mean that's not like way off. I wonder if it's some kind of skill because I know that sometimes I am also bad at estimating measurements initially" (Mrs. Grey, December 13). Mrs. Grey also described Hailey's thinking when she used the word rows and said that there were three rows in each square foot. Mrs. Grey wondered if Hailey was confusing a unit with a row or a column, because her answer was still correct.

On the second day of the lesson, students transitioned into comparing smaller units, such as a square inch and 3-inch square to the square foot and the square yard. Mrs. Grey noticed two groups laying out one row and one column; she conjectured that these groups were starting to visualize area as the number in each row and the total number of 
rows. She stated, "I think they are thinking about it as the rows and columns, but it is more like if I had them explain they wouldn't explain the formula they would give more of a repeated addition like there are this many rows that have this many (units)" (Mrs. Grey, December 13).

Mrs. Grey noticed that some students were also starting to think about multiplication in relation to rows and columns. One group measured that the space was composed of 12 rows each containing 12 square units, but stated that 12 x 2 was 144 . Mrs. Grey conjectured that maybe they saw 12 × 12 like $2 \times 12$ because there are two 12 's represented by the rows and columns.

On the final day of the lesson, Mrs. Grey also commented on a group that was having some difficulty understanding area. This particular group repeatedly asked for more tiles to fill the space. Mrs. Grey thought that, even after instruction, they could not visualize the space or connect number with space and were thinking about area as individual units.

Language confusion. During two of the days of instruction, Mrs. Grey commented on how students perceived mathematical language. Students seemed to mix up names of units as well as area versus perimeter. Mrs. Grey thought that the concepts and words were relatively new to the students, so they were not distinguishing between the two. She also conjectured that possibly students confused perimeter and area concepts because they are often taught simultaneously and students do not see them as disjoint. She stated,

If I had anything that I would still hammer home, it would be that difference between perimeter and area and how they still keep interchanging those in their 
vocabulary. I don't know if it is just spend more time on them separately because it seems like as soon as you try to pull them together the students are not sure which is which, and they confuse the two ideas (Mrs. Grey, December 13).

Personality and past experiences. Mrs. Grey often discussed student's personalities and past experiences related to an action rather than their understanding. In two of the events, Mrs. Grey referenced the student's past experience as either a rational for the student's action or in defense of the student. For instance, when Rey, a student whom Mrs. Grey thought of as a higher performing student, only predicted that four square feet would fit into a yard, Mrs. Grey was very surprised. She stated, At the beginning he said four (square feet would fit into a yard), and I was really surprised because as far as testing goes, he's like the blue, which is above grade level. He is the only person that came with multiplication facts memorized and formulas at the beginning of the year. He was the one who could rattle them off and he was the one who said 'I think four' (Mrs. Grey, December 13).

Although Mrs. Grey was surprised by Rey's answer, she then stated that even she has trouble visualizing measurement sometimes, so perhaps Rey was having this issue.

In another instance, Kirby, a student whom Mrs. Grey considered high performing, did not want to make a prediction for how many square inches it would take to tile a square foot. Mrs. Grey attributed his action to his rushed personality. She stated that she thought he was so bright that to him making a prediction seemed like a waste of time. In these two cases, the students past performance clouded Mrs. Grey's interpretation of what they actually understood. 
Significance to Mrs. Grey. As Mrs. Grey discussed events, she often provided a rationale for why the event was important to her. For seven of the 13 events, Mrs. Grey provided some explanation of why the event was chosen. This was particularly true when she did not discuss the student's understanding in relation to the event. For most of the events, five of the seven, Mrs. Grey was surprised that students did not have a particular understanding mastered and for two of the events she thought they were important because they revealed that the class had gained an understanding.

Surprising events. For five of the seven events, Mrs. Grey marked the event because it was surprising to her. In many cases, she could not see or understand why a student had not mastered the concept or was thinking about a concept in a particular way. One idea that surprised her across the lessons was that students did not develop the area formula or call what they were doing the area formula. This surprised Mrs. Grey because students had heard the formula for area in third grade and also in some of their warm-up problems throughout the year.

Related to the area formula, Mrs. Grey was also surprised that students would not just use the formula to find the area; this was especially true toward the end of the lessons. Mrs. Grey was often surprised when students used a strategy that she felt was unsophisticated, given instruction.

Events related to the whole class. Mrs. Grey selected two of the events because they represented something about the class, as a whole. For example, when students were still confusing area and perimeter, Mrs. Grey selected this event because it was a pervasive misunderstanding across time. Mrs. Grey thought it was important to note that this misconception was difficult to unteach. 
Implications for instruction. For each day of the lesson, Mrs. Grey chose a total of four events that she related to instruction. These implications included determining if a student was ready for a new concept, the role of manipulatives, and allowing wait time during instruction.

Students ready for a new concept. On the first day of the lesson, Mrs. Grey noted that students' predictions were true to their drawings and she thought that maybe they were starting to make the connection that the size of the unit would determine the number of units it would take to tile a space. Following this comment, she mentioned that she thought this was an indicator that students were ready to explore smaller units in relation to the square yard, like square inches. This particular action helped Mrs. Grey to determine if her students were ready to move on to more difficult concepts.

Time to think. Mrs. Grey also indicated that students need more time to think about the concept and reason about the idea. During the first lesson, students struggled to find the area of larger spaces like the bulletin board or carpet with the square feet and square yards. Mrs. Grey was not sure exactly what they were thinking. She stated that maybe if she let them think about it overnight and tried the activity out again in the morning that they would have had time to think about it. She stated, "I was surprised that they seemed to struggle with the extension. It is a more difficult task so maybe I should have waited and started it tomorrow. Maybe when they come in, I will give them time at their tables to rethink their strategies." (Mrs. Grey, December 15)

Manipulatives and practice. On the second and third days of the lesson, Mrs. Grey noticed two events that indicated that students needed more practice using manipulatives to help check their predictions. Mrs. Grey noted that some students were 
still very far off in their predictions or unsure of even how to make a prediction. In both instances, Mrs. Grey discussed that this influenced her to allow students to use as many tiles as they needed to help them gain practice in predicting and checking. She also stated that students need more individualized attention over time in helping them make more accurate predictions.

\section{Area Conservation Lesson}

Mrs. Grey designed a final lesson focused on area conservation for the end of the unit. This lesson lasted for a day, and students worked together in groups to investigate the problems posed. The students were given 36 one-inch tiles and asked to make a rectangle with an area of 36 . They were then asked to make other shapes with an area of 36. After they constructed each shape, they were also asked to find the perimeter. The purpose of the lesson was for students to see that shapes with the same area could have different perimeters.

What Mrs. Grey noticed. During this lesson, Mrs. Grey noted three events that were important to her (shown in Figure 14). These events involved students' perceptions and representations of area through drawings as well as their language usage in relation to perimeter and area. Mrs. Grey discussed students' understanding in each of the events and two of the events led to instructional implications. 


\begin{tabular}{|c|c|c|c|}
\hline \multicolumn{4}{|c|}{ Area Conservation Lesson: December } \\
\hline What Mrs. Grey Noticed & Interpreted Understanding & Implication for Teaching & Significance \\
\hline $\begin{array}{l}\text { Language Usage: } \\
\text { Interchanged area with } \\
\text { perimeter with non- } \\
\text { rectangular regions. (whole } \\
\text { class) }\end{array}$ & $\begin{array}{l}\text { Students see area and perimeter as } \\
\text { the same since they are taught so } \\
\text { close together. }\end{array}$ & $\begin{array}{l}\text { Teach perimeter and area in } \\
\text { distinct units. }\end{array}$ & $\begin{array}{l}\text { Surprised, given } \\
\text { instruction. }\end{array}$ \\
\hline $\begin{array}{l}\text { Drawing Strategy: Better } \\
\text { overall/Area units are } \\
\text { uniform and connected } \\
\text { without gaps or overlaps. } \\
\text { (all students) }\end{array}$ & $\begin{array}{l}\text { Students understand area units are } \\
\text { uniform and that measuring area } \\
\text { means the entire space needs to be } \\
\text { covered. }\end{array}$ & (none provided) & (none provided) \\
\hline $\begin{array}{l}\text { Drawing Strategy: } \\
\text { Struggled with } \\
\text { representing the picture on } \\
\text { paper/ wants units to scale. } \\
\text { (Nadine) }\end{array}$ & $\begin{array}{l}\text { Sees the } 1 \text { inch square as } 1 \text { inch } \\
\text { and cannot scale down for a } \\
\text { picture. }\end{array}$ & $\begin{array}{l}\text { Use larger paper and a } \\
\text { smaller number of squares. }\end{array}$ & (none provided) \\
\hline
\end{tabular}

Figure 14. Events that Mrs. Grey noticed during Area Conservation Lesson. Events highlighted in gray had instructional implications

Drawing strategies. Two of Mrs. Grey's comments referred to students' abilities to represent area through drawings. Mrs. Grey noted that over all the class's drawings had improved across the unit. She saw that students were making units uniform and were also not leaving gaps or overlaps in their representations. She stated, "In their drawings today all of the one inch units were connected and there weren't as many with gaps. In the pictures that I saw the students draw, their depiction of the square unit was better" (Mrs. Grey, December 18).

Mrs. Grey also referenced one student in particular, Nadine. Nadine represented several students in the class who had difficulty drawing because she could not visualize how to scale her figure down. When asked to sketch a drawing of what she made, Nadine made each unit exactly a one-inch square and could see no other way to make a sketch. This was problematic because the paper was not large enough to accommodate all of the square units to scale. Mrs. Grey stated, "Then I thought ohhhh, so they (the students) were mindful of if it is one inch then it needs to be one inch (in their drawing). Like Nadine said, 'it isn't going to fit on the paper' and I said, 'what if we made it (the scale) 
smaller' and she said, 'you mean like less tiles?"' (Mrs. Grey, December 18). In this lesson, Mrs. Grey had encountered an entirely new problem with students representing area.

Language usage. Area and perimeter confusion was persistent across the unit, but for many students had become better over time. This lesson confused students because students were allowed to make non-rectangular regions and letters of the alphabet. Mrs. Grey noticed that when students made letters of the alphabet, like the letter "g" they found the perimeter of the outside of the shape but did not know what to do with the inside of the shape. She stated, "They did a fairly good job with the rectangles but then when we went to make any shape they would measure the outside of the tile but not the inside" (Mrs. Grey, December 18). Even though students had made improvements in their understanding of area and perimeter, this task seemed to further confuse some.

Interpreted understanding. In each of the events that Mrs. Grey noted, she was able to provide an interpretation of what she thought the student or students understood. These interpretations primarily related to students' understanding of area and perimeter and also their visualization of area.

Area and perimeter. After Mrs. Grey noticed that students were still confusing area and perimeter, she conjectured that possibly it was because of the way that area and perimeter are taught to the students. When perimeter and area are introduced, they are often taught around the same time. Mrs. Grey conjectured that it is probably difficult for the students to tease the two apart in their minds given that they are always presented together. She stated 
We haven't done a lot of perimeter lessons this year, so a lot of it is based on what they learned in third grade. I don't know if it is just whenever we have our four quarter plans we have measurement and as they get older more things are added on. So they have always had perimeter and area and I think it might be crammed together in such a tight space that they start connecting them and it gets confused in their minds (Mrs. Grey, December 18).

Understanding of area. Mrs. Grey also commented on students' visualization of area. For two of the events, Mrs. Grey described the students' understanding of area visualization. Mrs. Grey noticed that students' drawings were becoming better. She thought that students had clearer picture of what area meant in that area means units that are uniform and cover the space without any gaps and overlaps. She also noted that for some students, like Nadine, representation is direct and students' have difficulty scaling a picture because they do not see the picture and what they have built as the same.

Significance to Mrs. Grey. When students still confused area and perimeter, Mrs. Grey was described this as important to her because she was surprised that this was still happening this late in the unit of instruction. She stated that it was a misunderstanding that she had been thinking about the entire time and why it still persists.

Implications for instruction. Because the unit on area was over, Mrs. Grey provided ideas for teaching in subsequent years related to two of the events. In general, regarding the lesson, she stated that area and perimeter may need to be taught at different times to help students see a difference between the two. She stated that if students learned 
the two concepts separately, then the difference between the concepts may be better retained.

Specifically to this unit, Mrs. Grey noted that students had difficulty representing a scale drawing of their rectangle or figure. She stated that in the future she would give them larger paper and a smaller number of unit squares so that if they wanted to draw the picture to scale they could.

\section{Summary}

Across three sets of student interviews and the unit of instruction, Mrs. Grey noted many events, specifically 46 events and 57 student actions that she found important. For 35 of the events, Mrs. Grey described a student or students' understanding in relation to the action she noted. She described implications for instruction for 14 of the actions. Figure 16 presents the summary of the data pertaining to the types of student actions that Mrs. Grey noticed during the study. 


\begin{tabular}{|c|c|c|c|c|c|c|}
\hline & \multicolumn{3}{|c|}{$\begin{array}{c}\text { Interviews } \\
\text { (22 events; } 27 \text { student actions) }\end{array}$} & \multicolumn{3}{|c|}{$\begin{array}{c}\text { Lessons } \\
\text { (24 events; } 30 \text { student actions) }\end{array}$} \\
\hline & $\begin{array}{c}\text { One } \\
(6 \\
\text { events; } \\
6 \\
\text { student } \\
\text { actions }) \\
\end{array}$ & $\begin{array}{c}\text { Two } \\
\text { (11 events; } 15 \\
\text { student } \\
\text { actions) }\end{array}$ & $\begin{array}{c}\text { Three } \\
\text { (5 events; } 6 \\
\text { students } \\
\text { actions) }\end{array}$ & $\begin{array}{c}\text { Smartboard } \\
\text { (8 events; } 11 \\
\text { student } \\
\text { actions) }\end{array}$ & $\begin{array}{l}\text { Relationship } \\
\text { Between } \\
\text { Units } \\
\text { (13 events; } \\
\text { 16 student } \\
\text { actions) } \\
\end{array}$ & $\begin{array}{c}\text { Area } \\
\text { Conservation } \\
\text { (3 events; } 3 \\
\text { student actions) }\end{array}$ \\
\hline Drawing & 4 & 7 & 3 & 3 & 1 & 2 \\
\hline Statement & 2 & 5 & 2 & 2 & 3 & 1 \\
\hline $\begin{array}{r}\text { Written } \\
\text { Strategy }\end{array}$ & 0 & 1 & 0 & 1 & 0 & 0 \\
\hline $\begin{array}{r}\text { Length } \\
\text { Measurement } \\
\text { Strategy }\end{array}$ & 0 & 1 & 0 & 0 & 0 & 0 \\
\hline $\begin{array}{r}\text { Area } \\
\text { Measurement } \\
\text { Strategy }\end{array}$ & 0 & 1 & 0 & 0 & 4 & 0 \\
\hline $\begin{array}{r}\text { Area } \\
\text { Counting } \\
\text { Strategy }\end{array}$ & 0 & 0 & 0 & 3 & 2 & 0 \\
\hline $\begin{array}{r}\text { Journal } \\
\text { Account }\end{array}$ & 0 & 0 & 0 & 1 & 5 & 0 \\
\hline $\begin{array}{r}\text { Student to } \\
\text { Student } \\
\text { Interaction } \\
\end{array}$ & 0 & 0 & 0 & 1 & 0 & 0 \\
\hline Behavior & 0 & 0 & 1 & 0 & 0 & 0 \\
\hline $\begin{array}{r}\text { Language } \\
\text { Usage/Compr } \\
\text { ehension } \\
\end{array}$ & 0 & 0 & 0 & 0 & 1 & 0 \\
\hline
\end{tabular}

Figure 15. Summary of all student actions Mrs. Grey noticed. The types and frequency of student actions that Mrs. Grey noticed within events in each of the interviews and lessons. Cells highlighted in gray indicate events that Mrs. Grey interpreted in terms of instructional implications.

\section{Interviews: Events Noticed and Implications for Instruction}

Across the three student-teacher interviews, Mrs. Grey noticed 27 student actions within 22 events. Mrs. Grey primarily noticed students through their drawings (52\%, 14 out of 27) as well as their statements (33\%, nine out of 27). She noticed students' area measurement, length measurement, and a written strategy each once across the interviews. Some of the interview tasks specifically directed students to draw, which could account for Mrs. Grey's attention to this particular event.

Mrs. Grey initially attended to how students thought about area but in relation to specific tasks. Referring to the four times as big task, she explained that students thought 
of the words "as big" meaning to grow. With regard to the area conservation task, she discussed that students' perceived rectangles with the same area to be different because of their perimeters. In the first interview, Mrs. Grey also placed her class overall within trajectory levels based on their understanding of unit structuring, such as leaving gaps or overlapping units.

In the second interview, Mrs. Grey continued to expand upon her students' understanding of area. She discussed that some students, like Devan, saw individual units while others saw rows and columns and even multiplicative relationships. In relation to area measurement she also discussed that students' conceptions of area did not always match what they drew, based on Lisa's tetris shapes. In addition to expanding on students' understanding of area measurement, she also attended to specific strategies in relation to different tasks such as students using their finger to measure the length of the missing side.

In the final interview, Mrs. Grey primarily attended to growth and misconceptions over time. She noticed that students' drawings of units had become more uniform and they understood that areas could be changed to make different rectangles. She also commented that misconceptions, such as confusing area and perimeter, had persisted across the unit.

With regard to implications for instruction, Mrs. Grey realized that students needed more practice in Interview 1, but she did not articulate many ideas for tasks to help students. During the student interviews, Mrs. Grey was the most productive in thinking about implications during interview 2, which was closest to her unit of instruction. Mrs. Grey articulated several revelations about the interviews in relation to 
instructional practices. After discussing tasks with students and watching them draw, she realized that students cannot always express what they are thinking within a drawing, so it is important to give them opportunities to not only draw in class but also to discuss their thinking. Her attention was also drawn to students' unit structuring in Interview 2 and this theme surfaced across her unit of instruction, as well. She decided after the first interview that she needed to give students multiple units and multiple places to measure to help establish students' conceptions of unit structuring. During the final interview, Mrs. Grey did not provide any implications for instruction.

Mrs. Grey reflected in the final interview that the student interviews were productive in the sense that they highlighted students' possible misconceptions and gave her a sense of where students were in their thinking.

\section{Instructional Unit: Events Noticed and Implications for Instruction}

During instruction, Mrs. Grey noticed 24 events and 30 students actions within those events. As shown in Figure 15, Mrs. Grey noted students' thinking through students' strategies such as drawings (20\%, six out of 30) as well as area counting and measurement strategies (30\%, nine out of 30). She also noticed students' verbal accounts through statements (20\%, six out of 30$)$ and explanations written in mathematics journal accounts (20\%, six out of 30). Mrs. Grey also noticed a few events within student-tostudent interactions as well as language usage. Mrs. Grey implemented teaching strategies within her classroom such as writing and drawing so this may account for why she noticed so many written forms of students' thinking.

During classroom instruction, Mrs. Grey also expanded upon her interpretation of students' understanding of area. At the beginning of the unit, she was able to discuss that 
students' might think that the unit must match the space to be measured. She also explained that students' drawings, statements, and counting strategies were not always in sync with one another and the students' understanding. For example, Lisa could articulate the number of units in a row and the number of rows in a rectangular region verbally but drew tetris-like figures.

As the unit progressed, Mrs. Grey attended to multiple students' understanding. She discussed that some students saw area units just as units while some students could see rows and columns and even a multiplicative relationship. She also realized, through the area conservation lesson, that students may not be able to visualize area.

Perimeter in relation to area measurement was a theme that also emerged across the lessons. Mrs. Grey continually discussed that students misunderstood the two in relation to each other, but she had difficulty expanding upon why this misconception occurred and what students understood. Within the classroom context, other types of understandings emerged that were not found in interviews such as detailed descriptions of students personalities as well as connections to other mathematical topics. There were several events that Mrs. Grey indicated as important because the strategy was higher or lower then she expected from that particular student based on their standardized test scores and past experiences within the classroom.

As Mrs. Grey enacted the area measurement unit, she primarily developed tasks and implications for instruction based on students' understanding of unit structuring. This included providing students will different tools and manipulatives to measure different size spaces and to check their answers as well as providing students with different mediums (e.g., paper, discussion time, squares) to discuss their thinking and reasoning. 
Mrs. Grey also developed instructional implications that related to herself and her teaching practices rather than tasks. This included allowing students to struggle and think through tasks as well as teaching perimeter and area further apart.

\section{Mrs. Grey's Perceptions of the Learning Trajectory Based Professional Development}

Underpinning this study is the learning trajectory itself and the learning trajectory professional development in which Mrs. Grey was a participant. During our interviews, sometimes unprompted, Mrs. Grey discussed the strengths and weaknesses of the professional development as well as her ability and inability to relate to the learning trajectory document. In the following section, Mrs. Grey's perceptions of both the learning trajectory and the professional development are discussed below as well as instances that highlight these ideas from her teaching. In Figure 16, questions that were posed to Mrs. Grey during the final interview of the study are shown as well as summaries of her responses. 


\begin{tabular}{|c|c|}
\hline Questions Posed & Mrs. Grey's Response \\
\hline $\begin{array}{l}\text { In your opinion, what are components } \\
\text { of ineffective professional } \\
\text { development? }\end{array}$ & $\begin{array}{l}\text { - } \quad \text { Professional development that is not in-depth. } \\
\text { We are given written instructions but we don't have anyone to talk } \\
\text { with that has actually used it in their classroom or in conjunction } \\
\text { with the current curriculum. }\end{array}$ \\
\hline $\begin{array}{l}\text { In your opinion, what are components } \\
\text { of effective professional } \\
\text { development? }\end{array}$ & 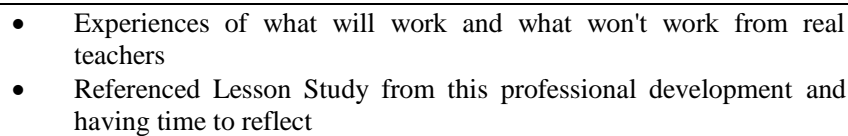 \\
\hline $\begin{array}{l}\text { If you could design a PD, what would } \\
\text { it entail? }\end{array}$ & $\begin{array}{l}\text { - Visit classrooms of teachers who have been working with the } \\
\text { material longer. } \\
\text { - Talking about it and actually doing it are two different things. } \\
\text { Have time to discuss as a team or a grade level because otherwise } \\
\text { you just move on to the next thing. }\end{array}$ \\
\hline $\begin{array}{l}\text { What are components, if any, of this } \\
\text { professional development did you feel } \\
\text { transitioned well into your classroom? }\end{array}$ & $\begin{array}{l}\text { Working collaboratively with other teachers to design and modify } \\
\text { lessons. }\end{array}$ \\
\hline $\begin{array}{l}\text { What are components, if any, of this } \\
\text { professional development did you feel } \\
\text { did not transition well into your } \\
\text { classroom? }\end{array}$ & $\begin{array}{l}\text { Anticipating and Reflecting on students' thinking. It is important but } \\
\text { difficult to do. }\end{array}$ \\
\hline $\begin{array}{c}\text { What role do you feel that the learning } \\
\text { trajectory played in your lesson } \\
\text { planning process? }\end{array}$ & $\begin{array}{l}\text { A tool to see where your students are and what misconceptions or } \\
\text { understanding they might have. } \\
\text { Gives you an idea of what tasks to pose to maybe move them to the } \\
\text { next level of thinking. } \\
\text { - Students do not move quickly. It takes them time to learn and to } \\
\text { struggle through concepts. }\end{array}$ \\
\hline $\begin{array}{l}\text { What do you see as weaknesses, if } \\
\text { any, of the current trajectory } \\
\text { document? }\end{array}$ & $\begin{array}{l}\text { - language is too technical } \\
\text { it is very verbose with few examples of what students work might } \\
\text { look like. What if we did not do that particular task? } \\
\text { People see things in different ways and it is especially difficult to see } \\
\text { behaviors when you have } 20 \text { students and you are a new at working } \\
\text { with the document. }\end{array}$ \\
\hline $\begin{array}{c}\text { How would you amend the current } \\
\text { document to make it easier for you to } \\
\text { use? }\end{array}$ & $\begin{array}{l}\text { Each trajectory level would have more detail with several examples } \\
\text { of student work to highlight that level. }\end{array}$ \\
\hline $\begin{array}{l}\text { What do you see as strengths, if any, } \\
\text { of the current trajectory document? }\end{array}$ & $\begin{array}{l}\text { - The length trajectory is easier to understand because I have worked } \\
\text { with it longer, more practice looking at it and thinking about it. }\end{array}$ \\
\hline
\end{tabular}

\section{Figure 16. Mrs. Grey professional development questions.}

\section{Perceived Strengths of the Professional Development}

When discussing this professional development, Mrs. Grey and I first began by

discussing professional development in general and what components she felt made up

both effective and ineffective programs. Through these broader questions, I hoped to see

if she would reference the current professional development. She discussed that, in 
general, poor professional development provides written curriculum but few resources to help teachers with use in the classroom. In contrast, she thought effective professional development spanned longer periods of time and investigated how components of the professional development could be integrated into classrooms effectively. This included teacher interaction and group meeting times. Following these questions, we discussed this particular professional development.

Allow children to think, reason, and struggle through concepts. Mrs. Grey stated that one of the biggest philosophies that she had gained from this professional development was that children think differently and that they need time to work through their ideas. She reflected on her experiences in the professional development and her own learning. She stated that it is interesting to see what children naturally knew and what they struggled with. By letting them work through their ideas, the ideas seem to resonate and remain with the students. She stated,

I think just doing the lesson on area and seeing the different thinking that comes out of the students if they are able to work through the whole thing without being given rulers or the formulas from the beginning and letting them work through it. To see what they catch on to and what they have trouble with and see what they disagree with each other about and what they kind of have to work through to get the answer. I think that helps it stick in their minds because they had to work at it more than if it was something that we had done for a day and I told them all the rules. So I think it sticks better that way. And things stick better that way for me too, not just for them (Mrs. Grey, December 19). 
Relating to allowing students to struggle, Mrs. Grey reflected that she came to view measurement as a process through learning about the trajectory. She realized that students could think about a topic in many ways and that it might take time for them to grow in their understanding. This is what she said about the learning trajectory:

I think it is a tool to see where your students are and what misconceptions or understandings they might have. It also gives you some idea of what tasks to pose to sort of move them toward that next level. You might not get through an entire level in a school year, depending on the student, but at least get them thinking more toward that next level. (Mrs. Grey, December 19)

Mrs. Grey also referenced several ideas that went beyond the learning trajectory document itself and focused more on components of interaction built into the professional development.

Learning from other teachers. When discussing effective professional development, Mrs. Grey reflected on the importance of working with other teachers and trying ideas out in the classroom. She stated that when teachers see methods from a professional development first hand, within a classroom, it makes them seem more applicable to individual classrooms. It was specifically important for her to be able to reflect on lessons and modify them to fit her own classroom. She stated,

I think the lesson study was probably the most helpful to me in the last couple of years. So much of it was collaboration between lots of teachers and talking about their experiences of what will work and what won't work. A lot of the other things that have been implemented haven't been as in depth. They kind of give it to us without talking to anyone that has actually used it or know how it's going to work. 
So I think discussing with other teachers and trying it out in other classrooms has been very important. (Mrs. Grey, December 19)

Mrs. Grey felt that, in a perfect world, all professional development would be composed of experiments and trial and error within real classrooms. She stated that by visiting other classrooms, she could visualize how these ideas might look within her own classroom instead of just reading or talking about it. She said that being in a real classroom also helped her to visualize the pitfalls or misconceptions that could arise, as well.

Anticipation and reflection are important. The last idea that Mrs. Grey took from the professional development was the cycle of anticipation and reflection. She felt that anticipating and thinking through tasks was an important but difficult skill to master that she had learned about through the professional development. She stated that past experiences with the students and interviews, to some extent, helped her to anticipate. She also stated that anticipation and reflection are not easy to do and takes practice, so it is important to allow teachers the time to meet and discuss lessons. She stated,

Reflection is important and time to discuss it as a grade level or team after you have done the lesson. Because, if you don't do that then it seems like you just move on to the next thing. They you don't remember the things that you wanted to change by the time you come back to it the following year (Mrs. Grey, December 19).

At the end of the instructional unit, Mrs. Grey stated that she valued having the time to sit down and reflect with me and other teachers. It allowed her to think about her teaching and reason through concepts that she might not have otherwise. She stated, 
I think it helped me as a teacher to be able to slow down and spend probably more time than usual on one topic and really think about how my students understood that topic. I was also able to implement different ideas to help those students that were confused or having difficulty (Mrs. Grey, December 19).

\section{Perceived Difficulties of the Professional Development}

Even though Mrs. Grey valued many philosophies and concepts related to the learning trajectory and within the professional development experience, she also expressed ways in which the process could be improved as well as difficulties she experienced while using the learning trajectory document to analyze students' thinking.

The language of the learning trajectory. Mrs. Grey reflected that the most difficult piece of the learning trajectory was the technical language. Mrs. Grey appreciated considering how different students think about area, but she found it very difficult to categorize their thinking using the learning trajectory in its current form. Mrs. Grey felt that the document itself was too verbose, and the meaning of one or two words would confuse her. She also stated that there was only one picture of student work per level of tiling a pre-existing rectangle. She was not sure how this picture would be helpful if they were doing a different activity related to area measurement such as building an area from one unit. She stated,

It's too technical! I feel like sometimes it's not even, like sometimes so wordy and then there's one example of what student work might look like. But if that is the only example that you have to go off of then I feel like it is really rigid...like well we didn't make that (area activity) so if I didn't do that how can I tell (the level)? 
And that's where I struggle and I get stuck on two or three key words and I am like well (Mrs. Grey, December 19).

Mrs. Grey was also asked, during the interview, how she might make the current document more teacher friendly. She stated that she would incorporate more tasks and discuss how different students might respond to each task. It was hard for her to tell how the words match up to what her students are doing.

Lack of tasks. Mrs. Grey stated that many of the tasks she created were in conjunction with other teachers and researchers from the professional development. In the learning trajectory document, there were a limited number of tasks described. It was also unclear what tasks to provide to help students think or progress to the next level. Mrs. Grey reported that she thought it was easier to provide accommodations for struggling students but it was harder to determine what to do next with advanced students.

Different perspectives and expertise. Mrs. Grey also commented that understanding students' thinking takes time. She stated that she felt more comfortable using the learning trajectory on length because she had used it for two years and it was starting to make more sense to her. She stated,

I think that it (the area trajectory) is harder for me for some reason. And I don't know if it is because we kind of spent a little bit of time on it (the length trajectory) last summer and this summer so I feel like I have had more practice looking at it, using it, and talking about it (Mrs. Grey, December 19).

Within this conversation, Mrs. Grey discussed the importance of perspective. She compared learning about students' thinking to the television show The Voice. The Voice 
is a television show in which judges rate people's singing abilities. She stated that when she watches the Voice, she does not always agree with the judges on their selections of contestants. Similarly, when watching students, she does not always see the same details that other teachers or professors notice. Below is an excerpt from the transcript where she discussed this.

Mrs. Grey: It's (using the LT) even like watching the Voice, because my husband and I watch the Voice

Megan: I watched it last night and was like," that woman won?" I don't like her voice and it doesn't sound that great.

Mrs. Grey: Right! and we did that the whole time. My husband kept saying my ears must be broke because that sounded really bad, but all the judges would push their buttons and say that they (the singers) were really good. So, I have no idea. I think if you don't have that expertise and you haven't really studied that or learned that or practiced that you don't catch all those small details. So, I feel like when the PI's are here or when we are doing a lesson study, people catch things that I don't catch. This could be because when you are teaching you are trying to scan 20 (children) which is different than sitting by four or five (children), but, also, I think that is someone else's perspective. What I have focused in my mind isn't going to be the same as what they have focused in their mind (Mrs. Grey, December 19).

For Mrs. Grey, some ideas and philosophies of the learning trajectory transitioned into her ideas and thoughts about students' thinking and classroom instruction, but others 
were hard for her to identify with or to use. She valued being able to discuss the application with real teachers who were using research in similar ways.

\section{My Perspective and Interpretation of Mrs. Grey}

Throughout this study, I was an observer within Mrs. Grey's classroom and was able to reflect on concepts or ideas that perhaps Mrs. Grey did not mention in her reflections. Within this section, I will discuss my interpretation, from my notes, of Mrs. Grey's student interviews, classroom instruction, and her perceptions and use of the learning trajectory

\section{Student Interviews}

As I observed Mrs. Grey, there were several themes and ideas that I drew from her student interviews. Mrs. Grey was able to think about the student interviews as a form of formative assessment, in that, she was able to think about individual students' thinking in terms of the entire classroom. This was evident when she thought about Lisa's tetrisshapes. Instead of relating this only to Lisa, she was able to think about this more broadly in terms of her entire classroom and the difficulties they might face.

Although, Mrs. Grey drew information from the interviews about instruction, I perceived that it was difficult for her to think about hierarchical structure for each student and among students. I thought, following the interviews, she might think about students' responses at each level and reflect on how she could move them forward. Instead, she seemed to view the trajectory document more as a classification system rather than a fluid trajectory of varied levels of thinking. This was evident when she continued to pose the same interview tasks even though students found them to be easy and rushed through them. 


\section{Classroom Instruction}

Within classroom instruction, I also observed several themes that emerged in Mrs. Grey's teaching. One idea that is evident in the data tables for Mrs. Grey is the way in which she noticed events. Mrs. Grey noticed in a way that was different from the other teachers. Instead of capturing students' dialog, Mrs. Grey would often use the Déjà Vu camera as a way to capture photos of students' drawings. Looking at and discussing students' drawings seemed to be the most productive way for Mrs. Grey to remember the conversation surrounding the event that occurred.

Something that is not evident in Mrs. Grey's reflection on the professional development is the role of Mrs. Purl. Mrs. Grey, Mrs. Purl, and I were often together prior to school starting, at lunch, or during recess duty. Mrs. Grey would not only discuss her ideas with me, but she would often reiterate these ideas to Mrs. Purl. Mrs. Purl and Mrs. Grey acted as sounding boards for each other. They compared and contrasted the students within their classrooms and discussed implications for instruction based on these ideas.

\section{Role of Professional Development}

Mrs. Grey participated in this professional development for two years. Throughout the year prior, to this study, she realized the value of thinking about students' thinking in relation to instruction, so I felt that she valued the incorporation of students' thinking into her practice. I witnessed this as she discussed her views on teaching and how she had changed in her beliefs about instruction. She stated that, in the past, she would have just shown the children the formula, similar to the other fourth-grade teachers, and told them how to calculate the area of a rectangle. From the professional 
development, she realized that children see area in multiple ways and conceptualize the unit and the structuring of units differently, as well.

This idea was evident in Mrs. Grey's exploration of units lesson. Mrs. Grey could see students counting individual units, counting rows and columns, skip counting, and using multiplication. She viewed each of these ways as a valid way of finding area. It was also evident that her students conceptualized area beyond the formula and many of them claimed they did not see the purpose in using the formula.

Even though Mrs. Grey could discuss how certain students understood area and valued that they thought about area in different ways, I also saw that her role as a teacher conflicted with her perceptions of research. She was comfortable, up until the end of the lessons, with students finding area in multiple ways. Toward the end of the unit, I witnessed her and Mrs. Purl in a debate on the role of the area formula during lunch. They discussed that, in one sense, the students understood area, but in another sense they needed to know the formula for area for standardized testing. They were not sure if they were meeting the standard of understanding how to find the area of a rectangle if the students did not know area in this way. I saw this as a conflict of interests between the goals of teaching versus the goals of research.

I also noticed that even though Mrs. Grey stated that students were at different levels of thinking, and they might not move through these levels very quickly, she still remained surprised that students did not adopt the formula for area after instruction. She thought that once students saw a more sophisticated way of measuring they would then adopt that way. Her instruction and how she viewed the role of instruction seemed to be at odds with what she believed about students' thinking at varying levels. 
Lastly, I noticed that much of what Mrs. Grey noticed and reflected about was not worded in the language of the learning trajectory. Mrs. Grey was able to reflect about her students' thinking in productive ways, but required time to discuss students' thinking in terms of trajectory levels. The only time she used learning trajectory language was following the first student-teacher interview when she had several days to reflect. This caused me to reflect on the purpose of language. Mrs. Grey was able to do, in many ways, what a trajectory-based philosophy values. She was able to realize that students think about a concept in different ways and respond to this in her teaching. Although she did not refer to the document in our conversations or use technical language from the document, I observed that she had incorporated a new philosophy of teaching. 


\section{CHAPTER V}

\section{MRS. PURL}

\section{Description of Mrs. Purl and Her Classroom}

At the time of the study, Mrs. Purl was a fourth-grade teacher at Terrace Elementary School. She had 15 years of teaching experience with certifications to teach $\mathrm{K}-8$, as well as endorsements in early childhood education and English Language Learners (ELL). She also held a master's degree and was considered a highly qualified teacher. In the past Mrs. Purl spent eight years of her teaching career as an early childhood teacher. This year was her second as a fourth-grade teacher and her classroom was designated as the ELL fourth-grade classroom at Terrace.

Mrs. Purl's classroom had 20 students. Of these students, 11 were boys, nine were girls, 10 were Black, four were Hispanic, three were White, and three were Asian. Mrs. Purl's daily teaching practices included students working together in teams to solve problems and also much questioning and discussion between students and Mrs. Purl. Mrs. Purl said that she encouraged students to discuss to help them improve their vocabulary and argumentation skills. She stated, "I know that they need it because I have some ELL children in there. But as a class, this population of students, has a low vocabulary to begin with, so they need to be listening and speaking" (Mrs. Purl, September 28). 
Mrs. Purl's students were grouped into teams by ability to solve mathematical problems. By grouping them together by ability she thought they could relate to one another and help each other through misconceptions. She also encouraged students to use other resources like rulers, paper, and manipulatives to help them solve problems. She stated, "I want them to get used to the idea that they can look for resources to help them find answers to things" (Mrs. Purl, September 28).

Because Mrs. Purl encouraged group problem solving as well as discussion, her room was very active but also very welcoming. I witnessed the students expressing themselves and their mathematical ideas with one another and with Mrs. Purl often. Mrs. Purl's planning for instruction included group planning with other fourth-grade teachers in the building to help maintain a consistent pace among the different classes. Mrs. Purl discussed that she was comfortable using sources, other than the textbook, to help inform instruction and readily shared worksheets and ideas with other teachers in the building

At the beginning of the school year, as part of the larger professional development program, Mrs. Purl was asked to choose three or four students as a representative sample of her classroom to interview across the year. Mrs. Purl chose four students based on their perceived mathematical abilities as well as their gender and demographics. Mrs. Purl determined mathematical ability by standardized test scores as well as behavior in the classroom. She chose, in order of ability from high to low, Liam, a white male, Abby, a white female, Jose, a Hispanic male, and Daisy, a black female.

\section{School Year Events}

In this section, I discuss activities that Mrs. Purl participated in as part of the study. These activities included three student-teacher interviews as well as a 
measurement area unit composed of several sets of lessons. In each activity, events that Mrs. Purl indicated as important are described as well as student understanding and implications for instruction that she noted.

This was Mrs. Purls first year as a participant in the professional development program. During the summer of 2012, she experienced two weeks of professional development on learning trajectories as a formative assessment tool and using students' thinking to inform instruction.

\section{Interview 1}

Mrs. Purl conducted her first set of interviews with students at the end of September. The purpose of these interviews was for Mrs. Purl to determine a baseline of how her students were thinking about measurement in terms of area in relation to the learning trajectory. During the summer professional development, Mrs. Purl, along with other fourth-grade teachers, developed an interview protocol from tasks shown during the professional development. Mrs. Purl explained that they had chosen four tasks that they thought were representative of four key measurement ideas that she would be teaching during the school year. Mrs. Purl stated, during the summer professional development, that these interview tasks would be administered at each interview, and she would record changes in the students' responses and growth as well as what level the students' thinking signified within the learning trajectory. Mrs. Purl used the same interview tasks as Mrs. Grey (see page 72).

What Mrs. Purl noticed. Following her first student interview, Mrs. Purl described five different events that pertained to the strategies students used or to students' understanding of terminology. These events are highlighted in figure 17. Three of the 
events involved small groups or the whole class of students and two involved individual students, Daisy and Liam.

\begin{tabular}{|c|c|c|c|}
\hline \multicolumn{4}{|c|}{ Interview 1: September } \\
\hline What the Teacher Noticed & Interpreted Understanding & $\begin{array}{c}\text { Implication } \\
\text { for } \\
\text { Teaching }\end{array}$ & Significance \\
\hline \multicolumn{4}{|c|}{ All Tasks } \\
\hline $\begin{array}{l}\text { Area Counting Strategy: Found } \\
\text { area through repeated addition and } \\
\text { multiplication. (Jose, Liam, Abby) }\end{array}$ & (none provided) & $\begin{array}{c}\text { (none } \\
\text { provided) }\end{array}$ & $\begin{array}{l}\text { Basic skills } \\
\text { that are } \\
\text { needed. }\end{array}$ \\
\hline \multicolumn{4}{|c|}{ Area Conservation Task } \\
\hline $\begin{array}{l}\text { Drawing Strategy: She could not } \\
\text { draw a rectangle with } 12 \text { square } \\
\text { units in multiple ways. (Daisy) }\end{array}$ & $\begin{array}{l}\text { Knowledge seems inflexible and more rote } \\
\text { memorization. }\end{array}$ & $\begin{array}{l}\text { (none } \\
\text { provided) }\end{array}$ & $\begin{array}{l}\text { (none } \\
\text { provided) }\end{array}$ \\
\hline \multicolumn{4}{|c|}{ Tiling Task } \\
\hline $\begin{array}{l}\text { Area Counting Strategy: } \\
\text { Incorrectly used algorithm to find } \\
\text { area. (Liam) }\end{array}$ & Not sure what to think. & $\begin{array}{l}\text { (none } \\
\text { provided) }\end{array}$ & $\begin{array}{l}\text { (none } \\
\text { provided) }\end{array}$ \\
\hline $\begin{array}{l}\text { Language Comprehension: When } \\
\text { asked to measure the area of a } \\
\text { nonstandard shape students revert to } \\
\text { perimeter. (class) }\end{array}$ & $\begin{array}{l}\text { Not sure if they have an understanding of } \\
\text { area beyond the rectangle. }\end{array}$ & $\begin{array}{l}\text { (none } \\
\text { provided) }\end{array}$ & $\begin{array}{l}\text { (none } \\
\text { provided) }\end{array}$ \\
\hline $\begin{array}{l}\text { Area Counting Strategy/Drawing } \\
\text { Strategy: Saw several one-to-one } \\
\text { counting and even Jose who drew in } \\
\text { rows and columns numbered each } \\
\text { one. (Interview students/Whole } \\
\text { Class) }\end{array}$ & Primitive understanding. & $\begin{array}{l}\text { Push them } \\
\text { and take } \\
\text { away tiles to } \\
\text { see what } \\
\text { they do. }\end{array}$ & $\begin{array}{l}\text { (none } \\
\text { provided) }\end{array}$ \\
\hline
\end{tabular}

Figure 17. Events that Mrs. Purl noticed during Interview 1. Events highlighted in gray had instructional implications.

Area counting strategies. At the beginning of the interview, Mrs. Purl discussed strategies that she expected for all of the students in comparison to her students from the previous year. Mrs. Purl commented that, in prior years, students struggled immensely with multiplication and repeated addition, so it was important to investigate if her current students were able to skip count or use multiplication as strategies to find the area of a figure. She considered the skills of skip counting and multiplication facts essential to solving problems related to area measurement. She stated,

Well, when I was doing the interviews, actually I was looking to see if they had multiplication facts or repeated addition because those are some of the basic skills they need. I kind of thought of last year's fourth-graders who were really, really 
low in math. So, I was worried that if this year's was a low as last years, that the tasks would have been really difficult to even start with.

(Mrs. Purl, September 28)

Mrs. Purl noticed that Jose, Liam, and Abby all understood that they could use these strategies to find area and she found this somewhat surprising given that it was the beginning of the school year.

The second event that Mrs. Purl noticed related to the area counting strategy and Liam's incorrect attempt to use an algorithm to determine the number of units to fill in a rectangle that measured four units by five units (with several units drawn in). She noted that Liam multiplied five units by five units but that he realized his mistake as he drew in lines to tile the figure and counted the total.

Mrs. Purl also noticed the counting strategies that students were using during a whole-class task she assigned the day after the interviews. She commented that she saw several student using a one-to-one counting strategy and that some students who drew in rows and columns using a ruler still went back to count each unit. She considered these strategies less sophisticated counting strategies because the students still had to check the total by counting individual units.

Drawing strategy. Mrs. Purl also noticed students' use of a drawing strategy, sometimes in conjunction with their counting strategies, as indicated above with Liam. During the whole class activity, she noticed that Jose drew rows and columns within a figure in his textbook to help show students that the square unit could tile a region even if the figure was not a rectangle. She remarked that some students seemed lost without tick marks drawn on the region to be measured. 
Focusing on a different task, area conservation, Mrs. Purl noticed that Daisy was only able to draw one rectangle that was composed of 12 square units. She commented that this indicated that Daisy did not have as many strategies, or was not as flexible in her thinking about area as the other students.

Language comprehension. Another event that Mrs. Purl noticed related to the whole-class activity of finding the area of a nonstandard shape (e.g., an L-shaped region). She noted that some students focused on the perimeter of the region rather than the area. Mrs. Purl thought this was language comprehension because the students had demonstrated earlier that they could find the area of rectangular regions. She thought perhaps they were interchanging the terminology.

Interpreted understanding. For each of the events Mrs. Purl noticed, she was asked to reflect on what she thought the student or students understood at that particular moment. She interpreted the students' understanding for three of the five events, and her interpretation was the same for each—that students had a limited, inflexible, or unsophisticated understanding of area measurement. For example, Mrs. Purl hypothesized that Daisy's understanding of area was rigid and that she was not able to think about multiple shapes having the same area. She stated, "[Daisy] did not seem to know how to use her knowledge in a context or be flexible in changing (the shape)" (Mrs. Purl, September 28). With regard to the whole-class activity, she thought that perhaps her students did not truly understand area or that they understood it in an unsophisticated way. To Mrs. Purl, a true understanding of area measurement was the ability to see that areas of different shapes could be the same. She also thought that being able to skip count 
or multiply to find the total number of square units indicated understanding. She made the following assessment:

Currently, I think that the students have a primitive understanding of area because they had to use one to one (counting), the majority of them. Although even Jose, who drew in the lines, still wrote in each box how many there were (Mrs. Purl, September 28).

Implications for teaching. Mrs. Purl discussed implications for teaching for only one of the events that she noticed. Following the discussion of her students' primitive understanding of area, she suggested that students needed to be challenged to test their "true" understanding of structuring units. She saw that students could draw rows and columns, but they counted using individual units. She wanted to push students to see if they could visualize finding the area of a region through counting rows, columns, or even using the algorithm. In the following excerpt, she referred to a task in which students would use tiles to cover a region to determine the area:

If I had to do a whole-group lesson, the majority of them, I would like to see if the children that needed to use the tiles, maybe what they could do if I didn't let them have the tiles. If I said let's try to solve this without the tiles

(Mrs. Purl, September 28).

Mrs. Purl's discussion about challenging her students also expanded to include how she would monitor her students and watch for their thinking. She discussed her plans for measurement and how the professional development had caused her to rethink several of her classroom practices. As mentioned in Mrs. Purl's description, she was a preschool teacher earlier in her career. She stated that the learning trajectory reminded her of being 
a pre-k teacher and the method that she used to record students' thinking and progress.

Below is her description of her experiences in the pre-k classroom:

Taking anecdotal notes because in pre-K you don't really have, in early childhood friendly classes you don’t really have a curriculum, per se. You have a set of standards and but as the teacher you are kind of free to develop okay my students are low in this. How you would know this is that during their free choice time. In centers, you're a mindful watcher and you are recording that you saw so and so take all of the yellow bears and put them in a pile, and all the red bears, and all the blue bears and then you make a note of that. Because that is learning in context versus you sitting there saying "okay sort all your cheerios, now who can do it?". Sometimes there is more of a push to do the quantitative but it is a slippery slope to do with 3-and 4-year olds because what if they just aren't very verbal yet or they don't have the auditory processing skills to see what you are asking. They can do it but they just can't... Anyway, so that was my world for several years. (Mrs. Purl, September 28) Mrs. Purl claimed that thinking about the learning trajectory and trying to understand children's actions and thinking motivated her to try to implement some of the ideas of pre-k into her fourth-grade classroom.

\section{Interview 2}

Mrs. Purl reported on nine events that were significant to her during the second set of student interviews (see Figure 18). Three of these events were tagged using the video camera, and she mentioned others during my interview with her. Mrs. Purl noticed things about each of the students and commented on the understanding indicated by their 
actions. However, she interpreted only three of the events with regard to implications for instruction (highlighted in gray in the figure).

\begin{tabular}{|c|c|c|c|}
\hline \multicolumn{4}{|c|}{ Interview 2: December } \\
\hline What The Teacher Noticed & Interpreted Understanding & $\begin{array}{l}\text { Implication for } \\
\text { Teaching }\end{array}$ & Significance \\
\hline \multicolumn{4}{|c|}{ Area Conservation Task } \\
\hline $\begin{array}{l}\text { Drawing Strategy: Able to draw a } \\
\text { second rectangle with area of } 12 \\
\text { units. } \\
\text { (Jose, Abby, Liam) }\end{array}$ & $\begin{array}{l}\text { More concrete understanding } \\
\text { of area. }\end{array}$ & $\begin{array}{l}\text { Review area since task } \\
\text { was difficulty. } \\
\text { Have multiple units and } \\
\text { multiple places to } \\
\text { measure to challenge } \\
\text { students. }\end{array}$ & (none provided) \\
\hline $\begin{array}{l}\text { Drawing Strategy: Could not make } \\
\text { a new rectangle. (Liam) }\end{array}$ & $\begin{array}{l}\text { Does not understand area but } \\
\text { maybe understands } \\
\text { perimeter. } \\
\text { Understanding is rigid and } \\
\text { does not apply it. }\end{array}$ & (none provided) & $\begin{array}{l}\text { Surprised given } \\
\text { ability. }\end{array}$ \\
\hline $\begin{array}{l}\text { Drawing Strategy/Counting } \\
\text { Strategy: Drew } 11 \text { tick marks on } \\
\text { each side of the unit square. Used } \\
\text { doubling strategy to say each square } \\
\text { unit would have perimeter of } 44 \text {. } \\
\text { Then multiplied } 12 \times 44 \text { to find total } \\
\text { perimeter. (Liam) }\end{array}$ & $\begin{array}{l}\text { He is thinking outside the } \\
\text { box, but his thinking has } \\
\text { diverged. }\end{array}$ & (none provided) & (none provided) \\
\hline $\begin{array}{l}\text { Language Comprehension: } \\
\text { Confused area and perimeter. } \\
\text { Correctly found perimeter when } \\
\text { asked for area. (Abby) }\end{array}$ & $\begin{array}{l}\text { Understands each process but } \\
\text { confuses the terminology. }\end{array}$ & (none provided) & $\begin{array}{l}\text { Impressed by } \\
\text { thinking. }\end{array}$ \\
\hline \multicolumn{4}{|c|}{ Missing Length Task } \\
\hline $\begin{array}{l}\text { Visualization Strategy: Visualized } \\
\text { and iterated a smaller length in his } \\
\text { mind to see that the longer length } \\
\text { would be } 7 \text { or twice as big as the } \\
\text { smaller length. (Liam) }\end{array}$ & $\begin{array}{l}\text { He must have a good } \\
\text { spatial/visual awareness. }\end{array}$ & (none provided) & $\begin{array}{l}\text { Unexpected } \\
\text { strategy. }\end{array}$ \\
\hline $\begin{array}{l}\text { Length Measurement } \\
\text { Strategy/Language } \\
\text { Comprehension: Measured the } \\
\text { missing side with his pinkie and } \\
\text { stated it was the width of his pinkie } \\
\text { long. (Jose) }\end{array}$ & $\begin{array}{l}\text { He understands perimeter } \\
\text { but misunderstood the word } \\
\text { measure. }\end{array}$ & $\begin{array}{l}\text { Be mindful of how we } \\
\text { word things with ELL/ } \\
\text { students measuring vs. } \\
\text { how long is it. }\end{array}$ & \\
\hline $\begin{array}{l}\text { Statement: Immediately said } 5 \\
\text { without thinking. (Daisy) }\end{array}$ & (none provided) & (non provided) & $\begin{array}{l}\text { Lack of growth. } \\
\text { Representative } \\
\text { of class. }\end{array}$ \\
\hline \multicolumn{4}{|c|}{ Tiling Task } \\
\hline $\begin{array}{l}\text { Drawing Strategy/Counting } \\
\text { Strategy: Able to draw in tiles for } 3 \\
\text { x } 5 \text { rectangle but did not want to } \\
\text { count pre-existing squares. (Daisy } \\
\text { and Liam) }\end{array}$ & $\begin{array}{l}\text { No growth in understanding } \\
\text { for Daisy. }\end{array}$ & $\begin{array}{l}\text { Wording within } \\
\text { problems can confuse } \\
\text { students }\end{array}$ & Lack of Growth. \\
\hline \multicolumn{4}{|c|}{ Four Times as Big Task } \\
\hline $\begin{array}{l}\text { Drawing Strategy: Drew a square } \\
\text { unit true to size but did not maintain } \\
\text { the scale when drawing a rectangle } \\
\text { four times as big. (Abby) }\end{array}$ & (none provided) & (none provided) & $\begin{array}{l}\text { Made } \\
\text { connections and } \\
\text { this is one of her } \\
\text { classroom goals. }\end{array}$ \\
\hline
\end{tabular}

Figure 18. Events that Mrs. Purl noticed during Interview 2. Events with instructional implications are highlighted in gray. 
What Mrs. Purl noticed. Mrs. Purl noticed six types of events—drawing strategy, counting strategy, language comprehension, visualization strategy, length measurement strategy, and statements — across the four tasks she posed during the interviews with her students.

Drawing and counting strategies. The first event Mrs. Purl discussed referred to the area conservation task and the fact that three of the students were able to draw more than one rectangle with an area of 12 square units.

They were, this time they were able to make, I believe three of them were able to make a new rectangle that had the same square area (12 square units) as the other one whereas before they were not able to do that. They were able to make one, but they would say that there is only one choice (Mrs. Purl, December 7).

A related event pertained to Liam's inability to draw a second rectangle with 12 square units. Mrs. Purl discussed that she was surprised that Liam simply turned the rectangle horizontally and diagonally, positioning it differently but not creating a different rectangle. She explained: “Even though he couldn't make a new one...the second time.....and Liam is one of my better students as far as math is concerned, so I was really surprised that he couldn't. He just flipped it, and he thought the third way was to make it [the rectangle] diagonally (Mrs. Purl, December 7).

Liam's strategy for determining the perimeter of the rectangle he had drawn was another event that Mrs. Purl noticed. Liam drew $1 \mathrm{~cm}$ marks along each of the sides of the square unit (which he had initially drawn as the measure for constructing the 12 square unit rectangle). According to Mrs. Purl: 
These little lines are um, it looks like maybe centimeter markings. You can see that they are almost evenly spaced. There are 11 of them (on each side of the unit square). He said, "Well there is 11 on this side of the square, 11 on this side, 11 on that side, and 11 on this side, so that's $44 . "$ And I think he came at that using multiplication or doubling. He did 11 and 11 is 22 and 22 and 22 is 44 . But either way, then he said the perimeter of the whole rectangle is $44 \times 12$ because there are 12 squares (Mrs. Purl, December 7).

Mrs. Purl noticed that two students (Daisy and Liam) had difficulty with the tiling task. Although they were able to draw in the square units on a $3 \times 5$ rectangle that had five square units already drawn along the diagonal, they were confused about whether to count the five pre-drawn squares when determining the area of the rectangle.

Finally, Mrs. Purl noted an event pertaining to Abby's solution to the Four Times as Big task (draw a rectangle four times as big as a given 1-inch square). She noticed that although Abby was able to accurately draw a representation of the square unit, she did not attend to scale when drawing the larger rectangle, which was much smaller than it should have been (i.e., not four times the size of the given square).

Language comprehension/usage. Mrs. Purl noticed that Abby initially confused area and perimeter when she was asked to compare these measurements for the rectangles she had drawn for the Area Conservation task. When asked to find the area, Mrs. Purl discussed that Abby methodically found the perimeter and when asked to find perimeter Abby correctly found the area. During the interview, Mrs. Purl noted that Abby corrected herself mid-task and realized her misunderstanding. 
Visualization strategy. Mrs. Purl noticed that when Liam was asked to find the missing length of a segment of a rectilinear figure, given the other side lengths (Missing Length task) that he was able to visualize a solution to the problem.

He was able to go, if this is three [referring to a labeled side of the figure] and if you double that it and a little more it would be three. He iterated the segment out but perpendicular to the missing [part of the] perimeter.... and turned it in his mind to match there (Mrs. Purl, December 7).

Even though Liam's strategy was accurate and correct, Mrs. Purl was surprised that he did not use a subtraction strategy that she had expected students to use.

Length measurement strategy. Jose's solution to the Missing Length task also garnered Mrs. Purl's attention. All of the students had given numerical solutions to the problem, but, when Jose was asked what the length was he placed his pinkie finger down on the paper and stated that the missing length measured the width of his pinkie.

Statement. Lastly, Mrs. Purl noticed that Daisy’s response to the Missing Length task was what she would expect from many of the other students in her class. As soon as Daisy was given the task, she exclaimed that the answer was 5 but could not provide a rational for her answer.

Interpreted understanding. Mrs. Purl interpreted students' responses in terms of their understanding for seven of the nine events she identified, albeit somewhat vaguely. Two themes characterize her interpretations: descriptions of students' understanding of length and area measurement and students' misunderstanding of vocabulary.

General understanding of length and area measurement. Mrs. Purl made broad sweeping statements that students did or did not understand concepts of area or length 
measurement and commented that some students had made progress in their understanding since the first interview. She provided no rationale for any of these claims. When she discussed students' understanding, Mrs. Purl expressed happiness or disappointment with the student's progress over time. For example, she made the following comment about Abby but it is it is unclear what she meant by "understands" because she did not provide any further elaboration:

I liked that Abby, at first got perimeter and area mixed up but then she realized, whoa wait a minute, she got them mixed up. She did the perimeter without me even asking what the perimeter was. She understood both area and perimeter and I was impressed that she was able to do two different rectangles (Mrs. Purl, December 7).

When she commented on Daisy's immediate response to the Missing Length task, she indicated that Daisy was not trying or putting thought into her response. She explained that it was not uncommon for students to guess on measurement tasks but that she was not sure why.

I noted that when Mrs. Purl talked about Liam's incorrect responses, she did not comment on his actual understanding of length or area. Instead, she gave him credit for thinking differently. For example, Liam incorrectly found the perimeter of a rectangle by finding the perimeter of each individual square that was drawn to construct the rectangle rather than finding the perimeter of the rectangle itself. Instead of acknowledging that perhaps Liam did not understand perimeter, Mrs. Purl stated, "So there is some kind of good higher level thinking there but yet he has diverged way out into left field" (Mrs. Purl, December 9). In all of the events involving Liam responding incorrectly to a 
problem, Mrs. Purl stated that perhaps he was thinking about the problem in a different way rather than interpreting what he did and did not understand.

Vocabulary. Students' language and word choice was another theme that emerged in Mrs. Purl's discussions. When Jose used his pinkie finger to measure a missing length and when Abby confused perimeter and area, Mrs. Purl commented that the students understood the words differently than the actual meaning. In relation to Jose, she stated,

So he has the concept, it seems like....I don't know if it is the way I worded the question...because I may have said how long is this side. Well he is hearing I have to measure it so he used is pinkie as a tool (Mrs. Purl, December 7). Mrs. Purl stated that she attended to word choice and the use of language frequently in her instruction because she worked with English language learners. It is something that she was frequently drawn to and reflected on in her own teaching.

Significance to Mrs. Purl. In describing students' understanding, Mrs. Purl often reflected on the importance of the event to her. She stated that she chose many of the events because they indicated a presence or absence of growth in students' understanding. Mrs. Purl also marked events that she found surprising in relation to students' past experiences. This was particularly evident with Liam. Even though Mrs. Purl was surprised by Liam's thinking, she still defended him as a higher-level student. Reflecting on the interview as a whole, Mrs. Purl stated,

I was just really surprised by Liam because as far as math is concerned he is probably one of the highest scores in the class, you know, right up there with my kids that are either bright or gifted, so it just surprised me. So I guess his thinking 
is either too rigid or too memorized versus how to apply it (Mrs. Purl, December 7).

Implications for teaching. Mrs. Purl linked three events to an instructional implication. The events centered on the themes of conceptualizing area units and spaces as well as mindfulness in wording.

Conceptualizing Area. Mrs. Purl, together with Mrs. Grey, discussed that she realized how difficult the area conservation task had been for students in both sets of interviews. This indicated to the teachers that they should do a day of review and allow students to play with different types of units and measure different spaces before starting the unit of instruction. She thought that students would benefit from a concrete experience that they could refer back to during the unit.

Secondly, Mrs. Purl noted that for two of the four students, the idea of covering a space was not completely understood. She thought that this confusion might be pervasive for many of the students in her class, so she discussed that this gave her something to look for and to think about during instruction. If problems arose in their understanding, she stated she would think more about what to do next.

I feel like some of them struggled with the question of how many squares does it take to cover this and granted I know that some of them thought that the five already there shouldn't be counted. They don't quite have the concept of covering because the question said how many does it take to cover this rectangle. So that is the piece that I want to look for to make sure that they don't have misconceptions about that (Mrs. Purl, December 7). 
Mindfulness in wording. Lastly, Mrs. Purl commented that word usage seemed to be an issue throughout the interviews. She stated that, in her classroom, she would be more mindful of how her students interpreted the words she used. She stated, "I need to be especially mindful of how I words things especially when working with students that are second language learners" (Mrs. Purl, December 7).

\section{Interview 3}

Interview 3 took place following Mrs. Purl's unit on area measurement in the middle of December. She again sat down with Jose, Abby, Liam and Daisy and interviewed them about their area measurement conceptions. Mrs. Purl was encouraged to modify or add tasks if she thought it was appropriate. For this particular interview, she modified two of the tasks to make them more difficult for particular students. Instead of asking students to form multiple rectangles with an area of 12 , she modified the problem to ask for several rectangles with the same perimeter. She also challenged students to think about the missing length task in multiple ways to challenge their thinking.

Mrs. Purl noticed five events during this interview that held meaning for her (as shown in Figure 5.3). Three of the events were documented via video camera and two were recalled during our interview. In this particular interview, Mrs. Purl stated that students' strategies to the original problems had not changed, so she primarily attended to strategies the students used in her modification problems. She discussed students' understandings for each of the events and provided implications for teaching for four (as highlighted in gray). 


\begin{tabular}{|c|c|c|c|}
\hline \multicolumn{4}{|c|}{ Interview 3: December } \\
\hline $\begin{array}{l}\text { What The Teacher } \\
\text { Noticed }\end{array}$ & Interpreted Understanding & $\begin{array}{l}\text { Implication for } \\
\text { Teaching }\end{array}$ & Significance \\
\hline \multicolumn{4}{|c|}{ All Tasks } \\
\hline $\begin{array}{l}\text { Behavior: Easily finished } \\
\text { all of the initial tasks. (Jose } \\
\text { and Abby) }\end{array}$ & $\begin{array}{l}\text { Conceptual understanding of area and } \\
\text { perimeter rather than memorized } \\
\text { facts. }\end{array}$ & $\begin{array}{l}\text { This is why teaching in } \\
\text { this way is important. }\end{array}$ & (none provided) \\
\hline $\begin{array}{l}\text { Behavior: Difficulty } \\
\text { completing many of the } \\
\text { tasks. (Daisy) }\end{array}$ & $\begin{array}{l}\text { Wonders if she understands even } \\
\text { basic conservation tasks. }\end{array}$ & $\begin{array}{l}\text { Create more basic } \\
\text { interview tasks. }\end{array}$ & (none provided) \\
\hline \multicolumn{4}{|c|}{ Area Conservation Task } \\
\hline $\begin{array}{l}\text { Drawing Strategy: He } \\
\text { created an } 8 \times 2 \text { and a } 6 \times 2 \text {. } \\
\text { He realized that the } 8 \times 2 \\
\text { had a larger perimeter and } \\
\text { took off } 4 \text { squares but did } \\
\text { not realize he had made the } \\
\text { same rectangle again. (Jose) }\end{array}$ & $\begin{array}{l}\text { Task is more difficult. Thinking } \\
\text { through process. }\end{array}$ & $\begin{array}{l}\text { Honor the process that } \\
\text { students go through. }\end{array}$ & (none provided) \\
\hline \multicolumn{4}{|c|}{ Missing Length Task } \\
\hline $\begin{array}{l}\text { Length Counting } \\
\text { Strategy/ Visualization: } \\
\text { Recognized he could } \\
\text { subtract but the numbers } \\
\text { did not make sense with } \\
\text { scale of the drawing. } \\
\text { (Liam) }\end{array}$ & $\begin{array}{l}\text { It does not make sense to him } \\
\text { because the drawing is not to scale. }\end{array}$ & (none provided) & (none provided) \\
\hline $\begin{array}{l}\text { Length Counting } \\
\text { Strategy: . Stated the } \\
\text { lengths in the picture are } \\
\text { half of the actual measure. } \\
\text { So since the missing side } \\
\text { measures } 3.5 \text { the actual } \\
\text { length would be seven. } \\
\text { (Abby) }\end{array}$ & $\begin{array}{l}\text { Connection to ratio and proportion } \\
\text { and could see a relationship between } \\
\text { the actual length and the number. }\end{array}$ & $\begin{array}{l}\text { Reaffirms why they } \\
\text { need to do hands-on } \\
\text { math. }\end{array}$ & $\begin{array}{l}\text { This was } \\
\text { something that } \\
\text { they had not } \\
\text { covered yet. }\end{array}$ \\
\hline
\end{tabular}

Figure 19. Events that Mrs. Purl noticed during Interview 3. Events highlighted in gray had instructional implications.

What Mrs. Purl noticed. During the final interview, Mrs. Purl attended to four different types of students' strategies, behavior, length counting, length visualization, and drawing. Each of these strategies primarily related to tasks that Mrs. Purl modified.

Behavior. Mrs. Purl first made broad sweeping statements about Jose and Abby. in that they worked quickly through each of the tasks from previous interviews. Because of this, she decided to challenge them by posing extension tasks. She said,

I looked at what they did on the fifth of December and I said okay they have mastered this task, they have mastered that task; they have mastered all the tasks. 
So I decided to change the task to draw a new rectangle with the same area...I switched that to draw a new rectangle or a new shape with the same perimeter. I wanted to challenge them, and that really stretched them (Mrs. Purl, December 18).

Mrs. Purl then continued on to discuss the mathematics within Jose's strategy in more detail, but did not discuss Abby's.

Mrs. Purl also discussed Daisy's behavior more broadly, as well. She stated that Daisy continued to do many of the tasks incorrectly even though she had seen them many times. She often did not know how to attempt the task.

Drawing strategy. Mrs. Purl discussed Jose's strategy specifically in relation to drawing different rectangles with the same perimeter. She stated that Jose drew an $8 \times 2$ rectangle and checked it to see if it had the same perimeter. Discovering that it did not, he erased four of the squares and rechecked. This rectangle had the same perimeter as the original, but Jose did not realize that it was also the same rectangle as the original. Mrs. Purl stated,

Jose had actually drawn an $8 \times 2$ rectangle and then said, "Ugh the perimeter is too big." Well, I said "Can you take something off maybe?" And he did, he took four squares off, and he ended up with a $6 \times 2$. He took off the bottom four and said, "oh now there you go" and I said, "that's great, you're right, but it happens to be the same as the original (Mrs. Purl, December 18).

Mrs. Purl then stated that Jose never realized that the rectangles were the same and he was unable to make a second rectangle with the same perimeter. 
Length counting and visualization strategies. For two of the events, Mrs. Purl commented on students' length counting and length visualization strategies. She stated that Liam realized that subtraction was an option in solving the missing length problem but did not believe it was accurate. When he looked at the side lengths in comparison to one another, he thought that the numbers did not look in proportion to the side lengths. Mrs. Purl stated,

When I asked Liam the same question he said "well you could add these three sides and then subtract" but he looked at it and said "this one side is 20 and this is 13 and the top is 15 and the bottom is 18 " and he goes "well it says that the top measurement is 15 and the bottom is 18 but I don't think that they are three (units) apart. I think that they are just two (units) apart” (Mrs. Purl, December 18). Mrs. Purl stated that Liam trusted his intuition because it was truer to the scale of the figure.

Mrs. Purl also discussed that Abby grabbed a ruler and discovered a relationship between the actual length and the stated length. She could see that the actual length in centimeters was half of the stated length, so she could measure the length of the segment and double it to get the answer. Mrs. Purl described the event as follows

She (Abby) said well there is another way to do it and she grabs the ruler and says “It is messed up. These aren't (pointing the figure) centimeters, and it measures 10 (pointing to the stated length) but it is actually five centimeters." So she says, "You could just double it." So when she measured that missing side it is 3.5 centimeters with the ruler and she said seven for the written length. I said how did 
you get that and she said "well, it's seven or eight," because she was not exactly sure what to do with the half (Mrs. Purl, December 18).

Mrs. Purl was excited that Abby discovered a proportional relationship between the actual length and the stated length.

Interpreted Understanding. For the last interview, Mrs. Purl discussed students' understanding in relation to each of the events but vaguely. Themes of understanding centered around students' conceptual understanding of perimeter or area beyond thinking the formula as well as her pride in their improvement in problem solving.

Improvement. Reflecting on students' work, in general, Mrs. Purl was pleased in the strides students made and their growth over time. Students' growth reaffirmed her teaching practices. She stated,

I think my biggest take away again is this is why we do hands-on math, this is why we let the children lead some of the discoveries, it's making them work, and I am not just spoon-feeding them an answer. And that is what I like most about all of it...So I don't think this cover area in a day because it is the process and they need time to figure it out (Mrs. Purl, December 18).

Conceptual understanding. Across the tasks, Mrs. Purl acknowledged that mathematics is a process of understanding a concept over time. When Jose and Abby tried to create rectangles with the same perimeter, it was difficult for them. Instead of giving up, they worked through the problem and tried to make sense of it. Mrs. Purl stated that she realized that perimeter and area are conceptual processes that students work through, and it is much more than knowing a formula. 
More specifically, with regard to conceptions of length, Mrs. Purl stated that Liam, in the missing perimeter task, saw the figure for what it was. It was difficult for him to attend to and make sense of the figure when it was not drawn to scale. For Abby, she had developed a different conceptions of length. She ignored how the figure looked and was able to develop and connect ideas of ratio and proportion between the actual measurement and the noted measurement.

Significance. Unlike other interviews, Mrs. Purl only commented on the significance of the one of the events. One of Mrs. Purl's classroom goals was for students to make mathematical connections between topics. She commented that she was pleased and excited when Abby developed ideas of ratio and proportional reasoning to solve the missing perimeter task. She was forming new mathematical ideas and connecting topics in her problem solving.

Implications for instruction. Since this was the final interview, much of what Mrs. Purl reflected on, in terms of instruction, were components of her practice that she found valuable over the course of the unit that also surfaced in the interviews. Themes emerged such as honoring the process of problem solving and power of hands-on mathematics as well as

Honoring the process. When Mrs. Purl saw students' struggling, she commented that it was important to value the process and not just the right answer. She learned that it is important to modify task difficulty and challenge students to help them conceptualize area and perimeter beyond the formula and it is good for students to struggle. Below is a segment of the transcript in which we discuss what might have been different or what students might have done if Mrs. Purl only covered area in a day. 
Megan: What do you think would have been different? What do you think they would have walked away with if you just covered (area) it in a day?

Mrs. Purl: well a fourth of them would have been fine because they have their multiplication facts. They would have been able to remember that you do length times width, but the rest of them would either add, they'd forget, they'd be lost, or they still would be mixing up perimeter with area...And the other piece is that they might not understand what area is...So they might be good at memorizing rote information, but not have a true understanding.

(Mrs. Purl, December 18)

Interview tasks. Mrs. Purl briefly discussed interview task difficulty. She stated Daisy had difficulty with many of the problems posed. If she completed this activity again, she would need to rethink tasks that were more appropriate for students like Daisy.

\section{Instructional Unit on Area Measurement}

In the month of December, Mrs. Purl taught a two-week instructional unit on area measurement. The unit was organized as three lessons. The first lesson was considered a review of finding area by counting units and was conducted on the Smartboard. The second lesson, conducted over three days, engaged the students in comparing and contrasting different units of measure (square inches, 3-inch squares, square feet, and square yards). The final lesson addressed the concept of area conservation; students constructed different rectangles with the same area and compared and contrasted aspects of the various rectangles. This instructional unit mirrored the one taught by Mrs. Grey (see that chapter for details). 


\section{Smartboard Lesson}

After discussing students' strategies following the student-teacher Interview 2, Mrs. Purl and Mrs. Grey decided to begin the unit with a review lesson. Mrs. Purl commented that the interviews helped her to determine that the students needed review of concepts such as counting units or skip counting by rows and columns. She stated that noticed in her first two sets of interviews that she had one lower student, Daisy, and she felt that she needed to cater to her in the first lesson. She stated,

I talked to Mrs. Grey about this. I felt that, after our interviews, mine were higher. I was trying to but I had some that were low, like Daisy, she is really low, and she's one you know that is one of my four (interview students). So it's kind of like, okay, I've got this really low one and I've got these three here so what do I do? I don't want to leave her in the dust because obviously her understanding of area is lower. So, I guess from the interview tasks I guess the first day's lesson is going to be geared more toward students like Daisy...I didn't look at a specific area of the trajectory and say okay there here and I need to move them here because there is just so many kids and how do you do that with 20, 21 kids? Maybe aim for the middle of the road and make sure if there is a bunch on the lower end then you try to address that first and move on, I am not sure? (Mrs. Purl, December 11).

Mrs. Purl hypothesized that there might be other students like Daisy in her classroom, so it seemed best to start with an easier task like counting to find the area of a small rectangular region and build up to more complex ideas like multiple units and larger space. She also referenced the learning trajectory and stated that she had not considered it 
for all of her students because there were so many different levels of thinking. She decided to begin teaching with a focus toward the "lower" students and work up.

Within this lesson, Mrs. Purl began by having students write and discuss their interpretations of the meaning of area. She followed this discussion by working through problems in the Smartboard file discussed in Mrs. Grey's chapter.

Prior to discussing Mrs. Purl's events, she was asked what she expected from her students during the lesson. She stated,

Well, I figured there would be a lot of one-to-one counting because the squares were already there... Which in a way, I was glad because I didn't want them to jump right into the area formula. I mean, I kind of feel like if they are touching or seeing and having to count each box within the square or the rectangle that maybe that would help their area understanding better (Mrs. Purl, December 11).

Mrs. Purl felt that by having the students count pre-existing units they would be able to see and better connect with the idea of unit structuring. 


\begin{tabular}{|c|c|c|c|}
\hline \multicolumn{4}{|c|}{ Smartboard Lesson: December } \\
\hline What the Teacher Noticed & $\begin{array}{c}\text { Interpreted } \\
\text { Understanding }\end{array}$ & Implication for Teaching & Significance \\
\hline \multicolumn{4}{|c|}{ Finding the Area of a Rectangle } \\
\hline $\begin{array}{l}\text { Drawing Strategy: Made } \\
\text { little tick marks around each } \\
\text { unit. (Liam) }\end{array}$ & $\begin{array}{l}\text { Confused as to why he is } \\
\text { doing this. } \\
\text { He needs to break things } \\
\text { down. Perhaps he is } \\
\text { picturing a ruler? }\end{array}$ & $\begin{array}{l}\text { Ask students what they are doing and } \\
\text { why. } \\
\text { Ask about differences in units. }\end{array}$ & $\begin{array}{l}\text { Similar to } \\
\text { interview. }\end{array}$ \\
\hline $\begin{array}{l}\text { Question/Area } \\
\text { Visualization: Wondered } \\
\text { what the area of a circle } \\
\text { would look like. Stated that } \\
\text { she thought that the arc of } \\
\text { the circle would cut the units } \\
\text { possibly into halves that you } \\
\text { could count to wholes. } \\
\text { (Abby) }\end{array}$ & $\begin{array}{l}\text { Visualize area } \\
\text { decomposition. }\end{array}$ & (none provided) & $\begin{array}{l}\text { Impressed by } \\
\text { thinking. }\end{array}$ \\
\hline $\begin{array}{l}\text { Area Counting Strategy: } \\
\text { Attempted to find the area of } \\
\text { an L-shaped figure by using } \\
\text { a doubling strategy for the } \\
\text { longer piece and then } \\
\text { individually counting the } \\
\text { horizontal piece. Had } \\
\text { difficulty adding everything } \\
\text { together. (Liam) }\end{array}$ & $\begin{array}{l}\text { Understands area but is } \\
\text { limited by his lack of } \\
\text { multiplication facts. }\end{array}$ & $\begin{array}{l}\text { Focus more on memorization and } \\
\text { less calculator use as a district. }\end{array}$ & (none provided) \\
\hline $\begin{array}{l}\text { Area Counting Strategy: } \\
\text { Found the area of a } \\
\text { rectangular region by } \\
\text { portioning the regions into } \\
\text { groups of four and skip } \\
\text { counting. Circled each } \\
\text { group of four and crosses it } \\
\text { out as she counts. (Micki) }\end{array}$ & $\begin{array}{l}\text { More efficient ways to do } \\
\text { count. Four might be a } \\
\text { "friendly" number for } \\
\text { Micki. }\end{array}$ & (none provided) & (none provided) \\
\hline $\begin{array}{l}\text { Area } \\
\text { Visualization/Counting } \\
\text { Strategy: Walked off area } \\
\text { using tiles on the floor. } \\
\text { (Tammi) }\end{array}$ & $\begin{array}{l}\text { Understands tiles can } \\
\text { represent units. }\end{array}$ & (none provided) & $\begin{array}{l}\text { Interesting } \\
\text { connection. }\end{array}$ \\
\hline $\begin{array}{l}\text { Area Counting Strategy: } \\
\text { Used a doubling row } \\
\text { strategy to find the area of a } \\
\text { rectangular region. } \\
\text { (Campbell) }\end{array}$ & (none provided) & (none provided) & $\begin{array}{l}\text { Efficient } \\
\text { strategy. }\end{array}$ \\
\hline
\end{tabular}

Figure 20. Events that Mrs. Purl noticed during Smartboard Lesson. Events highlighted in gray had instructional implications.

What Mrs. Purl noticed. During the Smartboard lesson, Mrs. Purl noticed six events during instruction that related to the themes of drawing strategies, questions, area visualization, and area counting. Of these six events, Mrs. Purl discussed students' understanding within five of the events and implications for instruction in two (as highlighted in gray in figure 20). All six of the events were recorded using the video camera, and one event was also discussed freely during our interview. Mrs. Purl 
discussed five students within these events and two of the students were her interview students.

Area counting strategies. Mrs. Purl chose three of the six events because of the student's counting strategy. In many of the problems posed, students were asked to find the area of a rectilinear region that was already tiled with square units. Mrs. Purl first discussed Liam in terms of his counting strategy. She stated that Liam had a unique counting strategy in which he partitioned an L-shaped figure into two rectangles and then used a doubling strategy by rows to find the answer. As the doubles became larger, it became more difficult for Liam to operate on them. It was not clear to the other students what Liam was doing because he did most of the work in his head. Mrs. Purl thought that Liam's strategy confused the other students because after all of his work, he ended with an incorrect answer, and they could not see his process. Mrs. Purl stated, "Poor Liam's thinking confused everybody because he put the wrong answer up there. He understood the task and used a correct strategy but he doesn't know his (multiplication) facts" (Mrs. Purl, December 11).

Mrs. Purl also discussed that when a student, Micki, was asked to find the area she circled groups of four and crossed them out, even though the figure was not divisible by four. Mrs. Purl discussed that she liked that Micki kept track of the units she had counted, but she was a little confused by Micki's thinking and why she would resort to counting by fours. Mrs. Purl stated, "I marked this one because I wondered why Micki would think it is the most efficient way...but I liked how she is marking squares, knowing that she had to keep track of what she has already marked" (Mrs. Purl, December 11). 
Lastly, Mrs. Purl discussed her student Campbell who used a strategy similar to Liam but he boxed in rows as he doubled so students could see what he was counting. Mrs. Purl identified this strategy because it seemed more efficient to her than the other students' strategies.

Drawing strategy. Mrs. Purl picked one event involving drawing because it was similar to something she saw within her interviews. Mrs. Purl noticed that Liam began to draw little tick marks around each of his square units in a similar way that he had done in the interview. Mrs. Purl hypothesized that maybe Liam was thinking about a ruler, but overall she was confused by this action. He continually made tick marks equally spaced around each unit in each of the rectangles he drew.

Question/area visualization. Mrs. Purl also attended to events where students pictured area in new ways. She noticed that Abby wondered early in the lesson how the area of a circle might be measured. Before Mrs. Purl could respond, Abby stated that she thought the arc of the circle might cut the square units into halves and the pieces could be added together. Mrs. Purl stated, "I marked this one because I wondered in her mind if she was picturing a circle sitting on a grid and each arc would cut the square units into halves...I was kind of impressed by her thinking because she already kind of figured out what to do with those pieces" (Mrs. Purl, December 11).

Mrs. Purl also noticed area visualization when a student, Tammi, related an area problem to the square tiles on the floor. Mrs. Purl posed an area problem for which the length and width were known but the area was not tiled. Tammi got out of her chair and began to walk off the tiles in the room to mark out the rectangle. Mrs. Purl stated, "Tammi was measuring, and at first she wouldn't tell me (what she was doing) but I could 
tell by the way she was walking because she was counting steps that were the same distance apart that she was measuring out the area. So that's what it was, I was just kind of impressed that she made that connection" (Mrs. Purl, December 11).

Interpreted understanding. As Mrs. Purl discussed students' actions, for five of the six events, she was able to provide some evidence of what she thought students were thinking with regard to their strategies. For three of the events, Mrs. Purl described students' visualization of area, and, for two of the events, Mrs. Purl described their understanding in relation to another mathematical topic, such as multiplication.

Students'visualization of area. Mrs. Purl discussed students' visualization of area in three of the events that she chose. For Abby and Tammi, Mrs. Purl conjectured how the two girls might see area. She conjectured that, when Abby was picturing the area of the circle, she could see the circle sitting on a piece of grid paper and could visualize how the arcs of the circle might intersect the square units. Mrs. Purl also conjectured that, when Tammi was using the floor to help her solve the area problem, she pictured each floor tile as a square unit.

Mrs. Purl also discussed students' visualization of area when discussing Liam's unusual strategy of making tick marks along each side of the square unit. She wondered if, in third grade, Liam had practiced breaking a square foot into square inches and was repeating this skill. To her, she could almost picture Liam seeing a ruler along the side of the rectangle. She stated,

It is almost like he is picturing the marks on a ruler...he put marks along each of the tile squares and then going down the other side (one side of the rectangle) there are marks here and along the other side there are marks here. So it's like 
maybe, at some point, in third grade, they broke down the square foot into inches. But he keeps falling back on that, and I am not sure why (Mrs. Purl, December 11).

Understanding of area in relation to other mathematical topics. For two of the events, Mrs. Purl discussed that she thought the student's understanding of other mathematical topics affected their strategy and their understanding. She stated when Micki decided to count by fours, when the rectangle was not divisible by four that Micki was influenced by school initiatives to practice skip counting. Students were told that certain numbers were "friendlier" than others and easier to skip count by. Mrs. Purl stated, "I am wondering now if she is kind of getting confused with our new initiative with more efficient ways to do math. So she is thinking that she likes grouping in fours because adding fours and doubling with fours is easier" (Mrs. Purl, December 11).

Mrs. Purl also discussed multiplication in relation to Liam's use of a doubling strategy to find the area of an L-shaped region. Mrs. Purl concluded that his mistake was made due to an initiative for students to use calculators. Even though he understood the process of finding the area, he lacked his basic skills to correctly compute the result.

Significance. For four of the events, Mrs. Purl discussed why the events stood out to her and why they were selected. Mrs. Purl chose events because they were similar to student interviews, connections that students' made, and also when students used an efficient strategy. For example, when Campbell used a doubling strategy with rows to find the area of a rectangle, Mrs. Purl marked it because it was an efficient strategy that she thought was clever. 
Implications for teaching. Mrs. Purl discussed possible instructional

implications for two of the events noted. These implications centered around the themes of questioning students about their work, the role of the unit, and less reliance on the calculator. When she was unsure of why Liam was making tick marks around each square unit, she stated that it is a good reminder to continually ask students why they do something.

Also in relation to this event, Mrs. Purl thought that for Liam, and possibly other students, the concept of different units might be foreign. She thought that a possible next step might be to have students to investigate different size units and describe how they are different and what makes them different. She stated, "I could see where it could be confusing that I refer to this tile as one square foot but this tile here as one square yard when they are both $1 \ldots$ It might be good to ask how are they (the units) different, and how are they not different? I think that is what is possible throwing him off and that is why he feels the need to break it down to even smaller units" (Mrs. Purl, December 11).

Lastly, Mrs. Purl also described an implication for instruction when Liam understood the task but could not correctly multiply. She stated that she thought students should not be allowed to use calculators as frequently in the classroom, but she felt that she had no control over this matter.

\section{Relating Units of Measure Lesson}

Following Mrs. Purl's introduction lesson, she taught a three-day lesson relating different units of measure to one another. These units included square inches, 3-inch squares, square feet, and square yards. This lesson is described in more detail in the 
chapter on Mrs. Grey. The events Mrs. Purl noticed during this lesson are presented in

Figure 21.

Going into the lesson, Mrs. Purl believed that all of the students would find the first task, finding the number of square feet in a square yard, fairly simple. She stated, "I would have expected more than half of them to go right to the formula (for finding area) and have an answer right away, because they would see that there were three across the top and three down... and they would have gone to right away okay that's three times three so that's nine" (Mrs. Purl, December 12).

Mrs. Purl also discussed that going into the lesson she purposefully did not give the units a name. She wanted students to discover properties about each of the units and see the relationship for themselves rather than knowing that three feet were in a yard.

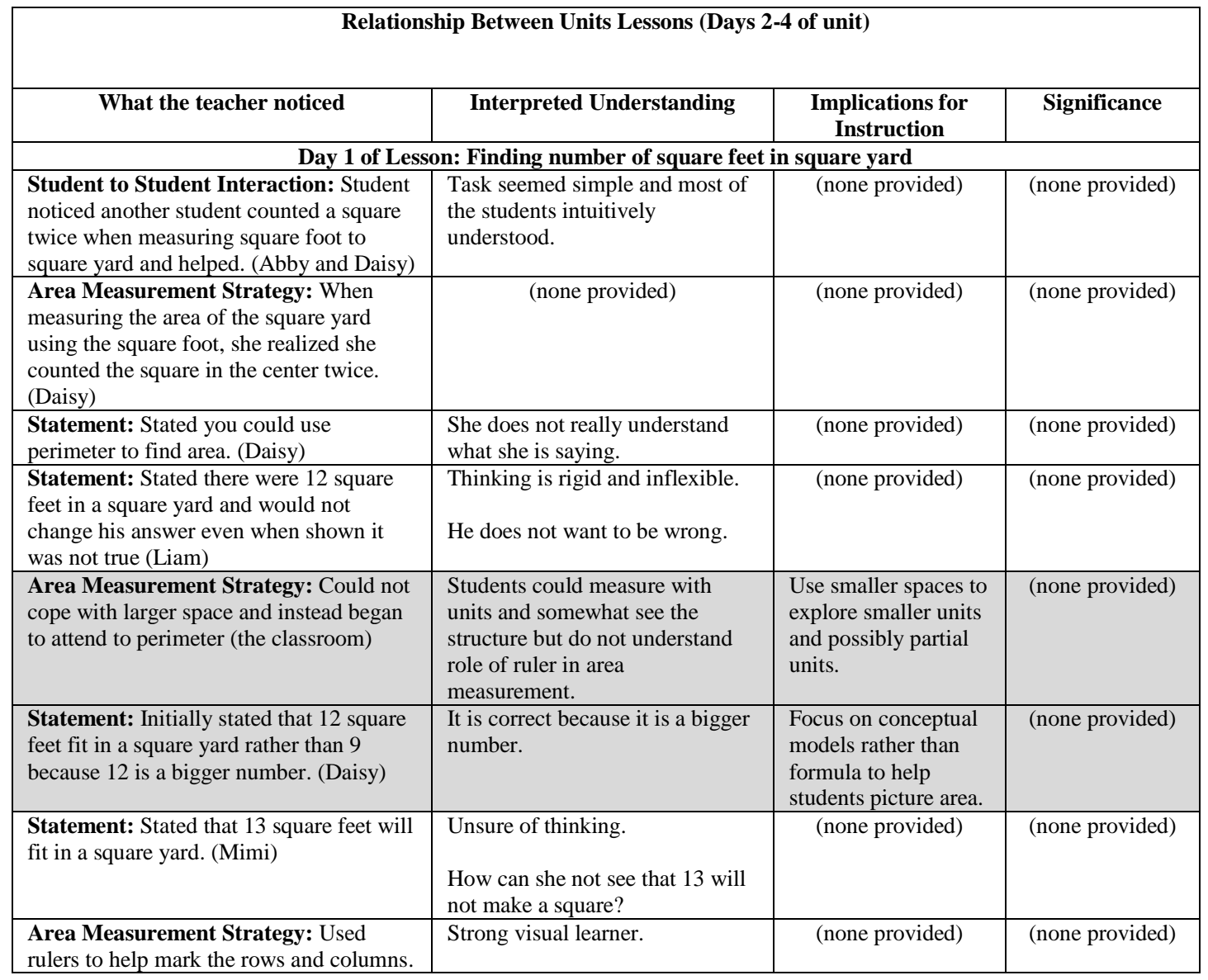




\begin{tabular}{|c|c|c|c|}
\hline (John) & $\begin{array}{l}\text { Lower end of the trajectory } \\
\text { because he needs visual } \\
\text { manipulatives. }\end{array}$ & & \\
\hline $\begin{array}{l}\text { Area Measurement Strategy: Borrowed } \\
\text { a second square foot from another group } \\
\text { to help them measure. (Mimi and Stacy) }\end{array}$ & $\begin{array}{l}\text { They needed the other square } \\
\text { foot to help iterate and keep } \\
\text { track. }\end{array}$ & (none provided) & (none provided) \\
\hline $\begin{array}{l}\text { Area Counting Strategy: Discussed that } \\
\text { you could count the top row and skip } \\
\text { count the number of rows to find the } \\
\text { answer. (Liam) }\end{array}$ & $\begin{array}{l}\text { Visualized each row and saw that } \\
\text { they were the same. }\end{array}$ & (none provided) & (none provided) \\
\hline \multicolumn{4}{|c|}{ Day 2: Determining number of 3inch squares in square foot and square yard. } \\
\hline $\begin{array}{l}\text { Area Visualization/Statement: Realized } \\
\text { she needed more smaller size units to fill } \\
\text { a space then larger size. (everyone except } \\
\text { Daisy) }\end{array}$ & $\begin{array}{l}\text { The size of the unit determines } \\
\text { its structuring. }\end{array}$ & $\begin{array}{l}\text { No students used } \\
\text { what they knew } \\
\text { about nested units, so } \\
\text { she wants to try to } \\
\text { force them to not } \\
\text { iterate. }\end{array}$ & $\begin{array}{l}\text { Relates to } \\
\text { decimal thinking }\end{array}$ \\
\hline $\begin{array}{l}\text { Student to Student Interaction/Area } \\
\text { Measurement Strategy: Used rulers to } \\
\text { make rows and columns. The rulers took } \\
\text { up a whole unit of space and Mimi } \\
\text { realized this and showed Stacy that their } \\
\text { answer was incorrect. (Mimi and Stacy) }\end{array}$ & $\begin{array}{l}\text { They needed the structure, but } \\
\text { they were able to realize that the } \\
\text { rulers took up space. }\end{array}$ & $\begin{array}{l}\text { Let students struggle } \\
\text { through tasks. }\end{array}$ & (none provided) \\
\hline $\begin{array}{l}\text { Statement/Area Counting Strategy: } \\
\text { Realized the formula for area and tried to } \\
\text { articulate it. (Abby) }\end{array}$ & $\begin{array}{l}\text { She has a low reading level so } \\
\text { maybe she could not organize her } \\
\text { thoughts to articulate them. }\end{array}$ & (none provided) & (none provided) \\
\hline $\begin{array}{l}\text { Area Visualization/Statement: Stated } \\
\text { that as the units become smaller the area } \\
\text { becomes larger. (Abby) }\end{array}$ & $\begin{array}{l}\text { Understood that as the units } \\
\text { become smaller more units are } \\
\text { needed and she is started to see } \\
\text { conversion. }\end{array}$ & (none provided) & (none provided) \\
\hline $\begin{array}{l}\text { Area Measurement Strategy: Used } \\
\text { rulers again to mark off rows and } \\
\text { columns. (John) }\end{array}$ & $\begin{array}{l}\text { He does not have row and } \\
\text { column structure in his mind. }\end{array}$ & $\begin{array}{l}\text { Have him draw what } \\
\text { he has done to see if } \\
\text { he includes the rulers. }\end{array}$ & (none provided) \\
\hline \multicolumn{4}{|c|}{ Day 3 of the Lesson: Finding number of square inches in square yard. } \\
\hline $\begin{array}{l}\text { Area Counting Strategy: Used a nested } \\
\text { units strategy to find the total number of } \\
\text { square inches in a square yard. (Dani) }\end{array}$ & $\begin{array}{l}\text { She could see the units within } \\
\text { units and the relationships } \\
\text { between. }\end{array}$ & (none provided) & $\begin{array}{l}\text { Impressed by } \\
\text { thinking. }\end{array}$ \\
\hline What the teacher noticed & Interpreted Understanding & $\begin{array}{c}\text { Implications for } \\
\text { Instruction }\end{array}$ & Significance \\
\hline $\begin{array}{l}\text { Language Comprehension: Does not } \\
\text { know how to answer the question of what } \\
\text { math process they have been doing. } \\
\text { (Abby and others in class) }\end{array}$ & $\begin{array}{l}\text { Students understand } \\
\text { measurement to be length only. }\end{array}$ & (none provided) & (none provided) \\
\hline $\begin{array}{l}\text { Area Counting Strategy: Used nested } \\
\text { units strategy but accidently multiplied by } \\
10 \text { instead of } 12 \text { for the number of } 3 \text {-in } \\
\text { squares in a square foot. (Abby) }\end{array}$ & $\begin{array}{l}\text { She could see the units within } \\
\text { units and the relationships } \\
\text { between. }\end{array}$ & (none provided) & $\begin{array}{l}\text { Impressed by } \\
\text { thinking. }\end{array}$ \\
\hline $\begin{array}{l}\text { Drawing Strategy: Drew each square } \\
\text { inch unit on the floor inside of the square } \\
\text { yard. (Student Group) }\end{array}$ & (none provided) & (none provided) & $\begin{array}{l}\text { Surprised } \\
\text { because of } \\
\text { ability. }\end{array}$ \\
\hline $\begin{array}{l}\text { Area Measurement Strategy: Laid out } \\
\text { square units to measure math book then } \\
\text { laid out math books to measure space. } \\
\text { (John) }\end{array}$ & $\begin{array}{l}\text { Understood the book could also } \\
\text { be used as a measurement unit. }\end{array}$ & (none provided) & (none provided) \\
\hline $\begin{array}{l}\text { Area Measurement Strategy: Thirty six } \\
\text { square inches made up the length of the } \\
\text { yard stick so that would be one column } \\
\text { but then sloppily iterated the yard stick } \\
\text { across to find the width. (Jose) }\end{array}$ & $\begin{array}{l}\text { He doesn't see the yard as a } \\
\text { square or that the sides needs to } \\
\text { be the same measurement. }\end{array}$ & (none provided) & (none provided) \\
\hline $\begin{array}{l}\text { Length Measurement Strategy: Did not } \\
\text { measure the length and width of the } \\
\text { square yard to be the same. (all students) }\end{array}$ & $\begin{array}{l}\text { Understands properties of square } \\
\text { but this does not translate to } \\
\text { measurement. } \\
\text { Possibly next step within LT. }\end{array}$ & (none provided) & Surprising. \\
\hline $\begin{array}{l}\text { Language Usage: Interchanged words } \\
\text { perimeter, length, width. (Abby) }\end{array}$ & $\begin{array}{l}\text { Conceptually understands the } \\
\text { difference but still interchanges } \\
\text { words. }\end{array}$ & $\begin{array}{l}\text { This is why math } \\
\text { dictionaries are so } \\
\text { important for the } \\
\text { students to keep track }\end{array}$ & (none provided) \\
\hline
\end{tabular}




\begin{tabular}{|c|c|c|c|}
\hline & & of their thinking. & \\
\hline $\begin{array}{l}\text { Length Measurement Strategy/Student } \\
\text { to Student Interaction: Jose read off the } \\
\text { end of the ruler when it is not lined up at } \\
\text { the zero point. Abby caught his error. } \\
\text { (Jose and Abby) }\end{array}$ & $\begin{array}{l}\text { Abby understood the } \\
\text { measurement did not make sense. } \\
\text { Jose could not see the end so he } \\
\text { maybe did not realize he did not } \\
\text { start at } 0 .\end{array}$ & (none provided) & (none provided) \\
\hline
\end{tabular}

Figure 21. Events that Mrs. Purl noticed during Relating Units of Measure Lesson. Events highlighted in gray had instructional implications.

What Mrs. Purl noticed. Across the three days of instruction, Mrs. Purl noted 24 events, 18 were tagged on the video and 14 were recalled during our interview (some of the events were recalled freely as well as noted by video). These events involved statements made by students; student-to-student interactions; drawing, counting, and measurement strategies; visualization; and language comprehension and usage.

Area measurement strategies. Mrs. Purl noted seven events across the lesson that involved students' area measurement strategies or structuring of area units. Mrs. Purl primarily noted how the student placed the unit down and iterated it. For instance, when Daisy measured how many square feet it would take to measure the square yard, she overlapped her units, so she measured 12 square units instead of nine. Mrs. Purl stated, "She answered 12 because she did not go all the way to the edge when she was measuring and overlapped units" (Mrs. Purl, December 12).

Other events related to students using tools, within their classroom, to help them structure space. Three of the seven events related to students' use of a ruler to help them make rows and columns. John, Mimi, and Stacey, consistently grabbed rulers across each day of the lesson and used them to create rows and columns within the figure they were measuring. Below is an excerpt from the transcript in which Mrs. Purl and I discussed John's use of the rulers on the last day of the lesson. 
This is where John laid out the rulers on the floor. Looking back at this now it is interesting that he has kept this concept of having to use these rulers the whole time. He has not deviated from it, even when the next day he saw that the units had to touch he still kept with it. So if I had to either add terminology to the trajectory or say it in a way the teachers understand I would probably have to say that this would put him lower on the trajectory because he visually has to see the squares, or the structure (Mrs. Purl, December 16).

Mrs. Purl discussed that this strategy is incorrect because the ruler in between units creates gaps. As the lesson progressed, Mimi and Stacey realized this misconception while John did not.

Mrs. Purl also noted that when one student, Stacey, measured the number of square feet in a square yard, she could not do it with an individual unit and grabbed a second from a different group. Mrs. Purl noted that Stacey moved the units one at a time, over each other, to help measure.

Related to Stacey's strategy, Mrs. Purl also noted that another student, John, grabbed several math books to help him and his group with the task. He measured the square inches for each math book and then began to tile the math books. Mrs. Purl stated: I thought it was kind of cool that since they did not have enough rulers, John measured. I thought they were just playing with the books, but that John measured the books so that they could help use the books to help measure the space. I would be curious to see where that would have gone if we had more time. I wonder if he would have just said that nine books is the answer or would he have related it to the units in the book (Mrs. Purl, December 17). 
Area counting strategies: Mrs. Purl commented on four events that involved students' area counting strategies. On the first day, she commented that Liam stated that he measured the number of tiles in the first row and then counted the total number of rows to find his answer. Mrs. Purl stated, "He had the idea that if this top row is all you know or if you have the top row then it is going to mean everything, all the rows, will be the same, and you can just count them" (Mrs. Purl, December 17).

Mrs. Purl also noticed area counting strategies that related to multiplication. In three of the events, Mrs. Purl noted students' connections to multiplicative properties in relation to area measurement. This was especially relevant in the last lesson when students were finding the number of square inches within a square yard. Two students, Abby and Dani, both were able to use properties of multiplication and nested units to find the answer. Even though both girls did not end up with the correct answer, Mrs. Purl thought that their solutions were interesting and showed that they were connecting ideas together. Mrs. Purl described the strategy in the following way,

Their answer was in the 2000s. So I need to look at it because I was impressed that Dani realized that she could use the work that we had previously done to get the answer...Dani said nine is the area of the tile (number of square inches in a 3 inch square), 16 of those tiles (16 3-inch tiles in a square foot), $9 \times 16 \times 9$, because of the 9 square feet in the square yard. I think her answer was incorrect because she skipped that 16 part and instead multiplied by 12 (Mrs. Purl, December 17).

Drawing strategy. On the last day of the lesson, students were asked to determine the number of square inches with a square yard. During this day of the lesson, Mrs. Purl 
noted that one group had to draw out all of the units inside of the square yard and could not see the structure of rows or columns within the square yard.

Language comprehension. Mrs. Purl discussed two events in which students were using the wrong terminology or incorrect language to discuss their strategies. Mrs. Purl posed a question to Abby and to the rest of the class asking them to further describe the process they were using when tiling or measuring the number of square units, hoping the students would say measuring. Each of the students she called on could not think of the term or find the right word to describe it.

Okay, so I wanted her to come up with that it was called measurement. So I marked it because I want her to tie her thinking to an actual term and again I feel like that this is what some of them are missing, that vocabulary and knowledge of the correct terminology. It was surprising that many of them don't get that it is called measuring, like only measuring can happen with a ruler or something? (Mrs. Purl, December 17).

A similar situation occurred in the last day of the lesson when Mrs. Purl described that students were interchanging the words perimeter, length, and width. Mrs. Purl discussed that she understood what the students meant and the students understood the process that they were using but that they were using the incorrect words.

Student helping another student with a misconception. Mrs. Purl valued collaboration and group discussion within her classroom so she noticed four events that highlighted a student noticing another student's measurement misconception and helping them with it. For example, when Mimi and Stacey used rulers to help structure a space, Mimi noticed that the rulers take up space so their answer would not be correct. Mimi 
was able to articulate this idea to Stacey and show her why their initial strategy was wrong. Mrs. Purl stated,

I loved that Stacey and well Mimi at first picked up and then helped Stacey. The ruler idea seemed like a great idea but then Mimi realized that they were missing the space under the ruler where you used them... because they noticed the error, argued, and helped each other fix it (Mrs. Purl, December 13).

Later in the lesson, Mrs. Purl noticed a student helping another student measure the number of square inches in a square yard. Abby and Jose had worked together to find out that the yard stick showed how many square inch units would be along the side of the square yard. Jose framed the square yard using the yardsticks and read off the measurements. Some of the yardsticks were not lined up at the zero points, so Jose had different measures for each side. Abby noticed and asked Mrs. Purl if she had made the square yards actually squares and then told Jose they should be getting the same measures for each side.

Visualization of area in relation to square units. Several times during the lesson, students articulated how they visualized area. Mrs. Purl noticed, in two events, that several of her students could articulate that as a unit became smaller it would take more of the unit to cover the same space. Mrs. Purl described one student, Abby, and how Abby described this relationship,

She said that when you divide it in smaller units she could see that the area would be bigger. Yes, but the area would not be any bigger but I think what she was picturing was that the number would get bigger and more units would fit in the same space and that is why I picked this event (Mrs. Purl, December 14). 
The other events that Mrs. Purl chose were very similar to this event with Abby. Mrs. Purl speculated on how the student or students saw the area unit changing in relation to the space and that they understood the smaller the unit, the larger the quantity of units needed.

Statements. Mrs. Purl chose eight statements as events mainly because the statements, overall, were disconnected or confusing for Mrs. Purl. This primarily occurred with Mrs. Purl's interview student, Daisy, who made small mistakes or often blurted out ideas but could not articulate what she meant. For instance, when measuring how many feet were in a square yard, the students had two conjectures, 12 square feet and 9 square feet. When asked which one is correct, Daisy said that it was 12 because 12 was the larger number. Mrs. Purl found this statement to be both confusing and troubling and decided to mark it as important to help her remember to consider Daisy' s reasoning.

Length measurement strategy. As students considered the area of a square yard, Mrs. Purl saw strategies arise that involved length measurement. Mrs. Purl noted three length measurement strategies that occurred during the last day of the lesson. While Abby and Jose were measuring the length of the square yard, as described in the student interaction section, Mrs. Purl commented that perhaps Jose could not see the edge to see that it was not lined up at the 0 , but he knew that he should read off the endpoint to find the measure.

Interpretation of understanding. Although Mrs. Purl interpreted students' actions in terms of their understanding for 21 of the 24 events she identified, her interpretations were not very detailed. For the most part, she described what students understood about area and how students interpreted the structure of the area unit, often in 
relation to the properties of a square. She frequently related students' understanding to their personalities and past experiences. As Mrs. Purl reflected on students' thinking, she questioned the learning trajectory and defined new levels of thinking for her students.

Understanding of area unit structuring. Throughout the lesson on comparing units, Mrs. Purl commented on students' understanding of area in relation to structuring area units. Twelve of her comments on students' understanding related to students understanding of area. On Day 1 of the unit, after watching students measure a square yard using one square foot, Mrs. Purl commented that most students in her class understood that area could be measured by iterating a unit without gaps or overlaps. After asking the class to measure a larger space, she realized that even though students understood iterating area units they did not see row and columns yet and did not understand how these units might tile a larger space. Mrs. Purl stated, "I think they have a better understanding of what area is, that it is the inside. Although they did use the square foot unit to measure, I am not confident they could take a ruler and figure it out that way" (Mrs. Purl, December 11).

On Day 1, and throughout the lesson, Mrs. Purl noticed that students were outlining rows and columns using rulers. For example, Mrs. Purl described that John had to visually see the rows and columns to count them. Even though I did not ask Mrs. Purl what this would signify within the learning trajectory, she explained that this would place John at a lower level of thinking. An excerpt from the transcript in which we discussed John's thinking following the lesson is shown below.

Mrs. Purl: So if I either had to add terminology to the trajectory so that teacher would understand, I would probably have to say that this would put him lower on 
the trajectory because he visually has to see the squares...right even, you know, does that mean his is a strong visual learner and he has to see it?

Megan: I think so, or maybe it is just a way for him to check himself?

Mrs. Purl: Yeah but I don't think it is a way for him to check his answer because this one, he started right away with it, I believe (Mrs. Purl, December 17).

In days two and three of the lesson, Mrs. Purl discussed students who could see beyond individual units and who understood row and column structure and units-withinunits. For example, Liam articulated to Mrs. Purl that all he needed to know was the number of square units in the first row and he could find the total area. Mrs. Purl attempted to connect her reasoning about his thinking to the trajectory and described his thinking as follows:

I don't know what to call that level but he seems to know that you don't have to fill it in completely in order to get the area. If you see the top row than all the other rows underneath will be the same (Mrs. Purl, December 14).

With regard to students' understanding of structuring of units, Mrs. Purl was able to discuss how different students worked with units, both physically and mentally.

Understanding of a square. With regard to unit structuring, Mrs. Purl reflected on students' understanding of working with a square. Throughout the three days of the lesson, Mrs. Purl was confused about how students could think of the properties of a square hypothetically but that these properties did not translate into their understanding of measurement. On Day 1, several of the students guessed that it would take 10 or 13 square feet to tile a square yard. Mrs. Purl wondered how students structured the space and thought they must not have the units structured in rows and columns. She stated, "It 
just surprises me that they don't see a number like 10 and realize it would be a square with a unit hanging off" (Mrs. Purl, December 15).

Mrs. Purl also wondered where understanding of a square fit within the learning trajectory. She stated that it would be interesting to know if the next step in the trajectory, after developing row and column structure, would be to know that a square must have the same measures on each side. She stated, "Okay it would be interesting to know if some of the next understanding is that they understand that if this side is 4 and that side is 4 of whatever (units) you have made a square” (Mrs. Purl, December 15).

Students' understanding of the square resurfaced on the last day of the lesson. Several groups of students were measuring sides of the square yard and coming up with vastly different numbers. Mrs. Purl was surprised that this thinking still persisted and that there was a disconnect between the definition of square and measuring a square. She stated, "It still amazes me. It amazes me that they see a square and they know that a square has equal sides but yet during these tasks they aren't applying that thinking to the task" (Mrs. Purl, December 17).

Language comprehension. In two of the events that Mrs. Purl identified, she discussed students' understanding of language with regard to measurement terms. Mrs. Purl explained how Abby interchanged vocabulary words:

Which reminds me, Abby keeps talking about the perimeter, well you use the perimeter to, She has these like disjoint ideas....I think what she is doing is that instead of calling that length or width, she is calling it perimeter... well I think she is confusing the terminology when she should say I took the length and the width, she is just saying I took the perimeter (Mrs. Purl, December 15). 
Mrs. Purl mentioned that students often hear the word measurement and do not associate it with area — to the students, to measure means to use a ruler. She highlighted the importance of language, specifically in an ELL classroom and reported that she constantly monitored students' language to help them clarify terms and their understanding.

Student personality and past experiences. For four of the events Mrs. Purl discussed, she commented on a student's personality or past experiences (e.g., reading level, standardized test scores, with other teachers) instead of what the student understood. For one particular student, Liam, this idea surfaced somewhat regularly. On the first day of the lesson, Liam stated that 12 square feet would cover a square yard instead of 9. Even after other students showed him he was incorrect, he would not change his answer. Mrs. Purl stated that Liam is a bright student but he hates to be wrong, so that is why he did not correctly answer the problem. Below is an excerpt from the transcript where we discussed Liam:

Mrs. Purl: I think I marked this one because there are times that he just wants to prove how smart he is

Megan: Yeah.

Mrs. Purl: And so he wont,...

Megan: Do the activity?

Mrs. Purl: Yeah he will just say, "Oh I have the right answer." You know what I mean?

Megan: Oh, okay. 
Mrs. Purl: And then if he is wrong, He is stuck in "oh my gosh, what should I do"? So maybe that is why I marked it. He is so smart with math but is it because of his rigidity (Mrs. Purl, December 13).

Even though Liam might have had a possible misconception, Mrs. Purl attributed his behavior to his personality rather than his understanding.

Mrs. Purl also discussed students' past experiences with other teachers as well as learning difficulties they had in relation to reading and mathematics. For instance, when Mrs. Purl asked students what they were doing when completing area tasks, none of the students understood that what they were doing was measurement. When I asked Mrs. Purl why the students thought this, she attributed it to their past experiences with other teachers. She stated, "I don't know if they are so used to always having to have the right answer and that is how they have been typically taught that the only way to get the right answer is to use the ruler" (Mrs. Purl, December 14).

Significance. In addition to discussing students' understanding, Mrs. Purl often discussed the events significance to her. Mrs. Purl discussed four events in this way. For the most part, these events stood out to Mrs. Purl as impressive or surprising. For instance, when Abby saw that she could use what she knew about other units to find out how many square inches were in a square yard, Mrs. Purl was surprised and proud that Abby made this connection. Many of the moments that stood out to her as a teacher were ones for which she could celebrate a students' success or a student making a mathematical connection.

Implications for instruction. Of the many events that Mrs. Purl noted, only six events were connected with implications for instruction. Even though Mrs. Purl did not 
connect all of the events to instruction, she did reflect on students' thinking overall to determine how the lesson should be modified or changed.

Day one. On day one of the lesson, Mrs. Purl noted that the task of finding the number of square feet in a square yard seemed relatively easy for many of her students. She could see that they could iterate units in small spaces but that this knowledge did not transfer to larger spaces. She stated that she wanted to challenge the students in some way to expand their understanding of area. She thought that she could either do this by introducing smaller and partial units within the smaller space or having students measure larger areas: "I think that they did well with this task so tomorrow I would like to do, measuring the area of other objects in the room, or reigning them back and having them measure smaller areas with different size units" (Mrs. Purl, December 11).

Mrs. Purl also discussed that, after watching me teach mathematics intervention, she realized that area conversion was a critical piece of understanding area. She stated that eventually she would like to prepare a lesson in the coming weeks focusing on building multiple rectangles with the same area. She stated,

Or, if this rug, so you have told me that this rug is however big can you make a different rug that is the same area. I want to do that now and see if they can create...because you did some of that yesterday in intervention (Mrs. Purl, December 11).

Mrs. Purl described that, of these options, she decided to examine the relationship of different size units first. Since it was difficult for students to structure space and to picture unit structuring, she wanted them to develop reasoning about how different size units might cover the space. She stated, "I am not sure if it was the right direction but I 
wanted to make sure that they had um and I don't know what the official term would be that they understand the smaller the unit, the more there will have to be" (Mrs. Purl, December 11). She also stated that she thought the square foot was fairly easy for the students to use, so she wanted to challenge them with smaller units. She stated, "I kind of thought yesterday was easy for them, so I wanted to give them something more challenging like smaller or partial units" (Mrs. Purl, December 12).

Day two. Reflecting on day two of the lesson, Mrs. Purl was surprised that students had not transitioned to multiplicative reasoning or at least used what they knew about units in relation to each other to determine how many 3-inch squares would tile a square foot. She thought about challenging the students again the next day. She stated, "Well I feel like I need to go, since I saw so many of them today flipping that tile across the whole figure, I feel like I need to say, is there a more efficient way we could do this?" (Mrs. Purl, December 13). Mrs. Purl discussed that perhaps she had let the students use too many units, and she would limit how many units they were allowed to use to make iterated the unit more difficulty. She hoped this would force them to use other types of reasoning that were more efficient.

On day two, Mrs. Purl had one or two moments that reaffirmed her teaching practices and encouraged her to keep teaching in the same manner. When Mimi helped Stacey to see that the rulers took up area, Mrs. Purl saw that both of the girls were excited that they found the answer on their own and had worked through misconceptions. Mrs. Purl stated:

I thought that was really cool. It was one of those moments where I was like good see this is why you make kids work through a problem rather than just giving 
them the answer. Because she (Mimi) was definitely so excited when she figured it out (Mrs. Purl, December 13).

Mrs. Purl described that she started a mathematics dictionary to help students remember and articulate mathematical terminology to help them work through problems and be self-sufficient. Even though students, like Abby, had difficulty and mixed up mathematical terms, Mrs. Purl felt the initiative had helped students overall. She stated: Yeah and from last year that is why I started the math dictionary part of their notebook this year. Because they are not connecting what they are doing with actual terms and you know there is only so long that these posters can stay up on the walls (Mrs. Purl, December 13).

Day three. On day three of the lesson, Mrs. Purl primarily discussed all three days of the lesson collectively. There was not one particular event that stood out to her, but she had much to say about mathematics and students' understanding. Mrs. Purl stated that she felt pressure to keep up with the other fourth-grade teachers.

Mrs. Purl: It just feels like our math in general needs some more layering, so that maybe we should be covering area at the same time we are talking about skip counting or multiplication or

Megan: so they see it as connected?

Mrs. Purl: Right, because honestly with our four-quarter plans, Mrs. Grey and I are actually behind because you know the other teacher who is doing the plans, they have done volume already. They spent like a day on area which I don't think is good enough for understanding (Mrs. Purl, December 15). 
Throughout the three-day unit, Mrs. Purl noticed events that helped her to challenge students' thinking as well as reaffirm her own teaching practices. She also reflected on mathematics instruction as a whole and wondered what could be done to help create a more conceptual understanding for students.

\section{Area Conservation Lesson}

The concept of area conservation was the focus of the final lesson of the instructional unit; students built rectangles with the same area and compared the properties of the different rectangles they constructed. More about this lesson can be found in Mrs. Grey's chapter. The events that Mrs. Purl noted during the area conservation lesson are presented in Figure 22. Events that are highlighted in gray are events that led to an instructional implication. 


\begin{tabular}{|c|c|c|c|}
\hline \multicolumn{4}{|c|}{ Conservation of Area Lesson: December } \\
\hline $\begin{array}{c}\text { What the Teacher } \\
\text { Noticed }\end{array}$ & Interpreted Understanding & $\begin{array}{l}\text { Implication for } \\
\text { Teaching }\end{array}$ & Significance \\
\hline $\begin{array}{l}\text { Building Strategy: } \\
\text { Surprised that students } \\
\text { don't just shove tiles } \\
\text { together to make a } \\
\text { rectangle. (all students) }\end{array}$ & $\begin{array}{l}\text { Lack experience with } \\
\text { materials like these. }\end{array}$ & (none provided) & (none provided) \\
\hline $\begin{array}{l}\text { Statement: Could not } \\
\text { articulate properties of a } \\
\text { rectangle. (all students) }\end{array}$ & (none provided) & $\begin{array}{l}\text { Students need a better } \\
\text { understanding of } \\
\text { mathematical } \\
\text { terminology before they } \\
\text { can even attempt the task. }\end{array}$ & (none provided) \\
\hline $\begin{array}{l}\text { Drawing Strategy/ Area } \\
\text { Counting Strategy/Area } \\
\text { Visualization: Asked for } \\
\text { graph paper to draw his } \\
\text { rectangle on smartboard. } \\
\text { Drew his rectangle and } \\
\text { counted each box. (Kevin) }\end{array}$ & $\begin{array}{l}\text { He is not comfortable with } \\
\text { the formula or he needs the } \\
\text { boxes to be able to count one } \\
\text { by one. }\end{array}$ & (none provided) & (none provided) \\
\hline $\begin{array}{l}\text { Area Measurement } \\
\text { Strategy: Continued to } \\
\text { used rulers to outline rows } \\
\text { and columns. (John) } \\
\end{array}$ & $\begin{array}{l}\text { He needs this to visually see } \\
\text { or to create a structure. }\end{array}$ & (none provided) & (none provided) \\
\hline $\begin{array}{l}\text { Drawing Strategy: Drew } \\
\text { a unit over and over again } \\
\text { and counted to make a } \\
\text { rectangle rather than } \\
\text { pushing them together. } \\
\text { (Liam) }\end{array}$ & $\begin{array}{l}\text { Mrs. Purl thought this was an } \\
\text { inefficient strategy and she } \\
\text { was trying to push him but he } \\
\text { did not see any other way. }\end{array}$ & (none provided) & (none provided) \\
\hline $\begin{array}{l}\text { Area Visualization: } \\
\text { Students want all sides of } \\
\text { rectangle labeled. She is } \\
\text { surprised that they don't } \\
\text { see the sides to be the } \\
\text { same. (Many students) }\end{array}$ & (none provided) & $\begin{array}{l}\text { She doesn't want to label } \\
\text { all the sides because she } \\
\text { does not want them to } \\
\text { confuse it with perimeter. }\end{array}$ & (none provided) \\
\hline $\begin{array}{l}\text { Area Measurement } \\
\text { Strategy: Framed a } 1 \times 20 \\
\text { rectangles with rulers and } \\
\text { asked if it was correct and } \\
\text { was unsure if it worked. } \\
\text { (Kevin) }\end{array}$ & $\begin{array}{l}\text { He sees a line of } 1 \text { and not a } \\
\text { rectangle. He is using the } \\
\text { rulers to make the boundaries. }\end{array}$ & (none provided) & (none provided) \\
\hline
\end{tabular}

Figure 22. Events that Mrs. Purl noticed during Area Conservation Lesson. Events highlighted in gray had instructional implications.

What Mrs. Purl noticed. Mrs. Purl noticed seven events, six were tagged using the video camera and the other two were brought up during the interview. Mrs. Purl noticed strategies in relation to building area, visualizing area, counting and measuring area and students' statements. All of the strategies that she noted related in some way to students' perceptions of the rectangle.

Properties of and visualizing a rectangle. Mrs. Purl initially discussed that it was difficult for students to brainstorm and list all of the properties of a rectangle. She noticed 
three events that related to students' understanding of properties and visualizing rectangles. When she asked students what makes a shape a rectangle several of them told her incorrectly that a rectangle has four acute angles. She also noticed that when she drew rectangles on the board, students did not see that the opposite sides of the rectangle were the same length and were not content if all of the sides were not labeled.

Building and drawing rectangles. Mrs. Purl was surprised that the task seemed difficult to the students. She stated, "it surprises me how many of them, even when I give them the tiles, don't just shove them into a rectangle. It isn't that hard I don't think" (Mrs. Purl, December 18). She thought that students would push the tiles together to make a rectangular form.

She noticed that several of the students still seemed to attend to individual units. For example, although Liam had 20 units, he only used one unit and iterated it across to make a rectangle. He continually had to stop and recount his units to see if he had enough. Mrs. Purl stopped and discussed his strategy with him, hoping that she could push him to try another way. She stated,

He (Liam) said it is an easier strategy. I was hoping to move him to an efficient strategy. So I said to him "oh it's just easier for you to draw it numerous times" trying to get him to say "oh hey wait a minute I could just lay them all out." But, he is just so particular (Mrs. Purl, December 18).

Another student, Kevin also attended to individual units. When Mrs. Purl asked for volunteers to draw their rectangles on the front board, Kevin would not draw his rectangle unless Mrs. Purl projected graph paper. Mrs. Purl stated, "I marked that because to me I saw that he is not comfortable with the formula and he still needs those boxes to 
draw and count one by one" (Mrs. Purl, December 18). Mrs. Purl also noted how Kevin counted area, one unit at a time.

Area measurement strategies. Mrs. Purl noticed two events related to area measurement strategies. She commented that several students wanted to use rulers to outline their rectangles or to form rows and columns. She noticed that John, who used rulers throughout the unit to make rows and columns, continued to use them in this lesson. She also had an interesting encounter with one student in which the student created a $1 \times 20$ unit rectangle. The student outlined the rectangle with rulers but was unsure if it counted as a rectangle. Below Mrs. Purl described the encounter.

Mrs. Purl: He got all 20 (tiles) out, but then I was surprised because he was like is this the right answer, is this right?

Megan: Why do you think he didn't see it as a rectangle? Or was unsure?

Mrs. Purl: Well the only thing that I can think of is that because it is just a row of 1 that he does not see that truly as a rectangle, maybe he just sees it as a line...He doesn't see, maybe that's what it is because I would see these outside edges as making lines (Mrs. Purl, December 18).

In each of these different events, Mrs. Purl attended to either how students defined and understood rectangles or how they constructed rectangles.

Interpreted understanding. As Mrs. Purl described important events, she was asked what the actions within the events meant in terms of students' understanding. In five of the seven events, Mrs. Purl commented on what she thought students understood. Four of the five comments were related to how students visualized units and the structuring of units, one comment focused on students' past experiences. 
When students had difficulty creating rectangles, Mrs. Purl commented that she thought building rectangles was very much like playing with blocks. She speculated that maybe some students had not had those types of experiences at home. She stated, "But to me, maybe that kind of says to me that maybe when they were younger they didn't play with blocks or have that hands-on manipulative practice" (Mrs. Purl, December 18).

The other four understandings that Mrs. Purl discussed all related to students' understanding of structure and units. Mrs. Purl realized that students experienced difficulty visualizing rows and columns and that some students were so focused on individual units that they did not even see the rows and columns. For example, Mrs. Purl made the following comment about John, who used rulers to create rows and columns:

I guess I think he just feels like he needs that visual. They seem to want to create, some of them seem to want to create or need to create structure. I don't know if it is too open ended for them to, but you would think pushing them (the units) up right against each other would give them enough structure that he would feel the need not to have the rulers (Mrs. Purl, December 18).

Many of Mrs. Purl's students, even after several weeks focused on area measurement, still focused on the unit itself rather than a larger structure of rows and columns. Mrs. Purl was able to conjecture what the students were thinking but was still surprised by it.

Implications for instruction. Mrs. Purl discussed two events in relation to implications for instruction. When students could not articulate properties of a rectangle, she commented that students needed a stronger understanding of mathematical terminology. She realized, through this experience, that she needed to be careful in how 
she worded questions and that she needed to think about how to pose tasks in different ways so students could learn about the properties. She stated:

I did not realize that some of them don't know what a rectangle is or they can't, they might, if you show them a rectangle they might know what it is. But here's a good example of presenting things to children in an alternate way. Don't just show them the rectangle and explain it, give them the definition of what a rectangle is and then ask them what shape it is...to see if they have a good understanding because typically how we present is here's a rectangle and tell me about it. So I tried going from the other way...I am going to give you some characteristics of this shape now you tell me what the shape is (Mrs. Purl, December 18).

Mrs. Purl also posed a question to the students related to labeling all of the side lengths of a rectangle. When students labeled all of the sides of the rectangle, Mrs. Purl was surprised. She did not want students to label all of the sides of the rectangle when finding area because she thought it would encourage them to confuse perimeter with area. At this point, Mrs. Purl questioned whether or not she should allow students to label all of the four sides, but was unsure of what she should do.

\section{Summary}

Across the three sets of student interviews and the unit of instruction, Mrs. Purl noted 56 events and described 69 student actions. For 48 of the events, Mrs. Purl described a student or students' understanding in relation to the actions she noticed. She described implications for instruction for 18 of the events. Figure 23 presents a summary 
of the data pertaining to the types of student actions that Mrs. Purl noticed during the study.

\begin{tabular}{|c|c|c|c|c|c|c|}
\hline & \multicolumn{3}{|c|}{$\begin{array}{c}\text { Interviews } \\
\text { (19 events, } 23 \text { student actions) }\end{array}$} & \multicolumn{3}{|c|}{$\begin{array}{c}\text { Lessons } \\
\text { (37 events, } 46 \text { student actions) }\end{array}$} \\
\hline & $\begin{array}{c}\text { Interview } \\
1 \\
\text { (5 events; } \\
6 \text { student } \\
\text { actions) }\end{array}$ & $\begin{array}{c}\text { Interview } 2 \\
\text { (9 events; } 11 \\
\text { student } \\
\text { actions) }\end{array}$ & $\begin{array}{c}\text { Interview } 3 \\
\text { (5 events; } 6 \\
\text { student } \\
\text { actions) }\end{array}$ & $\begin{array}{c}\text { Smartboard } \\
\text { (6 events; } 8 \\
\text { student } \\
\text { actions) }\end{array}$ & $\begin{array}{l}\text { Relationship } \\
\text { between } \\
\text { Units Lesson } \\
\text { (24 events; } \\
29 \text { student } \\
\text { actions) }\end{array}$ & $\begin{array}{c}\text { Area } \\
\text { Conservatio } \\
\mathbf{n} \\
\text { (7 events; } 9 \\
\text { student } \\
\text { actions) }\end{array}$ \\
\hline Drawing & 2 & 5 & 1 & 1 & 1 & 2 \\
\hline Statement & 0 & 1 & 0 & 0 & 7 & 1 \\
\hline Question & 0 & 0 & 0 & 1 & 0 & 0 \\
\hline $\begin{array}{r}\text { Length } \\
\text { Measurement } \\
\text { Strategy }\end{array}$ & 0 & 1 & 0 & 0 & 2 & 0 \\
\hline $\begin{array}{r}\text { Length } \\
\text { Counting } \\
\text { Strategy } \\
\end{array}$ & 0 & 0 & 2 & 0 & 0 & 0 \\
\hline $\begin{array}{r}\text { Area } \\
\text { Measurement } \\
\text { Strategy }\end{array}$ & 0 & 0 & 0 & 0 & 8 & 2 \\
\hline $\begin{array}{r}\text { Area } \\
\text { Counting } \\
\text { Strategy } \\
\end{array}$ & 3 & 2 & 0 & 4 & 4 & 1 \\
\hline $\begin{array}{r}\text { Area } \\
\text { Visualization }\end{array}$ & 0 & 1 & 1 & 2 & 2 & 2 \\
\hline $\begin{array}{l}\text { Building } \\
\text { Strategy }\end{array}$ & 0 & 0 & 0 & 0 & 0 & 1 \\
\hline $\begin{array}{r}\text { Student to } \\
\text { Student } \\
\text { Interaction }\end{array}$ & 0 & 0 & 0 & 0 & 3 & 0 \\
\hline Behavior & 0 & 0 & 2 & 0 & 0 & 0 \\
\hline $\begin{array}{r}\text { Language } \\
\text { Usage/Compr } \\
\text { ehension }\end{array}$ & 1 & 1 & 0 & 0 & 2 & 0 \\
\hline
\end{tabular}

Figure 23. Summary of all student actions Mrs. Purl noticed. Cells highlighted in grey indicate events that Mrs. Purl interpreted in terms of implications for instruction.

\section{Interviews: Events Noticed and Implications for Instruction}

Across the three student-teacher interviews, Mrs. Purl noticed 23 student actions within 19 events. Eighteen of the actions pertained to the strategies students used when solving interview tasks. The strategy she referred to most frequently involved students' drawings (44\%, 8 out of 18) and this was followed closely by area and length counting strategies (38\%, 7 out of 18). Mrs. Purl noted other strategies (length measurement and area visualization) and actions relating to students' behavior, language usage, and 
statements less frequently. Some of the interview tasks specifically directed students to draw, which could account for Mrs. Purl's attention to this particular type of event. As findings reported earlier in this chapter indicate, over the course of the interviews the number of events related to individual students increased and Mrs. Purl began to interpret students' actions in terms of their understandings. During the first interview, she did not say much about students except that they had a limited understanding of area. In the second and third interviews, Mrs. Purl commented on specific students' understanding of area and length, understanding of measurement vocabulary, and changes that she noticed in their thinking. She referred to students' actions in past interviews and sometimes expressed approval or disappointment with students based on their performance. In the case of Daisy, her focus was on the student's lack of improvement over the three interviews. However, her perception of the other interview students changed over the course of the study. Mrs. Purl came to realize that Liam was not as high performing as she initially thought. She also realized that Jose and Abby were able to respond to questions and extend their thinking in ways she did not know they could. Mrs. Purl stated:

Well, I think about the interviews in that mainly what I tried to do when I picked the students to interview trying to pick whom I thought was low, one that I thought was high, and two that were in the middle. And then I think honestly what happened was yes, my low is still my low but Liam is not quite where I thought he would be and I think the interviews helped to show that. Yes, he is always one that has the answer so he kind of appears to be better at math than he really is. Whereas Jose and Abby were nice surprises. I think that they caught on quickly 
and through the interviews picked up the concepts that I hoped they would pick up and can explain them fairly decently and apply them in other situations (Mrs.

Purl, December 19).

As highlighted in figure 23, Mrs. Purl discussed instructional implications for a variety of events. During the first interview, Mrs. Purl realized that students were not thinking about area in a sophisticated way so she proposed that she should challenge students by taking manipulatives away. After the second interview, Mrs. Purl realized that her students had trouble structuring a rectangular region, so she conjectured that she should have them investigate units of varying size in varying spaces as well as begin with a review unit. She also reminded herself to be mindful of the word choices she uses when posing problems. In Interview 3, Mrs. Purl reflected on students' growth through problem solving and concluded this was a worthwhile endeavor in her classroom. She also discussed that she needed to rethink easier tasks for students, like Daisy, who struggled.

In Mrs. Purl's final interview, she remarked that she constantly thought about students' thinking and hypothesized what they might be thinking, but she admitted that she thought about students differently in individual interviews than with regard to classroom instruction. When Mrs. Purl was asked to reflect on how her experiences interviewing students had informed her teaching practices, she explained that the interviews allowed her to learn more and challenge her conceptions about individual students. However, she reported that they had not served as formative assessments with regard to the entire class. 


\section{Instructional Unit: Events Noticed and Implications for Instruction}

During instruction, Mrs. Purl's noticed 46 student actions and attention to student strategies developed and became more diverse. Her attention shifted from drawing strategies (9\%) and became more focused on students' statements (17\%) as well as their strategies related to measurement, counting, and visualization of area (54\%). Mrs. Purl's classroom activities did not involve as many opportunities for drawing, which appears to be reflected in her shift in focus to other actions like dialog. With regard to area measurement and counting strategies, she noticed different ways in which students counted area such as counting individual units, counting rows and columns, and multiplicative properties. She also noticed how students structured space using available tools.

New actions also emerged within the classroom that were not present in the interviews. These themes included student-to-student interactions, questions, and building strategies. Mrs. Purl encouraged students to interact with each other and discuss concepts, so she was able to notice ideas through their interactions and their questions. This did not happen within the interviews because she interviewed students independently.

In the classroom setting, Mrs. Purl began to reference different facets of students' understanding not referenced within the interviews, and she became more attuned to subtleties in student's thinking. For example, instead of just discussing students' conceptions of area she discussed their conceptions of a square unit, structuring of units, and areas of square figures as well as how this related to their other mathematical 
understandings. She was able to expand more on what she thought students understood and the different ways in which they understood.

The classroom is a complex web of social interactions and Mrs. Purl's classroom highlights this. While describing understanding, Mrs. Purl also referenced personalities, past experiences, and past instruction throughout the instructional unit.

During the unit of instruction, Mrs. Purl initially focused on having students explain their thinking so she could understand more about their strategies. As the unit progressed, she developed tasks like using smaller units, partial units, and limiting manipulatives to challenge students' thinking and promote growth. Later in the lesson, she reflected on students' vocabulary and the importance of students understanding mathematical terminology. Mrs. Purl also reflected on her own teaching practices in relation to the unit of instruction that included letting students struggle and affirming the use of a math dictionary.

\section{Mrs. Purl's Perceptions of the Learning Trajectory Based Professional Development}

Underpinning this study is the learning trajectory itself and the learning trajectory professional development that Mrs. Purl was a part of. Throughout the study, Mrs. Purl discussed the strengths and weaknesses of the professional development as well as her ability and inability to relate to the learning trajectory document. Sometimes, Mrs. Purl would discuss these ideas spontaneously and other times I prompted her. In the following section, Mrs. Purl's perceptions of both the learning trajectory and the professional development are discussed below as well as instances that highlight these ideas from her teaching. Figure 24 highlights questions that Mrs. Purl was asked about the professional development and her responses are also summarized. 


\begin{tabular}{|c|c|}
\hline Questions Posed & Mrs. Purl's Response \\
\hline $\begin{array}{l}\text { In your opinion, what are } \\
\text { components of ineffective } \\
\text { professional development? }\end{array}$ & $\begin{array}{l}\text { - Sitting through the same professional development over and over } \\
\text { again. } \\
\text { It is relatable but it is not differentiated. I cannot always tell how it } \\
\text { relates to me and my teaching practices. } \\
\text { I don't get time to practice the information in the professional } \\
\text { development }\end{array}$ \\
\hline $\begin{array}{c}\text { In your opinion, what are } \\
\text { components of effective professional } \\
\text { development? }\end{array}$ & $\begin{array}{l}\text { - Time to stop, reflect, and say how does this relate to me as a teacher. } \\
\text { - } \quad \text { Time to discuss with other teachers. }\end{array}$ \\
\hline $\begin{array}{l}\text { What are components, if any, of this } \\
\text { professional development did you } \\
\text { feel transitioned well into your } \\
\text { classroom? }\end{array}$ & $\begin{array}{ll} & \text { Group planning } \\
\text { - } & \text { Thinking about development phases in students' reasoning } \\
\text { - } & \text { Tasks, videos of students working on tasks } \\
\end{array}$ \\
\hline $\begin{array}{l}\text { What are components, if any, of this } \\
\text { professional development did you } \\
\text { feel did not transition well into your } \\
\text { classroom? }\end{array}$ & $\begin{array}{l}\text { - Anticipation of what students might do during a lesson and possible } \\
\text { misconceptions } \\
\text { - } \quad \text { How do we assess and instruct simultaneously? } \\
\text { - Span of thinking in older classrooms is too wide and difficult to keep } \\
\text { track of. }\end{array}$ \\
\hline $\begin{array}{l}\text { If you could design a PD, what } \\
\text { would it entail? }\end{array}$ & $\begin{array}{l}\text { - } \quad \text { Hands-on, multiple experiences for teachers to keep us engaged. } \\
\text { - } \quad \text { Time for dialogue with colleagues }\end{array}$ \\
\hline $\begin{array}{l}\text { What role do you feel that the } \\
\text { learning trajectory played in your } \\
\text { lesson planning process? }\end{array}$ & $\begin{array}{l}\text { Interviews helped to identify possible misconceptions but did not } \\
\text { highlight everything } \\
\text { - } \quad \text { Help to gauge where to introduce a lesson topic }\end{array}$ \\
\hline $\begin{array}{l}\text { What do you see as weaknesses, if } \\
\text { any, of the current trajectory } \\
\text { document? }\end{array}$ & $\begin{array}{l}\text { - } \quad \text { Higher levels need to be articulated. } \\
\text { Differences in perspective. It takes time to see and understand what } \\
\text { students are doing }\end{array}$ \\
\hline $\begin{array}{l}\text { How would you amend the current } \\
\text { document to make it easier for you } \\
\text { to use? }\end{array}$ & 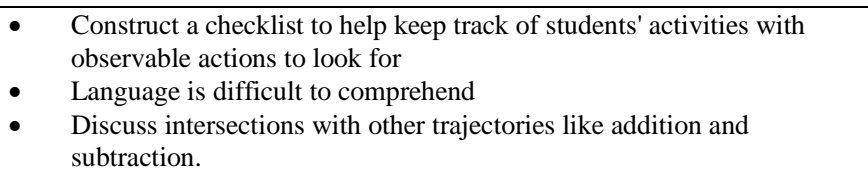 \\
\hline $\begin{array}{l}\text { What do you see as strengths, if any, } \\
\text { of the current trajectory document? }\end{array}$ & $\begin{array}{l}\text { - Help students, especially those who have fallen behind, understand a } \\
\text { topic. }\end{array}$ \\
\hline
\end{tabular}

Figure 24. Mrs. Purl professional development questions.

\section{Perceived Strengths of the Professional Development}

Because of Mrs. Purl's pre-kindergarten experiences, she embraced many aspects

of learning trajectory based instruction. This included taking qualitative notes rather than

quantitative measures, keep tracking of thinking over time, and posing tasks in multiple

ways. 
A pre-kindergarten perspective. Following the first interview, as Mrs. Purl was asked to reflect on students' thinking, Mrs. Purl reflected about the trajectory, unprompted, within our interview. When asked to reflect on students' thinking. Mrs. Purl described how she envisioned using the learning trajectory. She stated that it would be similar to her experiences as a pre-K teacher taking anecdotal notes and this is why she liked it. She stated that some of the ideas from the professional development had caused her to think about her past teaching practices and how she could implement them in the fourth-grade classroom. She stated,

I like that you are thinking about student thinking because that is what I got to do in preschool. I felt like we were always looking at how they were learning, what they were learning what the knew, broken down into, because when you have multi-age group you are supposed to access a multi-age group you have to know what the developmental sequence is. You are looking at well they are five years old but their pre-literacy skills are that of a two-year old. So we were always looking for that. It has been interesting trying to do that in this world (Mrs. Purl, September 28).

Mrs. Purl experienced tension between implementing these ideas and the realities of her classroom. She discussed several times that, even though she had done something similar with preschool children, this was much more difficult to do with fourth-grade students. She described that this process is tenuous and difficult to plan and accomplish with over 20 children. For example, after the first set of interviews, she believed that trajectory levels would be most useful in describing students below grade level to help with accommodations. She stated, 
I have been thinking about that question because when I taught early childhood and I was telling you a little bit about the assessment they use there. I think that truly that would be the only way that I would really get deep into thinking about their trajectory level before doing any planning. Because with that it was every three weeks you need to pencil mark where you thought they were developmentally in all areas. Whereas with this the trajectory level is nice, but I think I see myself using it with a child, not at grade level...as far as planning, I guess I probably didn't look at the specific area of the trajectory and say ok there here I need to move them here cause there is just so many (kids) and how do you do that with 20, 21 kids. Maybe aim for the middle of the road and make sure if there is a bunch on the lower end then you address that first and then try to move forward? I don’t know? (Mrs. Purl, September 28).

Task design. Mrs. Purl discussed that one piece of the professional development that she found invaluable were the tasks presented at different levels of the trajectory. She liked seeing what students would do, but the tasks gave her a different way to address a topic. Given new tasks, she could assess students' understanding in different ways to reveal misconceptions that might not have arisen with past tasks. She reflected specifically on the broken ruler task and stated,

Mrs. Purl: I liked seeing, um, I liked seeing the actual activities like I never would have thought about doing a broken ruler task. I measure that way at home. You know like if I can't scoot the ruler as far as I need to, I'll measure from two to eight to get six but I never thought like oh duh that is probably something you 
should use so that you know that a child has a good understanding of how to measure. Um, so I liked those different things that I hadn't thought about Megan: And how do you feel like you have transitioned that into your own classroom?

Mrs. Purl: Well, um, just in thinking about different ways to present tasks not just going with maybe the first idea that you come up with I guess. Um, to try to think of a different way to present it or. I am having a difficult time trying to figure out how to say it. You know, not just going with the standard way to present (Mrs. Purl, December 19).

Mrs. Purl was also asked during the interview what pieces of the professional development she found valuable or transitioned well into her classroom. The two key ideas that Mrs. Purl reflected upon were the roles of reflection and collaboration

Reflection. Mrs. Purl commented that reflection was one of the key philosophies that she embraced from the professional development and that it is a factor in how what she learns is implemented into the classroom. She stated that for the most part, teachers are asked to implement new teaching strategies without seeing them or having time to practice and reflect. She enjoyed this process because she was given time to think and reflect on ideas. She stated,

Mrs. Purl: Well some of it is the issue that I don't get an opportunity to actually practice it right then and there

Megan: Okay, during the PD?

Mrs. Purl: During the PD or given time to reflect upon it to make it meaningful to me and how it relates to my own teaching practice. It is kind of like we push 
right up to the last second and then okay now go and you jump right into setting up the day. There is not time to stop and go "oh okay."

Megan: How does this relate to me?

Mrs. Purl: Right! That is part of the problem.

Discussion and reflection with teachers. Mrs. Purl also reflected on the relationship that developed between her and Mrs. Grey through the process. She valued being able to discuss lessons with Mrs. Grey as well as other teachers. Mrs. Purl found that by discussing student thinking on a daily basis with another teacher she was able to work through glitches in instruction and have a sounding board for ideas. Mrs. Purl thought that was it was reassuring to have another person going through the same experiences and helping to inform instructional decisions. She stated,

And that would be the other piece that I loved about this is that Mrs. Grey and I have been talking back and forth about what did your students do today and what did mine do. You know how did they respond to it. That is typically not something that we had done this year with any other unit even though we all do the same thing (Mrs. Purl, December 19).

In addition, Mrs. Purl valued being able to see other teachers in the professional development teach. After watching a lesson she was able to think about how she might modify or add to the lesson to make it more suitable to her students. Mrs. Purl discussed how important it is for professional development to be tested and for her to have time to use and think about ideas presented in relation to herself and other teachers. 


\section{Perceived Difficulties of the Professional Development.}

Even though there were many concepts from the learning trajectory based professional development that Mrs. Purl adopted, she also voiced difficulties in evaluating and thinking about students' thinking on a daily basis. These difficulties included anticipating students' actions, the role of interviews, monitoring students, using the trajectory in its current form, the language of the trajectory, and using a tool meant for assessment as an instructional tool.

Anticipation. Mrs. Purl commented that she valued the idea of anticipation but it was also the most difficult for her to enact. Even though she understood anticipation is important, it was difficult for her to anticipate how students might solve problems and take the time to write down ideas before instruction. She commented on this in the transcript below.

Mrs. Purl: Well just getting to being able to truly, and I wrote it in my professional growth plans, reflect beforehand, what the misconceptions would be, like actually writing it, getting it on paper.

Megan: Okay, okay.

Mrs. Purl: Like, you know, I kind of try to think oh, but I didn't write it down, you know? I think it is taking the time to actually record it, is harder to transition into the classroom (Mrs. Purl, December 19).

Interview and classroom connection. In relation to anticipation, when Mrs. Purl was asked in her final interview how the interviews informed her lessons, she said that they gave her a basic idea of what to expect but definitely did not prepare her for everything. She stated that they helped to highlight common misconceptions but it was 
difficult to use the information to tailor her lesson planning. She still struggled with how she could get to know all of her students and plan according to all of their thinking. The interviews gave her a vague entry point into the lesson.

Monitoring students' thinking. In relation to thinking about students, Mrs. Purl reflected on her unnoticed students. She realized, through the process that some students were noticed more than others and some students were hardly ever noticed. Specifically, she realized that she hardly ever called on her higher-level students and frequently called on Abby. She reflected that Abby often posed good ideas that the rest of the class could easily relate to and understand so this is why she thought she called on her so often.

Language. Even though Mrs. Purl was able to identify important events and discuss thinking at a range of levels, the technical language of the trajectory never really emerged in our daily interviews. To account for not using this language, Mrs. Purl often puts things in her own words. For example, in the excerpt below, Mrs. Purl described why she thinks a student, Jack, needs to use rulers to mark rows and columns.

Looking back at this now it is interesting that he has kept this concept of having to use these rulers the whole time. Like he hasn't deviated from it, even when the next day they saw that they had to touch he still kept with it. So if I had to either add terminology to the trajectory so that teachers would understand I would probably have to say that this would put him lower on the trajectory because he visually has to see the squares (square units) (Mrs. Purl, December 18). At one point, Mrs. Purl compared the language of the trajectory to her experiences learning Spanish. She stated that initially learning a language sounds much like just sounds, but with more exposure she could hear syllables and words. To her, learning the 
trajectory, in its current form is much like hearing Spanish for the first time. Mrs. Purl viewed the trajectory as a tool that takes time and practice to learn and the language is not necessarily intuitive.

During our interviews, Mrs. Purl often gave suggestions or ideas to about how she would change the trajectory to make it better or more user-friendly. One suggestion that arose numerous times was a checklist. Mrs. Purl felt that the current trajectory is too cumbersome for classroom use especially when trying to observe and monitor twenty children. Mrs. Purl related to the idea of the trajectory from her experience as a pre-K teacher, but she thought that if a checklist with observable skills was created that this would make the trajectory more accessible to teachers and easier to use and understand. The excerpt below illustrates these ideas.

Mrs. Purl: Well I think just the time to actually look at where they are at. To use the trajectory as a teacher to figure out where they are at you need to be able to step back and watch them do the activities, then you have to have the tool there, so either you have a checklist of observable skills um like if I were to design it like across the top there would be um can measure, measures with a ruler starting at 0 , understands that ...you know you would have the observable skills?

Megan: Like benchmarks?

Mrs. Purl: Yeah and observable skills where as the trajectory is still kind of written in "doctorese."

Megan: Research jargon?

Mrs. Purl: Yeah, you white coat people (Mrs. Purl, December 19). 
Even though Mrs. Purl embraced the overall philosophy of reflecting upon and understanding students' thinking there were several components that were difficult or took time for her to enact.

\section{My Perspective and Interpretation of Mrs. Purl}

While working with and observing Mrs. Purl over the course of the study, I was able to reflect on concepts and ideas that perhaps Mrs. Purl did not mention. Within this section, I will discuss my interpretation, from my notes, of Mrs. Purl's interviews, classroom instruction, and perceptions and use of the learning trajectory.

Even though it was Mrs. Purl's first year within the professional development, she embraced the ideas presented without hesitation. I observed, through interviews and classroom observations, that Mrs. Purl valued the ideas presented within the professional development because she, herself, had come from the pre-K world. The ideas of developmental progressions and describing students using qualitative notes were concepts that Mrs. Purl had seen and implemented before. She embraced the idea of trying to integrate these ideas into her own teaching practices such as keeping qualitative notes of students' actions in different subfolders.

\section{Student Interviews}

For Mrs. Purl, the student interviews did not entirely serve as formative assessment as I thought they would. Instead, Mrs. Purl used the interviews as a means to get to know individual students. Through the interviews she noted that she was able to question expectations and notions that she had about particular students. For instance, she realized that she should not be quick to label students as higher or lower based on their 
actions in class. After getting to know students through interviews, she saw that some of her students knew more than she initially thought.

The first interview helped Mrs. Purl to gauge that structuring units might be difficult for students, but, following that, there were relatively few ideas that Mrs. Purl drew from the interviews that informed her instruction.

Even though Mrs. Purl embraced the idea that students think at varying levels and could attempt a task in multiple ways, she did not reference the learning trajectory while analyzing students' thinking or actions. She also did not reference the document in determining how to integrate what she observed into instruction.

\section{Classroom Instruction and Role of the Professional Development}

Within daily classroom practices, Mrs. Purl was able to notice, understand, and respond to students' thinking in a variety of ways. Since Mrs. Purl already had similar experiences within the pre-school classroom, I believe it was easier for her to observe and respond to students' thinking and details in their strategies. I also think that Mrs. Purl's focus on group discussion allowed her to notice students' thinking through means such as questions, statements, and student-to-student interactions.

Even though Mrs. Purl noticed many actions and reflected on them, she rarely referenced the learning trajectory to determine her instructional practices. She relied on her own intuitions and understanding she had developed from summer professional development to determine what might be appropriate to challenge students.

As Mrs. Purl tried to make sense of students' thinking and apply it to instruction, I noticed two themes emerge. These themes included bridging assessment and instruction as well as developing her own learning trajectory. 
Creating her own trajectory. During classroom instruction, Mrs. Purl often came across student behaviors that were related to area measurement but it was not clear exactly how they fit in relation to the levels of the trajectory. Instead of pinning students to one level of the trajectory or another, Mrs. Purl brainstormed about how different ways of thinking might fit together, including future levels of the learning trajectory. She noted them and then wondered where they would fit within the trajectory. One concept that arose that Mrs. Purl wanted to explore more about was the children's understanding of a square. Even though the students knew that a square would have equal sides they were often comfortable with expressing the sides as two drastically different lengths when measuring. This puzzled Mrs. Purl and she wondered how it would fit into the trajectory and what would come next. She stated:

Okay, I would be interested to know if some of the next understanding is that they understand that you have to use a shape that is square to measure square units or that if you did non-standard units that if this side is four and that side is four of whatever that you have made a square. (Mrs. Purl, December 19)

Mrs. Purl also wondered how different trajectories might inform one another and how levels might interact with one another. She wondered specifically if students' understanding of the four operations might affect their understanding of measurement topics. She stated, "Yeah and some of what we are doing lends itself to the addition and subtraction trajectories in relation to measurement. So you know they kind of cross multiple trajectories at the same time" (Mrs. Purl, December 19). In many ways, Mrs. Purl thought beyond the document itself to understand students' thinking. 
Even though Mrs. Purl rarely referenced the learning trajectory in her own teaching practices, she understood the idea of it. She realized that students think about topics in varying ways and questioned her students thinking in this way.

Assessment versus instruction. Another idea that surfaced throughout our conversations on students' thinking was how to use the trajectory as an instructional tool. Based on her statements, Mrs. Purl valued the learning trajectory as a way to assess students and to think about the process of their thinking. Mrs. Purl and Mrs. Grey developed an assessment for the entire classroom to help them think about students' thinking and their progress. Mrs. Purl commented that it was difficult to design assessments that reflect a span of student thinking while still recording correct versus incorrect. This was something that she continually worked to understand with regard to the learning trajectory. Below is her description of the assessment

This assessment, you know we are not looking for the right answer we are looking for what like how they solved it and then putting them on the trajectory based off of that. So their test grade would be more I think what we had talked about was if their test grade was at where they should be at in the trajectory... I didn't want to penalize them if they couldn't do the math correctly but we kind of wanted to see where they were at. We wanted to give them credit for their thinking not just the right answer (Mrs. Purl, December 17).

Even though Mrs. Purl thought about the process of how students learn, she was still confused about how assessing the students should relate to her instruction. At the end of the first unit, she realized that her students were learning about area, but she never formally introduced the formula to find area. She wondered how the formula should 
relate to the hands-on tasks that the students have done and whether she can leave the unit without ever directly instructing them to use the formula.

Mrs. Purl: That is what Mrs. Grey and I talked about and we both realized, now wait a minute, we didn't introduce the formula to them. We did all the stuff with area and then we were like ooo we need to tie this too

Megan: The formula?

Mrs. Purl: Right so tying the hands-on information that we learned with actual formulas or like the route

Megan: Get back, like tie the two together?

Mrs. Purl: Or when is it appropriate to? Because for me yeah it should be driven by hands-on but at what point do you introduce now here's the foundational knowledge you need now here's the that's how it works (Mrs. Purl, December 17).

In is evident in this excerpt that Mrs. Purl did not think the hands-on activities were enough to solidify students' understanding of area. She wondered if they needed an affirmation from the teacher of exactly what they were doing and why.

Overall, it seemed that Mrs. Purl valued the philosophy of learning trajectories, the idea that students think about topics at varying levels. Because of her background as a pre-K teacher, she understood the idea of students' understanding growing across time and monitoring observable indicators of growth. She struggled with being detailed and referencing the trajectory to determine where students might be in their thinking and where to go next. For instruction, she relied on herself and her own intuitions. 


\section{CHAPTER VI}

\section{MRS. BROWNSTEIN}

\section{Description of Mrs. Brownstein and Her Classroom}

At the time of the study, Mrs. Brownstein was a fifth-grade teacher at Terrace Elementary School. Mrs. Brownstein had 18 years of teaching experience, but this was her first year teaching fifth-grade mathematics and science. Prior to teaching fifth grade, Mrs. Brownstein had primarily taught third-grade. Mrs. Brownstein held a Master's degree and had endorsements in science, social studies, reading, and language arts. She was also considered a highly qualified teacher.

Mrs. Brownstein taught several classes a day to different groups of fifth and sixth grade students. For fifth grade, she taught two math classes per day. This study focused on the group of fifth-graders that Mrs. Brownstein taught in the morning. The demographics of this class matched the typical demographics of Terrace Elementary. There were 22 students in Mrs. Brownstein's classroom. There were seven girls and 16 boys. Of the students, 18 were Black and four were White.

Mrs. Brownstein's classroom was in the center of the school. She had three sets of windows that overlooked a courtyard. Mrs. Brownstein's classroom was long and narrow. She had students arranged in groups at long tables. There were six tables, two tables by three tables, with three to four students at each table. Mrs. Brownstein's desk was in the corner 
of the classroom along with a semi-circle table and supply table. On the other side of the classroom, there was a student computer workstation as well as a desk for the special education teacher with whom Mrs. Brownstein shared her room. Mrs. Brownstein's walls, like the other teachers, were covered with posters of formulas and definitions that students referenced during standardized testing.

Mrs. Brownstein encouraged discussion between students during classroom instruction. She asked students to present, discuss, and question ideas, but to also remain on task and focused. She typically had students work together in groups to solve problems and then present their solutions for the class. As students presented, Mrs. Brownstein questioned them and also had them write down notes. On a typical day, Mrs. Brownstein's classroom was usually active in discussion or listening to different groups present for most of the class period.

Since Mrs. Brownstein was the only fifth-grade math teacher, she did all of her planning independently. This year was her first teaching fifth grade, so she experimented with different activities and supplements to see how they went.

\section{School Year Events}

In this section, I discuss activities that Mrs. Brownstein participated in as part of the study. These activities included three student-teacher interviews as well as a volume measurement unit composed of several sets of lessons and an assessment. Events that Mrs. Brownstein indicated as important are described as well as student understanding and implications for instruction.

It is important to note that Mrs. Brownstein wanted to use the volume learning trajectory for her fifth-grade unit. Mrs. Brownstein had two weeks of intense professional 
development focused on the length and area learning trajectories in the summer of 2012, but she only had one to two days of experience working with and examining the volume learning trajectory.

Mrs. Brownstein chose four students from her classroom to interview, Xavier, a white male, Keron, a black male, Ali, a white female, and Mariah, a black female. Mrs. Brownstein said that she picked the four students to represent varying levels of thinking within her classroom. She stated, "I talked to some of the ladies who were in it (the professional development) from last year and they said to pick medium, high, and low, so I knew Xavier would be high and I thought Keron would be in the middle. Ali and Mariah I wasn't so sure. I knew they would fall somewhere between middle and low" (Mrs. Brownstein, September 13). Mrs. Brownstein also picked these four students because she knew that they could work well with one another. She wanted them to be together at the same table so that she could observe them more easily.

The interview tasks Mrs. Brownstein used throughout the three sets of interviews are presented in Figure 25.

\section{Interview 1}

The first interview took place in early September of the school year. Mrs. Brownstein worked with four students for about 40 minutes each in the school office and administered each of the tasks described below to students. Mrs. Brownstein used a variety of interview tasks related to area measurement. Her goals were to see how students thought about structuring area units, the unit itself, and how they compared different regions. Each task is shown below along with the prompt that Mrs. Brownstein posed. 


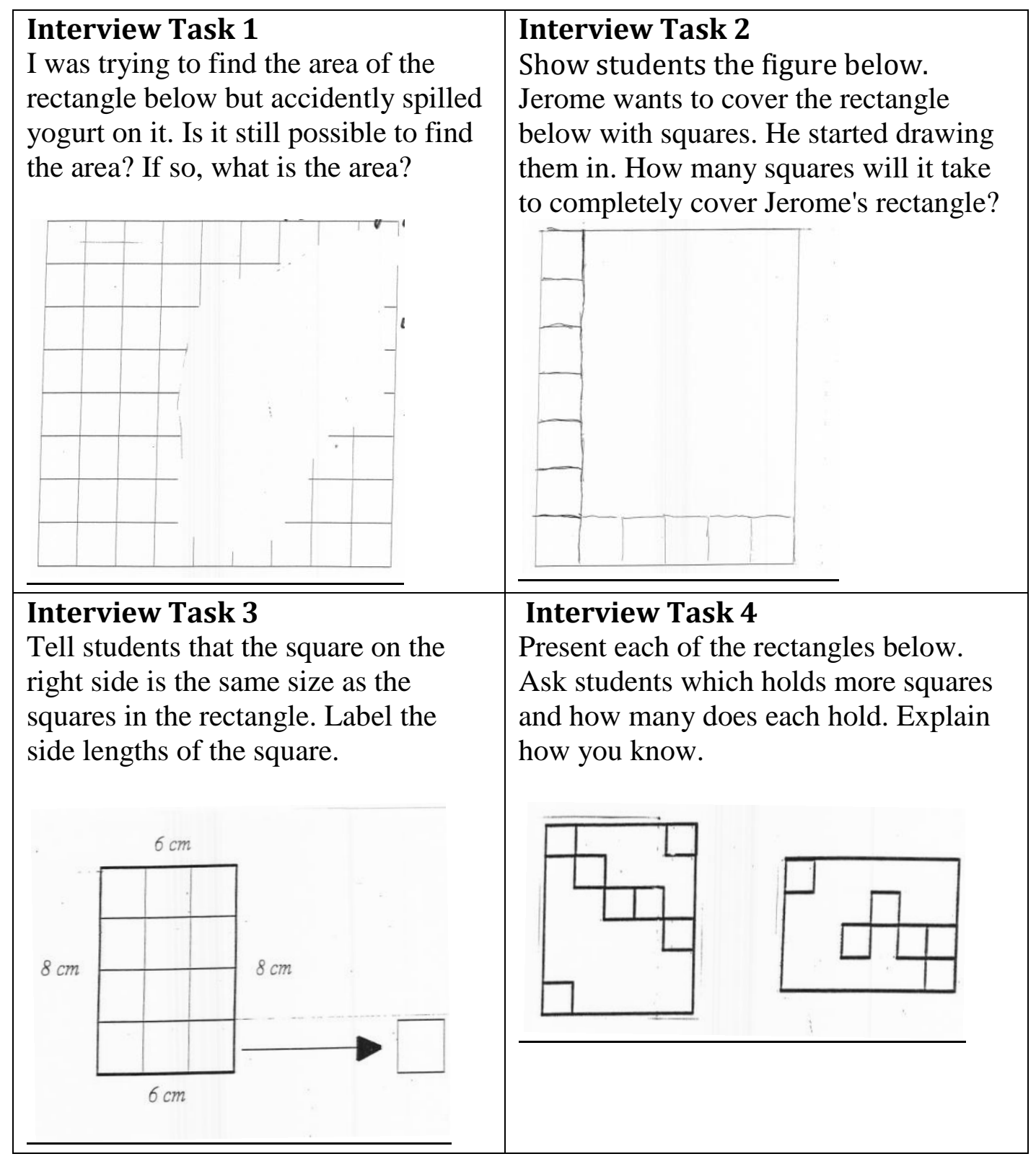

Figure 25. Mrs. Brownstein interview tasks.

What Mrs. Brownstein Noticed. Mrs. Brownstein noticed 11 events (as shown in Figure 26) that she found to be important in the first interview. She referenced individual students six times and two or more students five times. Of these events, she discussed students' understandings for all 11 events but did not form any implications for 
instruction. Most of the events that Mrs. Brownstein discussed involved drawing and

\section{counting area units and area visualization to compare areas or find a unit size.}

\begin{tabular}{|c|c|c|c|}
\hline \multicolumn{4}{|c|}{ Interview 1: September } \\
\hline What the Teacher Noticed & Interpreted Understanding & $\begin{array}{c}\text { Implications for } \\
\text { Instruction }\end{array}$ & Significance \\
\hline \multicolumn{4}{|c|}{ Spilled Yogurt Task/Tiling Tasks } \\
\hline $\begin{array}{l}\text { Area Visualization: It was hard for him } \\
\text { to see where all the area units are going } \\
\text { to line up so he didn't even want to mark } \\
\text { them in. (Keron) }\end{array}$ & He can't see the units. & (none provided) & $\begin{array}{l}\text { (none } \\
\text { provided) }\end{array}$ \\
\hline $\begin{array}{l}\text { Drawing Strategy/ Area Counting } \\
\text { Strategy: Drew rows and columns but } \\
\text { then carefully counted every square. } \\
\text { (Ali) }\end{array}$ & $\begin{array}{l}\text { Understands structuring of square } \\
\text { units. }\end{array}$ & (none provided) & $\begin{array}{l}\text { (none } \\
\text { provided) }\end{array}$ \\
\hline $\begin{array}{l}\text { Drawing Strategy: For several of the } \\
\text { tiling tasks, students drew in individual } \\
\text { units and did not see row and column } \\
\text { structure. (all students) }\end{array}$ & $\begin{array}{l}\text { She feels that their understanding } \\
\text { conflicts. They can skip count by } 3 \text {, } \\
\text { so why can't they count the area by } \\
\text { columns of three. }\end{array}$ & (none provided) & $\begin{array}{l}\text { Surprised they } \\
\text { were counting } \\
\text { every single } \\
\text { unit. }\end{array}$ \\
\hline $\begin{array}{l}\text { Drawing Strategy/ Area Visualization: } \\
\text { Students drew in individual units and } \\
\text { could not see the row and column } \\
\text { structure in a small rectangle }(3 \times 6) \text {. } \\
\text { (Three interview students) }\end{array}$ & $\begin{array}{l}\text { Students are seeing area as } \\
\text { individual pieces instead of rows and } \\
\text { columns. }\end{array}$ & (none provided) & $\begin{array}{c}\text { (none } \\
\text { provided) }\end{array}$ \\
\hline $\begin{array}{l}\text { Drawing Strategy/Area Visualization: } \\
\text { Ali and Mariah had to draw in each } \\
\text { individual square when looking at a } \\
\text { partially tiled rectangle but Keron could } \\
\text { see the missing squares. (Keron, Ali, and } \\
\text { Mariah) }\end{array}$ & $\begin{array}{l}\text { Keron could see where the missing } \\
\text { squares might go but the two girls } \\
\text { felt that they had to draw in each } \\
\text { square. }\end{array}$ & (none provided) & $\begin{array}{c}\text { (none } \\
\text { provided) }\end{array}$ \\
\hline $\begin{array}{l}\text { Drawing Strategy/Area Counting } \\
\text { Strategy: When tiling the } 6 \times 7 \text { rectangle, } \\
\text { he added an extra square unit that didn't } \\
\text { belong to the second to last column. He } \\
\text { was making dots but not actually } \\
\text { drawing in the squares to keep track. } \\
\text { (Keron) }\end{array}$ & $\begin{array}{l}\text { The big open space was confusing } \\
\text { him because he couldn't see the } \\
\text { squares. }\end{array}$ & (none provided) & $\begin{array}{c}\text { (none } \\
\text { provided) }\end{array}$ \\
\hline $\begin{array}{l}\text { Area Counting Strategy: Skip Counting } \\
\text { during some problems. (Ali) }\end{array}$ & $\begin{array}{l}\text { Row and column structurer because } \\
\text { she sees rows as rows and columns } \\
\text { as columns. }\end{array}$ & (none provided) & $\begin{array}{c}\text { (none } \\
\text { provided) }\end{array}$ \\
\hline $\begin{array}{l}\text { Area Counting Strategy/Drawing } \\
\text { Strategy/Area Visualization: Drawing } \\
\text { and counting but not seeing rows as rows } \\
\text { (she put in one extra little teeny row). } \\
\text { (Mariah) }\end{array}$ & Partial Row Structurers. & (none provided) & $\begin{array}{c}\text { (none } \\
\text { provided) }\end{array}$ \\
\hline $\begin{array}{l}\text { Area Counting Strategy: Multiplied to } \\
\text { find the area. (Xavier) }\end{array}$ & $\begin{array}{l}\text { Linear Measures: understands that } \\
\text { each row can be used as a multiple. }\end{array}$ & (none provided) & $\begin{array}{c}\text { (none } \\
\text { provided) }\end{array}$ \\
\hline \multicolumn{4}{|c|}{ Comparing Rectangular Regions Task } \\
\hline $\begin{array}{l}\text { Area Measurement Strategy: When } \\
\text { comparing two different rectangular } \\
\text { regions, the students matched up one the } \\
\text { lengths to determine which rectangle had } \\
\text { a larger area. (All students) }\end{array}$ & $\begin{array}{l}\text { Intuitively knew which one was } \\
\text { bigger and the task was not as } \\
\text { difficult as she thought it would be. }\end{array}$ & (none provided) & $\begin{array}{c}\text { (none } \\
\text { provided) }\end{array}$ \\
\hline \multicolumn{4}{|c|}{ Unit Square Task } \\
\hline $\begin{array}{l}\text { Length Counting Strategy: } \\
\text { Determining the side length of a unit } \\
\text { square, given the side lengths of the } \\
\text { rectangle, was difficult for all students. } \\
\text { (All students specifically Xavier) }\end{array}$ & $\begin{array}{l}\text { Thinking about multiples of two is } \\
\text { not that hard but they are not seeing } \\
\text { this one tile or square as being able } \\
\text { to be more than one of something. }\end{array}$ & (none provided) & $\begin{array}{c}\text { (none } \\
\text { provided) }\end{array}$ \\
\hline
\end{tabular}

Figure 26. Events that Mrs. Brownstein noticed during Interview 1. Events highlighted in gray had instructional implications. 
Drawing and counting square units. Eight of Mrs. Brownstein's events related to students tiling and counting the area of a rectangular region. Mrs. Brownstein commented overall that she was very surprised by students drawing and counting strategies. For the first month of school, students had practiced skip counting using arrays as a visual reminder. Mrs. Brownstein commented that, even though students were practicing with arrays, they did not connect this knowledge to the interview tasks. With regard to tiling and counting, Mrs. Brownstein primarily discussed the spilled yogurt problem and the $6 \mathrm{x}$ 7 rectangle problem.

Mrs. Brownstein discussed that the spilled yogurt problem was the first problem that she posed to all her students. The purpose of the spilled yogurt problem was for her to see if students had an idea of row and column structure or if they would draw in each unit individually. Mrs. Brownstein stated that she was surprised by Keron's response when she posed this task. Instead of trying the problem, Keron stated that it was not possible and did not even attempt to draw units in. Mrs. Brownstein stated, "Maybe it is because it was so hard to kind of see where all of these are going to line up (area units) that he didn't even want to try to mark them in?" (Mrs. Brownstein, September 13).

In contrast to Keron, Mrs. Brownstein discussed that another student, Ali, could draw in square units for all of the tasks she posed. Ali was able to draw in rows and columns but would count each individual square. Mrs. Brownstein commented that she should have posed harder questions to Ali since she was able to answer the yogurt question so readily. She stated, "Then I realized with Ali that I was having her do too much of that maybe? Because once she had shown that she knew to fill in the rows and 
the columns and she was counting every single unit I probably should have gone to a harder task" (Mrs. Brownstein, September 13).

In the $6 \times 7$ rectangle task, Mrs. Brownstein was surprised that students seemed to become lost when tiling the center of the rectangle. Many of the students did not attend to rows and columns and freely counted where they thought squares would go. She discussed one student, Keron, specifically. She stated,

He kept like adding an extra one in the second to last column. And we were discussing maybe this big open space was confusing him because he couldn't see the squares as much with that big open space. Because he did that on the second to last row and maybe he was just losing track. But you know he was making the dots, he wasn't actually drawing in each one, each square. He was making a dot where each one (square) would be, but again not seeing the rows and the columns at all. I was really surprised by that (Mrs. Brownstein, September 13).

Overall, it seemed that many of the tasks surprised Mrs. Brownstein because students' were not seeing row and column structure.

Area visualization. In four of the events, Mrs. Brownstein discussed students' visualization of area. Mrs. Brownstein asked students to compare a rectangular region composed of five units by six units to a rectangular region composed of four units by five units. Mrs. Brownstein commented that she thought this task would take time for students to complete and required much thought. She, noticed, after the first interview, that most of the students compared the widths of the rectangles, without comparing the lengths, and stated the 5 unit by 6 unit rectangle was larger. She stated, "They could see it automatically which one was bigger, but it was interesting how some of them were just 
matching this length up with that length and saying well that's bigger. They weren't even seeing that it (the rectangle) was turned" (Mrs. Brownstein, September 13). Mrs. Brownstein did not expect the students to be able to solve this problem so quickly and easily.

After asking students which rectangle was larger, Mrs. Brownstein asked them to find the total number of square units in each rectangle. She commented that she thought Keron was able to visualize the missing squares, but Ali and Mariah had to draw each square in to find the total. She stated, "He (Keron) was at least able to see the missing pieces, but I don't know if he saw the whole missing row. Rather than Mariah and Ali who felt like they had to draw in each square and I am not sure what they saw on this one if I asked them"(Mrs. Brownstein, September 13).

Length counting strategy. Mrs. Brownstein noticed a length counting strategy for one task for which students were asked to find the length of 2-inch square, given the side lengths. Mrs. Brownstein noticed that this task was difficult for all students, and they could not attempt it. She expected them to be able to see based on the rows and columns that each unit would measure two inches by two inches. She was surprised especially by her student Xavier that she thought was a higher student and just used what he knew about rows and columns. She stated,

Well they have to think in terms of more than one. They have to think in the twos a multiple of two. Which you wouldn't think would be very hard. You would think it would be almost innate, two, four, six, eight, and put a two on that. But I guess they are not seeing this one tile or square as being able to be more than one of something. I was really surprised with Xavier that he was mixed up. I thought 
that he would just use his rows and columns and know (Mrs. Brownstein, September 13).

Interpreted understanding. Mrs. Brownstein was able to discuss students' thinking and reasoning, sometimes in great depth, for all of the 11 events noted. Mrs. Brownstein primarily discussed how students saw units and structuring of area but also discussed students' past and personality as well as how she felt their thinking related to levels in the learning trajectory.

Seeing area as individual units. Almost all of Mrs. Brownstein's comments on students' understanding focused on their knowledge of a unit versus knowledge of rows and columns. Mrs. Brownstein expected her interview students to see area as a structure of rows and columns even though she had learned about multiple levels of thinking during professional development. Her expectations were challenged and she reflected that this process had been rather shocking for her. She stated,

Well, the learning trajectory for me has been almost shocking because I thought all fifth-graders would have or would find it rather easy to see rows and columns and to also be able to skip count. So the trajectory has been very interesting for me to see this progression of how they start out not even understanding how to cover the area. I guess it seems shocking that there is so much behind something that seems so simple like area. That there can be so many different ways that kids don't see it or that they do see it (Mrs. Brownstein, September 13).

In many of Mrs. Brownstein's comments about students understanding, she highlighted that students understand or see area as individual units rather than rows or columns. This was particularly surprising to her because students spent the first three 
weeks reviewing skip counting. Mrs. Brownstein thought that for problems like tiling the $3 \times 6$ rectangle or even the $6 \times 7$ rectangle that students might skip count across and intuitively see the rows or columns. When students had to draw in every unit, she began to see that they are not associated skip counting with area and have to see and draw in every square. She stated,

I think they are still seeing area as individual pieces rather than rows or columns. Which as I said, in here when they are doing arrays, up until this point I would have thought that all three of these kids would use some of what we have done here in class with arrays to extrapolate a little into the interview questions. And I don't think I saw it all with these three, so that was really surprising to me. We have worked on that for three weeks, we haven't done it every day, but they have seen it a variety of times (Mrs. Brownstein, September 13).

Lastly, Mrs. Brownstein described that she thought her students could not see a square unit as more than 1 of something. This was apparent in the task where Mrs. Brownstein asked students to find the length of the unit square. Students had great difficulty determining what the square length should be given the length and width of the rectangle.

Overall, Mrs. Brownstein was very surprised that fifth-grade students did not see row and column structure and focused so much on the unit square. She thought that the tasks she posed would be relatively easy for students to solve and not have to count each unit. 
Personality and past experiences. For one of the events, Mrs. Brownstein discussed the student's personality. When Keron was unable to draw in units for the spilled yogurt task, Mrs. Brownstein was surprised because she considered him a good student. She stated that maybe it was because he was nervous in the interview setting or because he did not want to get the answer wrong. She stated, "he was a little nervous and he tends to be a little nervous anyway. He doesn't want to get the wrong answer. He doesn't want to look dumb" (Mrs. Brownstein, September 13). This was the only time that Mrs. Brownstein referenced a students' past or their experiences in relation to performance on task.

Students are at varying levels in the trajectory. At the end of our discussion, Mrs. Brownstein discussed what levels of the trajectory she placed each of the students in and why. This was a piece of Mrs. Brownstein's reflection and she wanted to tell me what she had written. Mrs. Brownstein read off varying levels and discussed whom she thought would represent that level and why. She discussed that Ali might be a row and column structurer because she skip counted on some of the tasks. She stated,

Now it says for row and column structurers that they draw and count rows as rows and columns as columns but it also says that they count the number of squares and can iterate them. So if they were doing skip counting, like Ali was doing some skip counting on the smaller one, would that allow her to be in that trajectory? I don't know. (Mrs. Brownstein, September 13)

Mrs. Brownstein is unsure of her placement because Ali responded to tasks differently depending on the task. 
Mrs. Brownstein described that she though Mariah might be a partial row structurer because she could draw and count units, but she was seeing full rows. She stated, "then I have the partial row structurer where they are drawing and counting some but not all rows as rows. There were some alignment mistakes on Mariah's and she almost put in like an extra teeny row so I could see her in that category" (Mrs. Brownstein, September 13).

Lastly, Mrs. Brownstein described Xavier. She stated that she thought Xavier had the highest level of thinking of the four and she thought that he could see rows and columns as a multiplicative relationship to find area. She stated,

Then the highest one, using linear measures, or similar indicators, multiplicatively and iterates. The only one that I saw maybe Xavier could be in that one. He would be one that I would consider for that...I saw that he understood the dimensions of the area as the numbers he needs to multiply and hopefully he understood that each row could be used as a multiple. (Mrs. Brownstein, September 13)

Because Keron had such a variety of responses, Mrs. Brownstein was not exactly sure where to place his thinking within the trajectory.

Implications for instruction. Even though Mrs. Brownstein was surprised by students' thinking and discussed their understanding in several cases, she did not connect any of interview events to her instructional practices. When asked what she might expect from students in upcoming lesson or things that she learned for instruction, she discussed that she had not had much experience teaching fifth grade, so she was unsure of what to expect. For the past eight years, Mrs. Brownstein taught third-grade, so she felt more familiar with how third grade students might respond to the topics presented. She stated, 
Well here's the thing, I have taught math plenty because I have taught for 20 years. But last year, I taught third grade math. So I taught third-grade everything and this is my first year teaching fifth grade, not ever. But I probably haven't taught something like fifth grade math for 8 years...So I wouldn't have taught something like this topic (in third-grade). (Mrs. Brownstein, September 13)

\section{Interview 2}

Interview 2 took place in February of the school year prior to Mrs. Brownstein's unit on volume measurement. Since Mrs. Brownstein's measurement unit focused on volume, she added several volume questions to her interview protocol. These questions are described in greater detail below.

Mrs. Brownstein began by asking students to describe what they thought a cubic unit was and why it is used to measure volume. She then showed students a rectangular prism with the base filled and one column in place. She asked the student to find the volume of the first layer of the prism and also if they could calculate the total volume of the prism. Mrs. Brownstein thought that these two questions would give her an initial idea of how students conceptualized volume and counting strategies.

Several of Mrs. Brownstein's students had moved over the course of the school year including one of her interview students, Mariah. To replace this student, Mrs. Brownstein selected another student, Eunice, for the study.

What Mrs. Brownstein noticed. Following the second interview, Mrs. Brownstein noticed seven actions that stood out to her (as shown in figure 27). She freely recalled each of these actions after the interview. For two of the events, Mrs. Brownstein was able to provide an interpretation of the students' understanding and one of the events 
led to an instructional implication. Four of the events referenced all of the interview students or several interview students and two of the events referenced individual interview students directly. Mrs. Brownstein primarily noticed events that centered on students' area drawing strategies and students' volume counting strategies.

\begin{tabular}{|c|c|c|c|}
\hline \multicolumn{4}{|c|}{ Interview 2: February } \\
\hline What the Teacher Noticed & $\begin{array}{c}\text { Interpreted } \\
\text { Understanding }\end{array}$ & $\begin{array}{l}\text { Implications for } \\
\text { Teaching }\end{array}$ & Significance \\
\hline \multicolumn{4}{|c|}{ Drawing a Square Unit } \\
\hline $\begin{array}{l}\text { Drawing Strategy: Drew a centimeter square } \\
\text { without even picking up a ruler and didn't know } \\
\text { how to check. (all interview students) }\end{array}$ & (none provided) & (none provided) & (none provided) \\
\hline \multicolumn{4}{|c|}{ Tiling Tasks } \\
\hline $\begin{array}{l}\text { Drawing Strategy/Area Visualization: Drew } \\
\text { each individual square and doesn't see rows and } \\
\text { columns. (two of the four interview students) }\end{array}$ & $\begin{array}{l}\text { Understood that the } \\
\text { rows and columns need } \\
\text { to be the same size } \\
\text { when predicting, but } \\
\text { could not redraw to } \\
\text { make them look that } \\
\text { way. } \\
\text { Not row and column } \\
\text { structurers, maybe they } \\
\text { are using an intuitive } \\
\text { structure which would } \\
\text { classify them as area } \\
\text { unit relator and repeator. }\end{array}$ & (none provided) & $\begin{array}{l}\text { Surprised by } \\
\text { students' } \\
\text { thinking. }\end{array}$ \\
\hline $\begin{array}{l}\text { Drawing Strategy: Could not organize her } \\
\text { units when filling the } 7 \text { x } 6 \text { units. She left gaps } \\
\text { in between rows and used a perimeter spiraling } \\
\text { approach. (Mariah) }\end{array}$ & Primitive Coverer & (none provided) & (none provided) \\
\hline \multicolumn{4}{|c|}{ Finding Volume of Partially Filled Prism } \\
\hline $\begin{array}{l}\text { Statement/Volume Counting Strategy: Had } \\
\text { difficulty describing and finding the volume of } \\
\text { a layer. ( } 2 \text { of the } 4 \text { students) }\end{array}$ & (none provided) & (none provided) & $\begin{array}{l}\text { Surprised by } \\
\text { response. }\end{array}$ \\
\hline $\begin{array}{l}\text { Volume Counting Strategy/Volume } \\
\text { Visualization: Counted the volume by rods of } \\
\text { 10, but did not understand a layer. (Eunice) }\end{array}$ & (none provided) & $\begin{array}{l}\text { Make sure to think } \\
\text { about the layers and } \\
\text { the rods before } \\
\text { having students find } \\
\text { the volume. }\end{array}$ & (none provided) \\
\hline $\begin{array}{l}\text { Volume Visualization/Volume Counting } \\
\text { Strategy: Found the first layer and was able to } \\
\text { count the number of layers. (Xavier) }\end{array}$ & (none provided) & (none provided) & (none provided) \\
\hline $\begin{array}{l}\text { Behavior: Did not even know how to attempt to } \\
\text { find the volume. (Two of the four students) }\end{array}$ & (none provided) & (none provided) & $\begin{array}{l}\text { Surprised by } \\
\text { response. }\end{array}$ \\
\hline
\end{tabular}

Figure 27. Events that Mrs. Brownstein noticed during Interview 2. Events highlighted in gray had instructional implications. 
Drawing strategies to find area. Two of the events that Mrs. Brownstein noticed related to students conceptions of a square unit and how they used this unit to find the area of a rectangle. For one of the tasks, Mrs. Brownstein gave the students a ruler and asked them to draw a square centimeter followed by a square inch. Following this, she showed them a rectangle that measured 6 inches by 7 inches with one square inch drawn in the corner and asked them if they could completely tile the figure.

Mrs. Brownstein initially commented that all of the students drew a square centimeter without even picking up the ruler. She stated,

It was interesting because I had rulers there and um, the students didn't even pick up a ruler they just hand drew what they assumed with a centimeter square. And even when I asked them, you can measure it to see if you are close or how close you are they really didn't know how to use the ruler to see if it was a square centimeter and they certainly didn't attend to both dimensions of it. Pretty much just one (Mrs. Brownstein, February 13).

Mrs. Brownstein noted in her comment that students freely drew what they thought was a centimeter square but were unsure of how to check the square to see if it really was a centimeter square.

Following this, Mrs. Brownstein commented that she showed students the $6 \mathrm{x} 7$ inch rectangle and asked them to determine how many squares it would take to tile the rectangle. She commented that for three of the four students, this task was extremely difficult. The students did not associate the side length with the number of square units and instead began to draw in each unit. She stated, 
I told them that now that the see a unit can they find the area or use the ruler to find out. What I found was that didn't help a lot because the other three were trying to draw in each square and they weren't attending to the sides of it. It was getting all messed up. They were pretty much, a couple were drawing from the top but one was just trying to fill by going around the outside to the inside. I stopped her about halfway and said we don't have enough time to do that (Mrs. Brownstein, February 13).

Mrs. Brownstein, was overall, surprised that the students would not correlate the side length with the number of units and that their drawings did not always match their thinking. She stated that one student, Ali, left gaps between rows and did not structure units in columns. She also stated that two of her interview students were pretty good at predicting the number of units in a rectangle but could not draw them in the same way they discussed.

Volume counting strategies. Four of Mrs. Brownstein's comments related to how students found the volume of the prism by counting. She discussed that two of the students were unable to even attempt to find the volume of the prism while Eunice and Xavier used two different methods to find the volume. Xavier found the volume of one layer and then counted the number of layers to find the total. Mrs. Brownstein said that Eunice started counting each individual unit but saw that each rod was composed of 10 units and began to skip count by tens. She stated,

So then she started counting each one (unit), but then because they are in tens she stopped here and just started counting by 10s. I don't know if that is progress because they are in 10 s and that makes it so much easier to count by $10 \mathrm{~s}$ 
(Mrs. Brownstein, February 13).

Mrs. Brownstein was not sure if this strategy was more or less sophisticated then counting each individual unit. She was hoping that Eunice, like Xavier, would catch onto layers and count in that way.

Interpreted understanding. Mrs. Brownstein was only able to discuss students' understanding for two of the seven events. Directly following the student-teacher interview, Mrs. Brownstein experienced difficulty discussing student thinking and asked to have time to write up her notes and tell me her thoughts the following day.

After having a day to write up her thoughts, Mrs. Brownstein reflected back on two of the events specifically with regard to area. She reflected on how the students structured area units within the $6 \times 7$ rectangle. Given time, Mrs. Brownstein attempted to relate their thinking back to levels in the learning trajectory, but, as shown below, her thinking was somewhat jumbled. She stated,

Here is what I came up with after reflecting on their interview. I just said it appears three of the students are not row and column structurers only Xavier is. So let me see, those three students showed reliance on measuring from end-to-end but um counted only one dimension of the rectangle. They didn't seem to see the second dimension. Two of the students were able to predict very accurately how many square centimeters would be in the rectangle... There was one (Ali) who seemed to have less of an idea of how to organize the square units when filling the $7 x 6$ rectangle. She left gaps on between rows and then used a perimeter spiraling approach to count. So I saw that two of the students seem to be using an intuitive structure but do not use alignment coordinating with organization, which would 
classify them as unit relator and repeater but I would go back to primitive coverer for Ali (Mrs. Brownstein, February 18).

Mrs. Brownstein was more comfortable discussing students' thinking as well as relating thinking back to the learning trajectory after she had time to reflect and write down her thoughts.

Implications for instruction. Mrs. Brownstein only connected one student action to a possible adjustment in instruction. When Eunice counted rods of 10 to find the total volume, Mrs. Brownstein thought that she had taken an easy way to find the solution. She stated that she needed to think more about the number of cubic units in a rod to make sure students could not easily skip count by ten.

When asked directly about instruction, Mrs. Brownstein reflected on how difficult the process is. She did not expect that students would encounter difficulty in finding volume because she had always thought that it was a somewhat intuitive process. Her students' struggles took her by surprise and she reflected that she is not sure how to handle it and use it in her instruction. Below is an excerpt of the transcript in which we discuss this.

Mrs. Brownstein: That just shocks me. I truly see how difficulty using this information is when I see what they are doing and I am thinking.

Megan: Why isn't this intuitive or something like that?

Mrs. Brownstein: Right! I think for me to try to make my mind take the necessary steps to understand where they are coming from and how to get them to the next level is definitely a gap for me. I just, I don't understand how someone is missing these parts of this when it seems like it would be intuitive! 
(Mrs. Brownstein, February 13).

This excerpt highlights why Mrs. Brownstein was not able to provide much information about how she would connect students' thinking to instruction. It was difficult for her to conceptualize why this topic would be difficult for students.

\section{Interview 3}

Following the unit of instruction on volume measurement, Mrs. Brownstein conducted individual interviews for the last time with each of her interview students. Mrs. Brownstein administered the same tasks that were discussed in Interview 1 and Interview 2, except she added an extra task for Xaiver. She told Xavier that she has a treasure chest that will hold 30 cubic meters and he was asked to determine what the dimensions of the treasure chest could be.

Following the student-teacher interview, Mrs. Brownstein discussed that Keron and Eunice had remained mostly the same in the way they responded to tasks but she gained insight on Xavier and Ali's thinking. Because of this, she primarily discussed only Xavier and Ali.

What Mrs. Brownstein noticed. Mrs. Brownstein noted 4 events from the third set of interviews that she thought were important (as shown in Figure 28). Two of the events involved Ali, 1 event involved Xavier, and 1 event involved three of the interview students. Most of the events that Mrs. Brownstein noticed involved students' visualization of both area and volume and their drawing strategies. 


\begin{tabular}{|c|c|c|c|}
\hline \multicolumn{4}{|c|}{ Interview 3: February } \\
\hline Actions & Understanding & $\begin{array}{l}\text { Implications for } \\
\text { Teaching }\end{array}$ & $\begin{array}{l}\text { Important } \\
\text { to Mrs. } \\
\text { Brownstein }\end{array}$ \\
\hline \multicolumn{4}{|c|}{ Tiling Task } \\
\hline $\begin{array}{l}\text { Drawing Strategy/Statement: Did not } \\
\text { make whole boxes anymore except for the } \\
\text { last row. She knew that one has } 36 \text { and the } \\
\text { other } 40 \text { but she kept drawing in } 37 \text { (Ali) }\end{array}$ & $\begin{array}{l}\text { Intuitively knows area but does } \\
\text { not know how to express herself } \\
\text { with a drawing. }\end{array}$ & $\begin{array}{l}\text { Interesting but doesn't } \\
\text { know the implications } \\
\text { for teaching. }\end{array}$ & $\begin{array}{c}\text { (none } \\
\text { provided) }\end{array}$ \\
\hline $\begin{array}{l}\text { Area Visualization/drawing strategy: } \\
\text { Knows which one is a square centimeter } \\
\text { but doesn't care that there are gaps or that } \\
\text { they are non uniform when drawing. (Ali) }\end{array}$ & $\begin{array}{l}\text { Improvement in understanding } \\
\text { area but maybe what she sees in } \\
\text { her head is not what she is } \\
\text { writing down. }\end{array}$ & (none provided) & $\begin{array}{c}\text { (none } \\
\text { provided) }\end{array}$ \\
\hline $\begin{array}{l}\text { Area Drawing Strategy/Area } \\
\text { Measurement: Xavier knew what she } \\
\text { meant by a square unit and would attend to } \\
\text { the length of each side while Eunice and } \\
\text { Keron would freehand draw. (Xavier, } \\
\text { Eunice, and Keron) }\end{array}$ & $\begin{array}{l}\text { Xavier had a better } \\
\text { understanding of unit } \\
\text { Understands what it looks like } \\
\text { and can structure into rows and } \\
\text { columns. }\end{array}$ & (none provided) & $\begin{array}{c}\text { (none } \\
\text { provided) }\end{array}$ \\
\hline \multicolumn{4}{|c|}{ Treasure Chest Task } \\
\hline $\begin{array}{l}\text { Volume Visualization: Could think about } \\
\text { the dimensions of a prism that would have } \\
\text { a volume of } 30 \text { but had difficulty } \\
\text { expressing the side lengths. (Xavier) }\end{array}$ & $\begin{array}{l}\text { Surprised that he is good at } \\
\text { seeing multiplication facts and } \\
\text { good at seeing dimensions but } \\
\text { the two seem disconnected. }\end{array}$ & (none provided) & $\begin{array}{c}\text { (none } \\
\text { provided) }\end{array}$ \\
\hline
\end{tabular}

Figure 28. Events that Mrs. Brownstein noticed during Interview 3. Events highlighted in gray had instructional implications.

Visualization and drawing of area unit. Three of the events that Mrs. Brownstein noted were in relation to how students visualized and drew area. She noticed that Ali, as in Interview 2, could accurately predict which rectangle contained more square units when shown a $8 \times 5$ rectangle versus a $9 \times 4$ rectangle. When Ali was asked to draw in where the units would go, she drew in too many and left gaps between units. Mrs.

Brownstein stated,

All right, so on the first task, as far as her marking the area of the rectangles to compare them, she did on the last row just made the line straight down. So she wasn't making whole boxes for the last row, but basically here's what is interesting about this, when I asked her after she had made these which one was larger and by how much she immediately said this one is 40 , and this one is 36 . 
So she knew this one is bigger. I said when I was watching you make your squares, your units; you didn't make 36. How did you know it was 36 ?

(Mrs. Brownstein, February 20)

Mrs. Brownstein continued to discuss that Ali stated there were 36 in the rectangle even when Mrs. Brownstein pointed out there were 37 drawn in.

Mrs. Brownstein also compared and contrasted the other three students in relation to their understanding of a square unit. Mrs. Brownstein commented that she thought Xavier was the only student that would attend to both the length and width when making a square unit and understood what was meant by a square unit. Keron and Eunice drew a square free hand but did not attend to the sides.

Expressing dimensions of volume. One of the events that Mrs. Brownstein noted related to volume. She posed a new problem to Xavier and told him that she had a treasure chest that could hold 30 cubic units. She asked Xavier what he thought the dimensions of the box could be. Xavier stated that he could picture three layers each composed of ten cubic units. When asked what the length, width, and height of the box were Xavier said five, five, and two. Mrs. Brownstein described the event in the following way:

So I wanted to tell you one more thing, about Xavier's interview. I was able to go and do the box activity where it has to be 30 cubic meters. So what could the dimensions be if you wanted to make a toy box that could hold and he right away visualized ten on each layer and three layers. And then I asked him well how would the dimensions be with regard to length, width, and height. He first said five, five, and two. Five for the length, five for the width, and two for the height. 
But then I said didn't you say three layers? And he had to think about it, so he changed the height to three and said five, five, and three. So I said let me get this straight, there are 10 on each layer and it's three layers high, what are your dimensions again? And then he thought about it a little bit more and came up with two, five, and three. (Mrs. Brownstein, February 20)

Interpreted understanding. For all four of the events, Mrs. Brownstein was able to discuss what she thought students understood. These understandings primarily related to visualization of area versus drawing of area and expressing volume using three dimensions.

Visualization of area versus drawing area. In three of the events, Mrs. Brownstein discussed students' understanding of area units. The first student she discussed was Ali. She stated that even though Ali could not draw units using rows and columns, Ali has an intuitive sense of area that she can picture in her mind. Mrs. Brownstein stated:

So to me, and that kind of goes along with what I thought about her with the second interview, where she intuitively knew how many centimeters would fit in there. She could predict very accurately but when, when asked to show how she knew for sure she makes every single square and doesn't make them right. But she still seems to have an intuitive sense about that. (Mrs. Brownstein, February 20) Mrs. Brownstein also discussed, of all the students, Xavier understood area units best. He understood what a unit should look like, could see row and structure, and drew area constructions using straight lines rather than drawing each unit in individually. 
Expression of volume dimensions is not intuitive. Mrs. Brownstein commented on Xavier's thinking in relation to the 30 cubic unit box. She was surprised that even though Xavier understood multiplication well and could also visualize what the box looked like he could not articulate what the dimensions should be. She thought that this showed these pieces were not connected for him. She stated,

Now, I thought that was very interesting that he's pretty much really good with his multiplication facts and really good at seeing parts of it but he is still not accurately seeing the whole thing every time. Which I thought he would. I thought this would be simple for him. (Mrs. Brownstein, February 20) In this particular interview, Mrs. Brownstein realized that expressing length, width, and height is not always intuitive even if students understand and can picture layers. She also realized that drawings cannot always be considered an accurate representation of students' understanding of area.

Implications for instruction. In this particular interview, Mrs. Brownstein continued to state her surprise at students' thinking even though it was the end of the study. At several points, she stated that students' thinking was interesting, but she had no idea what it meant for instruction. It seemed for Mrs. Brownstein that her tasks were revealing thinking that she had never thought about before. Because of this, she experienced difficulty even speculating how it might fit within instruction.

Mrs. Brownstein reflected on the process overall and discussed that she thought the process of interviewing had opened her eyes to student thinking. She also discussed that it was difficult for her to incorporate into instruction with her tight teaching schedule and she hoped in the future she could use her volume tasks again. She stated, 
I do think that the idea of looking at giving kids tasks to see how they use and don't use things has been really big for me. The problem is incorporating it into a really tight schedule when I don't have anybody coming back to check on me to make sure I am doing it. I guess that is kind of sad to say about myself...Hopefully, the lesson I did this week with building prisms will be a way for me to start thinking about how I can incorporate more tasks into my practice. (Mrs. Brownstein, February 20)

\section{Instructional Unit on Volume Measurement}

In the month of February, Mrs. Brownstein taught a two-week instructional unit on volume measurement. The unit was organized as two lessons and an assessment. The first lesson was an investigation of volume by filling different solids. The second lesson, conducted over several days, investigated volume through building rectangular prisms as well as drawing nets. The assessment at the end of the unit assessed both lessons.

\section{Candy Filling Task}

The first lesson that Mrs. Brownstein developed was a task that investigated how students might fill different geometric solids. Each group received different solids like rectangular prisms, triangular prisms, and cylinders. Mrs. Brownstein also distributed different shapes of candies like rolos, starbursts, and small chocolate bars. During the lesson, students were asked two primary questions in relation to all of the prisms. First they were asked to find how many candies it would take to fill one layer of the prism as well as how many candies it would take to fill the entire prism. Mrs. Brownstein thought it would be interesting to give the students different shapes of candies and different types of geometric solids to see how they would cope with open spaces. She also admitted that 
she had not thought completely through the task to determine who should get what shape of candy and why. She stated,

I didn't want to pick ahead of time who to give those to and I probably should have. I just wanted to look at the idea of having the spaces in between and whether that made a difference with how many they would say would cover the base area and um I am still not quite sure (Mrs. Brownstein, February 14).

What Mrs. Brownstein noticed. As Mrs. Brownstein observed students, she noticed three events during instruction that she found important and she noted each of these events freely following instruction (shown in Figure 29). Two of the events referenced individual students while one event referenced the entire class. All of these events involved how students measured volume using the candies or counting strategies that they used to find the total volume of the prisms.

\begin{tabular}{|c|c|c|c|}
\hline \multicolumn{4}{|c|}{ Candy Filling Task: February } \\
\hline What the Teacher Noticed & Interpreted Understanding & $\begin{array}{l}\text { Implications } \\
\text { for Teaching }\end{array}$ & Significance \\
\hline $\begin{array}{l}\text { Volume Measurement Strategy: } \\
\text { Each group was able to find the } \\
\text { number of candies it would take } \\
\text { to fill the first layer. (whole class) }\end{array}$ & $\begin{array}{l}\text { Intuitively understood the meaning } \\
\text { of a layer. }\end{array}$ & $\begin{array}{l}\text { (none } \\
\text { provided) }\end{array}$ & $\begin{array}{l}\text { This was surprising } \\
\text { because } 3 \text { of the } 4 \\
\text { students in the } \\
\text { interview could not } \\
\text { do this. }\end{array}$ \\
\hline $\begin{array}{l}\text { Volume Measurement Strategy/ } \\
\text { Volume Counting Strategy: } \\
\text { Filled the base level and then } \\
\text { made one column and then knew } \\
\text { volume based on this information. } \\
\text { (Ethan) }\end{array}$ & $\begin{array}{l}\text { Ethan intuitively knew the formula } \\
\text { for volume. }\end{array}$ & $\begin{array}{l}\text { (none } \\
\text { provided) }\end{array}$ & (none provided) \\
\hline $\begin{array}{l}\text { Volume Measurement Strategy: } \\
\text { Filled the base with starbursts and } \\
\text { then stuck the starbursts in } \\
\text { sideways to fill the rest in. } \\
\text { (Xavier's Group) }\end{array}$ & $\begin{array}{l}\text { Should this count this as seeing one } \\
\text { layer. Are they really just seeing } \\
\text { half? }\end{array}$ & $\begin{array}{l}\text { Maybe start } \\
\text { talking about } \\
\text { surface area to } \\
\text { connect base } \\
\text { to area? }\end{array}$ & (none provided) \\
\hline
\end{tabular}

Figure 29. Events that Mrs. Brownstein noticed during Candy Filling Task. Events highlighted in gray had instructional implications.

Measuring of the first layer. Two of the events that Mrs. Brownstein noted involved students' conceptions of the meaning of a layer and filling of a layer. During Mrs. Brownstein's second student interview, 3 of the 4 students had difficulty finding and 
filling the first layer of a solid. She noted that she was surprised that so many of the students were able to accurately attempt this task and fill the first layer with candy. More specifically, she noted that some groups were more concerned with space than others. She noted that Xavier's group had used starbursts to fill a rectangular prism but were unhappy when extra space was leftover. The students decided to turn the starbursts on their sides to continue filling the base layer. Mrs. Brownstein noted how they filled the base but wondered if they were counting each turned starburst as a half or a whole unit. She stated,

I was wondering as they are filling their layers and that one group had taken their starburst and put them on their sides so that it made it a more complete layer, although it had parts sticking up and I started thinking about it. If they only count half of that starburst, even though it goes up into the other layer, I wonder how I should count that as far as thinking about a layer. If they are counting half of the part that is sticking up, then I should count that I think (Mrs. Brownstein, February 14).

Volume counting strategies and filling the solid. Mrs. Brownstein's noticed another event in relation to a students' counting strategy of filling the entire solid. As she walked around, a student, Ethan, pointed out that he did not need to fill the entire solid. He showed Mrs. Brownstein that he could fill the first layer and then make one column and multiply the two together. He discussed that the column would show him how many layers there would be. Mrs. Brownstein stated,

The other thing that I thought was interesting was when Ethan figured out that if he had the base covered and he then figured out one column he could figure out 
the whole volume. Because that is what we are moving toward, and he just knew it implicitly (Mrs. Brownstein, February 14).

Mrs. Brownstein noted this event because she was surprised that Ethan intuitively knew how to find volume in this way.

Interpreted understanding. In each of the three events, Mrs. Brownstein discussed students' understanding, although sometimes vaguely. She primarily discussed students' intuitive understanding as well as how she thought they saw a layer.

Intuitive understanding. For two of the events, Mrs. Brownstein discussed students' intuitions and how these intuitions had matched or not matched her expectations. Based on her student interviews, she thought students might struggle with the idea of a layer and what exactly the idea of a layer meant. She stated she was surprised that most of her students intuitively understood what she meant by the term layer and could find it.

She also discussed intuitive understanding in relation to Ethan's idea of finding the base and finding a column to find the total volume. Mrs. Brownstein was surprised that Ethan would intuitively understand that volume could be found in this way without instruction. In both of these incidences, Mrs. Brownstein's conceptions of what students understood were challenged by the students' actions.

Seeing a layer. Mrs. Brownstein also questioned and hypothesized about how one group of students might understand the idea of a layer. After Xavier's group turned starburst candies on their sides to tile the entire base, Mrs. Brownstein questioned how they understood the unit. She wondered if the students saw the starburst as a half unit or a whole unit and realized this impacted how they were thinking about a layer. She stated, "I 
need to somehow establish that they are only seeing the bottom half (of the unit) that makes the complete layer" (Mrs. Brownstein, February 14). Mrs. Brownstein understood that it was important for students to think about the layer as being flat rather than having pieces of units jutting out into the next layer.

Significance to Mrs. Brownstein. Mrs. Brownstein discussed the importance of the event in one of the cases. A student understanding the meaning of a layer was important to Mrs. Brownstein because it was in contrast to her student interviews. In her student interviews, three of the four students were unable to understand what a layer was. Because of this, Mrs. Brownstein was taken by surprise when she posed her initial task and so many students understood what she was asking for.

Implications for instruction. Following this lesson, Mrs. Brownstein was confused and unsure of where to go next. Based on Xavier's group, she wondered if she should discuss surface area next as a way to connect the base to the total volume. She stated, "I was wondering also if I should start talking about surface area now that we have the base covered? I wonder if I should talk about that? Or is that going to bring in something that is not good to bring in at this point?" (Mrs. Brownstein, February 14). She also felt that surface area might be a good concept to tie into this lesson because it is covered on the ISAT tests. In the end, Mrs. Brownstein decided to only focus on volume.

When I asked her where she thought she would go next based on what she saw from students today, she felt confused and was not sure how their thinking fit into instruction. She stated,

I am going to have to think about it, now everything is just swirling. Let me think about it...tomorrow with the boxes where they have the next without the top 
and they have to figure out how many cubic centimeters will fit or continue and make different volumes with 24 units. (Mrs. Brownstein, February 14)

Both ideas that Mrs. Brownstein referenced were lesson plans that she had already made in advance. Based on the day's lesson, she decided to continue on with her plans as she had scheduled.

\section{Building and Filling Lesson}

Following the candy lesson, Mrs. Brownstein spent four to five days working on different building and filling volume tasks. In the first task, Mrs. Brownstein had students create prisms with a volume of 24 cubic units in as many ways as they could. As they built the prisms, they were asked to record the length, width, and height of the prism.

On the second and third day of the lesson, students were given nets to cut out and construct into a prism. Prior to cutting the net, the students were asked to predict how many cubic units they thought the prism would contain and why. After constructing the prism, they were then asked to check their prediction and possibly correct it using centimeter cubes. Mrs. Brownstein hoped that the first through third days of the lesson would help students to discover the algorithm for finding volume through predicting and physically checking. She stated,

They get the net and they really have to focus on what is my bottom here (pointing to the prism), what is my base, and what are my sides. Because they have to make the box, the open box from the graph paper by looking at the net to figure out how many cubes are going to sit in there...and then we have the cubes to put in and see and the whole objective is to see can you make a prediction of 
how many cubes are going to fit in here based on what you see on the bottom and on the sides. And can you make a rule that you could use to predict every time accurately. (Mrs. Brownstein, February 15)

On the last two days of the lesson, the students were given several worksheets in which they were shown pictures of different rectangular prisms and asked to find the volume. Mrs. Brownstein gave them these pictures to help them think about volume in another way.

What Mrs. Brownstein noticed. Over the course of five days of instruction, Mrs. Brownstein noticed 15 events that stood out to her as important. Of these events, she noted 13 freely following instruction and two using the video camera. Eight of the events referenced small groups or the entire classroom and seven of the events referenced individual students. The types of events that Mrs. Brownstein primarily noted were in regard to students' understanding of layers, counting strategies, measurement language, and difficulty interpreting volume through drawings. Each of these themes is described in greater detail below.

\begin{tabular}{|c|c|c|c|}
\hline \multicolumn{4}{|c|}{ Building and Filling Lesson: February } \\
\hline What the Teacher Noticed & $\begin{array}{c}\text { Interpreted } \\
\text { Understanding }\end{array}$ & $\begin{array}{c}\text { Implications for } \\
\text { Teaching }\end{array}$ & Significance \\
\hline \multicolumn{4}{|c|}{ Day 1 of Lesson: Building Rectangular Prisms with 24 units } \\
\hline $\begin{array}{l}\text { Student to Student Interaction/Volume } \\
\text { Visualization: Kept changing the prisms } \\
\text { base and getting confused (especially if } \\
\text { the height was 1). Others in his group } \\
\text { were arguing that the height was } 1 \text { but he } \\
\text { argued it was } 0 \text {. (Hayden) }\end{array}$ & $\begin{array}{l}\text { Hayden doesn't see a layer } \\
\text { of one as a layer. }\end{array}$ & (none provided) & $\begin{array}{l}\text { Hayden is a top } \\
\text { student, so Mrs. B is } \\
\text { surprised that he } \\
\text { would not } \\
\text { understand that it } \\
\text { had a height of one. }\end{array}$ \\
\hline \multicolumn{4}{|c|}{ Day 2: Student's Using Nets to Construct Prisms } \\
\hline $\begin{array}{l}\text { Volume Visualization: Trouble with 2D } \\
\text { seeing the length and width. Students } \\
\text { focused on the height and either length or } \\
\text { width. (Whole Class) }\end{array}$ & (none provided) & (none provided) & (none provided) \\
\hline $\begin{array}{l}\text { Volume Visualization/Volume } \\
\text { Measurement: Did not recognize that the } \\
\text { prism was } 2 \text { layers of } 8 \text {. They only filled } \\
\text { the first layer. ( a few students) }\end{array}$ & $\begin{array}{l}\text { Maybe the students did not } \\
\text { think another layer would } \\
\text { fit? }\end{array}$ & (none provided) & (none provided) \\
\hline $\begin{array}{l}\text { Volume Counting Strategy: Students } \\
\text { were counting each individual unit as they } \\
\text { placed them into the prism. (many } \\
\text { students) }\end{array}$ & $\begin{array}{l}\text { The activity did not change } \\
\text { their understanding. }\end{array}$ & $\begin{array}{l}\text { It's hard to figure } \\
\text { out how much she } \\
\text { should tell them. }\end{array}$ & $\begin{array}{l}\text { She thought the } \\
\text { activity would be a } \\
\text { watershed moment } \\
\text { for students to }\end{array}$ \\
\hline
\end{tabular}




\begin{tabular}{|c|c|c|c|}
\hline & & & connect to algorithm. \\
\hline $\begin{array}{l}\text { Volume Counting Strategy: Counted by } \\
\text { layers or used the formula. (third of the } \\
\text { class) }\end{array}$ & $\begin{array}{l}\text { They are beginning to } \\
\text { understanding the formula } \\
\text { on their own. }\end{array}$ & (none provided) & (none provided) \\
\hline \multicolumn{4}{|c|}{ Day 3: Student's Using Nets to Construct Prisms } \\
\hline $\begin{array}{l}\text { Language Usage/Comprehension: Came } \\
\text { up with many words that concerned } \\
\text { measurement when asked what they had } \\
\text { been doing. (whole class) }\end{array}$ & $\begin{array}{l}\text { Ideas are still swirling in } \\
\text { their minds and they still } \\
\text { don't really know the } \\
\text { difference between area } \\
\text { and volume. }\end{array}$ & $\begin{array}{l}\text { Introduce surface } \\
\text { area or say the } \\
\text { words volume } \\
\text { and area more } \\
\text { frequently. }\end{array}$ & (none provided) \\
\hline $\begin{array}{l}\text { Statement: Made her own definition of } \\
\text { volume rather than looking up at the wall. } \\
\text { (one student) }\end{array}$ & $\begin{array}{l}\text { This reflected a good } \\
\text { understanding of what she } \\
\text { had learned and showed } \\
\text { that the concept made } \\
\text { sense to her. }\end{array}$ & (none provided) & (none provided) \\
\hline $\begin{array}{l}\text { Volume Counting Strategy: Starting to } \\
\text { think about the algorithm, (one at each } \\
\text { group) }\end{array}$ & $\begin{array}{l}\text { Counts the layers and the } \\
\text { number in each layer and } \\
\text { multiplies the two, }\end{array}$ & $\begin{array}{l}\text { Have them write } \\
\text { to help solidify } \\
\text { their ideas. }\end{array}$ & (none provided) \\
\hline \multicolumn{4}{|c|}{ Day 4-5: Students examine drawings to determine total volume } \\
\hline $\begin{array}{l}\text { Language Usage/Comprehension: } \\
\text { Students had difficulty expressing the } \\
\text { length/width/height of the prism. (whole } \\
\text { class) }\end{array}$ & $\begin{array}{l}\text { The activity did not seem } \\
\text { to translate for them. } \\
\text { Language issues/they can't } \\
\text { put into words what they } \\
\text { are thinking. } \\
\text { Low ability level. }\end{array}$ & (none provided) & (none provided) \\
\hline $\begin{array}{l}\text { Language Usage/Comprehension: } \\
\text { Started to use the correct vocabulary: } \\
\text { length, width, height. (whole class) }\end{array}$ & $\begin{array}{l}\text { Mrs. B does not think they } \\
\text { are connecting it to the } \\
\text { PRISM length of what, } \\
\text { width of what? }\end{array}$ & (none provided) & (none provided) \\
\hline $\begin{array}{l}\text { Language Usage/Comprehension: Said } \\
\text { inside and outside when discussing } \\
\text { volume, confused on her methods (Tay) }\end{array}$ & $\begin{array}{l}\text { Showed a lack of } \\
\text { understanding of volume. }\end{array}$ & (none provided) & (none provided) \\
\hline $\begin{array}{l}\text { Language Usage/Comprehension: Said } \\
3,3 \text {, and } 3 \text { for a } 3 \text {-inch cube but cannot } \\
\text { articulate any further (Ali) }\end{array}$ & $\begin{array}{l}\text { She is starting to see these } \\
\text { layers but she cannot } \\
\text { articulate a structure of } \\
\text { using a plan or a formula. }\end{array}$ & (none provided) & (none provided) \\
\hline $\begin{array}{l}\text { Volume Counting Strategy: Ethan was } \\
\text { counting the ends as separate layers and } \\
\text { Mrs. B was upset that the students were } \\
\text { not communicating well with each other. } \\
\text { (Christian, Neshawn, and Ethan) }\end{array}$ & (none provided) & (none provided) & (none provided) \\
\hline $\begin{array}{l}\text { Student to Student Interaction/Volume } \\
\text { Counting Strategy: While working with } \\
\text { another student realized that he counted } \\
\text { too many layers in his picture. (Lawrence) }\end{array}$ & (none provided) & (none provided) & (none provided) \\
\hline $\begin{array}{l}\text { Volume Visualization: Saw four slices of } \\
\text { four instead of seeing layers like Mrs. } \\
\text { Brownstein. (Kenan) }\end{array}$ & $\begin{array}{l}\text { Thought about volume in } \\
\text { terms of horizontal slices. }\end{array}$ & (none provided) & (none provided) \\
\hline
\end{tabular}

Figure 30. Events that Mrs. Brownstein noticed during Building and Filling Lesson. Events highlighted in gray had instructional implications.

Noticing in and of itself. Several times throughout the lesson, Mrs. Brownstein

discussed how difficult it was for her to notice students' actions, because she had not

thought about teaching volume in this way before. In the past, she primarily provided 
students with the algorithm and asked them to practice. Because she had little experience teaching in this new way, she felt that this influenced what she attended to. She stated, I know that as a teacher in the past, I never spent any time on volume. I would introduce the formula, and we would practice on a few worksheets and be done with it. So, teaching volume in an in depth way is brand new to me. So I don't really have any pre-conceived notions of what they might do (Mrs. Brownstein, February 15).

Area visualization. In the first few days of the lesson, Mrs. Brownstein noted two events related to students' visualization of layers. The first day of the lesson, she noticed that one of her top students, Hayden, experienced difficulty finding the volume of a prism with a height of 1 . If the prism had a height of 1 , he would state that the prism had a height of 0 or rotate the prism to find the volume. Mrs. Brownstein was perplexed as to why he did not see a layer of 1 as being a layer. She stated,

If I asked okay where are the layers here, I am trying to remember now. Their perception of the layers was different depending on how they turned it or something. They couldn't keep that constant how we had originally placed it...I was shocked today even one of my very best students, in here as far as math, kept wanting to turn it back again another direction to look at the layers. It was all on the one layers. They seemed to have problems. When I went and saw when they had two layers they could say that's two layers, but when its one layer they don't. I guess why don't they see one layer? What is it? (Mrs. Brownstein, February 15). On the second day, Mrs. Brownstein noted that students experienced difficulty with layers when filling a prism, as well. All of the students constructed prisms from 
paper nets. After constructing the prism, several of the student groups only filled the first layer of the prism, especially if the prism was 2-units high. Mrs. Brownstein thought that this could be because of the inaccuracy of the construction of the prisms. She stated, I noticed with at least a couple of pairs of students that they did not recognize that there was another layer needed on top of the bottom one. And, also, because of the taping on the corners, sometimes it was really hard to get that last cube or two in (Mrs. Brownstein, February 15).

Related to volume visualization, throughout the lesson, Mrs. Brownstein focused on students understanding and expressing volume from a length $\mathrm{x}$ width $\mathrm{x}$ height perspective. When students recorded the dimensions of the prism they were expected to record all three attributes. Mrs. Brownstein continually noted that students had difficulty expressing and recording all three dimensions. In worksheets as well as in conversation, she noted that students primarily wanted to discuss the height and only one other dimension rather than discussing all three dimensions.

Also in relation to visualization, in the final days of the lesson Mrs. Brownstein posed several of the worksheets that she had given in prior years. She noted several events in which she articulated how students' visualized the drawings. Without the physical representation to hold, students had trouble articulating how they saw the volume. For instance, one student Ali correctly found the volume of a 3-unit cube, but had difficulty articulating what she had done or what she saw. Mrs. Brownstein reflects on this below,

Well, Ali is pretty much seeing, I think she is seeing layers. I think she is seeing the ends as a layer. So maybe she is thinking of it like slices instead of levels. She 
kept saying three, three, and three. Was she talking about, I don't know if she was talking about $3 \times 3$ and then three layers, but I do think she is starting to see these slices and cannot articulate (Mrs. Brownstein, February 19).

Other students experienced confusion when considering the drawings. For instance, Mrs. Brownstein noted that for a student, Tay, she had difficulty understanding the faces of the prism in relation to the volume. And for other students like Ethan and Lawrence, they had difficulty counting layers or slices because they could not see how many layers or slices there would be.

Mrs. Brownstein also noted, through the drawings, that she could see that students visualized volume in different ways then she did. For instance, one student Kenan thought about four slices and how many cubes were in each slice versus four rows, like Mrs. Brownstein. She stated,

It was Kenan, I think. He was seeing four rows of four. He was seeing a slice of four, a slice of four, a slice of four, and a slice of four instead of seeing layers he was seeing four slices. So when I, I understood finally what he kept talking about four, because he kept getting the right numbers, but I was trying to figure out how it works. And then he was able to make me understand (Mrs. Brownstein, February 19).

Counting strategies. Across the entire lesson, Mrs. Brownstein attended to many different types of counting strategies. The aim of Mrs. Brownstein's lesson was for students to eventually begin to learn and to understand the algorithm for volume measurement. Because of this, she primarily attended to actions that showed students not attempting, attempting, or successfully using the algorithm. For instance, on the second 
day of the lesson, she noticed that students were counting each cubic unit as they placed them within the prism.

As the lesson progressed on, she saw that at least one or two students at each of the groups were attending to the number of layers and the height of the prism, and some even attended to the formula itself. She stated,

I definitely think that there are a few that can look at the faces and they know they are going to multiply this row times this length and get a number here. Or I am going to count the layers and multiply the two numbers. I definitely see maybe one or two at each table that I know understand (Mrs. Brownstein, February 18). Measurement terminology and language. As students delved deeper into the lesson, Mrs. Brownstein noticed that their measurement terminology was lacking, and the students could not always articulate what they were doing. Midway through the lesson, Mrs. Brownstein asked students to define, in their own words, what they had been studying. Many students responded that they were measuring area or building. Mrs. Brownstein stated,

But it is all still confusing for them. Like they can't put together how is volume different than area, most of them. When I asked that question today, I started off with what is the main topic that we have been studying and I got so many different answers. I was kind of shocked. Maybe I haven't been saying the word volume enough? (Mrs. Brownstein, February 18).

As the lesson continued, and Mrs. Brownstein had students write and discuss their reasoning more frequently, Mrs. Brownstein noted that she saw some improvement in 
their terminology usage, in that the students were starting to use the words more frequently but not always correctly. She stated,

I marked it because now they can say length and width. A lot of them will say those words. Some of them are saying length, width, height but when I ask what is the length of the this or what is the width of this (prism) they are starting to use the words but not always sure how it applies to the cube or the prism (Mrs. Brownstein, February 18).

Mrs. Brownstein also noted that some students were starting to think about volume in their own way. She noted that one particular student, Ali, tried to express her understanding in her own words while the rest of the class was still reading the definition from their book or the wall in the classroom. She stated,

Her definition was her own, and it made sense. It showed an understanding to me of what we had been doing. Whereas everyone else kept looking up at the wall...She discussed that we are looking at the inside of the shape and we need to consider the base and the height. I marked it because it was her own definition and I thought it made sense (Mrs. Brownstein, February 18).

Over the course of the lesson, Mrs. Brownstein attended to how students thought about measurement terminology and the ways in which they tried and both succeeded and failed in using appropriate terms.

Interpreted understanding. Mrs. Brownstein discussed student understanding in 12 of the events. At the beginning of the lesson, Mrs. Brownstein primarily focused on if the students' understanding was moving toward comprehension of the algorithm. She primarily discussed that the students' understanding had not changed or they were 
beginning to understand the formula on their own. It was difficult for her to understand what students' understood because she thought the concept should be intuitive. She stated,

It's really hard for me to not think why can't you see this? It's really hard for me, but it's instructive to me as a teacher how much variation there is in what kids understand. It doesn't seem to matter how much I tell them certain things. No difference at all (Mrs. Brownstein, February 15).

Variation in strategies. As the lesson progressed on, Mrs. Brownstein began to pay more attention to how students counted volume but still framed their understanding in relation to the formula. For instance, she discussed that she thought all of the terminology was floating around in the students' head and somewhat jumbled. As the days progressed, she noticed that Ali understood volume in terms of layers and that Kenan understood volume in terms of slices. She still reflected for both of these students that they could not articulate a structure or a formula to find the volume each time.

Implications for instruction. It was very difficult for Mrs. Brownstein to instructionally plan based on students' thinking. For three of the events, she discussed ideas related to teaching but these ideas did not necessarily impact her lessons that were already scheduled. In the first days of the lesson, Mrs. Brownstein thought that students would have some time of realization and come to understand the volume formula for themselves. She stated,

I thought yesterday that filling the box with the cubes, because its one cube at a time, I just thought the one to one correspondence would be a watershed moment for some people, but I am not sure, from what I saw yesterday, that it necessarily 
was. It seemed like the kids who kind of already got that did it anyway and the kids who didn't, it didn't really make a difference. (Mrs. Brownstein, February 15) After the first day's lesson, Mrs. Brownstein struggled with what to tell students. She wondered if she should just tell them what to do since they were not picking up on the formula through her hands-on activity. She stated that because I was there she would refrain from telling them directly what to do. She also expressed that she felt pressure for her students to know the formula or just to know to multiply because of standardized testing. She stated,

And I think there is this pressure with standardized testing, all this testing. That you just want them to know okay, when you have a problem that has choices of different things, just multiply them together. Just do it.

(Mrs. Brownstein, February 19)

It was evident in Mrs. Brownstein's comments that this new way of teaching was difficult for her to execute and she was somewhat impatient for students to come to understand volume.

Mrs. Brownstein also questioned bringing in the idea of surface area when students mixed up area and volume. She thought that by introducing students to surface area it might help to clarify the difference between area and volume. Even though she suggested this idea, she did not follow through with it.

Lastly, to help students come to understand volume, Mrs. Brownstein began to ask them to write more frequently. She thought that by asking them to write it would help to solidify their ideas. She stated, 
I think for today's lesson I am going to try to make them write for a period of time about their method for figuring out hoping maybe that will cement some things or get them there. (Mrs. Brownstein, February 18)

\section{Volume Assessment}

Following several lessons of instruction, Mrs. Brownstein decided to end the unit of instruction with an assessment. The assessment was two days in length. Mrs. Brownstein constructed several prisms that were completely full or partially filled in different shapes and size and with different units. The prisms were also labeled with letters of the alphabet so Mrs. Brownstein could keep track of them. During the assessment, the students took turns passing the many prisms from one student to another and recording the dimensions and total volume.

Prior to the assessment, Mrs. Brownstein had the students discuss as a class their conceptions of volume and what they learned over the course of the unit. She also gave them a practice prism to help define what she wanted them to do on the assessment.

As I watched Mrs. Brownstein discuss volume with the students, I noticed that her method of assessment had changed. She no longer asked students to define all three dimensions but was now encouraging them to write out the number of layers and the number of cubic units in a layer if it helped them. Because Mrs. Brownstein had not mentioned this in our past interview, I wondered what caused this change to come about. Later during the interview, I asked Mrs. Brownstein what had caused this change.

Mrs. Brownstein discussed that it had come about during a task she posed to another class. The class was asked to find the volume of an L-shaped prism, and none of 
the students felt comfortable discussing volume as length $\mathrm{x}$ width $\mathrm{x}$ height in this situation. The transcript below describes this conversation.

Megan: Ummm, well one thing I wondered about was when you were teaching. So before, I like I have noticed there has been you know more of an emphasis on let's write the length and the width and the height and today it seemed like you were more comfortable with them expressing themselves in terms of a layer and a height. So what did you, what was your thought process behind that? Did you have any thoughts over the last couple days that led to that point?

Mrs. Brownstein: Yes, yesterday we were discussing this one, I think it was this one (an L-shaped container) in the other class and kids just wanted to explain it by slices or layers but I just remember thinking that a lot of the kids in the other class were seeing it that way. Where they were just counting this (the layer) together as a whole part. They weren't going this times this times this, but they were still getting the correct number of cubes.

Megan: Will an L-shape that is kind of, it would be hard for them to talk about length times width, times height.

Mrs. Brownstein: Maybe on this one that's why I kept seeing that come out, so I kept thinking kids were getting that right and even another kid in the other class talked about seeing these as rods, and he was counting fives and he put a dot on each one. So, I never got to talk to this class about that yet...I just think that the discussion led me to believe that kids were seeing these dimensions as a product of two numbers rather than three. 
Even though this incident did not occur in this particular class, it is important to share because it frames how Mrs. Brownstein viewed her assessments and the types of answers she considered correct. For this particular assessment, she no longer forced students to write out all three dimensions, but instead allowed them to discuss layers, slices, or rods.

What Mrs. Brownstein noticed. Mrs. Brownstein noticed nine events freely following the assessment, as shown in Figure 31. Of the events, four related to how students discussed and pictured volume prior to the assessment and five related to how students counted and visualized volume problems on the actual assessment. Mrs. Brownstein was able to describe students' understanding for six of the events and two of the events led to instructional implications. 


\begin{tabular}{|c|c|c|c|}
\hline \multicolumn{4}{|c|}{ Volume Assessment: February } \\
\hline What the Teacher Noticed & Interpreted Understanding & Implications for Teaching & Significance \\
\hline \multicolumn{4}{|c|}{ Students' Metaphors and Explanations of Volume } \\
\hline $\begin{array}{c}\text { Volume } \\
\text { Visualization/Volume } \\
\text { Counting Strategy: Saw } \\
\text { volume as layers times height } \\
\text { or rods and getting the answer } \\
\text { correct. (other class) }\end{array}$ & (none provided) & $\begin{array}{l}\text { It is okay to let them express } \\
\text { themselves in other ways then } 1 \\
\qquad \mathrm{x} \mathrm{w} \mathrm{x} \mathrm{h.}\end{array}$ & $\begin{array}{l}\text { (none } \\
\text { provided) }\end{array}$ \\
\hline $\begin{array}{l}\text { Volume Visualization: } \\
\text { Explained the volume like a } \\
\text { waterfall, elevator, or } \\
\text { hamburger. (all students in } \\
\text { class) }\end{array}$ & $\begin{array}{l}\text { They are starting to get that it } \\
\text { is cubes not just faces and } \\
\text { understanding it is the whole } \\
\text { figure. }\end{array}$ & (none provided) & $\begin{array}{l}\text { (none } \\
\text { provided) }\end{array}$ \\
\hline $\begin{array}{c}\text { Volume Counting Strategy: } \\
\text { Described how to find volume } \\
\text { in ways that are not correct. } \\
\text { (Hayden) }\end{array}$ & $\begin{array}{l}\text { Still understands the material } \\
\text { but he is just trying to think } \\
\text { outside the box. }\end{array}$ & (none provided) & $\begin{array}{l}\text { (none } \\
\text { provided) }\end{array}$ \\
\hline $\begin{array}{l}\text { Volume Visualization: } \\
\text { Compared volume to an } \\
\text { elevator with floors. (Ken) }\end{array}$ & $\begin{array}{c}\text { Seems to be able to } \\
\text { understand and visualize area. }\end{array}$ & (none provided) & $\begin{array}{l}\text { Surprised } \\
\text { given low } \\
\text { grades. }\end{array}$ \\
\hline \multicolumn{4}{|c|}{ Responses to Volume Assessment } \\
\hline $\begin{array}{l}\text { Volume Counting Strategy: } \\
\text { Counted the length, counted } \\
\text { the width and then counted the } \\
\text { slices. (Rachael) }\end{array}$ & $\begin{array}{l}\text { Many ways you can mess up } \\
\text { volume. Not only does she } \\
\text { have to coordinate the sides } \\
\text { but also the layers/slices. }\end{array}$ & (none provided) & $\begin{array}{l}\text { (none } \\
\text { provided) }\end{array}$ \\
\hline $\begin{array}{l}\text { Length Counting Strategy: } \\
\text { Were coming up with a side } \\
\text { length that was } 2 \text { short. (Some } \\
\text { students on the assessment) }\end{array}$ & $\begin{array}{l}\text { They thought they needed to } \\
\text { subtract one from each of the } \\
\text { side from where the bases } \\
\text { met. }\end{array}$ & $\begin{array}{l}\text { Maybe go back to the unit on } \\
\text { parallel and perpendicular lines. }\end{array}$ & $\begin{array}{l}\text { (none } \\
\text { provided) }\end{array}$ \\
\hline $\begin{array}{l}\text { Behavior: The afternoon class } \\
\text { did better on their assessment. } \\
\text { (this class compared other } \\
\text { class) }\end{array}$ & $\begin{array}{l}\text { Mrs. B just thinks they are } \\
\text { smarter and better able to } \\
\text { understand. } \\
\text { Her teaching style changed. }\end{array}$ & (none provided) & $\begin{array}{c}\text { (none } \\
\text { provided) }\end{array}$ \\
\hline $\begin{array}{l}\text { Written Answer: Got all of } \\
\text { the answers wrong/right but } \\
\text { got/missed the } 10 \times 10 \times 1010 \text {. } \\
\text { (Korbin, James) }\end{array}$ & (none provided) & (none provided) & $\begin{array}{l}\text { (none } \\
\text { provided) }\end{array}$ \\
\hline $\begin{array}{l}\text { Written Answer: Missing the } \\
\text { partially filled tasks. They } \\
\text { seemed to be more difficult. } \\
\text { (Hayden and other students) }\end{array}$ & (none provided) & (none provided) & $\begin{array}{c}\text { (none } \\
\text { provided) }\end{array}$ \\
\hline
\end{tabular}

Figure 31. Events that Mrs. Brownstein noticed during Volume Assessment. Events highlighted in gray had instructional implications.

Volume metaphor and visualization. Prior to the assessment, Mrs. Brownstein asked students to describe volume in their own words and ideas that they had learned. As students discussed volume, they were able to describe metaphors that symbolized volume to them. Mrs. Brownstein stated, "I liked that a couple more people came up with visualizations like the waterfall, the elevator, the burger, the slices, or the layers which ever one you want to look at" (Mrs. Brownstein, February 21). Mrs. Brownstein noted 
these metaphors as well as how the students pictured the metaphor for three events. For instance, one student, Ken, pictured finding volume like an elevator. He described finding the volume of the first layer and then going up levels. Mrs. Brownstein stated, "When I heard him say elevator I thought he was describing this kind of motion (up and down). So I am thinking, I just thought that he was picturing the levels going up and down" (Mrs. Brownstein, February 21).

Even though students had developed several correct metaphors, there were also students who showed misconceptions. For instance, Hayden, described several incorrect ways to find volume but Mrs. Brownstein thought that perhaps he was just trying to think in different ways.

Assessment written answers and counting strategies. Following the assessment, Mrs. Brownstein commented on five events that highlighted written strategies and counting in relation to the assessment. Mrs. Brownstein found that because she had focused so much on three dimensions, students were confused on how to express themselves in terms of layers and number of layers. Mrs. Brownstein noted that one particular student, Rachael, counted the length, the width, and then the number of slices instead of the layers tall. She could not keep track of the different dimensions. Mrs. Brownstein stated:

Now after Rachael said, okay she counted the length, she counted the width, and she counted the number of slices. So I mean then I get thinking oh wow, so not only can you mess up by not remembering what side you started with perhaps, so not only do you have to coordinate these two sides are going the same direction so 
they are the same dimension, but you also have to coordinate that if you want to look at a slice how you are using the slice. There is a lot more to it (Mrs. Brownstein, February 21).

Mrs. Brownstein also noticed that students were confused on how to count three dimensions. Several of the students thought that if a cube had been counted for the length then it could not be counted for the height or the width. This caused students to be off in their measurements for each dimension by one or two units, which resulted in the total volume being incorrect. Mrs. Brownstein stated:

I could tell by certain papers with one dimension being one short and some cases they did not want to count it (the unit) two or three times. So they were subtracting one from the dimension. So they were thinking about the cubes rather than the length and not wanting to count a cube twice (Mrs. Brownstein, February 21). In addition to these strategies, Mrs. Brownstein also commented on written answers that were commonly missed or correct. She commented that students seemed to miss the partially filled tasks more frequently and that the 10-unit cube seemed to be an easy problem for all students except James. She stated,

A lot of people who got almost all of them wrong, got that one right (the 10x10x10 cube) Except James, who got all of them right got that one wrong. But you know he was able to recognize that it was $10 \times 10 \times 10$ but he wrote the volume was 200 (Mrs. Brownstein, February 21). 
Student understanding. For six of the eight events, Mrs. Brownstein discussed, to some extent, what the student understood. These understandings primarily related to students conceptions and misconceptions of volume measurement.

Conceptions and misconceptions of volume. Prior to the assessment beginning, Mrs. Brownstein discussed that the students' metaphors helped to show her how students understood volume. She felt more comfortable saying now that students understood volume was the whole figure and not just the surface area she stated, "For a lot more kids now it is a matter of them seeing layers or slices which means a middle part to the whole figure, you know?" (Mrs. Brownstein, February 21). She also acknowledged that she thought the students understood that the prism was composed of cubic units. She stated, "I think they're starting to get that it's cubes. They're solids. They have three dimensions. They are starting to get it" (Mrs. Brownstein, February 21).

Following the assessment, Mrs. Brownstein primarily commented on students' misconceptions of volume. The assessment seemed to reveal many more possible misconceptions to her. For instance, she was now able to see that students could confuse counting the cubic unit with the length. She also discussed that students could confuse how they counted such as length, width, layers, slices, rods, etc.

Ability. For three of the events, Mrs. Brownstein discussed students' ability. Each of these comments occurred prior to Mrs. Brownstein examining and grading the assessments. Mrs. Brownstein initially commented that she felt the afternoon class would do better on their assessment because they are a higher achieving class overall and are better able to understand the material. She stated, "This other class is ahead of them. 
They are, they just catch on quicker. They talk about math better and are just more advanced" (Mrs. Brownstein, February 21).

Mrs. Brownstein also discussed ability with regard to two students Hayden and Ken. Mrs. Brownstein regarded Hayden as one of her top students, but he was unable to describe volume in a correct way. Mrs. Brownstein attributed this to him trying to think outside the box, but she still thought he would get all of the answers on the assessment correct. She stated,

I think what Hayden is doing is trying to think outside of the box. I think he wants to come up with a new way to look at something or talk about it because I think he has gotten attention for that in the past. This is just my impression. So to me, he is coming up with ways that aren't correct but it is something different that nobody else has said. I bet you though that he will have all of these right (problems on the assessment) though (Mrs. Brownstein, February 21).

In a similar way, Ken, a student considered lower, conceptualized volume through the metaphor of an elevator. Mrs. Brownstein thought that his conception was particularly impressive considering he is her lowest functioning math student. These three examples show that, in some cases, Mrs. Brownstein's interpretation of student understanding was already determined by past actions and standardized test scores.

Implications for instruction. Following the assessment, Mrs. Brownstein was very discouraged. This particular class scored very low on the assessment while her afternoon class scored higher. In two of the events, she discussed possible implications for instruction. Her first implication was simply that having this class first makes their instruction not as effective as the afternoon class. By teaching this class first, she was 
able to work out any of the kinks in her instruction and teach better lessons for the afternoon class.

Next, she discussed that maybe the students do not understand the dimensions so they should go back and examine parallel and perpendicular lines so that students could better identify the three dimensions in relation to each other. She stated,

Oh, it's just so hard. It just makes me want to, just makes me want to throw in the towel. I mean seriously I don't know. Like I said to you, the only thing that I can think of is maybe when we took the test on parallel lines, perpendicular lines, they did really well, like even this class. Almost everyone passed and got like an 80 or above. So maybe if we went back to parallel lines and talked about parallel and perpendicular lines being different dimensions and same dimensions? (Mrs. Brownstein, February 21).

This final assessment opened up Mrs. Brownstein's eyes to different strategies that students might use to solve a problem, but it still remained difficult for her to connect these strategies to instruction.

\section{Summary}

Across three student interviews and a unit of instruction, Mrs. Brownstein noticed 49 events and described 66 student actions. Of these events 25 related to small groups or the whole class and 24 related to individual students. For 37 of the events, Mrs.

Brownstein described a student or students' understanding in relation to the action she noticed. She described implications for instruction for five of the events. Figure 32 presents the summary of the data pertaining to the types of student actions that Mrs. Brownstein noticed during the study. 


\begin{tabular}{|c|c|c|c|c|c|c|}
\hline & \multicolumn{3}{|c|}{$\begin{array}{c}\text { Interviews } \\
\text { (22 events; } 35 \text { student actions) }\end{array}$} & \multicolumn{3}{|c|}{$\begin{array}{c}\text { Lessons } \\
\text { (27 events, } 31 \text { student actions) }\end{array}$} \\
\hline & $\begin{array}{c}\text { One } \\
(11 \\
\text { Events; } \\
17 \\
\text { student } \\
\text { actions })\end{array}$ & $\begin{array}{c}\text { Two } \\
\text { (7 events; } \\
11 \text { student } \\
\text { actions) }\end{array}$ & $\begin{array}{c}\text { Three } \\
\text { (4 events; } 7 \\
\text { student } \\
\text { actions) }\end{array}$ & $\begin{array}{c}\text { Candy Filling } \\
\text { (3 events; } 4 \\
\text { student actions) }\end{array}$ & $\begin{array}{c}\text { Building and } \\
\text { Filling } \\
\text { (15 events; } 17 \\
\text { student actions) }\end{array}$ & $\begin{array}{c}\text { Assessment } \\
\text { (9 events; } 10 \\
\text { student } \\
\text { actions) }\end{array}$ \\
\hline Drawing & 6 & 3 & 3 & 0 & 0 & 0 \\
\hline Statement & 0 & 1 & 1 & 0 & 1 & 0 \\
\hline Written Answer & 0 & 0 & 0 & 0 & 0 & 2 \\
\hline $\begin{array}{r}\text { Area } \\
\text { Measurement } \\
\text { Strategy }\end{array}$ & 1 & 0 & 1 & 0 & 0 & 0 \\
\hline $\begin{array}{r}\text { Volume } \\
\text { Measurement } \\
\text { Strategy }\end{array}$ & 0 & 0 & 0 & 3 & 1 & 0 \\
\hline $\begin{array}{r}\text { Length Counting } \\
\text { Strategy }\end{array}$ & 1 & 0 & 0 & 0 & 0 & 1 \\
\hline $\begin{array}{r}\text { Area Counting } \\
\text { Strategy }\end{array}$ & 5 & 0 & 0 & 0 & 0 & 0 \\
\hline $\begin{array}{r}\text { Volume } \\
\text { Counting } \\
\text { Strategy } \\
\end{array}$ & 0 & 3 & 0 & 1 & 5 & 3 \\
\hline $\begin{array}{r}\text { Area } \\
\text { Visualization }\end{array}$ & 4 & 1 & 1 & 0 & 0 & 0 \\
\hline $\begin{array}{r}\text { Volume } \\
\text { Visualization }\end{array}$ & 0 & 2 & 1 & 0 & 3 & 3 \\
\hline $\begin{array}{r}\text { Student to } \\
\text { Student } \\
\text { Interaction }\end{array}$ & 0 & 0 & 0 & 0 & 2 & 0 \\
\hline Behavior & 0 & 1 & 0 & 0 & 0 & 1 \\
\hline $\begin{array}{r}\text { Language } \\
\text { Usage/Comprehe } \\
\text { nsion }\end{array}$ & 0 & 0 & 0 & 0 & 5 & 0 \\
\hline
\end{tabular}

Figure 32. Summary of all student actions Mrs. Brownstein noticed. Cells highlighted in grey indicate events that Mrs. Brownstein interpreted in terms of implications for instruction.

\section{Interviews: Events Noticed and Implications for Instruction}

Across the three student-teacher interviews, Mrs. Brownstein noticed 35 student actions within 22 events. Twelve of the actions (34\%) related to how students measured, counted, and visualized area while eight of the actions (22\%) were in relation to how students counted and visualized volume. Mrs. Brownstein also noted how students responded to tasks through drawings (34\%). Some of the interview tasks specifically asked students to visualize, draw, or count different area regions and volumes so this could account for Mrs. Brownstein's attention to these particular types of events. 
In the first interview, Mrs. Brownstein was able to discuss how students conceptualized area, individual units versus rows and columns. She also discussed that students understand a unit to be one of something and discussed what levels within the learning trajectory thinking might indicate. As she progressed into interviews about volume measurement, she became unsure of what students' were thinking and asked for time to write up responses. In Interviews 2, she was shocked that volume was not an intuitive process like she thought it might be for students and it was difficult for her to discuss students' thinking at all ( 2 of 7 events). In the final interview, Mrs. Brownstein was beginning to vaguely discuss that expression of volume is not intuitive and that students understand volume in different ways.

Throughout each of the interviews, Mrs. Brownstein was shocked by students' actions and it was difficult for her to even speculate how she might incorporate students' thinking into practice. In the final interview, I asked Mrs. Brownstein what role she thought the interviews played in her instruction. She responded:

The interview did not make much of a difference in my mind and maybe it's because I have never used that as a process before to try to use in my teaching. I would have to say that I really didn't put the interview and my teaching together. I mean I know it would have been good if I could have, but the truth is no. I understand the importance of the possibility of an interview and even like I said, with talking to Hayden he is a bright kid, and maybe we could get to the heart of what he was thinking here. With all kids you could learn a lot more about them...I think as a teacher I think more about big pictures (rather than the interviews) (Mrs. Brownstein, February 21). 


\section{Instructional Unit: Events Noticed and Implications for Instruction}

During instruction, Mrs. Brownstein's attention shifted from drawing statements and strategies to students' conceptions of volume. Of the 31 student actions noted, 19 $(61 \%)$ related to some aspect of counting, measuring, or visualizing volume measurement. Mrs. Brownstein noticed other actions such as student-to-student interactions as well as language comprehension. Much of Mrs. Brownstein's lessons consisted of students' building and filling prisms so this may have accounted for the shift from drawing activities.

Initially during the unit of instruction, Mrs. Brownstein wanted all of the students to express themselves using the algorithm. She slowly began to understand ideas like students' conceptions of a layer and acknowledged that students thought of area in different ways, but she still related these understandings back to the formula for volume. It was not until an L-shaped volume problem was posed, that Mrs. Brownstein became comfortable allowing students to think about volume as layers, slices, or rods. During the final component of the unit, the assessment, Mrs. Brownstein started to understand and elaborate on the fact that there were many ways students could understand volume, as well as many misconceptions.

As in the student interviews, Mrs. Brownstein had great difficulty relating students' thinking to instruction. She only discussed three instructional implications throughout the instructional units, but they were often ideas, like discussing surface area or just telling them what to do, that she never implemented. Instead, she referred back to her curriculum to determine the next lesson. At the end of the study, Mrs. Brownstein reflected that there is so much to notice during instruction that it was hard for her to slow 
down and see what students were doing. She also discussed that it was difficult for her to let students struggle and not just to tell them what they needed to know.

\section{Mrs. Brownstein's Perception of the Learning Trajectory Based Professional Development}

Underpinning this study is the learning trajectory itself and the learning trajectory professional development that Mrs. Brownstein was a part of. Throughout the process, Mrs. Brownstein discussed the strengths and difficulties of the program as well as her ability and inability to relate to the learning trajectory document. In the following section, Mrs. Brownstein's perceptions of both the learning trajectory and the professional development are discussed below as well as instances that highlight these ideas from her teaching. In Figure 33, questions that were posed to Mrs. Brownstein during the study are shown as well as summaries of her responses. 


\begin{tabular}{|c|c|}
\hline Questions Posed & Mrs. Brownstein's Response \\
\hline $\begin{array}{l}\text { In your opinion, what are components of } \\
\text { ineffective professional development? }\end{array}$ & $\begin{array}{l}\text { - One day seminar where there is no accountability to put the ideas } \\
\text { into practice. } \\
\text { You "go through the motions" of new ideas because you have to get } \\
\text { them done }\end{array}$ \\
\hline $\begin{array}{l}\text { In your opininon, what are components } \\
\text { of effective professional development? }\end{array}$ & $\begin{array}{l}\text { - This particular professional development was effective because it } \\
\text { was over a long period of time and I was asked to consider my } \\
\text { thinking over and over again. } \\
\text { - Long period of time where ideas can be revisited and put into } \\
\text { practice } \\
\text { Written reflection }\end{array}$ \\
\hline $\begin{array}{l}\text { If you could design a PD, what would it } \\
\text { entail? }\end{array}$ & $\begin{array}{l}\text { - Teachers working together for long period of time directly with PD } \\
\text { developers }\end{array}$ \\
\hline $\begin{array}{l}\text { What are components, if any, of this } \\
\text { professional development did you feel } \\
\text { transitioned well into your classroom? }\end{array}$ & $\begin{array}{l}\text { - Written reflection, although it is tedious } \\
\text { - } \quad \text { Giving kids tasks to see how they understand ideas } \\
\text { - } \quad \text { Focus on the importance of a unit in measurement } \\
\text { - } \quad \text { working together with other teachers }\end{array}$ \\
\hline $\begin{array}{l}\text { What are components, if any, of this } \\
\text { professional development did you feel } \\
\text { did not transition well into your } \\
\text { classroom? }\end{array}$ & $\begin{array}{l}\text { - Incorporating knowledge of students into practice when I already } \\
\text { have my teaching practices and routines in place. } \\
\text { - Accountability } \\
\text { - Individualized attention to students. It is so much work. } \\
\text { - Second guessing my effectiveness as a teacher because of the } \\
\text { investigating students' thinking. }\end{array}$ \\
\hline $\begin{array}{l}\text { What role do you feel that the learning } \\
\text { trajectory played in your lesson planning } \\
\text { process? }\end{array}$ & $\begin{array}{l}\text { - A new way to analyze and reflect on students' thinking that I had not } \\
\text { thought about before }\end{array}$ \\
\hline $\begin{array}{l}\text { What do you see as weaknesses, if any, } \\
\text { of the current trajectory document? }\end{array}$ & - $\quad$ Too broad more of a focus on one task \\
\hline $\begin{array}{c}\text { How would you amend the current } \\
\text { document to make it easier for you to } \\
\text { use? }\end{array}$ & 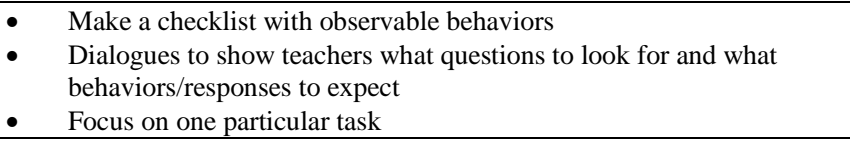 \\
\hline $\begin{array}{l}\text { What do you see as strengths, if any, of } \\
\text { the current trajectory document? }\end{array}$ & $\begin{array}{l}\text { - It breaks down thinking into small details that I have never } \\
\text { considered before. }\end{array}$ \\
\hline
\end{tabular}

Figure 33. Mrs. Brownstein professional development questions.

\section{Perceived Strengths of the Professional Development}

Analysis of students' thinking across time. Even though Mrs. Brownstein

experienced difficulty analyzing students' thinking, it was one of the components that she valued most about the professional development. She expressed that she thought the idea of learning about area or volume would be somewhat intuitive for students. It was fascinating for her to see that students think about volume and area in so many different ways and at varying levels.

Focus on the unit. Mrs. Brownstein discussed that the learning trajectory document and the tasks she saw within the professional development had helped her to see the importance of the unit. When thinking about her teaching in years past, she 
discussed that she viewed the unit as a label and primarily focused on the formula when teaching students. She stated,

Well, I think that the class that I took with you guys over the summer really focused me in on the unit. Whereas before I never thought about the unit. I mean it was something that I would put a label on the end of my answer. I never really thought of the significance of the unit in getting kids to understand the unit and so I think maybe that is the reason that I decided that they had to use the units and different kinds of units to see the understanding of the cubic unit. And, before the class, I really didn't. I don't know if I would have done anything with building volume at all. I think in the past when I taught volume it was all just pictures. And I just thought I'll teach them the formula. It is so easy. And of course, hardly any of them got it. So I think that focusing my mind on the unit was what changed my thoughts of how kids need to play with this to see it better (Mrs. Brownstein, February 21).

From this passage, it is evident that Mrs. Brownstein realized that to understand volume, the students must consider the cubic unit. This was evident in her teaching when she had students work with different size units as well as build volume and fill containers. She also had the realization, through these activities that students do not always see volume intuitively through pictures and they need time to play and work with physical prisms.

Beyond the learning trajectory, there were several pieces of the professional development that Mrs. Brownstein also valued and commented on during the process. 
Primarily she valued being able to reflect and think about how professional development might be incorporated into practice. She also valued discussion with other teachers.

Reflection. Mrs. Brownstein commented frequently she enjoyed having the opportunity to reflect and think about her teaching. Even though she valued the process of reflection, she also discussed how difficult it is to reflect and implement new ideas into instruction. She often stated that her routine already existed and it was difficult to incorporate new ideas without being held responsible. She stated,

So I think this professional development has been great because it was over a long period of time and it forced me to reexamine my thinking and my practices over and over again. It's kind of like that with my kids, when we are trying to learn something new you do you have to keep revisiting it and revisiting it. So I guess the main thing that makes great professional development is over a long period of time where it can be revisited and put into practice. If it is not put into practice it does no good whatsoever. I also do think that the reflective writing, even though it's kind of tedious, it is helpful to formulate your new ideas about what is new to you. So I would say reflective writing is helpful and over a long period of time where you get to put what you learn into practice (Mrs. Brownstein, February 21). This quote captured the process Mrs. Brownstein went through during the study. Daily, she participated in reflection, but often in the process she would complain or state how difficult it is to reflect. It also took multiple rounds of discussing similar situations for her to expand her thinking and begin to formulate how students might be thinking about volume. 
Peer interaction. Occasionally, Mrs. Brownstein also discussed the importance of peer interaction. Within her building, there were several other teachers involved in the professional development. Mrs. Brownstein would occasionally discuss aspects of the professional development with them and also observe their teaching. She stated, "And I

think the peer aspect of it where I have peers in my building who I can talk to about it and get how are you doing this. That is very helpful too" (Mrs. Brownstein, February 21). Mrs. Brownstein commented, though, that she wished there was another fifth-grade teacher in her building to collaborate with.

\section{Perceived Difficulties of the Professional Development}

Throughout the study, Mrs. Brownstein discussed difficulties that she experienced while interviewing and teaching students. Many of these difficulties stemmed from the fact that Mrs. Brownstein already had teaching practices in place and it was difficult for her to change her teaching and her mindset.

Established teaching practices. Mrs. Brownstein continually discussed that with any professional development it is difficult to incorporate new ideas into current teaching practices. Mrs. Brownstein had routines, lessons, and textbooks that she relied on throughout her years of teaching, so it was difficult for her to incorporate new ideas. She stated,

I think that I have thought about this a lot because I have done so much professional development that you touch on for one seminar and then you are given something but you are not forced to incorporate it. It is so easy just to not (incorporate it) because you already have your habits engrained. It's kind of like you are going through the motions (Mrs. Brownstein, February 15). 
The idea of "going through the motions" mirrored how Mrs. Brownstein came to understand student thinking over time. She agreed to participate in the study and complete certain expectations, but it was not until the end of the study that she began to see the importance of considering student thinking. It took experience in her classroom, working with her own students, for her to find importance and value in the process.

Accountability. Along with established teaching practices, Mrs. Brownstein also referenced accountability. She stated that if teachers were not held accountable over time then they would not continue to implement new ideas into practice. She stated that this dissertation study provided her with the "accountability factor" to encourage change. She stated, "So there is an accountability factor with this program that I think is pretty necessary to see practices change" (Mrs. Brownstein, February 21).

Mrs. Brownstein stated that throughout the process if I was not there she would not have thought as deeply about these ideas. Within conversations, it is evident that she valued the processes, but it was also difficult for her to grow and change in her thinking. Below is an excerpt in which Mrs. Brownstein discussed the tension between wanting to learn new things but also the confusion that comes along with it.

Mrs. Brownstein: I am stressed out right now. I mean I like doing this, but it's just nerve wracking but it will be fine.

Megan: I am really sorry. I don't want you to feel that way. If you want to stop the study it would be okay.

Mrs. Brownstein: No, it's not you. You are great. It is just stretching my boundaries, which is really uncomfortable but great at the same time. I need to do it. I want to do it, but, on the other hand, I just feel like I get really disconcerted. 
Too much to notice. Even though Mrs. Brownstein valued the idea of analyzing students' thinking overall, it became difficult for her to attend to details in the larger classroom. Mrs. Brownstein admitted that she often got caught up in the details of managing the classroom and often lost sight of the details of students' strategies. She stated,

I get so caught up, like I told you before, in the lesson itself and who's behaving and who's trying and who's not trying. I get caught up in so many generalities that I am not looking specifically at things that I could be. If I had something where it was more right in my face. Because I need focus, my focus is spread so thin because I am looking at a whole classroom of kids that I need to focus more on what they are doing and who's doing what and who's not doing what (Mrs.

Brownstein, February 19).

This perspective was evident throughout the chapter in that Mrs. Brownstein often had difficulty marking students' thinking with the camera and even referencing student actions after they happened. It was difficult for her to step back and take account of what students were doing or thinking.

Analysis versus application. The final aspect that Mrs. Brownstein struggled with was implications for instruction. Mrs. Brownstein appreciated the idea of analysis, but she found analyzing many students' behaviors was often confusing and took time. It also caused her to question her own teaching practices and whether or not they were effective. She stated,

Oh, a lot of it has been difficult. I mean I think there is a scrutiny involved here, which is good, but because of the scrutiny, I am second guessing myself a lot. Is 
that effective? That's not effective. I am not being effective. They should be getting this. Which is good and bad. I mean, I think there is a pressure for kids to get stuff and the scrutiny over thinking about each task and each little, each part of the learning trajectory or each question or how am I going to question, or how I am going to move them from this to this. That's been really good, but really difficult. I understand how difficult it is to be really effective. You would have to think about all the myriad of levels and tasks, and it's a way of teaching in a differentiated way that I think is harder and takes a lot of practice. It is just easier not to do that (Mrs. Brownstein, February 20).

This attitude is evident throughout the study. Mrs. Brownstein continually questioned what she should be teaching and how to best help students. It was a confusing process and she often did not have a resolution.

Modifications to the trajectory. In response to many of these difficulties, Mrs. Brownstein suggested a modification to the learning trajectories. She stated that she needed focus and objectives that she could visually look for. After stating this, she picked up a textbook that offered dialogues of possible questions and possible student responses, to show me how ideas from learning trajectories could be better presented. She stated, I am going back to this because this is all I see right now, but I see observation sheets that are attached with the program. Like this investigation program is awesome because it goes through dialogue boxes of these are questions that you might want to ask, and these are possible responses.

(Mrs. Brownstein, February 19) 
This quote also connects to Mrs. Brownstein's conception that effective professional development integrates into current practices. She stated that if the ideas were presented in that format then they would more easily be integrated into practice.

\section{My Perspective and Interpretation of Mrs. Brownstein}

Throughout this study, I was an observer within Mrs. Brownstein's classroom and was able to reflect on concepts or ideas that perhaps Mrs. Brownstein did not mention in her reflections. Within this section, I will discuss my interpretation, from my notes, of Mrs. Brownstein's student interviews, classroom instruction, and her perceptions and use of the learning trajectory.

\section{Student Interviews}

Through the act of interviewing students, I saw several themes arise in the case of Mrs. Brownstein. Throughout the study, I noticed that, even though Mrs. Brownstein received professional development, she did not entirely believe what was presented. From the beginning of the study, Mrs. Brownstein questioned the idea of students' understanding developing over time. She had taught measurement concepts in the past and thought that after a few days of instruction her students understood these topics very well. Her past experiences caused her to question the ideas of developmental progression and she often expected all of her students to perform very well on each task. It was not until she administered individual interviews for the first time that her perceptions started to shift. She stated, "Well the learning trajectory has been almost shocking to me because I thought all fifth-graders would find it rather easy to see rows as rows and columns as columns...I guess it seems shocking that there is so much behind something that seems so 
simple" (Mrs. Brownstein, September 13). The ideas presented were so new to Mrs. Brownstein that it took her time to acknowledge them.

Analyzing students' thinking. Throughout the interviews and unit of instruction, Mrs. Brownstein appreciated that the learning trajectory gave her a more in depth way to think about students reasoning, but I noticed this analysis rarely translated into her instruction. She stated, "I do think it is a very helpful tool to analyze what each child is doing in a very in depth way that I never thought about before" (Mrs. Brownstein, September 13). She also thought that the trajectory opened her eyes to students' thinking in different ways and she realized that learning content like area and volume are not as intuitive as she once thought. When asked what about the professional development was most helpful in analyzing students' thinking, Mrs. Brownstein stated that it was the videos of students' solving tasks. Mrs. Brownstein stated that these videos opened her mind to the idea that there are multiple ways to solve problems.

Even though she expressed these sentiments, they were disconnected from her teaching. Following each interview, she had difficulty discussing students' thinking in relation to her next lesson but, given time, she was able to write about students' thinking with regard to levels in the learning trajectory. It seemed to me that she saw the interviews as an assignment to complete rather than a connection to her classroom practices.

\section{Classroom Instruction and Role of the Professional Development}

As I observed Mrs. Brownstein teach, I noticed shifts in her attitudes about teaching measurement. Initially, even though she stated that students can think about volume in different ways, she only accepted answers that were written in the form length 
$\mathrm{x}$ width $\mathrm{x}$ height. As she worked with students directly, and we discussed, I noticed that her perception changed.

Beginning to see volume in multiple ways. At the end of the unit, Mrs.

Brownstein was starting to see that students could see volume in different ways and express volume in ways other than stating the three dimensions. This realization did not come easy to Mrs. Brownstein and she still struggled with how to incorporate these ideas into instruction. It took time for her to observe students working on tasks to realize that there were multiple ways to find volume.

In her teaching practices, again there seemed to be a disconnect between her stated beliefs and her teaching practices. She stated that the trajectory helped her to see that students think about volume in different ways, but it took time for this to filter into her practices. As she stated, she had established teaching practices and it is difficult to want to modify what is already established.

Changes in assessment. An indicator, to me, as an observer, of Mrs. Brownstein's change in instruction was her assessment. It showed that she realized different representations were needed to examine students' perceptions of volume measurement. Mrs. Brownstein commented that she designed the assessment so that it better complemented ideas that the students learned. She said that, in the past, she would have given students drawings of prisms and asked them to find the volume rather than use hands-on materials.

Even though the types of questions that Mrs. Brownstein posed were different, her views of assessment took longer to change. Initially, even though Mrs. Brownstein acknowledged that students think about volume in different ways, she still wanted 
students to express their answer through the three dimensions of volume. It was not until the end of the unit that Mrs. Brownstein realized that students could express themselves in other ways besides the three dimensions.

Overall, I saw Mrs. Brownstein has a distinct case compared to the other two teachers. Mrs. Brownstein discussed that often in professional development she goes through the motions and does what she is expected to do but does not always integrate it into her practices. In her particular case, I witnessed this phenomenon initially and then gradually, over time, the research and ideas became more important to Mrs. Brownstein. She did not have experience with research presented in the learning trajectory, so it took her time to think about and test the research presented. Initially, in her interviews and early instruction, even though she participated in assignments, she did not believe the research would hold true for her students. For her, it was a shocking experience that challenged her perceptions of what it meant to teach and to learn measurement. It took time and repeated reflection for her to even think about what these ideas meant for instruction. 


\section{CHAPTER VII}

\section{LOOKING ACROSS THE TEACHERS}

In this chapter, I interpret the findings for Mrs. Grey, Mrs. Purl, and Mrs. Brownstein, reported in the previous three chapters, to answer the following research questions: What aspects do teachers identify as important in revealing student thinking during clinical interviews that are intended to assess students' thinking? What aspects to teachers identify as important in revealing student thinking during classroom instruction?

First, I present a characterization of each teacher with regard to the events she noticed about student thinking, how her knowledge of student actions informed her teaching, and how she drew upon the learning trajectory when discussing noted events or students' actions. Then I look across the three teachers to draw conclusions about how they interpreted the knowledge they gained about student thinking and used that knowledge to inform their teaching.

\section{A Characterization of Mrs. Grey}

The types of events that Mrs. Grey noted when conducting interviews and during classroom instruction can be categorized according to four topics: measurement strategies, written accounts, verbal interactions, and student behaviors (see Figure 34). During student interviews, Mrs. Grey primarily noted students' written accounts (55\%) and their verbal interactions (33\%). Most of the interview tasks she posed required students to draw representations, so it is not surprising that the vast majority of student 
actions she noticed pertained to students' drawings, including the way students drew units and tiled spaces. All of the verbal interactions she noted referred to the students' answers or claims related to the questions she asked during the interviews.

During classroom instruction, Mrs. Grey’s focus was on written accounts (43\%), measurement strategies (30\%), and verbal interactions (27\%). Similar to the interviews, Mrs. Grey noticed the drawings students produced as written accounts of their work. However, during the instructional unit, she had students write in mathematics journals, which served as a tool to help students record their thinking. She often noted what students had written in their journals as important aspects of classroom instruction. Mrs. Grey also provided students with other tools and manipulatives to measure area; she noted nine events that pertained to the measurement strategies she observed students using. Most of the verbal interactions, Mrs. Grey noted, referred to the statements students made as they predicted and measured the total number of units in a rectangular region.

\begin{tabular}{|l|c|c|}
\hline & $\begin{array}{c}\text { Interviews } \\
(27 \text { student actions noted } \\
\text { across 22 events) }\end{array}$ & $\begin{array}{c}\text { Instructional Unit } \\
\text { (30 student actions noted } \\
\text { across 24 events) }\end{array}$ \\
\hline $\begin{array}{l}\text { Written Account } \\
\text { (drawing, written strategy or answer, journal accounts) }\end{array}$ & $\begin{array}{c}56 \% \\
15 \text { student actions }\end{array}$ & $\begin{array}{c}13 \text { student actions } \\
27 \%\end{array}$ \\
\hline $\begin{array}{l}\text { Verbal Interactions } \\
\text { (statement, question, student-to-student interaction, language } \\
\text { comprehension) }\end{array}$ & $\begin{array}{c}33 \% \\
9 \text { student actions }\end{array}$ & $\begin{array}{c}30 \% \\
\text { Measurement Strategy } \\
\text { (measurement, counting, visualization strategies) }\end{array}$ \\
\hline Behavior & $7 \%$ \\
\hline
\end{tabular}

Figure 34. Categories of events noted by Mrs. Grey during interviews and classroom instruction. Specific event types that comprise each category are presented in parentheses. 
For most of the events that Mrs. Grey noticed-68\% of interview events and $83 \%$ of classroom events - she also interpreted the students' actions in terms of what they implied about the students' understanding. Since events could be coded as several actions simultaneously, these percentages refer to the events rather than each student action. However, she discussed only a few events in which she interpreted students' understanding in terms of what they implied for her instruction (33\% of all interview events and $25 \%$ of all classroom events). As indicated in Figure 35, there were not many differences between the aspects of student understanding that Mrs. Grey discussed in the interview and instructional contexts. In both contexts, she referred to students' conceptions of unit and area, how they distinguished the perimeter and area of a region, limitations of students' drawings as illustrations of their thinking, and how students' personalities and past experiences influenced their learning. At different times over the course of the study, her discussion of these aspects of student understanding expanded to include implications for instruction.

There are three categories that characterize the nature of the implications for instruction that Mrs. Grey described: changing the mathematical tasks or tools given to the students, modifying a teaching practice (e.g., wording used in problem, questioning), and allowing multiple ways for students to express their thinking (e.g. through drawing, discussion, and writing). As indicated by the lines in Figure 35, Mrs. Grey’s interpretations of students' understanding of area measurement concepts (e.g., area, unit, and perimeter) mapped to each of categories of implications that she discussed. Her discussion of how students distinguished perimeter and area led to instructional implications that involved modifying a task or varying the tools given to help students 
visualize and distinguish between the attributes of length and area. Interpreting students' drawings prompted Mrs. Grey to think about the ways in which she allowed students to express their thinking. And finally, when Mrs. Grey interviewed students, she referred to their individual personalities or background experiences in ways that caused her to think about her own teaching strategies.

There were two notable exceptions, however, with regard to Mrs. Grey's interpretations of students' understanding that were limited to certain contexts and were never related to instructional implications. First, Mrs. Grey interpreted students’ understanding in terms of the learning trajectory only during the first interview. This is important to note because this study was rooted in the use of learning trajectories as a formative assessment tool. It was surprising that she did not draw on her notes or the formal trajectory document more frequently when discussing students' thinking. Second, although the concept of length permeates most measurement situations and was a focus of the professional development, Mrs. Grey noted this aspect of students' understanding only during Interview 2, in relation to a task that involved finding the length of a given side of a figure. 


\begin{tabular}{|c|c|c|}
\hline & Themes in Interpreted Understanding & Implications for Instruction \\
\hline $\begin{array}{c}\text { Student } \\
\text { Interviews }\end{array}$ & $\begin{array}{l}\begin{array}{l}\text { Discussion of Trajectory Placement } \\
\text { (Interview 1) }\end{array} \\
\text { Conceptions of Area (Interviews 2, 3) } \\
\text { Distinguishing Perimeter \& Area (Interviews 1, } \\
\text { Drawing (Interview 2) } \\
\text { Role of Personality and Past Experiences } \\
\text { (Interview 2) } \\
\text { Conceptions of Length (Interview 2) } \\
\text { Conceptions of Unit (Interviews 2, 3) }\end{array}$ & $\begin{array}{l}\text { Mathematical Task/Tools } \\
\text { Provided } \\
\text { (Interviews 1, 2) } \\
\text { Reflection on Teaching/Teaching } \\
\text { Strategies (Interview 2) } \\
\text { Student Discussion/Expression } \\
\text { (Interview 2) }\end{array}$ \\
\hline $\begin{array}{l}\text { Classroom } \\
\text { Instruction }\end{array}$ & $\begin{array}{l}\text { Distinguishing Perimeter \& Area (Lessons 1, 2, 3) } \\
\text { Conceptions of Unit (Lesson 1, 2) } \\
\text { Conceptions of Area (Lessons 2, 3) } \\
\text { Drawing (Lesson 1) } \\
\text { Personality and Past Experiences (Lessons 1, 2) } \\
\text { Connection to Other Mathematical Topics (Lesson 1) }\end{array}$ & $\begin{array}{l}\text { Mathematical Task/Tools } \\
\text { provided (Lessons 1, 2, 3) } \\
\text { Reflection on Teaching/Teaching } \\
\text { Strategies (Lesson 3) } \\
\text { Student Discussion/Expression } \\
\text { (Lesson 2) }\end{array}$ \\
\hline
\end{tabular}

Figure 35. Aspects of students' understanding and implications for instruction that Mrs. Grey discussed with regard to student interviews and the instructional unit. Lines indicate how Mrs. Grey related aspects of students' understanding to particular implications for instruction.

Although Mrs. Grey did not formally categorize students' thinking using learning trajectory terminology, she described several facets of students' understanding of area through interviews and the unit of instruction that paralleled the research within the learning trajectory. She noted the ways in which students understood a square unit such as the shape, consistency of size, and structure. She also noted the progression of students' understanding from regarding area as individual units, to considering rows and columns, and finally to using multiplicative reasoning. Throughout the study, she drew upon this knowledge to form instructional decisions. 


\section{A Characterization of Mrs. Purl}

The types of events that Mrs. Purl noted when conducting interviews and during classroom instruction are characterized by the same four categories described above for Mrs. Grey. As shown in Figure 36, the student actions Mrs. Purl noted during student interviews primarily focused on students' measurement strategies (43\%) and their written accounts (35\%). Most of the interview tasks she posed required students to draw representations, which might explain why the vast majority of student actions she noticed pertained to students' drawings, including the way students drew units and tiled spaces. As students drew figures, Mrs. Purl noted how they counted area units and used tools to help them structure and measure a space.

During classroom instruction, Mrs. Purl continued to focus on measurement strategies (57\%) and increased her attention on verbal interactions (30\%). Most of the student actions she noticed related to students' use of manipulatives and tools to measure space as well as their counting and visualization strategies. However, unlike during interviews, Mrs. Purl primarily used discussion as a means for students to express their ideas, and many of the student actions she noted related to verbal interactions between students as they solved problems and discussed ideas with one another. 


\begin{tabular}{|c|c|c|}
\hline & $\begin{array}{c}\text { Interviews } \\
\text { (23 student actions noted } \\
\text { across } 19 \text { events) } \\
\end{array}$ & $\begin{array}{l}\text { Instructional Unit } \\
\text { (46 student actions noted } \\
\text { across } 37 \text { events) }\end{array}$ \\
\hline $\begin{array}{l}\text { Written Account } \\
\text { (drawing, written strategy or answer, journal accounts) }\end{array}$ & $\begin{array}{l}35 \% \\
8 \text { student actions } \\
\end{array}$ & $\begin{array}{l}9 \% \\
4 \text { student actions } \\
\end{array}$ \\
\hline $\begin{array}{l}\text { Verbal Interactions } \\
\text { (statement, question, student-to-student interaction, language } \\
\text { comprehension) }\end{array}$ & $\begin{array}{l}13 \% \\
3 \text { student actions }\end{array}$ & $\begin{array}{l}30 \% \\
14 \text { student actions }\end{array}$ \\
\hline $\begin{array}{l}\text { Measurement Strategy } \\
\text { (measurement, counting, visualization strategies) }\end{array}$ & $\begin{array}{l}43 \% \\
10 \text { student actions } \\
\end{array}$ & $\begin{array}{l}57 \% \\
26 \text { student actions } \\
\end{array}$ \\
\hline Behavior & $\begin{array}{c}9 \% \\
2 \text { student actions }\end{array}$ & $\begin{array}{c}4 \% \\
2 \text { student actions }\end{array}$ \\
\hline
\end{tabular}

Figure 36. Categories of events noted by Mrs. Purl during interviews and classroom instruction. Specific event types that comprise each category are presented in parentheses.

For most of the events that Mrs. Purl noticed-84\% of interview events and $89 \%$ of classroom events - she also interpreted the students' actions in terms of what they implied about the students' understanding. For the events she provided understanding for, she was able to discuss over half $(56 \%)$ in terms of instructional implications during the interview setting and a fourth $(25 \%)$ in the classroom setting. As indicated in Figure 37, there were not many differences between the aspects of student understanding that Mrs. Purl discussed in the interview and instructional contexts. In both contexts, she referred to students' conceptions of unit and area, how they distinguished the perimeter and area of a region, connections they made to other mathematical topics, and how students' personalities and past experiences influenced their learning. During the instructional unit, Mrs. Purl also referred to students' language comprehension. This was often in reference to her non-native English speaking students and their understanding of a particular term. At different times over the course of the study, her discussion of these aspects of student understanding expanded to include implications for instruction. 
There are three categories that characterize the nature of the implications for instruction that Mrs. Purl described: changing the mathematical tasks or tools given to the students, modifying a teaching practice (e.g., wording used in problem, questioning), and allowing multiple ways for students to express their thinking (e.g. through drawing, discussion, and writing). As indicated by the lines in Figure 37, Mrs. Purl's interpretations of students' understanding of area measurement concepts (e.g., area, unit, and perimeter) mapped to each of categories of implications that she discussed. Her discussion of how students distinguished perimeter and area led to instructional implications that involved modifying a task or varying the tools given to help students visualize each attribute. Discussion of distinguishing area and perimeter, as well as length measurement, also caused Mrs. Purl to question her own teaching practices and the ways in which she posed and worded problems. Interpreting students' language comprehension and their understanding of other mathematical topics prompted Mrs. Purl to think about the tools and the resources that she provided students, like mathematical dictionaries. She thought that specific tools could help students work through misconceptions and come to understanding terminology.

There were two notable exceptions, however, with regard to Mrs. Purl's interpretations of students' understanding that were limited to certain contexts and were never related to instructional implications. First, during both the student interviews and unit of instruction Mrs. Purl referenced students' personalities and past experiences in describing students' thinking but never connected these ideas to instruction. Her reference of students' experiences and personality acted as a way for her to justify students' strategies rather than an understanding she could use to inform instruction. Second, Mrs. 
Purl reflected on students' strategies in relation to their understanding of other mathematical topics during both the instructional unit as well as the student interviews but only referred to instructional implications during the instructional unit. For Mrs. Purl, connecting mathematical topics together was her instructional goal for the year so it is surprising that she did not connect these together more frequently.

\begin{tabular}{|c|c|c|}
\hline & Themes in Interpreted Understanding & Implications for Instruction \\
\hline $\begin{array}{c}\text { Student } \\
\text { Interviews }\end{array}$ & $\begin{array}{l}\text { Distinguishing Perimeter \& Area } \\
\text { (Interview 2) } \\
\text { Role of Personality and Past Experiences } \\
\text { (Interview 2) } \\
\text { Conceptions of Area } \\
\text { (Interviews 1, 2, 3) } \\
\text { Conceptions of Length (Interview 2, 3) } \\
\text { Conceptions of Unit } \\
\text { (Interview 2) } \\
\text { Connection to Other Mathematical Topics } \\
\text { (Lesson 3) }\end{array}$ & $\begin{array}{l}\text { Mathematical Task/Tools } \\
\text { Provided } \\
\text { Interviews } 1,2,3 \text { ) } \\
\text { Reflection on Teaching/Teaching } \\
\text { trategies (Interviews } 2,3 \text { ) }\end{array}$ \\
\hline $\begin{array}{l}\text { Classroom } \\
\text { Instruction }\end{array}$ & $\begin{array}{l}\text { Distinguishing Perimeter \& Area } \\
\text { (Lessons 1,3) } \\
\text { Conceptions of Unit } \\
\text { (Lesson 2 ) } \\
\text { Conceptions of Area } \\
\text { (Lessons 1,2,3) } \\
\text { Language Comprehension } \\
\text { (Lesson 2) } \\
\text { Personality and Past Experiences } \\
\text { (Lessons 2, 3) } \\
\text { Connection to Other Mathematical Topics } \\
\text { (Lesson 1) } \\
\text { Conceptions of Length (Lesson 2) }\end{array}$ & $\begin{array}{l}\text { Mathematical Task/Tools } \\
\text { rovided (Lessons 1, 2, 3) } \\
\text { Reflection on Teaching/Teaching } \\
\text { trategies (Lesson 3) } \\
\text { Student Discussion/Expression } \\
\text { (Lesson 2) }\end{array}$ \\
\hline
\end{tabular}

Figure 37. Aspects of students' understanding and implications for instruction that Mrs. Purl discussed with regard to student interviews and the instructional unit. Lines indicate how Mrs. Purl related aspects of students' understanding to particular implications for instruction. 
It is important to note that Mrs. Purl never referenced students' understanding in relation to levels within the learning trajectory. This is particularly surprising given the amount of professional development Mrs. Purl received regarding the research. Even though Mrs. Purl did not formally categorize students' thinking using the learning trajectory terminology, throughout the study she reflected on students' understandings of area, units of measure, as well as distinguishing perimeter and area. She was able to describe and differentiate types of student thinking regarding area and understanding of a unit, including how they structured units and counting strategies. Students' progression in understanding of a square unit, in terms of unit size, structuring, additive, and multiplicative properties, was a central focus in the professional development. Other teachers in Mrs. Purl's school and district focused on students' mastery of formulas as understanding area. Mrs. Purl was able to use the ideas presented to reflect on more than the formula and see her students' progression of understanding. Even though the formal learning trajectory language was not evident in her interviews, she was able to integrate ideas presented in learning trajectory research in her own words. Throughout the study, she drew upon these understandings to form instructional decisions.

\section{A Characterization of Mrs. Brownstein}

The types of events that Mrs. Brownstein noted when conducting interviews and during classroom instruction can be categorized according to the same four topics as the other teachers (see Figure 38). During student interviews, Mrs. Brownstein primarily noted students' measurement strategies (57\%) and their written accounts (34\%). Most of the interview tasks she posed involving area measurement required students to draw representations, so it is not surprising that the vast majority of student actions she noticed 
pertained to students' drawings, including the way students drew units and tiled spaces. Mrs. Brownstein also posed many volume measurement tasks in which she asked students to count or measure the volume of a prism, so it is also not surprising that she attended to measurement strategies students used while finding volume.

During classroom instruction, Mrs. Brownstein's focus was on measurement strategies (65\%), and verbal interactions (26\%). Similar to the interviews, Mrs.

Brownstein posed several volume tasks that involved students building structures and filling prisms. In accord with these tasks, she noticed how students counted, measured, and visualized volume. During the instructional unit, Mrs. Brownstein relied on student discussion and interaction as a means for students to express themselves. She made inferences about students' thinking from the questions and statements they made individually and through interactions with each other as they solved volume problems.

\begin{tabular}{|l|c|c|}
\hline & $\begin{array}{c}\text { Interviews } \\
\text { Instructional Unit } \\
\text { (31 student actions noted } \\
\text { across } 27 \text { events) }\end{array}$ \\
\hline $\begin{array}{l}\text { Written Account } \\
\text { (drawing, written strategy or answer, journal accounts) }\end{array}$ & $34 \%$ \\
\hline $\begin{array}{l}\text { Verbal Interactions } \\
\text { (statement, question, student-to-student interaction, language }\end{array}$ & 12 student actions \\
comprehension) & $6 \%$ & 2 student actions \\
\hline $\begin{array}{l}\text { Measurement Strategy } \\
\text { (measurement, counting, visualization strategies) }\end{array}$ & 8 student actions \\
\hline $\begin{array}{l}\text { Behavior } \\
\text { actions }\end{array}$ & $57 \%$ \\
\hline
\end{tabular}

Figure 38. Categories of events noted by Mrs. Brownstein during interviews and classroom instruction. Specific event types that comprise each category are presented in parentheses.

For most of the events that Mrs. Brownstein noticed-73\% of interview events and $78 \%$ of classroom events - she also interpreted the students' actions in terms of what they implied about the students' understanding. From the events in which she discussed 
students' understanding, she was able to infer no implications for instruction from the interview setting and she discussed very few (30\%) from the classroom setting. Mrs. Brownstein discussed that the interviews had little to no impact on her instructional practices and this is evident in Figure 39. There were some differences between the aspects of student understanding that Mrs. Brownstein discussed in the interview and instructional contexts. In both contexts, she referred to students' conceptions of unit and volume and how students' personalities and past experiences influenced their learning. During the student interviews, she also discussed students' conceptions of area, with regard to particular interview tasks, and their level placement within the learning trajectory.

There are three categories that characterize the nature of the implications for instruction that Mrs. Brownstein described: modifying a teaching practice (e.g., wording used in problem, questioning), allowing multiple ways for students to express their thinking (e.g. through drawing, discussion, and writing), and connecting to other mathematical topics (e.g., introducing surface area to highlight volume more clearly). As indicated by the lines in Figure 39, Mrs. Brownstein's interpretations of students' understanding of volume measurement concepts (e.g., area, unit, and perimeter) was the only understanding that connected to instructional implications; in fact, it mapped to each of categories of implications that she discussed. Mrs. Brownstein was surprised that understanding volume was not intuitive for students, and she often questioned her teaching style and how much she should tell students. She also considered incorporating other means of expression, like writing, into her teaching and connecting other 
mathematical ideas to the topic at hand (e.g., discussing surface area and lines in relation to volume measurement).

There were three notable exceptions, however, with regard to Mrs. Brownstein's interpretations of students' understanding that were limited to certain contexts and were never related to instructional implications. First, Mrs. Brownstein only interpreted students' understanding in terms of the learning trajectory in the first and second interview. Mrs. Brownstein often discussed that she found the learning trajectory useful in interpreting students' thinking, but also difficult. She was able to use the learning trajectory as a tool to categorize her students' thinking from interviews that were similar to ones presented in the professional development, but it was difficult for her to infer what this meant for instruction. Second, although the concept of area permeates and connects to volume measurement situations, Mrs. Brownstein noted this aspect of students' understanding only during the interview settings, in relation to several area tasks she posed. Mrs. Brownstein discussed the idea of contrasting area and volume as well as discussing surface area in her instructional practices, but she never connected what she understood about students' thinking in terms of area to instructional practices involving volume. Third, Mrs. Brownstein reflected on students' conceptions of units throughout the study but never related these conceptions to instruction. Mrs. Brownstein reflected that understanding a unit was the most powerful piece of the professional development because she had never thought about teaching measurement with a focus on the unit. Because of the idea of the unit was new to Mrs. Brownstein, she focused on students' conceptions but was not sure exactly what they implied for instruction. 


\begin{tabular}{|c|c|c|}
\hline & Themes in Interpreted Understanding & Implications for Instruction \\
\hline $\begin{array}{c}\text { Student } \\
\text { Interviews }\end{array}$ & $\begin{array}{l}\text { Discussion of Trajectory Placement } \\
\text { (Interviews 1, 2) } \\
\text { Role of Personality and Past Experiences } \\
\text { (Interview 1) } \\
\text { Conceptions of Volume (Interviews 2, 3) } \\
\text { Conceptions of Area (Interviews 1, 2, 3) } \\
\text { Conceptions of Unit (Interview 1) }\end{array}$ & \\
\hline $\begin{array}{c}\text { Classroom } \\
\text { Instruction }\end{array}$ & $\begin{array}{l}\text { Conceptions of Volume } \\
\text { (Lesson 1, 2, Assessment) } \\
\text { Conceptions of Unit } \\
\text { (Lesson 2, Assessment) } \\
\text { Role of Personality and Past Experiences } \\
\text { (Lesson 2, Assessment) }\end{array}$ & $\begin{array}{l}\text { Connect to Other Mathematical } \\
\text { Topics (Lesson 1, Assessment) } \\
\\
\text { Reflection on Teaching/Teaching } \\
\text { Strategies (Lesson 2) } \\
\text { Student Discussion/Expression } \\
\text { (Lesson 2, Assessment) }\end{array}$ \\
\hline
\end{tabular}

Figure 39. Aspects of students' understanding and implications for instruction that Mrs. Brownstein discussed with regard to student interviews and the instructional unit. Lines indicate how Mrs. Brownstein related aspects of students' understanding to particular implications for instruction.

Although Mrs. Brownstein formally categorized students' thinking using learning trajectory terminology in two of the three student interviews, it was difficult for her to describe, in her own words, facets of students' understanding and how they related to one another and instruction. She relied on the learning trajectory document during interviews as a means to describe students' thinking by matching actions that she witnessed to terminology within the trajectory. She often used words from the learning trajectory document to categorize students' thinking but could not comment in her own words what she thought students understood. During the instructional unit, she did not formally draw on the learning trajectory document and experienced difficulty inferring students' understanding from the actions she observed. This may be because she had not thought 
about the tasks posed in terms of the learning trajectory document before. Mrs.

Brownstein used the learning trajectory document as a way to describe understanding when she did not always have a clear understanding, in her own terms, of what a student was doing and why.

\section{What Do We Learn From the Teachers in This Study?}

The motivation for the study was to further investigate how teachers make sense of student thinking using learning trajectory research and how they implement these findings within their classroom instruction. Other researchers (e.g., Bardsley, 2006; McCool, 2009; Wilson, 2009) have noted that teachers involved in learning trajectory professional development begin to focus more closely on students as they solve problems as well as modify their instructional practices to incorporate students' strategies and discussion. Researchers also noted that there were components that teachers found difficult such as determining implications for instruction (Bardsley; 2006; McCool, 2009) and incorporating professional development ideas with current curriculum and practices (Wilson, 2009). The purpose of this study was to look closer, from a teacher's perspective, to see how she made of her students' thinking and in what ways she used learning trajectory research in her interpretation.

I conjectured, based on my personal experiences and past work within the learning trajectory based professional development (Wickstrom et al., 2012), that perhaps understanding students' thinking and relating it to instruction is different within different contexts. Ball, Thames, and Phelps (2008) have indentified that one component of mathematical knowledge for teaching is knowledge of content and students - the teacher's ability to anticipate how students might solve problems and interpret their 
thinking. A second component, knowledge of content and teaching, is the teachers' ability to choose appropriate mathematical tasks and guide instruction within her classroom. Based on the findings of this study, I think that these two sub-domains take effort to coordinate and there may be another component, knowledge of content and students and teaching.

The teachers in this study were able to conduct interviews in a similar manner to what they were shown in professional development videos. Within the summer professional development, the teachers were shown videos of students working through measurement tasks. Following each video, the teachers were asked to reflect on important details they saw while watching the videos and follow-up questions that they would have wanted to ask the student being interviewed. These videos often highlighted students using tools or drawing to express their understanding of length, area, and volume. The researchers often focused teachers' attention on these actions as ways to denote differences in thinking. The drawings and measurement strategies that the researchers highlighted during professional development transitioned into the ways teachers noted details in interviews as well as explained students' thinking. Without asking many questions, within this study, the teachers were able to reenact measurement tasks and to infer what they thought the child might understand through their actions during tasks. Even though they did not use the learning trajectory document often, the interview was the only time in which they attempted to, similar to what was done within the professional development setting.

During classroom instruction, the teachers had less guidance in how they should teach specific topics. They worked on measurement lessons collaboratively, but they did 
not have an exact model to follow. It was up to the teacher to determine what student actions were important and if and how she would interpret and use the information to inform instruction. Teaching strategies (e.g., discussions, mathematics journals, drawings) focused the teachers' attention to other aspects of students' strategies that did not always arise in interviews. As Empson (2011) alluded to, teaching within a classroom is a complex act so there were strategies and ideas that arose unrelated to research presented within the learning trajectory. Similar to Myers (2013), the teachers noted students' abilities, past instructional experiences, personalities, and test scores in relation to their understanding of students' thinking.

Even though the classroom is a complex place and multiple facets of students' understanding arose, the teachers primarily focused on aspects of understanding related to the current instructional topic. For both the interviews and unit of instruction, the teachers discussed implications for instruction only if they understood and could discuss students' thinking in their own ways in relation to the content. Formal language from the learning trajectory and level classification was not indicative of understanding. This implies that teachers can enact interviews and report results similar to interviews they have seen in professional development, but, without interpreting the data for themselves, the information is not relayed to instructional implications. Daro, Mosher, and Concoran (2011) have implied that learning trajectories could be used as tools for teachers to formatively assess students' thinking over time. This study highlights that knowing how to use a learning trajectory to identify and assess students' thinking is different than knowing how to relate this information to classroom instruction. Teachers have to 
understand and make sense of research for themselves before it takes on meaning in their classroom.

If teachers have difficulty making sense of the research in their own terms, like Mrs. Brownstein, then they resort to mapping student strategies to levels within the trajectory without completely understanding the meaning or choosing not to interpret meaning. Other researchers (Bardsley, 2006; Wilson, 2009) have also noted this phenomenon with teachers in learning trajectory professional development. As Empson (2011) critiqued, this can be worrisome because teachers may just be going through the motions of identifying levels of thinking without considering implications for instruction.

For the teachers in this study, experiences like working collaboratively and watching one another teach helped them to envision and relate students' thinking to their own practices. If making sense of research in terms of one's on teaching practices is critical in implementation, then it is important to further investigate ways in which research can be made more real to teachers. 


\section{CHAPTER VIII}

\section{DISCUSSION AND FUTURE RESEARCH}

Using the analytical lens of teacher noticing (Jacobs, Lamb, \& Philipp, 2010) and the epistemological groundings of teacher research (Cochran \& Lytle, 1993), I sought to investigate the ways in which teachers integrate learning trajectory based research into practice. Specifically, I examined the use of clinical-based interviews with individual students as a means of formative assessment to inform whole-classroom instruction. This had been a goal of the professional development program in which the teachers in this study participated. I wanted to know what the teachers perceived as the advantages and disadvantages of using a learning trajectory to improve classroom instruction and student learning (the overarching research question for this study). Rather than relying solely on the teachers' reports of the benefits and constraints of using a learning trajectory, I studied their enactments of clinical interviews and a related unit of instruction to discern what the teachers identified as important about these activities for understanding student thinking and informing subsequent instruction. I also examined what role, if any, the teachers' knowledge of the learning trajectory played in this. My conclusions about that aspect of the study are reported in Chapter VII.

In this chapter, I discuss the findings and conclusions I have drawn from my research to answer the main research question: What are the advantages and disadvantages teachers perceive in participating in learning trajectory based professional 
development to improve classroom instruction and student learning? I present the implications of this study for learning trajectory based professional development and reflect on the limitations of the research. I close the chapter with recommendations for future research and my personal thoughts on this dissertation study.

\section{Teachers' Perceptions of Learning Trajectory Research}

Each of the teachers is this study perceived certain components of the learning trajectory-based professional development as important and tried to integrate those components into her classroom instruction. There were other components the teachers identified as important but found difficult to integrate into their teaching.

\section{Perceived Advantages}

Across the study, there were several themes that arose in what the teachers perceived as advantages of learning trajectory based professional development. These themes include: understanding students' thinking, the role of assessment, reflection and anticipation, and working with others.

Understanding students' thinking. All three teachers reported that the professional development helped them to see that students think about measurementlength, area, or volume - in different ways. The teachers commented that prior to the professional development, they would have taught students the formula, had them practice using it, and moved on to another topic. They commented that, initially, they thought that understanding measurement ideas was fairly intuitive for students. After seeing videos of students solving tasks and working with their own students, they realized that understanding measurement concepts is a process that develops over time.

Researchers (Bardsley, 2006; McCool, 2009) in the past have noted that teachers, 
involved in learning trajectory based professional development, begin to focus closely on students' mathematical strategies over time. Instead of focusing on correct or incorrect solutions, they progress in their thinking to see multiple details in strategies.

The teachers acknowledged that they had considered high standardized test scores and behaviors such as working quietly and answering a mathematics problems quickly and correctly as signs that a student understood mathematics. However, the tasks the teachers posed in this study, based on activities from the professional development, could not be answered quickly and often required perseverance over time. The teachers realized that different mathematical tasks required different skill sets and that knowing rote facts was different than problem solving. Through the professional development, they began to question their own perceptions of mathematics and what it means to understand mathematics.

The role of assessment. Related to students' thinking, the teachers acknowledged that they came to view assessment differently because of the professional development. Each of the teachers discussed that her views on assessment had changed. The teachers commented that, prior to professional development, their quizzes and tests consisted of drawings of rectangles and rectangular prisms with noted side lengths. Within these assessments, they asked students to find the area or volume of the figure shown. The teachers discussed that they now realize the necessity of assessing students' understanding of area and volume in multiple ways (e.g., hands-on materials, drawings, nets of figures) to see how students understand and structure the unit. They stated that students do not always see drawings of two-dimensional figures and three-dimensional figures as what they denote. 
The teachers also discussed that their ideas of grading assessments had also shifted. They reported that, prior to professional development, they would have looked for a single answer as the correct response, whereas they now realize that multiple solutions could be correct because students think about ideas on a continuum. They also noted that they started to notice the process the students went through to see partial correctness. The teachers reflected that thinking about students' thinking opened their mind to a broader perspective of what it means to assess students' thinking.

Anticipation. All three teachers valued the idea of anticipating students' solutions. As part of the professional development, the teachers used the 5 Practices for Orchestrating Productive Mathematics Discussions (Smith \& Stein, 2011) as a means to connect learning trajectory based research to practice. One of the five practices is anticipation - thinking through what students might say or do in response to a task. The teachers were asked to anticipate, by referencing the levels in the learning trajectory, how they thought their students would respond to a task posed during the professional development. Initially, the teachers found it very difficult to anticipate what their students might say or do because they had not posed similar tasks before. However, the teachers reported to me that it is important to take time to anticipate how students will respond to a task and consider what kind of thinking the task will elicit. They commented that anticipating allowed them to think about what students might say or do and how they could respond to them. Although they indicated that it was difficult for them to incorporate anticipation into their instructional planning, they each stated that it was a worthwhile practice that they hoped to improve upon. 
Reflection and working with others. During the professional development, the teachers met quarterly in groups to observe each other teaching as well as discuss students' thinking. The teachers were asked to investigate measurement concepts throughout the entirety of the school year. During these meetings, the teachers were encouraged to reflect on their classroom as well as their colleagues' classrooms to examine students' thinking. A major component of the professional development was allowing teachers time to observe lessons and reflect on students' thinking as well as classroom instruction.

The teachers explained to me that working with others and reflecting together helped them to better envision how they might use tasks or interpret students' thinking within their classroom. Mrs. Grey and Mrs. Purl valued being able to discuss and work with one another through the process and all three teachers valued being in a professional development with others at their school. By working with other teachers, they were able to see how others implemented ideas into the classroom and gain insight into how they might incorporate ideas into their teaching.

Other researchers (Bardsley, 2006; McCool, 2009; Wilson, 2009) have also reported that teachers find the support of others and reflection time important in integrating learning trajectory based research into practice. The findings of this study contribute to this research by indicating that the repetition and the reflection process is a crucial facet in noticing and understanding details about students' thinking. When the teachers interviewed students for the first time or observed them during class they were not sure exactly what the students' responses indicated. They expressed that they often push confusing ideas off and do not reflect on them. Because of the multi-year nature of 
the professional development, the teachers were able to bring students' work and reflections to subsequent meetings to discuss with other teachers. All three teachers commented that they felt the length of time of the professional development was crucial for them to test ideas, to reflect collaboratively, and to come to understand students' thinking.

\section{Perceived Disadvantages}

Along with perceived advantages, there were also several disadvantages that the teachers perceived. Themes emerged related to formative assessment, the language of research, the trajectory document, established teaching practices, and accountability.

Formative assessment. The overarching purpose of the professional development was for teachers to come to use learning trajectories (Sarama \& Clements, 2009) as a formative assessment tool. Our goal was for teachers to be able to interview a sample of students throughout the school year and use these interviews as both a means to inform instruction as well as an indicator of growth over time. Bardsley (2006) and McCool (2009) documented that teachers often have difficulty incorporating assessment into practice. It is difficult for them not to advise students what to do while problem solving. Each of the three teachers in this study stated that it was important for students to come to understand ideas for themselves and embraced the notion that students could think about measurement in different ways. The fourth-grade teachers had little difficulty letting students explore and not telling them directly what to do during instruction.

Even though the teachers incorporated assessment into practice and were able to see how different students thought about problems, they had standards that they needed to address within instruction. All of the teachers struggled with what it meant to 
"understand" measurement. They were unsure whether it was okay if students did not completely understand the formulas for area and volume. They each discussed that it was difficult to know where to let student-led discussion stop and to begin teacher-led discussion. Each of them reflected that to understand students' thinking they had to ask questions, but they were unsure of how to use these questioning techniques to reach set standards and curricular milestones. The teachers highlighted that their main goal was to help students understand a particular concept. Even though they recognized that students thought in varying ways, they wanted the class to leave with the same understandings. Thus it was difficult for them to integrate multiple solution strategies and different ways of thinking about a concept into their instruction.

Trajectory document and the language of research. Although the teachers rarely referred to the learning trajectory when discussing events they noticed during interviews or the instructional unit, they did spontaneously reflect on the written learning trajectory document as well as the language contained in the document. They often explained that the language inhibited their expression of what a student was thinking. When given several days to reflect on an interview or a lesson, Mrs. Grey and Mrs. Brownstein could discuss students' thinking in terms of trajectory levels, but each of the three teachers preferred to discuss students' thinking in her own words. They discussed that the current language is formal and almost like learning another language. To understand the research presented within the learning trajectory document (Sarama \& Clements, 2009), they expressed that they had to do multiple readings and were often unsure exactly of students' level placements. 
Language in mathematics education is often viewed as an indicator of teacher change. Goldsmith and Schifter (1997) stated that language is crucial in "becoming acculturated to new forms of mathematics teaching and new ways of communicating those thoughts and ideas" (p.45). Stemming from this, some researchers (e.g., Bardsley, 2006; Wilson, 2009) have looked to language as an indicator of learning trajectory based research in practice. Both Bardlsey (2006) and Wilson (2009) looked at the language teachers' used as an indicator of their use of learning trajectories. Wilson (2009) noted that, in many cases, teachers initially described a student's understanding as simply matching a trajectory level to a student without providing justification or evidence. In both of these studies, the researchers prompted teachers to examine trajectory research in relation to their classroom instruction.

This study presents a different perspective because the teachers were not asked to identify levels within the learning trajectory to describe student understanding. Instead, teachers were asked what the student understood to see if they would use the learning trajectory research as a reference. Because the teachers were not specifically asked about levels within the trajectory, they described student thinking in their own terms and in their own ways. Yet many of the teachers' descriptions paralleled the learning trajectory research. As the teachers stated, language can be inhibiting. However, by allowing teachers the freedom to discuss students' thinking in their own way, they felt more comfortable comparing and contrasting students' thinking. For the teachers in this study, the learning trajectory research became more than technical language or research jargon. For Mrs. Purl, this freedom was especially powerful, because she began to hypothesize about other trajectories and how trajectories might intersect or impede one another. 
Lack of tasks. All three teachers reported that the lack of tasks within the learning trajectory document affected their understanding of students' thinking. They stated that it was difficult to use the learning trajectory document to evaluate what their students had done because limited tasks were presented in the document itself. Mrs. Grey and Mrs. Purl noted that there was only one drawing shown at each level of the area trajectory so it was often difficult to decide how students' responses to the activities they developed related to the learning trajectory. All three teachers stated that if they had more tasks, along with possible student responses, it would help guide their teaching and make the research easier to share.

\section{Implications for Learning Trajectory Based Professional Development}

The three teachers involved in this study were part of a year-long professional development program that included a two-week summer session and follow-up sessions throughout the school year. Even though the program developers followed many of the recommendations for conducting effective professional development (e.g., Ginsburg, 2009; Lewis et al., 2012; Smith \& Stein, 2011), the teachers still experienced difficulties incorporating learning trajectory research into practice. The findings of this study have implications regarding the design and implementation of learning trajectory based professional development that include making research accessible, accountability, the role of student interviews, and the influence of teachers' beliefs on professional development.

\section{Accessibility of Research}

First and foremost, this study highlights that learning trajectories that describe students' thinking are beneficial to teachers. Even though the teachers found the language 
of the actual document to be cumbersome, they still found the information presented to be interesting, relevant, and applicable to their classroom. However, they explained that without professional development, they would not have been able to understand and relate to the research on learning trajectories. With this in mind, it is important to make documents that describe students' thinking more accessible to teachers.

Based on the findings of this study, I think it is important to reconsider the current format of learning trajectories (Sarama \& Clements, 2009). The language of the learning trajectory document was the greatest barrier to the teachers in this study. All three teachers were reluctant to use the formal language of the trajectory document, they considered it research jargon and often stated that the words were confusing. One suggestion for making the document more accessible to teachers would be to include a teacher complement that would consist of a variety of tasks and examples (including pictures and student dialogue) of how students might respond to those tasks at different levels of the trajectory.

\section{Accountability}

The findings of this study highlight the role of accountability in effective professional development. That is, teachers need to feel that they are being held accountable but they also need to feel that the researcher is accountable to them.

Each of the three teachers discussed established teaching practices and stated that incorporating new ideas was difficult because of time constraints and the standards they were required to maintain. All of the teachers, but especially Mrs. Brownstein, commented that accountability is a factor in whether professional development is incorporated into the classroom. She stated that although she might identify with the 
beliefs of the professional development, without proper support, she does not always implement what she learned. She explained that teachers can be stubborn and set in their ways.

Researchers (e.g., Gamoran et al., 2003; Nelson, 1998) have found that administrators and professional development providers play a crucial role in assuring that change occurs in the classroom. In order for teacher change to occur, administrators have to view professional development as a process over time rather than a one-day class. The findings of this study highlight the importance of teachers viewing professional development as a sustained effort, valued by their administrators, for which they will be held accountable. But it also shows the critical role that researchers can play with regard to accountability.

The conduct of this study itself acted as an accountability factor for the teachers in their professional development. Because I was there, the teachers reported that they enacted lessons and reflected on their teaching to an extent they would not have done without my presence. The teachers each stated that they felt they had made growth because I was there supporting them and encouraging them to reflect. I found this to be surprising because I was not answering their questions. Pugach and Johnson (1990) noted that reflection rarely occurs if teachers are not given time and strong collegial relationships. Darling-Hammond (1998) stated that reflection is one of the crucial facets of enacting teacher change. She stated, "Teachers need to be able to analyze and reflect on their practice to assess the effects of their teaching and to refine and improve their instruction. They must continuously evaluate what students are thinking and understanding and reshape their plans to account of what they have discovered" (p. 8). It 
is not enough to assume teachers will engage in reflection after school, on their own time. We, as researchers, have to carve out time and make ourselves accountable to the teachers in our studies. When we show that we value their thoughts and reflections, they begin to value their reflections as well.

\section{Research and Teachers' Beliefs}

It is important to consider teachers' beliefs in relation to the research presented. How teachers perceive themselves and the role of instruction is crucial in their ability to incorporate new ideas into their teaching. Goldsmith and Schifter (1997) stated, "Teacher's efforts to construct new forms of mathematical teaching can be affected considerably by the images they have of good teaching, the nature of collegial relationships, the criteria and procedures for job evaluations" (p.196). This study adds to this in terms of learning trajectory based professional development. One of the implications of the study was that the teachers beliefs about instruction and student learning impacted the ways in which and how quickly she incorporated research into practice.

Researchers (e.g., Borasi \& Fozani, 2002; Guskey, 1995) have noted that teachers often question their effectiveness and experience a great amount of anxiety when they attempt to change their instruction in ways that challenge their beliefs about teaching and student learning.. The findings of this study indicate that this applies directly to learning trajectory based professional development. Mrs. Purl and Mrs. Grey were better able to incorporate knowledge of students' thinking into practice because they had been exposed to research like this before and had previously integrated these ideas into practice. Mrs. Purl had used similar methods as a Pre-K teacher and Mrs. Grey was participating in the 
professional development for a second year. It was less of leap for them to incorporate ideas presented. Compared to the other teachers, Mrs. Brownstein was making a greater leap in her beliefs. Her teaching style with regard to measurement topics had been mostly direct instruction. She had never taught like this before and this caused her to question her role as a teacher and she was often out of her comfort zone.

The larger the leap between current teaching beliefs and professional development tenets the more difficult the transition seems. Thus researchers need to consider how well the beliefs tenets and theoretical framing of research-based professional development align with teachers' current practices. Moreover, it is important to consider the culture of the classroom when implementing research into practice. For learning trajectory research (Sarama \& Clements, 2009) it is important to also consider the roots of research. Sarama and Clements (2009) are deeply rooted in the culture of early childhood. The way in which children are taught at this level is different than in the later elementary grades. Research developed and centered in early childhood might need to be modified to be relevant in the later elementary grades.

\section{The Role of the Interview}

The final implication of this study for learning trajectory based professional development pertains to the role of student interviews. Daro, Mosher, and Concoran (2011) hypothesized that learning trajectory research could be used as a tool to help teachers formatively assess student thinking over time. They conjectured that teachers could use research to evaluate and interpret students' thinking through evidence collected during experiences like one-on-one interviews and then use this information to inform instruction. The professional development in which the teachers in this study participated 
was designed to provide teachers practice conducting interviews and opportunities to discuss how information about students gleaned from an interview could be used to inform classroom practice. I thought that the teachers could use the interviews as a way to inform instruction. One of the findings of this study is that even though the teachers had many experiences observing, conducting, and discussing student interviews during the professional development, they viewed the role of student interviews in different ways that influenced how they incorporated information gained from the interviews into their instruction.

Mrs. Grey viewed student interviews as formative assessment. She made decisions for her whole classroom based on responses recorded during the interviews. Mrs. Purl used the interviews as a means to come to know individual students as well as the entire classroom and Mrs. Brownstein gained very little from the interviews. Both Mrs. Grey and Mrs. Purl discussed that the interviews were informative but they did not provide the entire spectrum of students' thinking. It was difficult for the teachers to transition their knowledge of students gained in an interview setting to their classroom setting, even with guidance. Thus, as researchers, we need to evaluate the effectiveness of using interviews in learning trajectory professional development and further investigate ways to help teachers connect the knowledge they gain from interviewing their students to their instructional practice.

\section{Realizations During the Study}

In conducting this dissertation study, I came to realize the importance of reciprocity and being mindful of possible differences in perception between researchers and teachers. These realizations highlight points that all mathematics educators should 
take under consideration when designing and conducting research that bridges research and practice.

\section{Theoretical Groundings of the Study and the Role of Reciprocity}

This study was set within the epistemological and ontological groundings of classroom ecology (Cazden, 1986; Evertson \& Green, 1986) and teacher research (Cochran \& Lytle, 1993). Through these groundings, I hoped to make sense of the classroom through the perspective of the teacher. I found that it is one thing to say that you are looking through the eyes of the teacher but it is quite another thing to actually do this. To look through the eyes of a teacher, the researcher has to gain respect and trust. The teacher has to feel that her work is respected and valued.

As mentioned in Chapter 3, I realized early in the study that the teachers had limited time to discuss their daily activities with me. I decided to offer my time in exchange for their time and teach for them for an hour a day. During this hour they were able to plan and complete other duties so that they were free to interview with me later. In qualitative research, this exchange of responsibility is called reciprocity. Glazer (1982) defined reciprocity as "the exchange of favors and commitments, the building of a sense of mutual identification and feeling of community" (p. 50). Reciprocity was established within fields like anthropology because researchers did not want participants to feel like they were a means to the end of the researchers' choosing.

Initially, I thought that exchanging responsibilities would allow me to see the teachers' perspectives because I would have extra time to interview with them. In reality, the concept of reciprocity allowed a richness and depth to my study that I had not expected. In many ways, by teaching in the classrooms of the teachers in my study, I 
became a more legitimate member of the school community to the teachers. They appreciated that, in some way, I understood their students and their job. Because of these shared experiences, I perceived that the teachers felt more comfortable opening up to me about their strengths and difficulties implementing learning trajectory research into the classroom. They understood that I was not there to critique them but to gain insight into what they found useful as well as difficult.

Several researchers (e.g., Borasi \& Fonzi, 2002; Secada \& Adajian, 1997) have noted that for teachers to feel incorporated in professional development and research there must be teacher ownership and a shared vision. The concept of reciprocity helped to create ownership and shared vision within this study. Through teaching and working with students, the teachers saw that I cared about them, their students, and the school community. By sharing my study's purpose, the teachers felt invested in the idea and wanted to share their experiences. By sharing my purpose and school responsibilities, we created a working relationship that has enabled the study of continue to live on in many ways.

Holly (1991) stated, "The change process — with all its emotional undertow-is internalized and personalized to the point where the teacher action researcher becomes 'hooked' on the change agenda" (p.153). Each of the three teachers felt empowered to continue working on concepts they explored and implemented during the study. The teachers continue to use lessons that they designed during professional development as well as contact me with questions or possible ideas for lessons. Mrs. Purl and Mrs. Grey also incorporated the idea of keeping qualitative notes of student growth into their everyday practices. I remain in touch with the teachers and I have visited their classroom 
several times since the study to co-teach with them and discuss other mathematical topics. True to the definition of reciprocity, we have formed a mutual relationship in which we both value each other and our experiences.

\section{Evaluating Use of Research in Practice}

The second realization that I encountered during the study was how difficult it is to actually measure what a teacher gains from professional development. Going into the study, I knew that one way to evaluate teacher growth was by examining their attention to student-centered activities, discussions, and the questions teachers posed (Schifter, 1995; Fennema et. al, 1996). I thought I would witness good teaching through a teacher's discussions with students and the questions she posed. One way that I had envisioned and used learning trajectory based research in the classroom was through questioning, discussion, and modeling. When I used questions and discussions with students, these means allowed me to hear and observe what students were doing and thinking.

I realized, early in the study, that being able to facilitate discussion or ask questions does not imply that the teacher will know what to do with students' responses. Mrs. Brownstein often facilitated discussions within her classroom and posed thoughtful questions, but she had difficulty interpreting students' responses. In contrast, Mrs. Grey often had students work independently and quietly, but she was able to use their writings to make inferences about students' thinking. I realized that orchestrating discussion and using questioning techniques is not always connected with interpreting these responses for instruction. These encounters helped me to realize that one's first perceptions of a classroom may not be accurate and it is important to investigate further. By spending an 
extended period of time in the classroom, I was able to see the teachers over time and further investigate my initial perceptions.

When linking research and practice, it is especially important to consider how to evaluate teachers and teacher change. It is important to consider factors that the teacher perceives as important and ways in which she feels that she has grown. The teachers in this study gained understandings and insight from professional development that may not have been evident through their use of language. If the teachers' data had been analyzed in reference to their use of learning trajectory language, I would have missed how they interpreted learning trajectory research and how it influenced their teaching. I found that qualitative data like personal reflections and video diaries shed light on other ways to evaluate implementation of learning trajectory research in practice.

Related to teachers' perceptions, I also realized that the ways in which I viewed the classroom were not always parallel to the ways in which the teachers viewed the classroom. Throughout the study, while marking time stamps, I often thought I had an idea of why the teacher chose a particular video clip. When I discussed the video clip with the teacher, I was often wrong. For instance, a student action that I viewed as inefficient, like skip counting by twos, the teacher viewed positively because the student was using knowledge from a previous unit.

I realized, even though I was in the classroom frequently, I would never be the teacher or completely understand her perspective. It made me recognize that, just as with students, learning and meaning is negotiated. It was important for me not to assume the teacher saw or interpreted the classroom in the same way I did. 


\section{Limitations of the Study}

Within this study, there were several components that could be perceived as limitations. My analytical framework of mathematics teacher noticing (Jacobs, Lamb, and Philipp, 2010) could be considered a limitation of the study. It allowed me to focus

on events that teachers noticed and how they interpreted them but it drew my focus away from other aspects in their teaching. There were two components that I would have liked to consider more.

One aspect that I think my study is missing is a focus on the teachers' mathematical content knowledge and their own perceptions of measurement ideas. Since all of the teachers stated that they had not thought about mathematics like this before, I wondered if they were coming to know some of these mathematical concepts for the first time as well. It could be informative to investigate the mathematical growth they perceive within themselves.

A second area that I would like to have investigated is the role of the teachers' instructional practices and their beliefs about teaching. Each of the teachers enacted lessons in different ways. Even though I did not investigate it, I perceived that teaching strategies and beliefs made a difference in how the teachers noticed events and made sense of them. I think that by stepping back and considering their beliefs and instructional practices I could have made better sense of what motivated their noticing.

\section{Recommendations for Future Research}

There are multiple avenues of research that could stem from this research. The teachers in this study indicated that the learning trajectories they were introduced to during the professional development were not necessarily teacher friendly. Research is 
needed to investigate how learning trajectory documentation can be formatted most effectively for teachers.

It is also important to further examine teachers' beliefs in relation to learning trajectory based research and the teachers' implementation of research over time. Mrs. Purl identified with learning trajectory research and began to implement ideas into her classroom fairly quickly. She stated that the research related to her because of her Pre-K background. Mrs. Brownstein, on the other hand, needed time and support to make sense of teaching and assessing students in different ways. Researchers (e.g., Borko et al., 1997, Guskey, 1986) in mathematics education have acknowledged that when professional development is at odds with teachers' beliefs it is difficult for teachers to change their instructional practices. Cooney (2009) described that teacher change is a delicate balance between supporting teachers and unraveling and reconstructing their current beliefs about teaching. Mrs. Purl recognized learning trajectory based research in practice as feasible because she had enacted similar teaching practices. This indicates that not all first-year professional development participants enter with the same beliefs about teaching. It is important to consider how teachers' beliefs, with regard to learning trajectory research, affect their understanding and implementation of research.

It is also important to acknowledge the role of reciprocity in mathematics education within future professional development. Reciprocity has been used in other qualitative fields to develop mutual relationships with participants and explore their feelings in depth. Reciprocity assumes a more intimate relationship and it is still relatively unknown how reciprocity could be scaled up and incorporated on a larger scale. In mathematics education research, I envision that reciprocity could be used to create 
relationships and school communities in areas most in need. By using an approach based on reciprocity, both the school and the researcher would benefit. It is important to investigate how to develop partnerships and further investigate the role of reciprocity within larger partnerships.

It is also important to further investigate how teachers make sense of students' thinking especially with regard to past experiences. Within this study, teachers often dismissed students' thinking when it was not in accordance with test scores and grades. It took time and repeated experiences for the teachers to acknowledge that the student might not understand the concept. Concepts like smartness (Hatt, 2012; Sternberg, 2007) and mindset (Blackwell, Trzesnieski, and Dweck, 2007; Yeager and Dweck, 2012) could be used to investigate how teachers frame mathematical intelligence within their classroom and how their perceptions might change over time given professional development.

Researchers have shown that decisions teachers make on a daily basis directly impact student achievement and beliefs (e.g., Boaler \& Staples, 2008). Teachers assume powerful role in determining a students' mathematical identity and beliefs about himself/herself through classroom interactions (e.g., Barthomew, 2000). Researchers have documented that girls (e.g., Good, Rattan, and Dweck, 2012) as well as minority students (e.g, Berry, Thunder, \& McClain, 2011; Seymour \& Hewitt, 1997) can have good mathematics scores, but still perceive themselves as bad a mathematics. Researchers have shown that teachers who are supportive and caring help to foster positive mathematical identities for students (e.g., McGlamery and Mitchell, 2000; Berry, Thunder, and McClain, 2011; Seymour and Hewitt, 1997). Even though much is known about students' perceptions of mathematical identity and teachers' practices in relation to 
forming mathematical identity, there is little research investigating how teachers perceive what it means to be good at mathematics or smart at mathematics and how this is played out within the classroom. These perceptions can impact what a teacher looks for when teaching and evaluating students.

Lastly, it is important to acknowledge the researcher's perception in relation to the teacher's perception in further research. Throughout this study, I witnessed events alongside each of the teachers but often interpreted them differently. We saw the same student action through different eyes. I think it is important to further investigate and compare and contrast the ways in which researchers see students' understanding in contrast to the way teachers view it. Since these perceptions do not always align it is important to understand the concepts we assume are taken as shared when they are not always.

\section{Closing Thoughts}

Going into this study, my aim was to make sense of the tension that teachers feel as they navigate the bridge between research and practice. I realized from the start that the classroom is a messy place to conduct research, but I hoped to add to what we know and understand about incorporating mathematics education research into practice. Through this process, I realized that documenting perspectives requires trusting relationships and an extended period of time within the classroom. I really could not understand the perspective of any of the teachers until I was able to take on their role or walk around in their shoes. Even when taking on their role, I often did not see an event through the same eyes at the teacher and realized that teachers and researchers often view 
the classroom in different ways. This highlighted to me how important it is to constantly communicate thoughts and ideas to determine if they are shared.

To me, this study highlights that individual stories can bring to light the details of teaching that often go unnoticed in larger studies. Even though my study focuses on three individual teachers, their stories speak to the broader field of mathematics education.

Teaching is a complex act built on relationships. As with any life experience, there are commonalities that we share as well as ideas we can learn from one another. I feel like I am leaving this study with many more questions to answer and ideas to investigate, but I think this is true of all research 


\section{REFERENCES}

Ball, D.L., Forzani, F. (2009). The work of teaching and the challenge for teacher education. Journal of Teacher Education, 60(5), 497-511

Ball, D. L., Thames, M. H., \& Phelps, G. (2008). Content knowledge for teaching: What makes it special? Journal of Teacher Education, 59(5), 389-407.

Ball, D.L., Hill, H. (2009). The curious - and crucial - case of mathematical knowledge for teaching. Phi Delta Kappan, 91(2), 68-71.

Bardsley, M. E. (2006). Pre-kindergarten teachers' use and understanding of hypothetical learning trajectories in mathematics education (Doctoral Dissertation). Retrieved from Proquest.

Barrett, J.E., Jones, G., Thornton, C., \& Dickson, S. (2003). Understanding children's developing strategies and concepts for length. In D. Clements \& G. Bright (Eds.), Learning and teaching measurement yearbook (pp.17-30). Reston, VA: The National Council of Teachers of Mathematics.

Barrett, J.E., Sarama, J., Clements, D.H., Cullen, C., McCool, J., Witkowski-Rumsey, C. (2012). Evaluating and improving a learning trajectory for linear measurement in elementary grades 2 and 3:A longitudinal study. Mathematical Thinking and Learning, 14(1), $28-54$.

Bartholomew, H. (2000). Negotiating identity in the community of the mathematics classroom. Paper presented at the British Educational Research Association Annual Conference, September 7-10.

Battista, M. (2004). Applying cognition-based assessment to elementary school students' development of understanding of area and volume measurement. Mathematical Thinking and Learning, 6(2), 185- 204.

Berry III, R. Q., Thunder, K., \& McClain, O. L. (2011). Counter narratives: Examining the mathematics and racial identities of black boys who are successful with school mathematics. Journal Of African American Males In Education, 2(1), 10-23.

Blackwell, L. S., Trzesniewski, K. H., \& Dweck, C. (2007). Implicit theories of intelligence predict achievement across an adolescent transition: A longitudinal study and an intervention. Child Development, 4(1), 246-264.

Boaler, J., \& Staples, M. (2008). Creating mathematical futures through an equitable teaching approach: The case of railside school. Teachers College Record, 110(3), 608-645.

Borasi, R. \& Fonzi, J. (2002). Professional development that supports school mathematics reform. Foundations series of monographs for professionals in science, mathematics and technology education. Arlington, VA: National Science Foundation.

Borko, H., Mayfield, V., Marion, S., Flexer, R., Cumbo, K. (1997). Teachers' developing ideas and practices about mathematics performance assessment: Successes, stumbling blocks, and implications for professional development. Teaching and Teacher Education, 13, 259-278. 
Brophy, J. E., \& Good, T. L. (1986). Teacher behavior and student achievement. In M.C. Wittrock (Ed.), Handbook of research on teachers (3rd ed.). New York, NY: Macmillan.

Burkhardt, H., \& Schoenfeld, A. H. (2003). Improving educational research: Toward a more useful, more influential, and better-funded enterprise. Educational Researcher, 32(3), 3-14.

Carpenter, T.P., \& Fennema, E. (1992). Cognitively guided instruction: Building on the knowledge of students and teachers. International Journal of Educational Research, 17, 457-470 .

Carpenter, T. P., Fennema, E., Franke, M., Levi, L., Empson, S. B., \& Wisconsin Univ., M. E. (2000). Cognitively Guided Instruction: A Research-Based Teacher Professional Development Program for Elementary School Mathematics Research Report.

Carpenter, T. P., Fennema, E., Peterson, P. L., \& Carey, D. A. (1988). Teachers' Pedagogical Content Knowledge of Students' Problem Solving in Elementary Arithmetic. Journal For Research In Mathematics Education, 19(5), 385-401.

Carpenter, T.P., Fennema, E., Peterson, P.L., Chiang, C.P., \& Loef, M. (1989). Using knowledge of children's mathematics thinking in classroom teaching: An experimental study. American Educational Research Journal, 26, 499-531.

Cazden, C. (1986). Classroom discourse. In M. Wittrock (Ed.), Handbook of research on teaching (3rd edition). New York, NY: Macmillan

Clarke, D., Cheeseman, J., McDonough, A., \& Clarke, B. (2003). Assessing and developing measurement with young children. In D. C. Clements \& G. Bright (Eds.), Learning and teaching measurement: 2003 Yearbook of the National Council of Teachers of Mathematics (pp. 68-80). Reston, VA: National Council of Teachers of Mathematics.

Clements, D., Sarama, J., Spitler, M., Lange, A., and Wolfe, C. B. (2011). Mathematics learned by young children in an intervention based on learning trajectories: A largescale cluster randomized trial. Journal for Research in Mathematics Education, 42, 127-166.

Cobb, P., Wood, T., \& Yackel E. (1990).Classrooms as learning environments for teachers and researchers. In R. Davis, C. Maher, \& N. Noddings (Eds.), Constructivist views on the teaching and learning of mathematics. Journal for Research in Mathematics Education Monograph Series, (Volume 4, pp. 125-146). Reston, VA: National Council of Teachers of Mathematics.

Cochran-Smith, M., \& Lytle, S. L. (1993). Inside outside teacher research and knowledge. New York, NY: Teacher's College Press.

Cochran-Smith, M., \& Lytle, S. (1999). Relationships of knowledge and practice. Teacher learning communities. In A. Iran-Nejad \& P. Pearson (Eds.), Review of research in education. (Vol 24, pp. 249-305). Washington, DC: American Educational Research Association.

Confrey, J. (2008). A synthesis of the research on rational number reasoning: A learning progressions approach to synthesis. Paper presented at The 11th International Congress of Mathematics Instruction. Monterrey, Mexico. 
Confrey, J., Maloney, A., Nguyen, K., Mojica, G., \& Myers, M. (2009).

Equipartitioning/splitting as a foundation of rational number reasoning using learning trajectories. Paper presented at The 33rd Conference of the International Group for the Psychology of Mathematics Education, Thessaloniki, Greece. In M. Tzekaki, M. Kaldrimidou \& H. Sakonidis (Eds.), Proceedings of the 33rd conference of the international group for the psychology of mathematics education: In search for theories in mathematics education (Vol. 2, pp 345-352). Thessaloniki, Greece: PME.

Cooney, T. J. (1999). Conceptualizing teachers' ways of knowing. Educational studies in mathematics, 38, 163-187.

Creswell, J. (1998). Qualitative Inquiry and Research Design: Choosing Among Five Traditions. Thousand Oaks, CA: Sage Publications.

Darling-Hammond, L. (1998). Teacher learning that supports student learning. Educational leadership, 5, 6-11.

Daro, P, Mosher, F. A. , Corcoran, T. (2011). Learning trajectories in mathematics: A foundation for standards, curriculum, assessment, and instruction. Retrieved May 31, 2012http://www.cpre.org/images/stories/cpre_pdfs/learning\%20trajectories\%20in\%2 Omath_ccii20report.pdf

Dunkin, M. J., \& Biddle, B. J. (1974). The study of teaching. New York, NY: Holt, Rinehardt, \& Winston.

Evertson, C. M., \& Green, J. K. (1986). Observation as inquiry and method. In M. C. Wittrock (Ed.), Handbook of research on teaching (3rd ed). New York, NY: Macmillan.

Empson, S. B. (2011). On the Idea of Learning Trajectories: Promises and Pitfalls. Montana Mathematics Enthusiast, 8(3), 571-598.

Fennema, E., Carpenter, T. P., Franke, M. L., Carey, D. A. (1992). Learning to use children's mathematical thinking: A case study. In R. Davis \& C. Maher (Eds.), Schools, mathematics, and the world of the reality (pp. 119-134). Needham Heights: MA: Allyn \& Bacon.

Fennema, E., Carpenter, T. P., Franke, M. L., Levi, L., Jacobs, V. R., \& Empson, S. B. (1996). Mathematics instruction and teachers' belief: A longitudinal study of using children's thinking. Journal for Research in Mathematics Education, 27, 403-434.

Fennema, E., \& Franke, M. L. (1992). Teachers' knowledge and its impact. In D. Grouws (Ed.), The handbook of research on mathematics teaching and learning (pp. 147164). New York: Macmillian.

Gamoran, A., Anderson, C. W., \& Ashmann, S. (2003). Leadership for change. In A. Gamoran, C. W. Anderson, P. A. Quiroz, W. G. Secada, T. Williams, \& S. Ashmann (Eds.), Transforming teaching in math and science. How schools and districts can support change (pp. 105-126). New York: Teachers College Press.

Garfinkel, H. (1967). Studies in Ethnomethodology. Maldan, Massachusetts: Blackwell Publishing.

Ginsburg, H. P. (2009). The challenge of formative assessment in mathematics education: Children's minds, teacher's minds. Human Development, 52, 109-128.

Glaser, B., \& Strauss, A. (1967). The discovery of grounded theory:Strategies for Qualitative Research. Chicago, IL: Aldine. 
Glazer, M. (1982). The threat of the stranger: Vulnerability, reciprocity, and fieldwork. In J. Sieber (ed.), Ethics of Social Research: Fieldwork, Regulation, and Publication (pp.49-70). New York: Springer-Verlag.

Glesne, C., \& Peshkin, A. (1992). Becoming qualitative researchers : an introduction / by Corrine Glesne \& Alan Peshkin. White Plains, N.Y: Longman.

Goldsmith, L. \& Schifter, D. (1997). Understanding teachers in transition. Characteristics of a model for developing teachers. In E. Fennema \& B. S. Nelson (Eds.), Mathematics teachers in transition (pp. 19-54). Mahwah, NJ: Erlbaum.

Good, C., Rattan, A., \& Dweck, C. S. (2012). Why do women opt out? Sense of belonging and women's representation in mathematics. Journal of Personality and Social Psychology, 102(4), 700-717.

Guba, E. G. (1980). Naturalistic and conventional inquiry. Paper presented the American Educational Research Association, Boston.

Guskey, T. R. (1986). Staff development and the process of teacher change. Educational Researcher, 15(4), 5-12.

Guskey, T. R. (1995). Professional development in education. In T. R. Guskey \& M. Huberman (Eds.), Professional development in education: New paradigms and practices, (pp. 114-131). New York: Teachers College Press.

Hamilton, S. (1983). The social side of schooling: Ecological studies of classrooms and schools. Elementary School Journal, 83, 313-391.

Hatt, B. (2012). Smartness as a cultural practice in schools. American Educational Research Journal, 49(3), 438-460.

Heid, M. K., Larson, M., Fey, J. T., Strutchens, M. E., Middleton, J. A., Gutstein, E., King, K., \& Tunis, H. (2006). The challenge of linking research and practice. Journal for Research in Mathematics Education, 37(2), 76-86.

Heritage, M., Kim, J., \& Vendlinski, T. (2008). From evidence to action: A seamless process in formative assessment? Paper presented at the American Educational Research Association Annual Meeting, New York.

Holly, P. (1991). Action research: The missing link in the creation of schools as the centers of inquiry. In A. Lieberman \& L. Miller (Eds.), Staff development for education in the 90's: New demands, new realities, new perspectives (pp. 133-157). New York: Teachers College Press.

Jacobs, V. R., Lamb, L. L. C., \& Philipp, R. A. (2010).Professional noticing of children's mathematical thinking. Journal for Research in Mathematics Education, 41, 169202.

Lewis, C. C. (2002). Does lesson study have a future in the United States? Nagoya Journal of Education and Human Development, 2002, 1-23.

Lewis, C., Perry, R., Friedkin, S., Fisher, L., Disston, J., \& Foster, D. (2012). Building knowledge and professional community through lesson study. In J.M. Bay-Williams (Ed.) 2012 NCTM Yearbook. Reston, VA: National Council of Teachers of Mathematics.

Miles, M. B., Huberman, A. M., \& Saldaña, J. (2014). Qualitative data analysis : a methods sourcebook. Thousand Oaks, Califorinia : SAGE Publications, Inc.

McCool, J. K. (2009). Measurement learning trajectories: A tool for professional development. (Doctoral Dissertation). Retrieved from Proquest June 18, 2012. 
McGlamery, S., \& Mitchell, C. (2000). Recruitment and retention of African American males in high school mathematics. Journal Of African American Men, 4(4), 73-87.

Mojica, G. M. (2010). Preparing pre-service elementary teachers to teach mathematics with learning trajectories (Doctoral Dissertation). Retrieved from Proquest June 19, 2012.

Myers, M., Edgington, C., Wilson, P. H., Sztajn, P. (2013). Teachers' positioning of students in relation to ability/achievement in a professional development setting. In M. Martinez \& A. Castro Superfine (Eds.), Proceedings of the 35th Annual Meeting of the North American Chapter of the International Group for the Psychology of Mathematics Education (pp. 653-660). Chicago, IL: University of Illinois-Chicago.

Nelson, B. S. (1998). Lenses on learning: Administrators' views on reform and the professional development of teachers. Journal of Mathematics Teacher Education, 1, 191-215.

Pugach, M. C., \& Johnson, L. J. (1990). Developing reflective practice through structured dialogue. In R. T. Clift, W. R. Houston, \& M. C. Pugach (Eds.), Encouraging reflective practice in education: An analysis of issues and programs (pp.186-207). New York: Teachers College Press.

Reynolds, M. C. (1989). Knowledge base for the beginning teacher. Oxford: Pergamon Press.

Richardson, V. (1990). Significant and worthwhile change in teaching practice. Educational Researcher, 19, 10-18.

Sarama, J. \& Clements, D.H. (2009). Early childhood mathematics education research learning trajectories for young children. New York, NY: Routledge.

Secada, W. G., \& Adajian, L. B. (1997). Mathematics teachers' change in the context of their professional communities. In E. Fennema \& B. S. Nelson (Eds.), Mathematics teachers in transition (pp.193-219). Mahwah, NJ: Erlbaum.

Seymour, E., \& Hewitt, N. (1997). Talking About Leaving: Why Undergraduates Leave the Sciences. Boulder, CO: Westview Press.

Schifter, D. (1995). Teachers' changing conceptions of the nature of mathematics. Enactment in the classroom. In B. S. Nelson (Ed.), Inquiry and the development of teaching: Issues in the transformation of mathematics teaching. (pp. 17-25). Newton, MA: Center for the Development of Teaching, Educational Development Center.

Schifter, D., \& Fosnot, C. T. (1993). Reconstructing mathematics education. New York: Teachers College Press.

Shulman, L. S. (1986). Paradigms and research programs in the study of teaching. A contemporary perspective. In M. Wittrock (Ed.), Handbook of research on teaching ( $3^{\text {rd }}$ ed.). New York, NY: Macmillan.

Shulman, L. S. (1987). Knowledge and teaching: Foundations of the new reform: Harvard Educational Review, 57(1), 1-22.

Simon, M. A., \& Schifter, D. (1991). Towards a Constructivist Perspective: An Intervention Study of Mathematics Teacher Development. Educational Studies In Mathematics, 41(4), 309-400.

Simon, M.A., (1995). Reconstructing mathematics pedagogy from a constructivist perspective. Journal for Research in Mathematics Education, 26(2). 114-145.

Smith, R. S. \& Stein, M. K. (2011). 5 practices for orchestrating productive mathematics discussions. Reston, Virginia: The National Council of Teachers of Mathematics, Inc 
Sternberg, R. J. (2007). Who are the bright children? The cultural context of being and acting intelligent. Educational Researcher, 36(3), 148-155.

Sztajn, P., Confrey, J., Wilson, P., \& Edgington, C. (2012). Learning Trajectory Based Instruction: Toward a Theory of Teaching. Educational Researcher, 41(5), 147-156.

Wickstrom, M. H., Baek, J., Barrett, J., Cullen, C., \& Tobias, J. (2012) A teacher's noticing of children's understanding of linear measurement. In L. R. Van Zoest, J. J. Lo, \& J. L. Kratky (Eds.), Proceedings of the 34th Annual Meeting of the North American Chapter of the International Group for the Psychology of Mathematics Education. Kalamazoo, MI: Western Michigan University.

Wickstrom, M. H. (in press) Piecing It Together: Using Quilts to Investigate Area and Perimeter. Teaching Children Mathematics

Wilson, P.H. (2009). Teachers' uses of a learning trajectory for equipartitioning (Doctoral Dissertation). Retrieved from Proquest June 18, 2012.

Yeager, D., \& Dweck, C. S. (2012). Mindsets that promote resilience: When students believe that personal characteristics can be developed. Educational Psychologist, 47(4), 302-314.

Zumwalt, K. K. (1982). Are we improving or undermining teaching? In L. N. Tanner (Ed.), Critical issues in curriculum: 87th yearbook of National Society for the Study of Education. Chicago: University of Chicago Press. 
APPENDIX A

DESCRIPTION OF PROFESSIONAL DEVELOPMENT 


\section{The Professional Development}

This dissertation study is part of a larger longitudinal professional development study focused on teachers using a learning trajectory as a formative assessment tool. The larger study consisted of twenty-four elementary school teachers (k-5) from an urban school district in the Midwest. At the time of this study, the professional development was in its second year. Approximately half of the teachers enrolled in the professional development participated in the program the year before and half of the teachers were new participants. As a part of the larger study, the teachers participated in two summer sessions composed of ten days of professional development as well as four days of professional development during the school year.

The aim of the summer session was to prepare teachers to use the trajectory as a formative assessment tool in their classroom. This meant that teachers were expected to be able to interview individual students as assessment of student thinking, develop lessons from the student interviews, and re-interview students to reflect on the appropriateness of the lesson. Teachers were also expected to be able to watch students within their classrooms and others while noting student behavior and thinking. To help teachers connect all of the expected components, teachers were first made aware of expectations and then, throughout the summer professional development, different parts of the process were enacted and practiced.

The summer component of the professional development was divided into two sessions. The first session occurred directly after the end of the school year and lasted eight days. The focus of the first session was to help teachers to use a trajectory as an assessment tool to observe student actions, comment on student thinking, and to inform 
instruction. During the first week of the professional development the teachers were introduced to a learning trajectory on length measurement and a learning trajectory on area measurement (Sarama and Clements, 2009). The returning group of teachers had been introduced to the length trajectory the previous year, but were new to the area trajectory.

In addition to the learning trajectories, the teachers were also introduced to the 5 Practices for Orchestrating Production Mathematics Discussions (Stein \& Smith, 2011) as a tool to help incorporate the trajectory into practice. The five practices consist of anticipating, monitoring, selecting, sequencing, and connecting. Each of these components were addressed individually during the professional development and the teachers were encouraged to use the trajectory to aide in anticipating student responses and determining and connecting levels of sophistication within the classroom.

The first session consisted of three main components; content and video analysis, student interviews, and lesson observation and development. The learning trajectories were interwoven through all of the components of the summer session as tools to help teachers make sense of student thinking. These components acted as assessment tools for the research team to measure teacher knowledge as well as activities to help teachers grow in understanding of the trajectory. The first two components were enacted prior to the teachers being introduced to the trajectory to serve as baseline data.

The first component was content and video analysis. The purpose of the content and video analysis was to prepare teachers to anticipant student responses to tasks, observe student behavior, and comment on student thinking within their own classroom and others. Each day of the session, the teachers were posed a content question similar to 
what they may pose to their students. The teachers were asked to work through the content and then write how they thought students in their classroom might respond to the task. If they were able, they were asked to indentify levels of the learning trajectory strategies represented by the student responses. Following this activity the teachers were shown a video of a student working on the task.

After watching the video, similar to the Jacobs et al. (2010) study, the teachers were asked to describe in detail what the student did in response to the problem, describe what they learned about the student's understanding, and lastly, if they were the student's teacher what problem or problems would they pose next and why. The teachers were asked to write independently first and then discuss in groups. To an attempt to maintain the "individual" integrity of the response, the teachers' responses were captured on carbon copy paper and turned in prior to group discussion. During the group discussion, the teachers were able to share responses with one another, ask questions, and receive feedback from the principle investigators.

The second component of the session was conducting and interpreting interviews. The purpose of this activity was to prepare teachers to conduct interviews with their own students as well as use the interviews to inform instruction. During the first few days of the professional development the teachers focused solely on interpreting interviews. The teachers participated in a "round-robin" activity where at several stations they were shown different videos of students attempting the same task. The teachers took running notes of the student strategies and what they thought each student was thinking. When the teachers came back together they were asked to rank the students' responses in terms of sophistication of understanding and, after being introduced to the trajectory, in terms of 
the trajectory as well. Following this discussion, the teachers were asked to propose a lesson that would address the student understanding represented in the videos.

After the teachers felt comfortable analyzing video interviews, they were able to design and implement interview tasks with students at a local summer program. The goal of the interviews was to inform a classroom lesson. The teachers worked with small groups of students conducting individual interviews and then shared their results with the entire group. During the group discussion the teachers had to determine what would be an appropriate lesson for the group that they interviewed.

The last component of the session was incorporating the other two components into a cohesive lesson plan or unit and enacting it. Following group discussion of student interviews, the teachers created a lesson collaboratively with the principle investigators.

Then, the principle investigators enacted the lesson and the teachers were able to observe and determine if the content was appropriate in that it addressed student understanding within the classroom. The principle investigators volunteered to teach the first two lessons so that all of the teachers could observe the lesson and feel comfortable criticizing components of the lesson. On the last day of the first session the teachers were able to design lessons and teach small groups of students.

The second summer session occurred prior to the teachers returning to school in the fall. It consisted of two days of training and the focus was on developing lesson plans for the school year. It began with a short summary of what the teachers covered during the spring session. During the break between sessions, the teachers were asked to return with ideas for possible measurement lessons for the school year. The teachers were given 
time to work together in groups to choose or design measurement lessons and also develop interview tasks that will inform the lessons.

During the school year, the teachers participated in four professional development days. Each of the teachers enacted two measurement lessons within their classroom. The teachers went through the process of interviewing students, planning a lesson based on the interviews, enacting the lesson, re-interviewing students, and reflecting on the appropriateness of the lesson. The teachers were given an outline of this process with directions and questions to consider during each stage. These two days were videotaped and teachers were asked to share their experiences when they gathered back together during group professional development.

The second set of professional development days consisted of two observation days. Several teachers were asked to volunteer to be observed by other teachers and the principal investigators while they enacted their lesson. Similar to the summer sessions, the teachers focused on student behavior and thinking. Everyone gathered following the lesson and discussed observations and appropriateness. 
APPENDIX B

AREA LEARNING TRAJECTORY 


\begin{tabular}{|c|c|c|}
\hline Level & Observable Operations & Mental Actions on Objects \\
\hline $\begin{array}{l}\text { Area Pre- } \\
\text { Recognizer }\end{array}$ & & \\
\hline $\begin{array}{l}\text { Area Simple } \\
\text { Comparer } \\
\text { Area/Spatial } \\
\text { Structuring: } \\
\text { Incomplete } \\
\text { Coverer }\end{array}$ & & \\
\hline $\begin{array}{l}\text { Area/Spatial } \\
\text { Structuring: } \\
\text { Primitive } \\
\text { Coverer }\end{array}$ & $\begin{array}{l}\text { Draws a complete covering, but } \\
\text { with some errors of alignment. } \\
\text { Counts around the border, } \\
\text { then unsystematically in the } \\
\text { interiors, counting some twice } \\
\text { and skipping others. }\end{array}$ & $\begin{array}{l}\text { Applies explicit understanding } \\
\text { that entire region must be } \\
\text { covered with shapes. Implicit } \\
\text { visual patterning of multiple } \\
\text { concatenations of rectangles } \\
\text { guides placement of squares in } \\
\text { rows, approximately aligned with } \\
\text { parallel rows. }\end{array}$ \\
\hline $\begin{array}{l}\text { Area/Spatial } \\
\text { Structuring: } \\
\text { Primitive } \\
\text { Coverer and } \\
\text { Counter. }\end{array}$ & $\begin{array}{l}\text { Draws as above. Also, counts } \\
\text { corrects aided by counting one } \\
\text { row at a time and, often, by } \\
\text { perceptual labeling. }\end{array}$ & $\begin{array}{l}\text { Counts all objects once and only } \\
\text { once and use of rows as an } \\
\text { intuitive structure or explicit } \\
\text { application of labeling as marker, } \\
\text { allows child to keep track. }\end{array}$ \\
\hline $\begin{array}{l}\text { Area/Spatial } \\
\text { Structuring: } \\
\text { Partial Row } \\
\text { Structurer }\end{array}$ & $\begin{array}{l}\text { Draws and counts some, but } \\
\text { not all, rows as rows. May } \\
\text { make several rows and then } \\
\text { revert to making individual } \\
\text { squares, but aligns them in } \\
\text { columns. }\end{array}$ & $\begin{array}{l}\text { Applies a row as a composite unit } \\
\text { repeatedly, but not necessarily } \\
\text { exhaustively, as its application } \\
\text { remains guided by intuition. }\end{array}$ \\
\hline $\begin{array}{l}\text { Area/Spatial } \\
\text { Structuring: Row } \\
\text { and Column } \\
\text { Structurer. }\end{array}$ & $\begin{array}{l}\text { Draws and counts rows as } \\
\text { rows, drawing with parallel } \\
\text { lines. Counts the number of } \\
\text { squares by iterating the } \\
\text { number in each row, either } \\
\text { using physical objects or an } \\
\text { estimate for the number of } \\
\text { times to iterate. }\end{array}$ & $\begin{array}{l}\text { Applies a row as a composite unit } \\
\text { repeatedly and exhaustively to fill } \\
\text { the array. }\end{array}$ \\
\hline
\end{tabular}




\begin{tabular}{|c|c|c|}
\hline Level & Observable Operations & Mental Actions on Objects \\
\hline Area Conserver. & $\begin{array}{l}\text { Conserves area and reasons } \\
\text { about additive composition of } \\
\text { areas (e.g., how regions that } \\
\text { look different can have the } \\
\text { same area measure) and } \\
\text { recognize need for space filling } \\
\text { in most contexts. }\end{array}$ & \\
\hline $\begin{array}{l}\text { Area/Spatial } \\
\text { Structuring: } \\
\text { Array Structurer }\end{array}$ & $\begin{array}{l}\text { With linear measures, } \\
\text { multiplicatively iterates squares } \\
\text { in a row or column to } \\
\text { determine the area. Drawings } \\
\text { are not necessary. }\end{array}$ & $\begin{array}{l}\text { Mentally de/composes array into } \\
\text { rows by columns or individual } \\
\text { squares. The mental image may } \\
\text { be of a spatial array or a symbolic } \\
\text { array. }\end{array}$ \\
\hline
\end{tabular}


APPENDIX C

NOTICING REFLECTION PROMPTS FOR STUDENT INTERVIEWS

AND TEACHER LESSON PLAN PACKET 
- Please describe in detail what you think the child did or the strategy that he/she used in response to the task.

- Please describe what you learned about this child's understanding. (What do you think the student is thinking, and at what level of the learning trajectory would you place the student?)

- Pretend you are the classroom teacher of this student; what problem(s) or task(s) might you pose to the student next and why? 


\section{Lesson Plan Guide}

\section{Goal}

- What is your mathematical goal for the lesson (i.e., reference common core, your textbook, and your four quarter plans)?

- What do you want students to know and why (i.e., what do you want your students to understand? What is important for them to understand)? 


\section{Design/ Choose Interview Tasks}

- What are tasks that might inform the lesson and how will they inform the lesson?

- What do we need to know about our kids before we start the lesson? 


\section{Interview Tasks}

- Describe each task in detail (please describe in such detail that another teacher could administer the task by reading your description)

- What did you see each student do in response to each task?

- What do you think this means about their understanding (If possible, what level of the trajectory categorizes his or her thinking and why)?

- How will what you learned about your students inform your lesson? 


\section{Lesson Planning}

- Choose an activity (Give a short description of your planned activity)

- Based on your interviews, what level(s) of the learning trajectory should inform your lesson?

- Anticipation: How do you think the students you interviewed will respond to your lesson? 
- Monitoring: How will you keep track of what students are doing and what they understand?

- Selection and Sequencing: How will you structure the lesson to address their needs?

- Connections: How will you challenge students at multiple levels in your lesson? How will connect student responses? 


\section{Post-Lesson Reflection}

- Was the task appropriate for your classroom, why or why not?

- What did you see the students in your classroom doing?

- What do you think this means about their understanding (i.e., if possible, what level of the trajectory categorizes their thinking and why)? 
APPENDIX D

INTERVIEW QUESTIONS FOR STUDENT INTERVIEWS AND CLASSROOM LESSONS 


\section{Interview Following Student Interviews}

1. Will you tell me a little about the lesson you are planning related to these interviews?

a. What are your goals?

b. Why do you consider these goals important?

c. What do you want students to know or understand?

2. Can you describe a little about the lesson you are planning to enact i.e. what are the activities planned, what tools will the students use?

3. Prior to participating in this PD on learning trajectories, how would you have gone about teaching this lesson or a lesson similar to this?

4. What did you look for when considering if your lesson was effective?

a. What did indicators did you look for?

b. What was an important skill that they had to know?

5. Please describe any ways that you monitor student thinking on a daily or weekly basis?

6. Will you explain the rationale for choosing these interview tasks?

a. What were you hoping the tasks would tell you in helping inform your lesson?

7. Please tell me about the students that you have chosen for this interview and why they were selected.

8. (Look at events teacher selected) What types of responses did you see to this particular task or what happened in this event? 
9. Can you tell me what you think these responses mean in terms of student understanding?

10. Now that you have conducted this interview, how, if at all, will any of the events affect your goals for the lesson?

11. Based on these interviews, how do you think students will respond to your lesson?

a. What may be some difficulties that students face? 
Whole Class Interview

1. Please tell me a little about the lesson that you have planned for today. (i.e. goals, activities planned)

2. Will you tell me how do you monitor student thinking on a daily or weekly basis? What tools do you use? How does this come out in your lesson?

3. Can you describe ways in which this lesson is similar or different to your daily mathematics lessons?

4. If you reflect back on the interviews that you conducted, in what ways did they affect the lesson that you have planned for today?

a. In what ways (if at all) did your lesson change based off of the interviews?

5. What behaviors did you expect to see from your students today during the lesson?

a. Where there any signs that you noticed during the interviews that indicated to you how the students might respond?

6. In what ways did you try to incorporate what you anticipated from your students into your lesson?

7. (Look at events teacher selected) What types of responses did you see to this particular task or what happened in this event?

8. What did you see students doing in response to your lesson mathematically?

a. Describe student behavior, was it surprising? Or was it what you expected?

9. Can you tell me what you think these responses mean in terms of student understanding? 
10. What do you think your students were thinking about mathematically while attempting your task?

11. Now that you have conducted this interview, how, if at all, will any of the events affect your goals for the lesson? Please describe important instances that you thought revealed their thinking.

12. Please explain what you think the students took away from the lesson mathematically?

13. How will you follow this lesson? Based on student thinking, what questions or tasks do you think you should pose next to help them reach or exceed their goals?

14. What role does the learning trajectory play in the classroom setting? In what ways is it is helpful? Can you describe any other tools or experiences that are helpful as well? 


\section{Final Interview Questions}

1. In your opinion, what are components of ineffective professional development?

2. In your opinion, what are components of effective professional development?

3. If you could design a PD, what would it entail?

4. What are components, if any, of this professional development did you feel transitioned well into your classroom?

5. What are components, if any, of this professional development did you feel did not transition well into your classroom?

6. What role do you feel that the learning trajectory played in your lesson planning process?

7. What role do you feel that the interviews played in your lesson planning process?

8. What do you see as weaknesses, if any, of the current trajectory document?

9. How would you amend the current document to make it easier for you to use?

10. What do you see as strengths, if any, of the current trajectory document? 